RAÚL ELISEO ROJAS SALDÍVAR

\title{
RETROANÁLISE PROBABILISTA APLICADA À ANÁLISE DINÂMICA DA CRAVAÇÃO DE ESTACAS
}

Dissertação apresentada à Escola Politécnica da Universidade de São Paulo para a obtenção do título de Mestre em Engenharia. 


\section{RAÚL ELISEO ROJAS SALDÍVAR}

\section{RETROANÁLISE PROBABILISTA APLICADA À ANÁLISE DINÂMICA DA CRAVAÇÃO DE ESTACAS}

Dissertação apresentada à Escola Politécnica da Universidade de São Paulo para a obtenção do título de Mestre em Engenharia.

Área de Concentração: Engenharia Geotécnica

Orientador: Prof. Dr. Waldemar Coelho Hachich

São Paulo 
Este exemplar foi revisado e alterado em relação à versão original, sob responsabilidade única do autor e com a anuência de seu orientador.

São Paulo, 21 de maio de 2008.

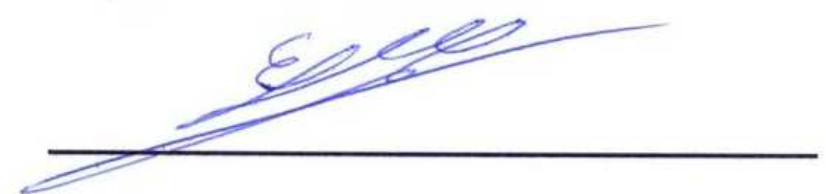

Assinatura do autor

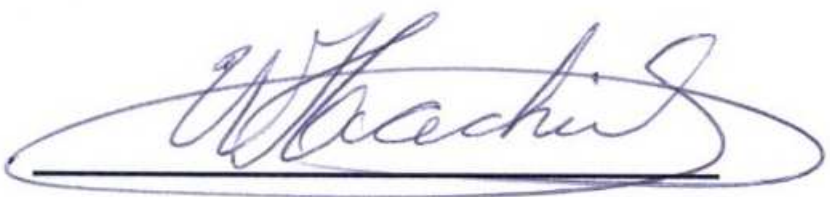

Assinatura do orientador

FICHA CATALOGRÁFICA

Rojas Saldívar, Raúl Eliseo

Retroanálise probabilista aplicada à análise dinâmica da cravação de estacas / R.E. Rojas Saldívar. -- ed.rev. -- São Paulo, 2008.

$159 \mathrm{p}$.

Dissertação (Mestrado) - Escola Politécnica da Universidade de São Paulo. Departamento de Engenharia de Estruturas e Geotécnica.

1.Fundações por estacas 2.Método probabilísticos I.Universidade de São Paulo. Escola Politécnica. Departamento de Engenharia de Estruturas e Geotécnica II.t. 


\section{Dedicatória}

A meus pais, Judith e Alejandro. 


\section{Agradecimentos}

A minha grande, querida e sempre recordada família, meus pais e irmãos, incentivadores incessantes do meu trabalho.

Ao meu orientador, professor Waldemar Hachich, por ter confiado em dar-me a oportunidade de trabalhar e desenvolver as suas idéias, pela admiração que inspira e a motivação que produz cada um dos seus ensinamentos

À Dra. Gisleine Coelho, da seção de fundações do IPT, pelas sugestões feitas na etapa do exame de qualificação, pela ajuda na etapa da utilização de equipamento no IPT, e as valiosas sugestões feitas ao longo da pesquisa.

Ao Dr. Werner Bilfinger, da Vecttor Projetos, pelas contribuições no exame de qualificação.

Ao Eng. Sergio Valverde, da PDI Engenharia, pelas sugestões e amizade ao longo da pesquisa.

Ao Marcio Santos, excelente colega e grande amigo, pelo apoio ao longo da pesquisa.

Aos amigos, Arturo Butrón, Alexei Najar, Jorge Suasnabar e Marco Flores, com quem teve a sorte de compartir o convívio nos anos do mestrado:

Aos amigos peruanos que encontrei na USP: Ricardo Llanos e Priscila Aguilar, e ao outro grande amigo e colega: Ricardo Oviedo.

Aos exemplares professores do mestrado: Carlos Pinto, Faiçal Massad, Marcos Massao, Milton Kanji, Paulo Cruz.

A CAPES pela ajuda financeira. 
EL INSTANTE

¿Dónde estarán los siglos, dónde el sueño de espadas que los tártaros soñaron, dónde los fuertes muros que allanaron, dónde el Árbol de Adán y el otro Leño?

El presente está solo. La memoria erige el tiempo. Sucesión y engaño es la rutina del reloj. El año no es menos vano que la vana historia.

Entre el alba y la noche hay un abismo de agonías, de luces, de cuidados; el rostro que se mira en los gastados espejos de la noche no es el mismo. El hoy fugaz es tenue y es eterno; otro Cielo no esperes, ni otro Infierno.

Jorge Luis Borges 


\section{RESUMO}

Um ensaio de carga dinâmica pode ser efetuado em tubulões, estacas hélice continua, estacas moldadas in situ ou estacas cravadas. Tal ensaio se baseia na Teoria da Propagação de Onda em estacas e visa avaliar a capacidade de carga estática mobilizada a partir do evento dinâmico. A análise do ensaio é feita mediante um programa (p.e. CAPWAP ou DLTWAVE), computacional que leva em conta tanto os sinais de força e velocidade obtidas em campo e o modelo do sistema estaca-solo

Este trabalho apresenta uma metodologia para atualização bayesiana dos parâmetros de Smith da teoria de propagação de onda, levando em conta não só os sinais registrados, mas também a informação geotécnica-probabilista prévia sobre estes parâmetros. Uma aproximação semelhante já foi aplicada pelo orientador da pesquisa à estimativa de parâmetros geotécnicos de rochas a partir de medidas de deslocamento em túneis, e de campos de permeabilidade a partir de observações piezométricas em barragens.

A técnica proposta está baseada firmemente em conhecimento empírico geotécnico que fornece o ensaio e erro do procedimento usual de comparação de sinais: a atualização bayesiana permite aos parâmetros afetados por incerteza maior ter um ajuste proporcionalmente maior de acordo com observações.

O máximo deslocamento elástico (quake), o fator de amortecimento (damping) e a resistência estática unitária, de cada trecho da estaca, são considerados variáveis aleatórias com distribuições prévias estimadas dependendo do local de cravação da estaca. Discute-se e calcula-se a correlação cruzada entre parâmetros diferentes e autocorrelação ao longo de profundidade da estaca.

As observações são escolhidas do sinal calculado por um software de análise de sinais de cravação, em espaços regulares ao longo do tempo. Postula-se um modelo linear de observação, pesquisa-se tal linearidade, também, deriva-se uma matriz de sensibilidade (ligando cada parâmetro a cada observação), e estimam-se também as incertezas nas observações (sinais).

O resultado final é uma distribuição de parâmetros de Smith ao longo da profundidade de estacas, atualizada de acordo com as observações.

A aproximação proposta é aplicada em sinais de um dos momentos da cravação, no final da cravação ('end of driving', EOD).

\section{Palavras-chave:}

- Comparação de sinais,

- Métodos dinâmicos em estacas,

- Modelo de Smith,

- Parâmetros de Smith,

- Atualização bayesiana,

- Retroanálise probabilista. 


\begin{abstract}
An dynamic loading test can be performed in concrete piles, bored piles, drilled shafts, auger cast-in-place (continuous flight auger) piles. Such essay bases on the Theory of the Propagation of Wave in piles with the aim of evaluate the capacity of static load mobilized from the dynamic event. The analysis of the test is made by a PC program (p.e. CAPWAP or DLTWAVE), that takes into account the signals of force and velocity obtained in field and the pile-soil model.
\end{abstract}

This work presents a methodology for bayesian updating of Smith's parameters, taking into account not just the recorded signals, but also the prior geotechnical-probabilistic information about these parameters. A similar approach has already been applied by the senior author to the estimation of rock geotechnical parameters from displacement measurements in tunnels, and of permeability fields in embankment dams from piezometric observations.

The proposed technique is deemed more firmly based on sound geotechnical knowledge than the usual trial and error signal matching procedure: bayesian updating allows for parameters affected by larger uncertainty to undergo proportionately larger adjustment according to observations.

Quake, damping and static resistance are considered random variables, with prior distributions assessed from information about the geotechnical characteristics of the soils the pile is driven into. Cross-correlation between different parameters and auto-correlation along pile depth are discussed and estimated.

Signals measured at some properly selected times are the chosen observations. A linear observation model, linking observations to parameters, is postulated, linearity is investigated, a sensitivity matrix (linking each parameter to each observation) is derived, and uncertainty in the observations (signals) is estimated.

The final result is a distribution of Smith's parameters along pile depth, updated in accordance with the observations.

The proposed approach is tested in end of driving (EOD) signal.

\title{
Key words:
}

- Signal Matching;

- Dynamic Loading Tests for Piles;

- Smith's Model;

- Smith's Parameters;

- Bayesian Updating;

- Probabilistic Back-analysis. 


\section{SUMÁRIO}

1 INTRODUÇÃO

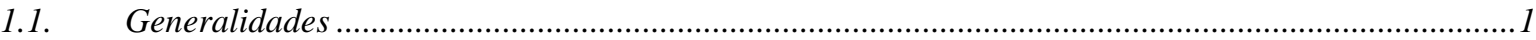

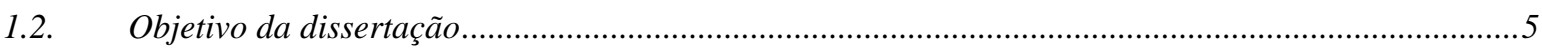

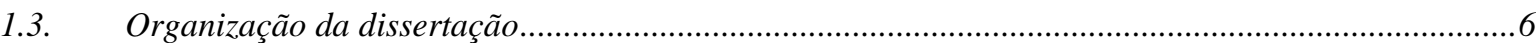

2 ENSAIOS DINÂMICOS: APLICAÇÃO DA TEORIA DE EQUAÇÃO DE ONDA.................................8

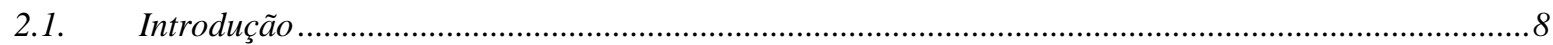

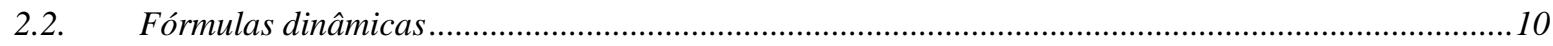

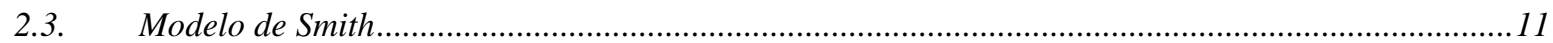

2.4. Análise Dinâmica sem Medições Dinâmicas...................................................................................17

2.4.1. Programa TTI (Texas) ………………………................................................................

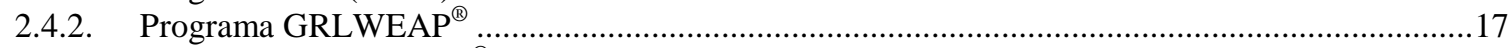

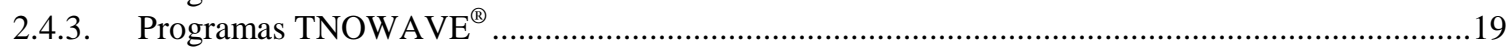

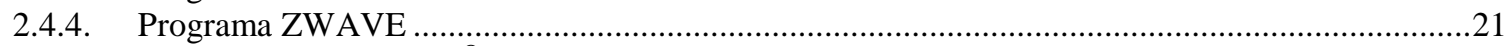

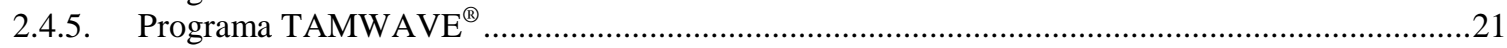

2.5. Medições Dinâmicas, Pile Driving Analizer $\left(P D A^{\circledR}\right)$.................................................................22

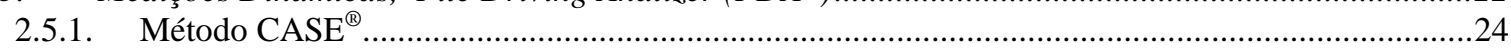

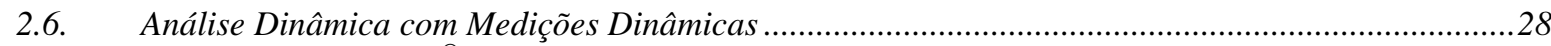

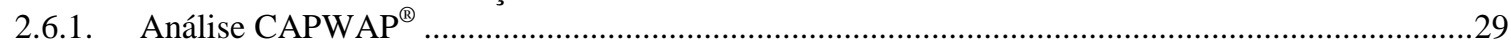

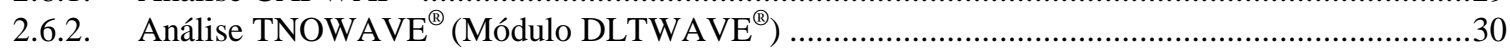

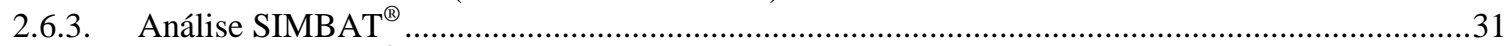

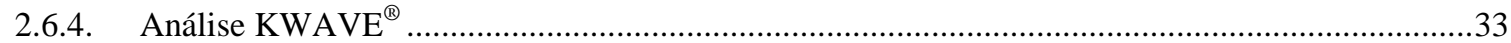

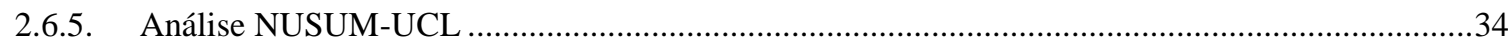

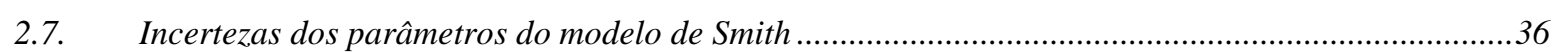

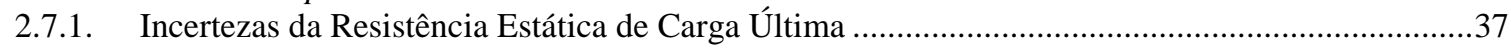

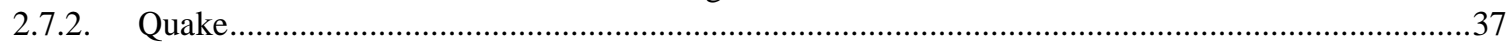

2.7.3. Incertezas do Fator de Amortecimento: damping ..........................................................................

3 FUNDAMENTOS DA EQUAÇÃO DE ONDA APLICADA À CRAVAÇÃO DE ESTACAS .............44

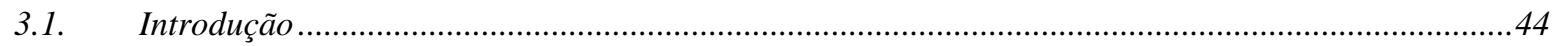

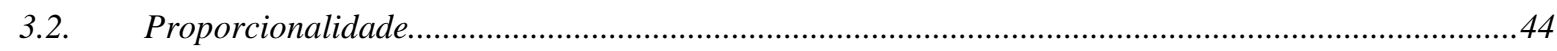

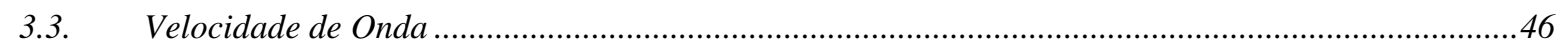

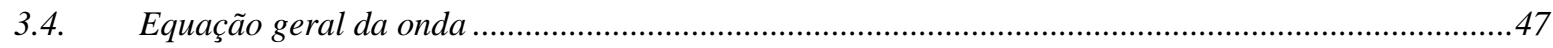

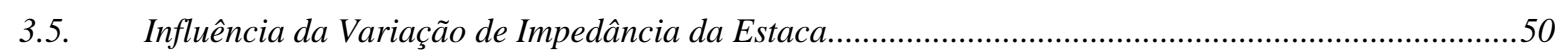

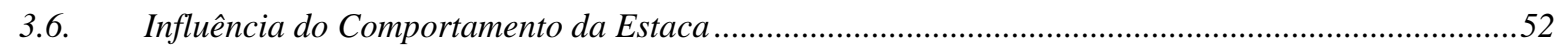

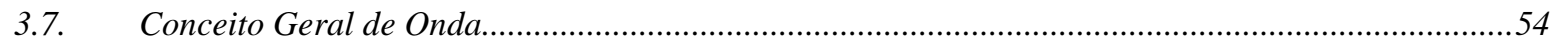

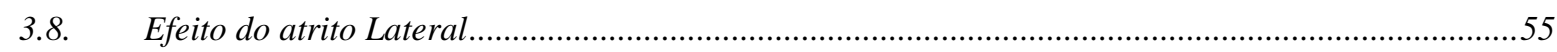

3.9. Comentários sobre as Hipóteses adotadas no presente Capítulo ......................................................59

\section{ASPECTOS TEÓRICOS SOBRE A ATUALIZAÇÃO BAYESIANA DOS PARÂMETROS DO}

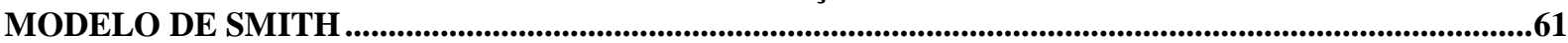

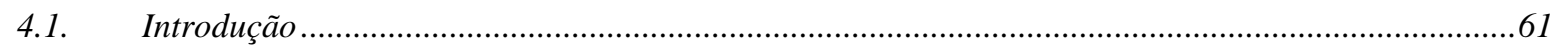

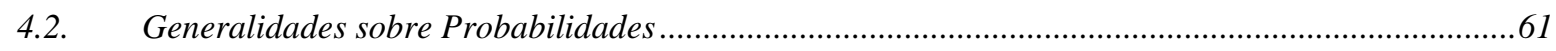

4.3. Hipótese de Independência dos Parâmetros de Smith......................................................................64 
4.4. Representação do campo estocástico: utilização dos segundos momentos......................................65

4.5. Determinação da Matriz de Covariâncias ................................................................................67

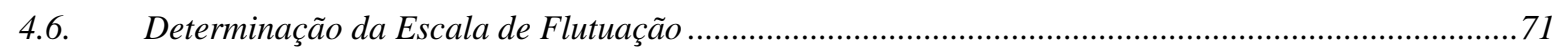

4.7. Determinação da Função de Redução da Variância .....................................................................72

4.8. Determinação da Função de Autocorrelação ...........................................................................72

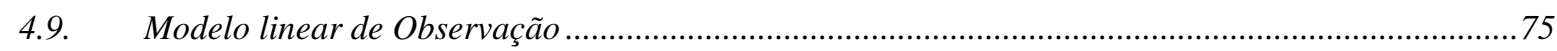

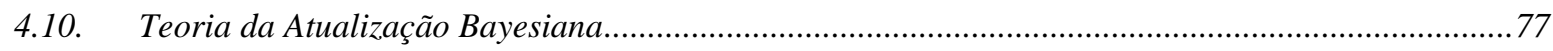

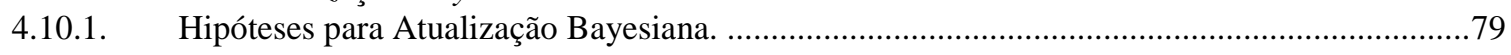

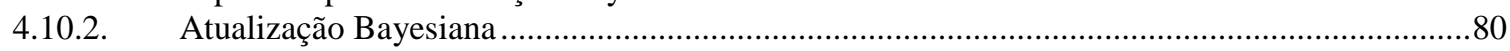

5 APLICAÇÃO PRÁTICA: ATUALIZAÇÃO DOS PARÂMETROS DE SMITH .................................83

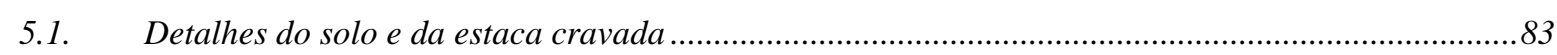

5.2. $\quad$ Análise de Sinais de Cravação para modelo inicial de solo ..............................................................84

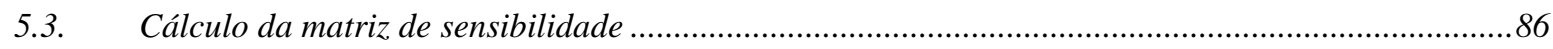

5.4. Estudo da Linearidade do Modelo de Observação ..........................................................................90

5.5. Cálculo da matriz de covariâncias..............................................................................................92

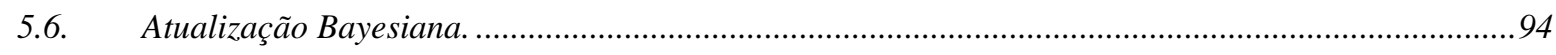

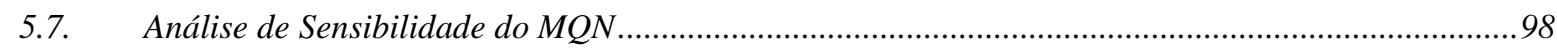

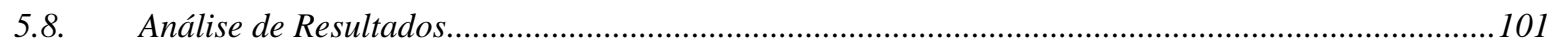

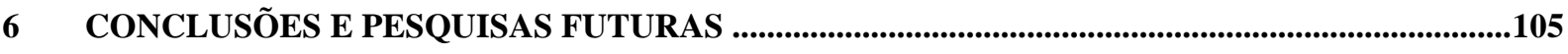

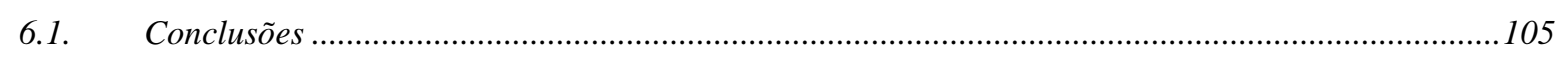

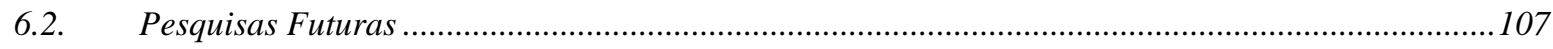

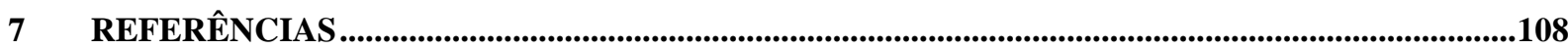

ANEXO A - Folhas Resumo da ANÁLISE de Sensibilidade realizada no CAPWAP .....117

ANEXO B - Matrizes de Covariâncias para as Análises de Atualização Bayesiana .........120

ANEXO C - Resultados da Atualização Bayesiana e das Análises CAPWAP de

Confirmação 121

ANEXOS D - Influência dos ‘outros’ Parâmetros nas Análises CAPWAP ............................139

ANEXO E - Match Quality Number 'MQN' na Análise inicial CAPWAP ............................142 


\section{LISTA DE FIGURAS}

FIGURA 1-1 CATEGORIAS DAS INCERTEZAS (BAECHER \& CHRISTIAN, 2003) ......................................

FIGURA 1-2 INCERTEZAS NA ESTIMAÇÃO DAS PROPRIEDADES DO SOLO …….................................

FIGURA 1-3 ESQUEMA DA METODOLOGIA UTILIZADA NA PRESENTE PESQUISA.............................6

FIGURA 2-1 ESTACA AXIALMENTE CARREGADA EM SOLO ELÁSTICO (WOOD, 2004, P. 396) ............8

FIGURA 2-2 FENÔMENO DA PROPAGAÇÃO DE ONDA EM UMA ESTACA ………..................................

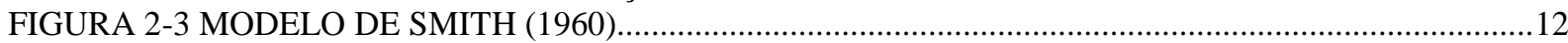

FIGURA 2-4 MODELO E PARÂMETROS DO SISTEMA ESTACA-SOLO (SMITH, 1960) ...........................13

FIGURA 2-5 COMPARAÇÃO DE RESULTADOS ENCONTRADOS PARA O EXEMPLO DE SMITH (1960)

FIGURA 2-6 DIAGRAMAS NA SIMULAÇÃO NO MATLAB ${ }^{\circledR}:$ (A) COMPORTAMENTO DA PONTA DA

ESTACA, E (B) COMPORTAMENTO DO CEPO, PARA O EXEMPLO DE SMITH (1960)...................16

FIGURA 2-7 VELOCIDADES SIMULADAS NO MATLAB ${ }^{\circledR}$ PARA O EXEMPLO DE SMITH (1960) ..........16

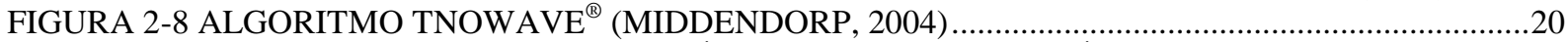

FIGURA 2-9 PROPAGAÇÃO DA ONDA NO MÉTODO DAS CARACTERÍSTICAS (MIDDENDORP, 2004)

FIGURA 2-10 CARACTERÍSTICAS COMPUTACIONAIS DO ZWAVE ${ }^{\circledR}$ (WARRINGTON, 1988)

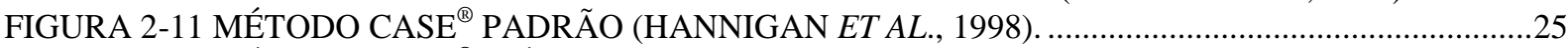

FIGURA 2-12 MÉTODO CASE ${ }^{\circledR}$ MÁXIMO (HANNIGAN ET AL., 1998) .....................................................26

FIGURA 2-13 FLUXOGRAMA DO CAPWAP ${ }^{\circledR}$ (GONÇALVES ET AL., 1999) ...............................................30

FIGURA 2-14 MODELO DA ESTACA-SOLO NO PROGRAMA SIMBAT ${ }^{\circledR}$ (CHARUE, 2004) …....................32

FIGURA 2-15 MODELO DE SOLO KWAVE ${ }^{\circledR}$ PARA TUBO DE ACCO CIRCULAR ……………….................33

FIGURA 2-16 MODELO DE SOLO NUSUM-UCL (CHARUE, 2004).........................................................34

FIGURA 2-17 POSIÇÃO DO TOPO E DA BASE DA ESTACA ANTES DO GOLPE (A) E, (B) OS

DESLOCAMENTOS MÁXIMOS APÓS O GOLPE (AOKI, 1991) ……………………………………....3

FIGURA 3-1 DEFORMAÇÃO DO ELEMENTO DL (NIYAMA, 1983) ………………...............................45

FIGURA 3-2 DEFORMAÇÕES DO ELEMENTO DA ESTACA DEVIDO À PROPAGAÇÃO DE ONDA

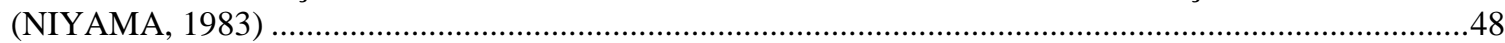

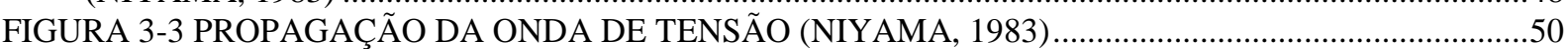

FIGURA 3-4 CONDIÇÕES DE CONTORNO NA PONTA DA ESTACA (NIYAMA, 1983)............................52

FIGURA 3-5 REFLEXÕES DAS ONDAS DE FORÇA E VELOCIDADE NA PONTA DA ESTACA

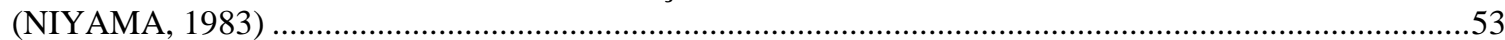

FIGURA 3-6 ILUSTRAÇÃO DAS ONDAS GERADAS NUM PONTO INTERMEDIÁRIO DA ESTACA (NIYAMA, 1983)

FIGURA 3-7 REFLEXÃO E TRANSMISSÃO DE ONDAS DE IMPACTO (BERRUIJT, 2005) .........................56

FIGURA 3-8 DIAGRAMA DE TRAJETÓRIAS DAS ONDAS (NIYAMA, 1983) ..........................................57

FIGURA 3-9 REGISTRO TÍPICO DAS CURVAS DE FORÇA E VELOCIDADE (NIYAMA, 1983) ..............58

FIGURA 4-1 FUNÇÃO DENSIDADE DE PROBABILIDADE PARA UMA VARIÁVEL K. ...........................63

FIGURA 4-2 CAMPO ESTOCÁSTICO UNIDIMENSIONAL DA VARIÁVEL $K$..........................................67

FIGURA 4-3 APROXIMAÇÃO DO SISTEMA ESTACA-SOLO PARA A ANÁLISE DE COVARIÂNCIAS.69

FIGURA 4-4 DEFINIÇÃO DOS ELEMENTOS VI (VANMARCKE, 1983) …………………………............70

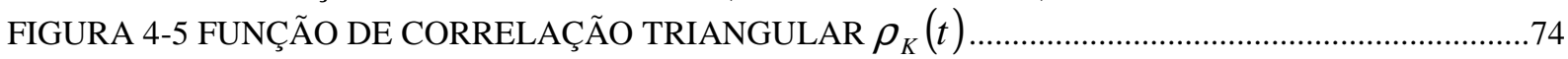

FIGURA 4-6 LOCALIZAÇÃO DOS INSTRUMENTOS DE MEDIÇÃO. .....................................................75

FIGURA 4-7 CURVA DE CALIBRAÇÃO DO INSTRUMENTO HIPOTÉTICO ……….................................76

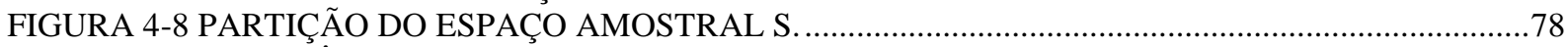

FIGURA 4-9 OCORRÊNCIA DE UM EVENTO A QUALQUER...................................................................78

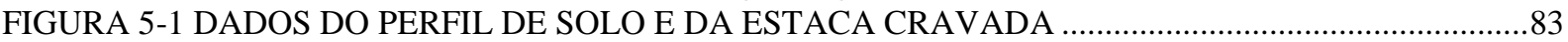

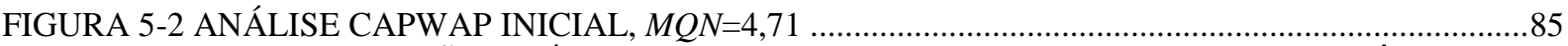

FIGURA 5-3 REPRESENTAÇÃO GRÁFICA DA MATRIZ DE SENSIBILIDADE PARA O PARÂMETRO QUAKE (DELTA $Q=1,00 \mathrm{MM})$

FIGURA 5-4 REPRESENTAÇÃO GRÁFICA DA MATRIZ DE SENSIBILIDADE PARA O PARÂMETRO

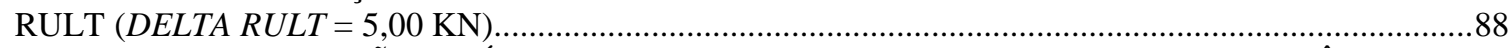

FIGURA 5-5 REPRESENTAÇÃO GRÁFICA DA MATRIZ DE SENSIBILIDADE PARA O PARÂMETRO DAMPING SMITH (DELTA JS $=0,05 \mathrm{~S} / \mathrm{M})$

FIGURA 5-6 VALIDAÇÃO DO MODELO DE OBSERVAÇÃO LINEAR PARA OS INSTRUMENTOS HIPOTÉTICOS PARA MUDANÇAS DE VALORES DA PONTA DA ESTACA (TRECHO 14) ...........91 FIGURA 5-7 DISPOSIÇÃO DE INSTRUMENTOS HIPOTÉTICOS COM VARIABILIDADE UNIFORME ..95 
FIGURA 5-8 DISPOSIÇÃO DE INSTRUMENTOS HIPOTÉTICOS COM VARIABILIDADE PONTUAL .....95 FIGURA 5-9 CURVA DE COMPARAÇÃO DO MQN DA ANÁLISE CAPWAP E A VARIABILIDADE DOS INSTRUMENTOS HIPOTÉTICOS 


\section{LISTA DE TABELAS}

TABELA 2-1 FATORES DE AMORTECIMENTO PARA O MÉTODO CASE PADRÃO .27

TABELA 2-2 MÉTODOS DINÂMICOS PARA AVALIAR A CAPACIDADE DE CARGA: VANTAGENS, DESVANTAGENS E COMENTÁRIOS (MODIFICADA DE PAIKOWSKY \& STENERSEN, 2000)....35 TABELA 3-1 VELOCIDADES RECOMENDADAS DE ONDA SEGUNDO AS PROPRIEDADES DA ESTACA (CAPWAP MANUAL, 1990)

TABELA 3-2 ONDAS REFLETIDAS PELA DESCONTINUIDADE DA ESTACA........................................51

TABELA 4-1 COEFICIENTES DE CORRELAÇÃO PARA PARÂMETROS DE SMITH (LIANG \& ZHOU, 1997)

TABELA 4-2 FUNÇÕES DE REDUÇÃO DA VARIÂNCIA PARA FUNÇÕES DE AUTOCORRELAÇÃO 1-

D. (MODIFICADO DE VANMARCKE , 1983; BAECHER \& CHRISTIAN, 2003)...................................73

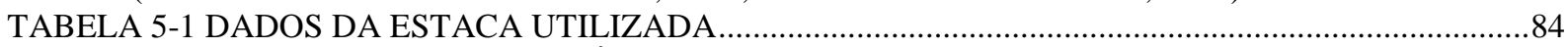

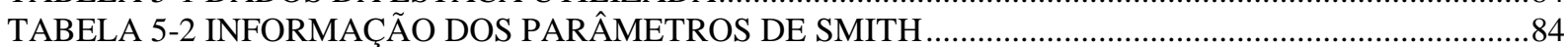

TABELA 5-3 VALORES MÉDIOS E VARIÂNCIAS DOS PARÂMETROS DE SMITH, PARA O PRESENTE CASO.

TABELA 5-4 MATRIZ DE COVARIÂNCIAS PARA RULT COM $D=1,0 \mathrm{M}, L_{S}=2,0 \mathrm{M}$, E $\sigma^{2}=0,25(\mathrm{KN})^{2}$.

TABELA 5-5 VALORES ADJACENTES Â DIAGONAL DA MATRIZ DE COVARIÂNCIAS, PARA

DIFERENTES ESCALAS DE FLUTUAÇÃO, COM LS $=2,0 \mathrm{M} \mathrm{E} \sigma^{2}=0,25(\mathrm{KN})^{2}$

TABELA 5-6 RESUMO DOS PARÂMETROS UTILIZADOS NA ATUALIZAÇÃO BAYESIANA ................94

TABELA 5-7 VALORES ATUALIZADOS DE RESISTÊNCIA ESTÁTICA ÚLTIMA (KN), COM $D=1,0 \mathrm{M}, L_{S}$ $=2,0 \mathrm{M}, \mathrm{E} \sigma^{2}=0,25(\mathrm{KN})^{2}$ VS. DIFERENTES VARIABILIDADE DE ERRO DOS INSTRUMENTOS HIPOTÉTICOS.

TABELA 5-8 VALORES ATUALIZADOS DE DAMPING SMITH (S/M), COM $D=1,0 \mathrm{M}, L_{S}=2,0 \mathrm{M}$, E $\sigma^{2}=0,25(\mathrm{KN})^{2}$ VS. DIFERENTES VARIABILIDADES DOS INSTRUMENTOS HIPOTÉTICOS .....97

TABELA 5-9 VALORES ATUALIZADOS DE $Q U A K E(\mathrm{MM}), \operatorname{COM} D=1,0 \mathrm{M}, L_{S}=2,0 \mathrm{M}, \mathrm{E} \sigma^{2}=0,25$ $(\mathrm{KN})^{2}$ VS. DIFERENTES VARIABILIDADES DOS INSTRUMENTOS HIPOTÉTICOS .

TABELA 5-10 VALORES DO MQN VERSUS A VARIABILIDADE DO ERRO DOS INSTRUMENTOS HIPOTÉTICOS (COVERRO), PARA D $=1,0 \mathrm{M}, \mathrm{LS}=2,0 \mathrm{M} \mathrm{E} \sigma^{2}=0,25(\mathrm{KN})^{2}$.. 


\section{INTRODUÇÃO}

\subsection{Generalidades}

No mundo da engenharia geotécnica algumas vezes se pensa da natureza dos fenômenos físicos que acontecem no mundo macroscópico das estruturas civis e dos processos geológicos, como se fossem "deterministas". Isso indicaria que para cada efeito se tem uma causa, ou que qualquer causa corresponde diretamente a seus efeitos. Existiriam então, leis que controlam o comportamento do mundo físico, leis com condições iniciais dadas com exatidão, nas quais poderia calcular-se com precisão o estado futuro das coisas.

Mas, se é verdade que o mundo é determinista, então, o que significa pensar no mundo das probabilidades, dos resultados aleatórios, das incertezas do modelo, das incertezas das variáveis?

Seguindo-se um ponto de vista de Laplace ${ }^{1}$ apud Jaynes (1996), a probabilidade é uma prova de que muitos fenômenos são de fato não previsíveis, principalmente devido ao fato de que nosso nível de conhecimento é insuficiente para inferir o comportamento real de certos parâmetros que caracterizam os fenômenos. Isto é, os fenômenos podem ou não se comportar segundo as bases da necessidade, desta forma, a realidade só pode ser descrita como se fosse aleatória.

Para definir o "mundo estocástico" basicamente deve-se entender as definições de aleatoriedade e de incerteza.

O termo aleatório pode ser definido sob duas perspectivas. Sob o ponto de vista objetivo, acredita-se que existe uma causa com a qual explicar qualquer fenômeno e que nada acontece por casualidade. Já no que se refere ao ponto de vista subjetivo, um fato casual é

\footnotetext{
${ }^{1}$ Laplace (1749-1827), “Essai philosophique sur les probabilités”.
} 
atribuível á falta de conhecimento para explicar tal fenômeno, portanto, a aleatoriedade uma propriedade da natureza eminentemente não previsível (Baecher \& Christian, 2003)

Segundo Baecher \& Christian (2003), na prática da engenharia geotécnica se lida com diversos tipos de incertezas, as que estão em função das leis naturais e as que dependem do estado do conhecimento. Na Figura 1-1, se apresenta o esquema das categorias de incertezas.

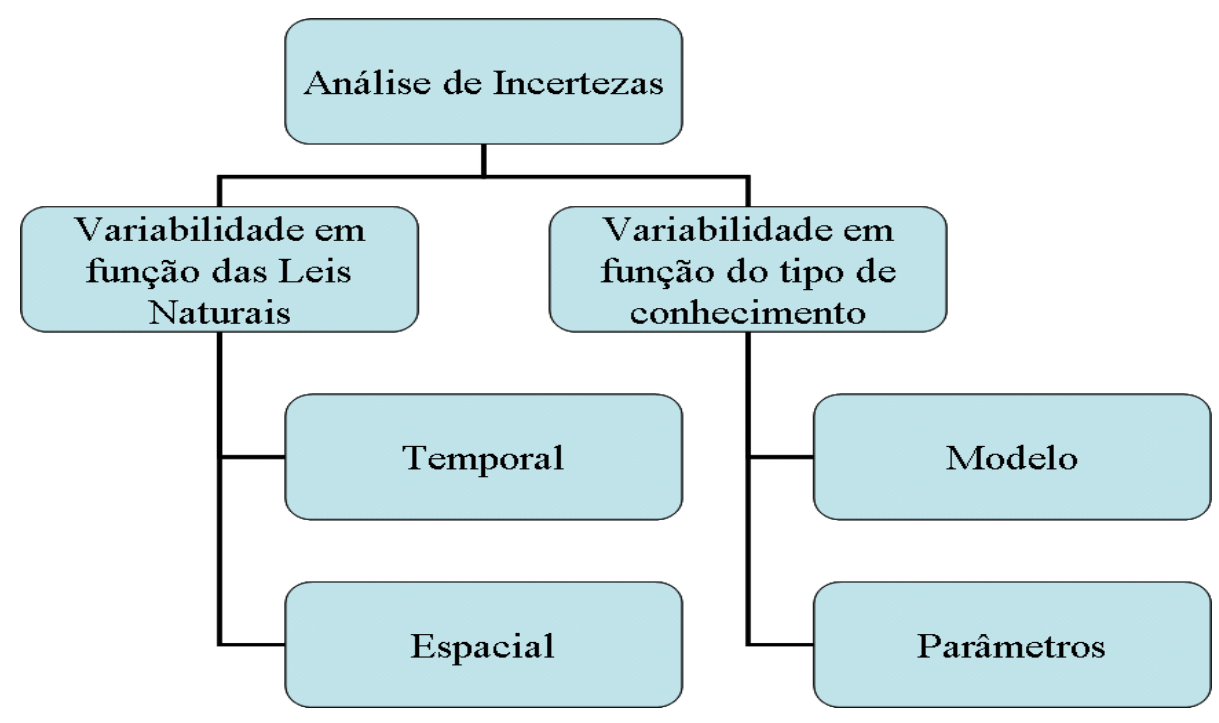

Figura 1-1 Categorias das incertezas (Baecher \& Christian, 2003)

Nota-se que no esquema da Figura 1-1, as incertezas naturais estão associadas com a inerente aleatoriedade manifestada de dois modos, uma variabilidade temporal, para fenômenos que tomam lugar em certo tempo, ou uma variabilidade espacial, para fenômenos que tomam lugar em determinado local. Por outro lado, também, as incertezas de conhecimento estão atribuídas à falta de dados, de informação entre eventos e processos, ou do entendimento das leis físicas que separam o modelo do mundo real.

Para Benjamin \& Cornell (1970), Phoon et al. (1995), e Baecher \& Christian (2003), a variabilidade geotécnica é um complexo atributo que resulta de muitas origens de incertezas. Podem-se citar três origens básicas de incerteza, a Figura 1-2 ilustra tais origens: 
a) variabilidade inerente, causada principalmente pelos processos naturais geológicos envolvidos na formação do solo;

b) erros de medida, atribuída ao equipamento, operador/procedimento, e aos efeitos aleatórios de ensaio; coletivamente essas duas fontes podem ser descritas como viés dos dados; e

c) incertezas no modelo de transformação, introduzida quando medições de campo ou de laboratório são transformadas em propriedades do solo usando modelos empíricos ou outros modelos de correlação.

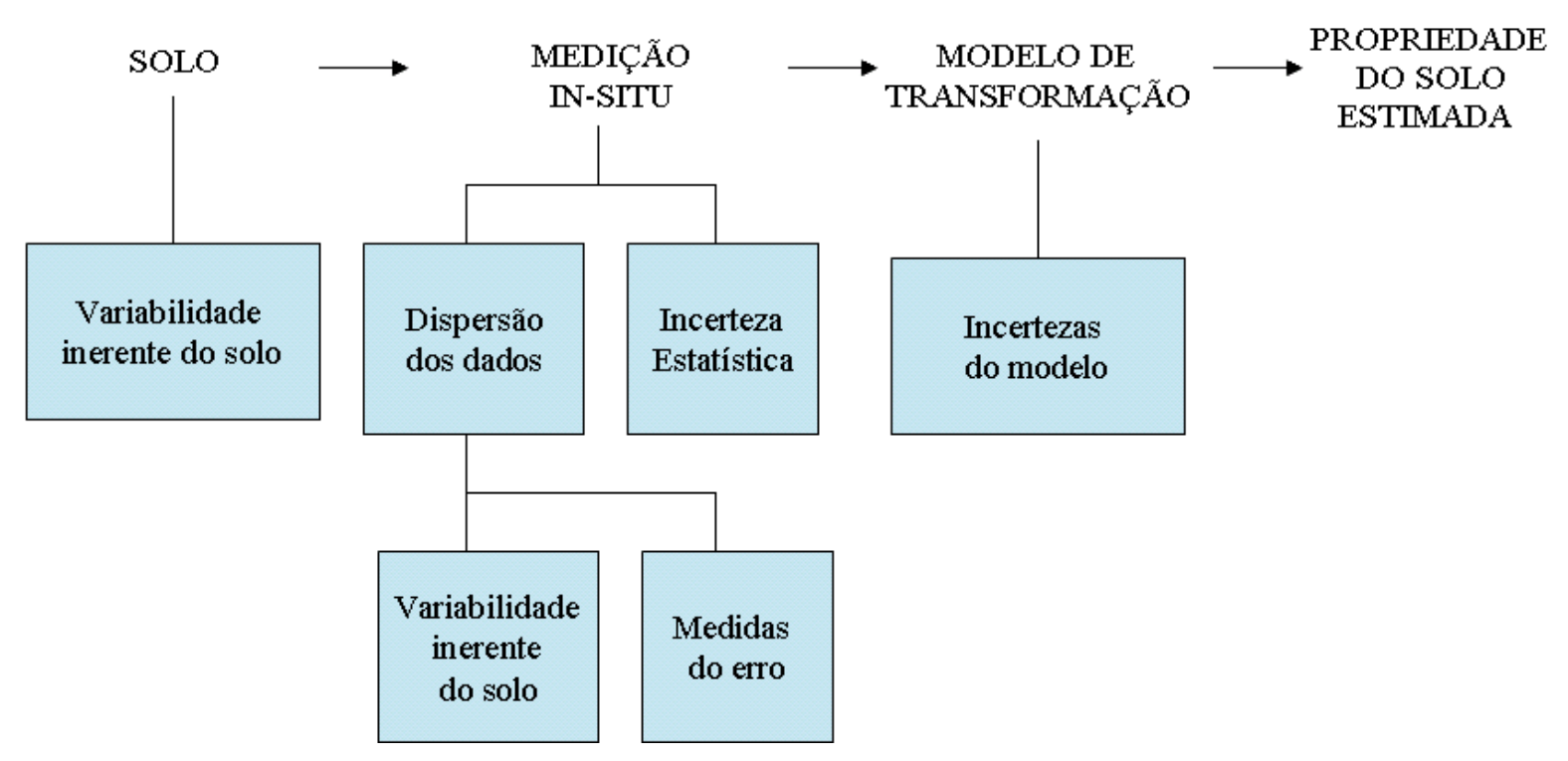

Figura 1-2 Incertezas na estimação das propriedades do solo

(Phoon et al., 1995)

Para Zagottis (1976) e Hachich (1978), o modelo numérico utilizado para a resolução dos modelos mecânicos pode-se classificar em função do tratamento das grandezas envolvidas: a modelagem determinista, quando as grandezas envolvidas são consideradas deterministas, ficando todas as incertezas e os erros implícitos nos valores encontrados. Por outro lado, na modelagem probabilista, quando as grandezas envolvidas na modelagem numérica são tratadas como variáveis aleatórias, embora o procedimento de cálculo do problema analisado seja considerado determinístico. 
Castillo \& Alonso (1983) ressaltam que a análise estatística e probabilista foi introduzida na Engenharia Geotécnica como uma ferramenta para racionalizar a heterogeneidade observada em depósitos de solo, a dispersão nos ensaios de campo e de laboratório e a propagação destas incertezas para parâmetros relevantes do projeto.

A formulação da análise probabilista tem vantagens devido ao fato de que os erros nas observações e a confiabilidade dos parâmetros estimados podem ser considerados de uma maneira direta, além disso, mediante a visão de atualização bayesiana é possível adicionar novas informações para a estimativa dos parâmetros (Hachich \& Vanmarcke, 1983; Ledesma et al., 1989). Ainda quando existe suficiente informação para análises estatísticas, uma estimativa muito mais robusta da variabilidade geotécnica pode ser obtida pela combinação de informações anteriores, usando técnicas de atualização bayesiana (Baecher \& Christian, 2003).

O modelo observacional probabilista constitui-se a extensão do método observacional idealizado por Terzaghi e Peck (1969) para atualização do projeto geotécnico em função das observações realizadas (Hachich, 1998). Tal metodologia aplica-se, no caso da presente pesquisa, para a atualização de parâmetros em função de observações feitas possibilitando deste modo a escolha da melhor ação, de acordo com o modelo de decisão preparado.

Este trabalho apresenta uma metodologia para 'atualização bayesiana' dos parâmetros de Smith, levando em conta não só os sinais registrados, mas também a informação geotécnicaprobabilista prévia sobre estes parâmetros. Uma aproximação semelhante já foi aplicada pelo orientador da pesquisa à estimativa de parâmetros geotécnicos de rochas a partir de medidas de deslocamento em túneis, e de campos de permeabilidade a partir de observações piezométricas em barragens.

A técnica proposta visa racionalizar um procedimento geotécnico usual na área de ensaios dinâmicos em fundações profundas: comparação de sinais por tentativa e erro. Ante esse fato, apresenta-se a atualização bayesiana, a qual permite que os parâmetros utilizados na comparação de sinais finais considerem, tanto as incertezas dos parâmetros iniciais como 
das imprecisões inseridas na comparação de sinais, para que ao final se obtenha um ajuste proporcional de acordo com observações.

No entanto, neste trabalho serão estudados somente os aspectos relacionados aos parâmetros do modelo mecânico de Smith: máximo deslocamento elástico (quake), o fator de amortecimento (damping) e a resistência estática última (Rult) de cada trecho da estaca. Tais parâmetros foram considerados variáveis aleatórias com distribuições prévias estimadas dependendo do local de cravação da estaca. Discute-se e calcula-se a correlação cruzada entre parâmetros diferentes e autocorrelação ao longo de profundidade da estaca.

As observações são escolhidas do sinal calculado no programa de análises de sinais de cravação, postula-se um modelo linear de observação; pesquisa-se tal linearidade; deriva-se uma matriz de sensibilidade (ligando cada parâmetro a cada observação); e também, estudase a variabilidade dos erros de observação.

O resultado final é uma distribuição de parâmetros de Smith ao longo da profundidade de estacas, atualizada de acordo com as observações.

Assim neste trabalho a aproximação proposta foi aplicada em uma estaca cravada, com sinais analisados no final da cravação (EOD).

\subsection{Objetivo da dissertação}

Com a utilização crescente de ensaios de carregamento dinâmico (NBR-13208) como método para estimativa da capacidade de carga estática de estacas a partir de um evento dinâmico, torna-se necessário considerar uma ferramenta estatística para formalizar a melhor escolha dos parâmetros dinâmicos de Smith no procedimento denominado de 'comparação de sinais' ou 'signal matching'

Esta pesquisa tem como principal objetivo apresentar uma metodologia probabilista que visa formalizar o procedimento de 'comparação de sinais' entre sinal medido e calculado, a partir 
da consideração da variabilidade dos parâmetros de Smith e das incertezas do local de cravação, p. e., dano/defeito nas juntas e comportamento de bucha na ponta de estacas maciças.

\subsection{Organização da dissertação}

Para atingir o objetivo proposto na presente pesquisa, seguimos a metodologia que fica esquematizada na Figura 1-3.

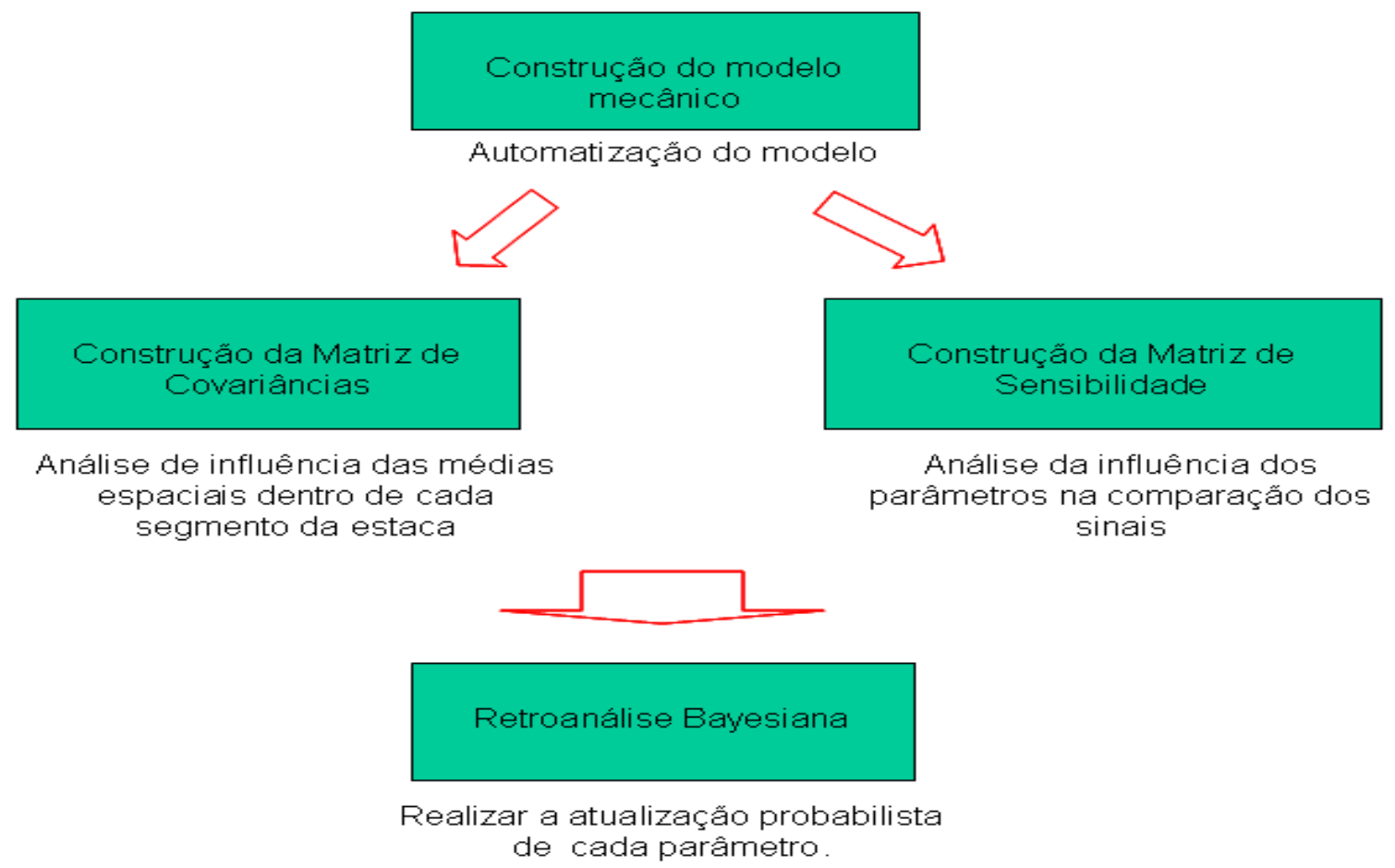

Figura 1-3 Esquema da Metodologia utilizada na presente pesquisa.

Nos parágrafos seguintes, apresenta-se uma descrição de cada capítulo do presente trabalho.

O texto está divido em 6 capítulos. Os 4 primeiros correspondem aos fundamentos teóricos e revisão bibliográfica relativa ao tema da teoria básica da onda, ao estado da arte nos ensaios dinâmicos baseados na teoria da equação de onda, e os fundamentos teóricos da teoria probabilista utilizada. Já os capítulos 5 e 6 dedicam-se à aplicação prática da metodologia proposta à análise de cravação de uma estaca maciça de concreto, à análise e apresentação de resultados, principais conclusões e pesquisas futuras. 
No capítulo 2 é feita uma revisão bibliográfica dos métodos dinâmicos utilizados no mundo inteiro para determinação de carga estática mobilizada a partir de um evento dinâmico na cabeça da estaca. No final do capítulo se apresenta uma revisão bibliográfica sobre as definições dos parâmetros dinâmicos de Smith.

No capítulo 3 se trata sobre a teoria básica da onda aplicada à cravação de estacas, a derivação das principais equações e comentários relativos à sua utilização.

No capítulo 4 é feita uma revisão dos fundamentos teóricos de atualização bayesiana de campos aleatórios unidimensionais a partir de um modelo de observação linear; também explica-se a derivação da matriz de correlação espacial e matriz de sensibilidade.

No capítulo 5 apresenta-se a aplicação prática da metodologia apresentada no Capítulo 4. Apresenta-se o caso dos sinais de cravação obtidos no momento do final da cravação de uma estaca maciça. Na parte final do capítulo é apresentada uma síntese dos principais resultados obtidos.

No capítulo 6 se apresentam as conclusões e sugestões para pesquisas futuras. 


\section{ENSAIOS DINÂMICOS: APLICAÇÃO DA TEORIA DE EQUAÇÃO DE ONDA}

\subsection{Introdução}

Primeiramente o fenômeno da cravação de estacas é normalmente descrito usando o modelo mental da Figura 2-1:

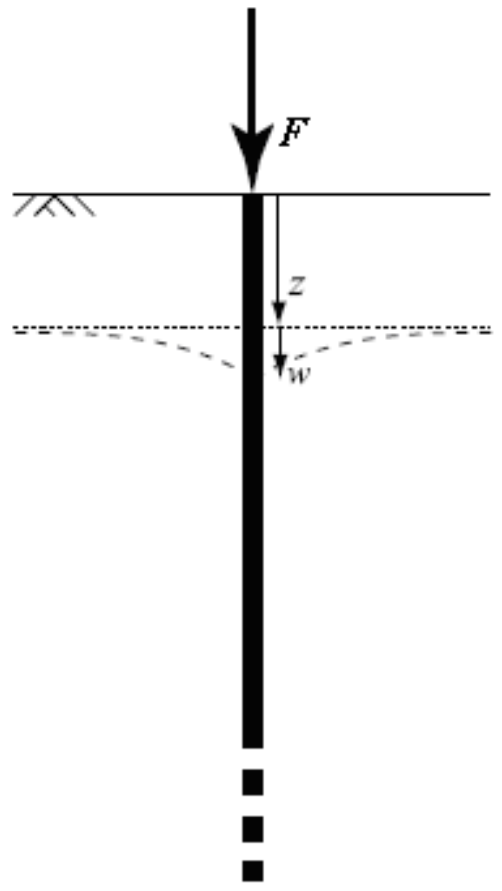

Figura 2-1 Estaca axialmente carregada em solo elástico (Wood, 2004, p. 396)

Para o modelo da Figura 2-1 a carga axialmente aplicada $(F)$ sobre a cabeça da estaca é transmitida ao solo por meio da fricção do fuste ao longo da estaca e pelo suporte da ponta fornecendo um deslocamento permanente ( $z$, nega) e um deslocamento elástico ( $w$, repique). O fenômeno da propagação de onda dentro da estaca está ilustrado na Figura 2-2. 


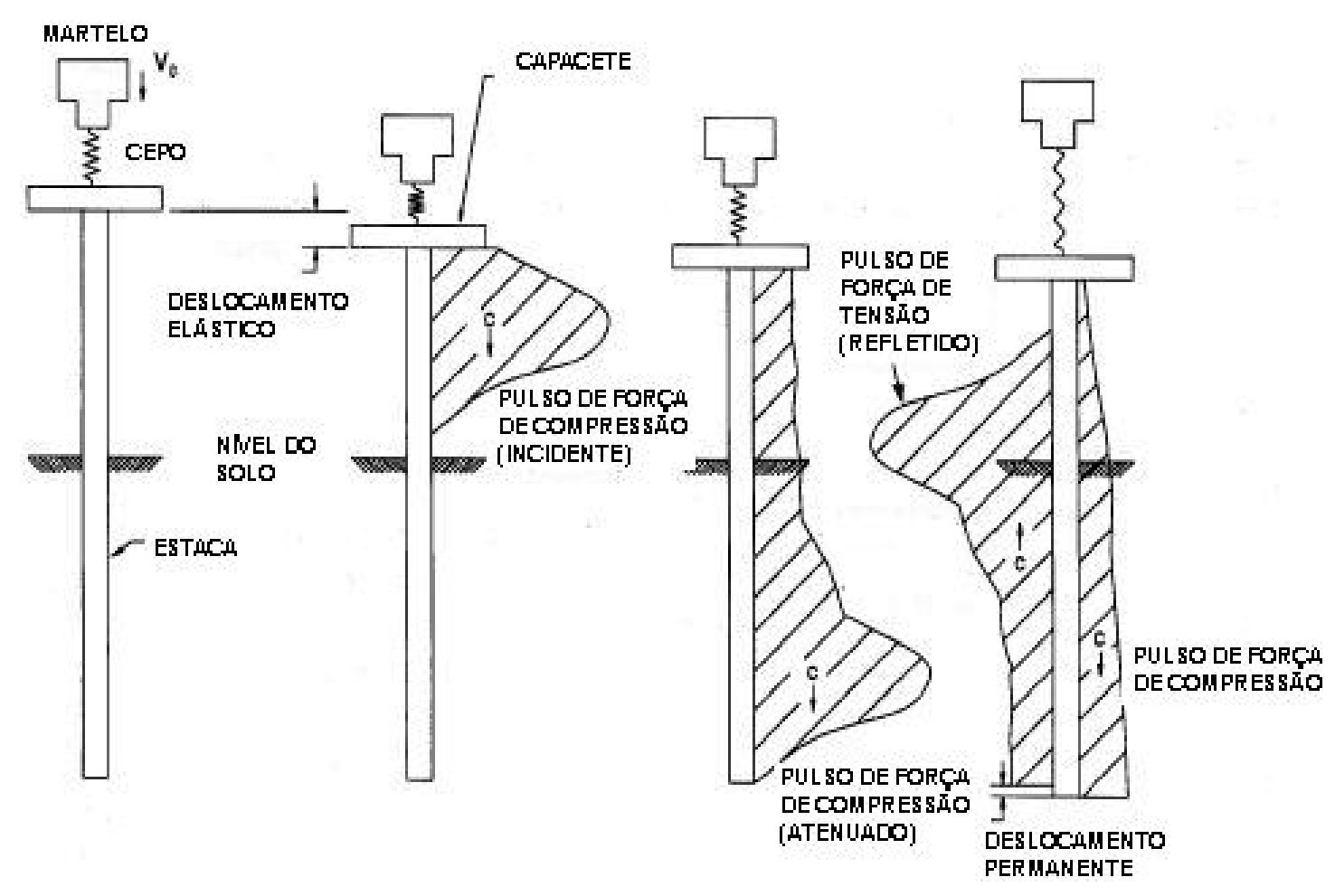

Figura 2-2 Fenômeno da propagação de onda em uma estaca (Hannigan et al., 1998).

As análises dinâmicas são métodos para a determinação da capacidade da estaca baseada no comportamento do sistema martelo-estaca-solo durante a cravação. Tais métodos estão baseados na idéia que as operações de cravação induzem à ruptura do sistema estaca-solo. Em outras palavras, o ensaio dinâmico é análogo a um ensaio de carga muito rápido sob cada golpe de martelo, onde teoricamente deve mobilizar-se a resistência estática do sistema estaca-solo. (Chellis, 1961; Paikowsky et al., 1994; Hannigan et al., 1998).

Segundo Hannigan et al., (1998) e Paikowsky \& Stenersen (2000), os ensaios dinâmicos de estacas estão aceitos e normalizados em numerosas especificações tais como 'ASTM D4945-89', 'AASHTO T298', também nas 'recomendações para ensaios de carga estáticos e dinâmicos de estacas da DGGT em Alemanha - 1997', ou especificações de vários países. No Brasil utiliza-se a NBR-13208, como recomendado pela NBR- 6422, para ensaios de carregamento dinâmico (NBR-13208, 2007). 
Segundo as hipóteses consideradas para a estimativa de capacidade de estacas existem basicamente dois métodos baseados na resistência dinâmica: as formulas dinâmicas e os métodos que utilizam a teoria da equação da onda.

\subsection{Fórmulas dinâmicas}

As fórmulas dinâmicas são utilizadas como complemento aos controles de campo. Dificilmente em uma obra instrumentam-se todas as estacas e, portanto, é necessário que de alguma forma se obtenha uma avaliação do estaqueamento em execução e que seja possível estimar a capacidade da estaca antes mesmo do ensaio de cravação.

Segundo o Manual ABEF (2002), estipula-se a nega ${ }^{2}$ e repique ${ }^{3}$ como parâmetros de controle que deverão ser obtidos para todas as estacas cravadas. O repique constitui a parcela elástica do deslocamento máximo da estaca e a nega vem a ser o deslocamento permanente da estaca (NBR-6122, 1996). Dentre eles, o conceito de 'nega' é bastante utilizado apesar das restrições técnicas atribuídas a este procedimento (Terzaghi, 1943; Chellis, 1961). Smith (1960) reportou que os editores do Engineering News Record tinham 450 fórmulas, todas elas baseadas no impacto Newtoniano.

Podem ser mencionadas algumas das assim chamadas fórmulas dinâmicas baseadas na 'nega', tais como Sanders, Engineering News, Eytelwein - Holandeses, Weisbach, Hiley, Jambu, Dinamarqueses, Gates, etc. Segundo Bilfinger (2002) a aplicação destas fórmulas aos mesmos dados, ou seja, local de cravação, peso e comprimento da estaca, peso do martelo, altura de queda do martelo, leva a uma variabilidade de resultados elevada, seja quando se deseja obter a capacidade de carga a partir de determinada nega, seja quando se deseja estimar a nega a partir de uma dada capacidade de carga.

A utilização de formulas dinâmicas como ferramenta única de projeto realmente é inadequado. Entretanto, como ferramenta de controle, a sua validade tem sido aceita na prática profissional, sendo em alguns projetos a medida da nega o único controle da cravação/decisão durante a execução da obra (Bilfinger, 2002).

\footnotetext{
${ }^{2}$ NEGA - penetração permanente da estaca provocada pela aplicação de uma série de golpes, em geral 10.

${ }^{3}$ REPIQUE - deslocamento elástico sofrido pela estaca (traduz as deformações elásticas do solo do fuste e da ponta).
} 
O critério do "repique" corresponde à obtenção da parcela elástica do deslocamento máximo de uma seção da estaca, originada a partir do impacto da cravação. Tal definição permite que as formulações dinâmicas para determinação da capacidade de carga suponham a utilização da estaca como um modelo do tipo "mola", utilizando as propriedades elásticas do elemento estrutural. Dentre as várias formulações dinâmicas baseadas no repique se podem mencionar as publicadas por Chellis (1961), Uto et al. (1985), Matsuo et al. (1989), De Rosa (2000) e, Velloso ${ }^{4}$ (1987) apud Niyama et al. (1998).

Há outra formulação simplificada baseada no balanço da máxima energia de cravação da estacas ao trabalho feito pelo sistema estaca-solo. Proposto originalmente por Paikowsky et al. (1994), como alternativa ao método CASE, tal formulação permite a aplicação direta dos resultados de medições feitas em campo, sem necessidade de instrumentação dinâmica.

\subsection{Modelo de Smith}

Isaacs $^{5}$ (1931) foi o primeiro que sugeriu que a ação da onda unidimensional fosse aplicada à análise de cravação de estacas. No curso da investigação, Isaacs lidou com um número de perguntas que tornar-se-iam centrais na análise de transmissão de ondas em estacas, os esforços de tensão em estacas de concreto, o efeito do peso do martelo, o efeito da rigidez do cepo e do coxim, e o peso do capacete, também, revelou a complexidade computacional da análise de transmissão de esforços (VULCANHAMMER.NET, 2007), logo após, Fox $\left(1932^{6}\right.$ e $\left.1938^{7}\right)$ publicou uma solução da equação da onda aplicada a estacas e para a sua utilização teve que contemplar várias simplificações em virtude dos recursos computacionais da época.

Nesse contexto, Edward A. L Smith (1960), engenheiro mecânico chefe da Raymond Company, interessado em encontrar uma forma de predizer a cravabilidade das estacas, com

\footnotetext{
${ }^{4}$ VELLOSO, P.P.C. 1987. Fundações -Aspectos Geotécnicos. Publi. Depto. Engenharia Civil da PUC - Rio de Janeiro, vol. 2/3 - Notas de Aula NA 01/82, 5a edição, setembro.

${ }^{5}$ ISAACS, D.V. 1931. REINFORCED CONCRETE PILE FORMULAE. Transactions of the Institute of Engineers, Australia, Paper No. 370, Vol XII, pp. 312-323.

${ }^{6}$ FOX, E.N. 1932. Stress Phenomena Occurring in Pile Driving. Engineering, vol. 134, Sept.

${ }^{7}$ FOX, E.N, et al, 1938, British Building Research. Paper No. 20, DSIR.
} 
ênfases nas tensões dinâmicas de cravação, produz a primeira solução geral para a aplicação da teoria de onda de esforços em estacas.

O método numérico de Smith (1960), formulado em diferenças finitas, tornou-se prático para ser programado segundo a tecnologia da época, considerado aparentemente como a primeira aplicação do computador digital na engenharia civil (Bowles, 1974; Poulos \& Davis, 1974; Hussein \& Goble, 2004). A Figura 2-3 descreve essencialmente o modelo mecânico de Smith (1960).

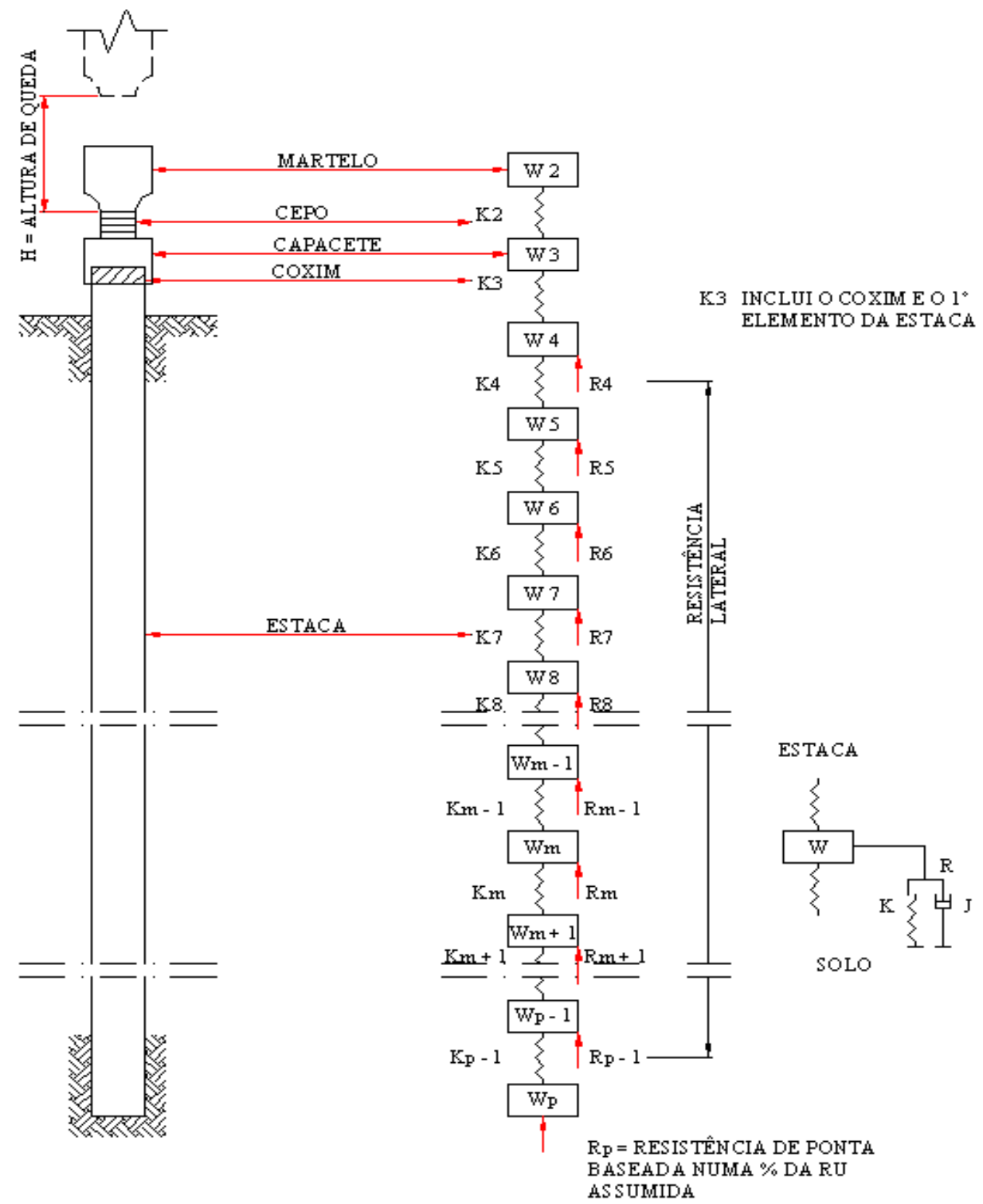

A) ESTACA $\quad$ B) MODELO DE DIFERENÇAS FINITAS

PARA SOLUÇÃO DA EQUAÇÃO DE ONDA

Figura 2-3 Modelo de Smith (1960) 
Os elementos básicos que Smith $(1955,1960)$ utilizou para descrever a interação dinâmica solo-estaca foram:

- Divisão da estaca em uma série de molas e massas. O martelo foi modelado como uma massa com um cepo (mola). O capacete também foi modelado como uma massa e coxim (outra mola).

- Utilização da técnica de diferenças finitas de primeira ordem.

- Modelagem do cepo e do coxim usando uma técnica de histerese "estática", definida como uma constante de mola elástica durante a compressão e modificada por um "coeficiente de restituição" durante o rebote.

- Modelagem do solo ao redor da estaca como uma combinação de deslocamentos dependentes das molas e velocidades dependentes dos amortecedores.

- Modelagem das não-linearidades do solo; por meio do modelo reológico conjugado (Zagottis, 1976), que combina deformações elasto-plásticas (representadas pelas molas) e deformações viscosas (representada pelo amortecedor), ver Figura 2-4.
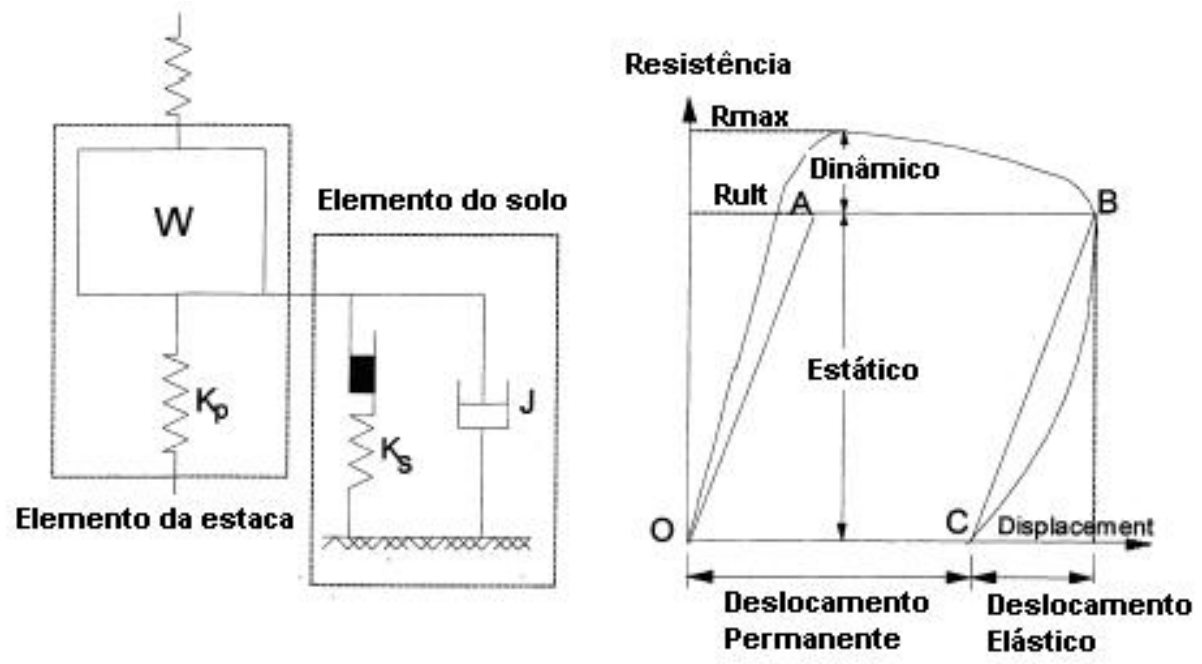

Figura 2-4 Modelo e parâmetros do sistema estaca-solo (Smith, 1960)

A Figura 2-4, ilustra a definição dos parâmetros do modelo de Smith (1960): componente elasto-plástica (deformação elástica máxima: quake, e, resistência estática última: Rult), e componente visco-linear (constante de amortecimento: damping). 
No modelo de Smith (1960), o martelo bate na estaca, produzindo um deslocamento no seguinte intervalo de tempo. Os deslocamentos das duas massas produzem uma compressão da mola entre elas; essa compressão na mola cria uma força de amortecimento, assim, as duas forças de amortecimento e a resistência atuante na massa criam uma força que acelera ou desacelera a massa e produz uma nova velocidade. Essa nova velocidade, por sua vez, produz um novo deslocamento no seguinte intervalo de tempo. Esse processo é repetido para cada massa em cada intervalo de tempo, até que a velocidade induzida seja nula.

Smith (1960) propôs o seguinte sistema de equações:

$$
\mathrm{D}(\mathrm{m}, \mathrm{t})=\mathrm{D}(\mathrm{m}, \mathrm{t}-\mathrm{l})+\operatorname{delt} * \mathrm{~V}(\mathrm{~m}, \mathrm{t}-\mathrm{l})
$$

$$
C(m, t)=D(m, t)-D(m+1, t)
$$

$$
\mathrm{F}(\mathrm{m}, \mathrm{t})=\mathrm{C}(\mathrm{m}, \mathrm{t}) \cdot \mathrm{K}(\mathrm{m})
$$

$R(m, t)=\left[D(m, t)-D^{\prime}(m, t)\right] \cdot K^{\prime}(m) \cdot[1+J(m) \cdot V(m, t-1)]$

$\mathrm{V}(\mathrm{m}, \mathrm{t})=\mathrm{V}(\mathrm{m}, \mathrm{t}-\mathrm{l})+[\mathrm{F}(\mathrm{m}-\mathrm{l}, \mathrm{t})-\mathrm{F}(\mathrm{m}, \mathrm{t})-\mathrm{R}(\mathrm{m}, \mathrm{t})] . \mathrm{g} * \operatorname{delt} / \mathrm{W}(\mathrm{m})$

Onde

$m$ é o número de segmento da estaca;

$t$ denota o número de intervalo de tempo;

delt é a medida do intervalo de tempo entre iterações;

$V(m, t)$ é a velocidade da massa $m$ durante o intervalo de tempo $t$ (em metros/seg.);

$C .(m, t)$ é a compressão da mola $m$ durante o intervalo de tempo $t$ (em $\mathrm{mm})$;

$F(m, t)$ é a forca exercida pela mola numero $m$ e $m+1(\mathrm{em} \mathrm{kN})$; e

$K(m)$ é o coeficiente de rigidez do elemento $m(\mathrm{em} \mathrm{kN} / \mathrm{m})$.

A seguir apresentam-se alguns resultados obtidos após a utilização do Modelo de Smith (1960). Visando simular o cálculo de sinais de força e velocidade na etapa inicial da pesquisa, foi necessária a elaboração de um programa computacional seguindo a 
metodologia proposta por Smith $(1955,1960)$. Para tal fim, utilizou-se o MATLAB ${ }^{\circledR}$ no intuito de calcular iterativamente as rotinas originais. A Figura 2-5 ilustra os resultados encontrados para o caso apresentado no artigo original de Smith (1960). Nas iterações finais encontram-se os parâmetros do modelo de Smith para a ponta da estaca: deslocamento permanente da estaca $(s)$, e deslocamento elástico (quake, Q).

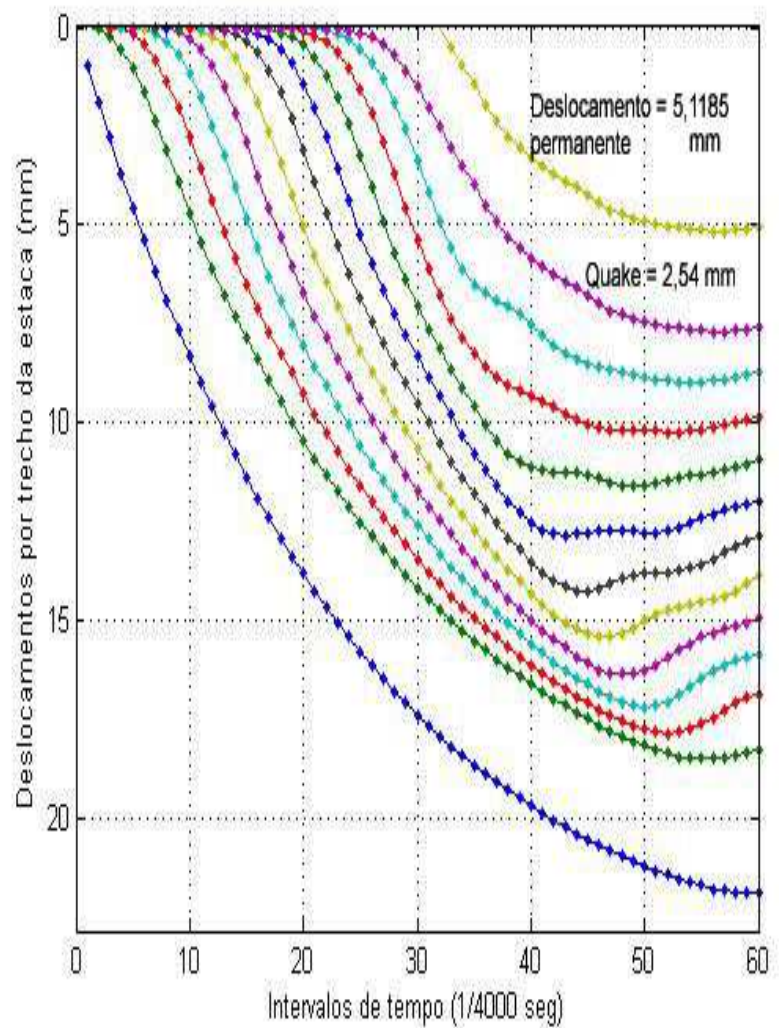

(a) Simulação no MATLAB ${ }^{\circledR}$

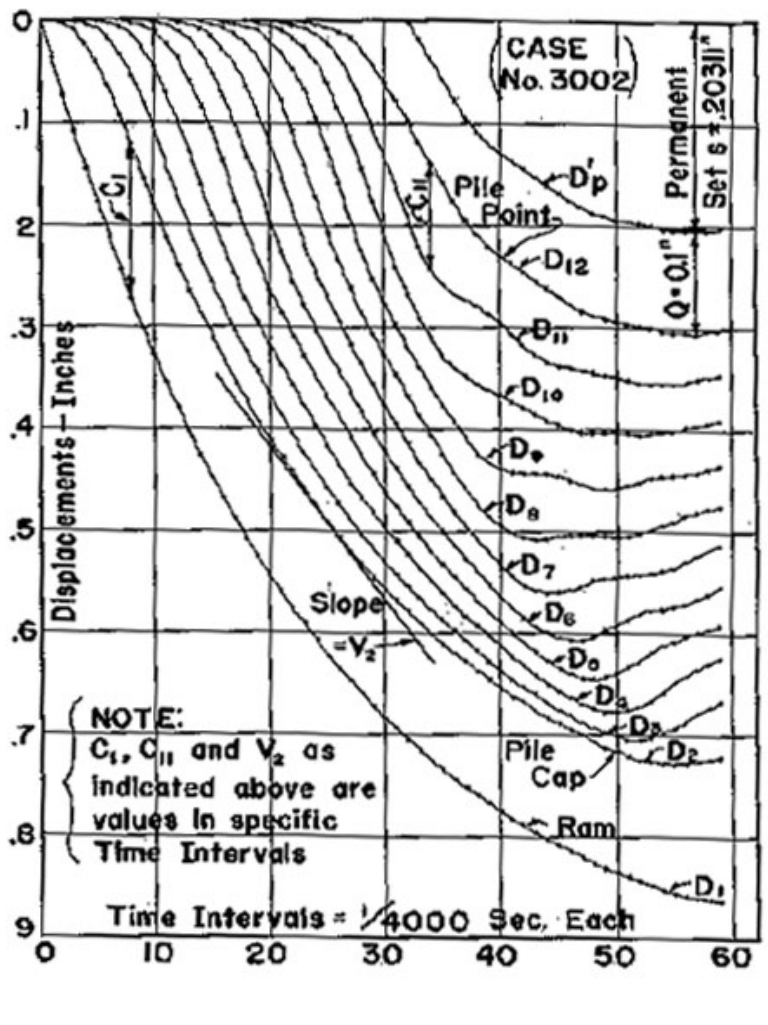

(b) Resultados de Smith (1960)

Figura 2-5 Comparação de resultados encontrados para o exemplo de Smith (1960)

A Figura 2-6(a) ilustra o deslocamento devido à força induzida no trecho da ponta da estaca, e na Figura 2-6(b) representa-se o comportamento do cepo $(e=0.50)$ na mola $\left(K_{l}\right)$ do primeiro trecho do modelo (ver Figura 2-3). 


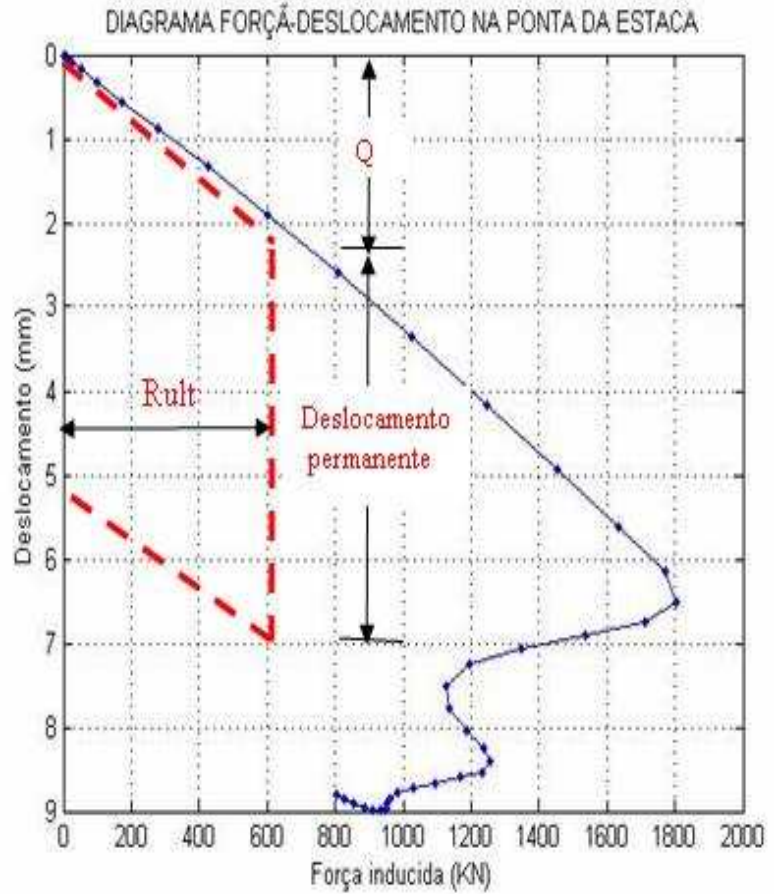

(a) Comportamento da ponta da estaca

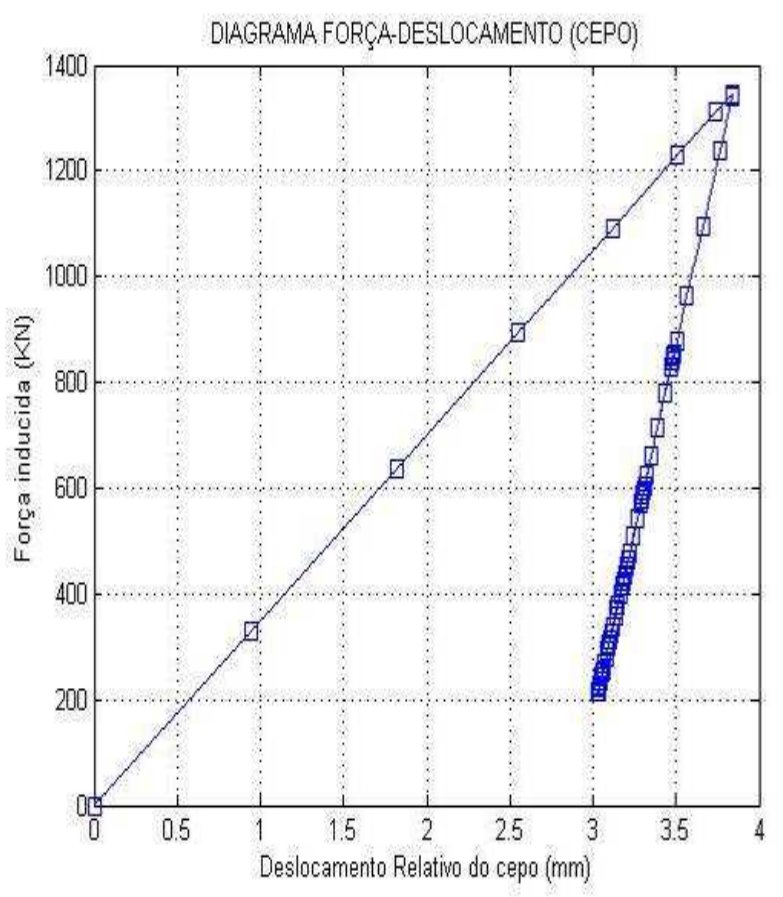

(b) Comportamento do Cepo

Figura 2-6 Diagramas na simulação no MATLAB ${ }^{\circledR}$ : (a) Comportamento da ponta da estaca, e (b) Comportamento do Cepo, para o exemplo de Smith (1960)

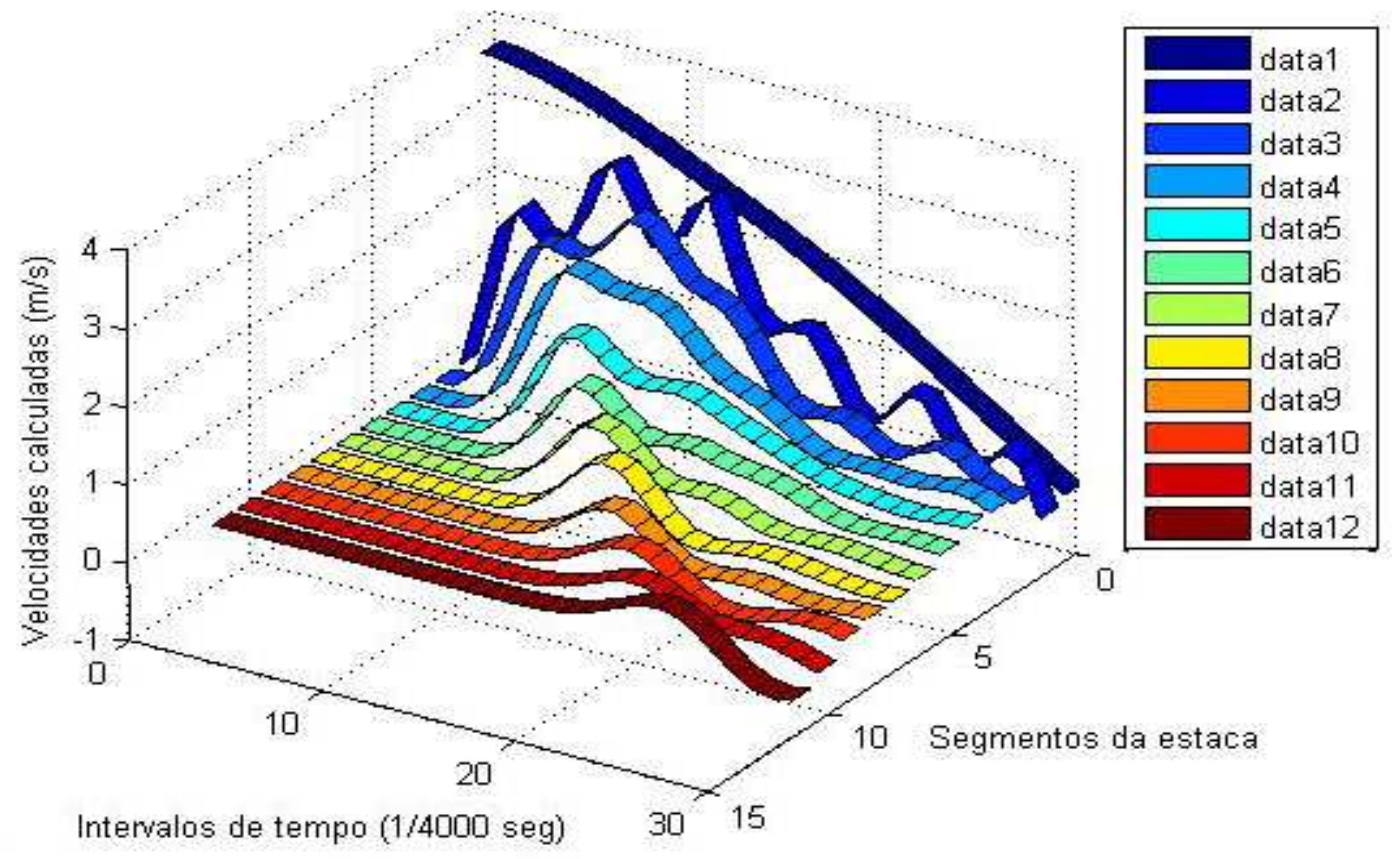

Figura 2-7 Velocidades simuladas no MATLAB ${ }^{\circledR}$ para o exemplo de Smith (1960) 
A Figura 2-7 ilustra os sinais de velocidades dos pulsos de onda simulados no MATLAB ${ }^{\circledR}$ para o mesmo exemplo de Smith (1960). Nota-se que os mesmos pulsos de velocidades são divididos para cada um dos trechos da estaca, incluindo o sinal de velocidades do martelo e do solo localizado na ponta da estaca. Pode-se construir o mesmo gráfico para: deslocamentos, ondas de forças de compressão ou tração.

$\mathrm{Na}$ atualidade as formulações da equação da onda são usadas de duas maneiras gerais: análises pré-cravação que não precisam de medições dinâmicas e, análises pós-cravação baseadas nas medições dinâmicas.

\subsection{Análise Dinâmica sem Medições Dinâmicas}

Entende-se por Análises Dinâmicas sem medições dinâmicas aqueles métodos que resolvem o problema da propagação de onda de impacto, simulando o sistema de cravação por inteiro mediante o modelo do martelo. A seguir apresentam-se em ordem cronológica os métodos que foram desenvolvidos a partir do Modelo de Smith (1960):

\subsubsection{Programa TTI (Texas)}

Na década de 1960, pesquisadores do Texas Transportation Institute (TTI) produziram um programa computacional de análise da equação de onda baseado fundamentalmente no método de Smith (1960), e desenvolveram importantes estudos numéricos relativos ao comportamento dinâmico de estacas. (Sanson et al., 1963; Lowery et. al., 1969).

O programa MICROWAVE ${ }^{\circledR}$ é a última versão do programa de equação de onda TTI. Desenvolvido no Texas A\&M University, é considerado a versão definitiva para estacas (Lowery, 1993).

\subsubsection{Programa GRLWEAP ${ }^{\circledR}$}

Nenhum dos programas baseados no modelo de Smith, mesmo o da TTI conseguiu modelar as complexidades de combustão de martelo diesel, que tornou-se popular nos EUA nos anos 1960. Tal deficiência foi corrigida pelo Programa WEAP ${ }^{\circledR}$ (Wave Equation Analysis of Pile driving), desenvolvido e apresentado por Goble \& Rausche (1976, 1986). 
O Programa WEAP ${ }^{\circledR}$ está baseado fundamentalmente no modelo de Smith (1960) e tem sido continuamente melhorado, tanto na facilidade de entrada de dados como nas características técnicas do programa, tais como: a análise de tensões residuais, modelagem da interface estaca-solo e, a análise de cravabilidade (Rausche et al., 1988)

Atualmente o WEAP $^{\circledR}$ é denominado GRLWEAP ${ }^{\circledR}$ e fornece uma base de dados diversificada para cerca de 650 modelos de martelos (martelos de impacto, acionados por ar, vapor, pressão hidráulica ou combustão de diesel, e martelos vibratórios), e sistemas de cravação (cepo, capacete e coxim). Também, podem-se utilizar informações da base de dados interna, como diversos tipos de estaca, e vários tipos de solo (Rausche et al., 2004).

GRLWEAP $^{\circledR}$ é um software disponível para simulação da cravação de estacas, que consegue estimar as tensões dinâmicas da estaca, capacidade de carga, contagem de golpes e tempo de instalação.

O GRLWEAP $^{\circledR}$ tem como principais características: (GRLWEAP Manual, 2003)

1. Determina análises de cravabilidade, que possibilita estimar os esforços de tração e compressão para uma determinada profundidade de cravação, ou se é atingida uma nega antes de uma profundidade estimada;

2. Estima as resistências de cravação, capacidade de suporte baseada na nega ou o número de golpes observados em campo, ara um sistema martelo-estaca dado;

3. Para martelos vibratórios, substitui o número de golpes com a velocidade de penetração;

4. Consegue ajudar com a seleção de um martelo apropriado e um sistema de cravação para um caso de obra onde o estaqueamento, os perfis de solo e as capacidades requeridas; e

5. Calcula o tempo total de cravação. 


\subsubsection{Programas TNOWAVE ${ }^{\circledR}$}

Embora a teoria de onda de tensão e medidas de onda de tensão já tinha sido aplicada na Holanda nos anos 1950, De Josseling de $\mathrm{Jong}^{8}$ (1956) foi o primeiro em utilizar o método das características na cravação de estacas baseado nas equações de Saint Venant ${ }^{9}$. Posteriormente, Voitus van Hamme et al. ${ }^{10}$ (1974) incorporou ao método em questão a resistência de fuste e de ponta, além do fenômeno de pressão neutra. Em 1978, o Governmental Research Institute (TNO) liberou a utilização do programa da equação de onda TNOWAVE ${ }^{\circledR}$ (Middendorp, 2004).

O método características derivado a partir da teoria da equação de onda, assume-se que a resistência de atrito se concentra em certos pontos discretizados ao longo do fuste da estaca. Entre cada dois desses pontos a estaca fica sem atrito, e a onda viaja sem apresentar resistência nenhuma. A onda viaja de um ponto a outro, chegando nele, uma parte da onda é refletida e a outra transmitida. As magnitudes das ondas refletidas e transmitidas dependem das propriedades da estaca, da fricção de fuste e da resistência de ponta. As equações para calcular tais ondas são derivadas a partir de duas condições básicas: a condição de equilíbrio e a condição de continuidade, resultando a Eq. 2-6 e Eq. 2-7, que explicam a trajetória das ondas refletidas e transmitidas, respectivamente.

$$
\begin{aligned}
& f_{n, i}^{\uparrow}=\left(-\frac{Z_{N}-Z_{N+1}}{Z_{N}+Z_{N+1}}\right) f^{\downarrow}+\left(\frac{Z_{N}}{Z_{N}+Z_{N+1}}\right)\left(2 f^{\uparrow}+W_{n, i}\right) \\
& f_{n, i}^{\downarrow}=\left(\frac{Z_{N}-Z_{N+1}}{Z_{N}+Z_{N+1}}\right) f^{\uparrow}+\left(\frac{Z_{N+1}}{Z_{N}+Z_{N+1}}\right)\left(2 f^{\downarrow}-W_{n, i}\right)
\end{aligned}
$$

A Figura 2-8, ilustra o algoritmo do método das características para o TNOWAVE ${ }^{\circledR}$

\footnotetext{
${ }^{8}$ DE JOSSELIN DE JONG, G. 1956, "Wat gebeurt er in de grond tijdens het heien" (What happens in the soil during pile driving) De Ingenieur, No. 25, Breda, The Netherlands,.

${ }^{9}$ SAINT-VENANT. B. de, 1867, Memoire sur le doc longitudinal de deux barres elastiques, Journal de Mathematique, 2, ser XII, pp 237-376.

${ }^{10}$ VOITUS VAN HAMME, et al.1974, Hydroblok and improved pile driving analysis, De Ingenieur, no 8, vol 86, pp 345-353, The Netherlands
} 

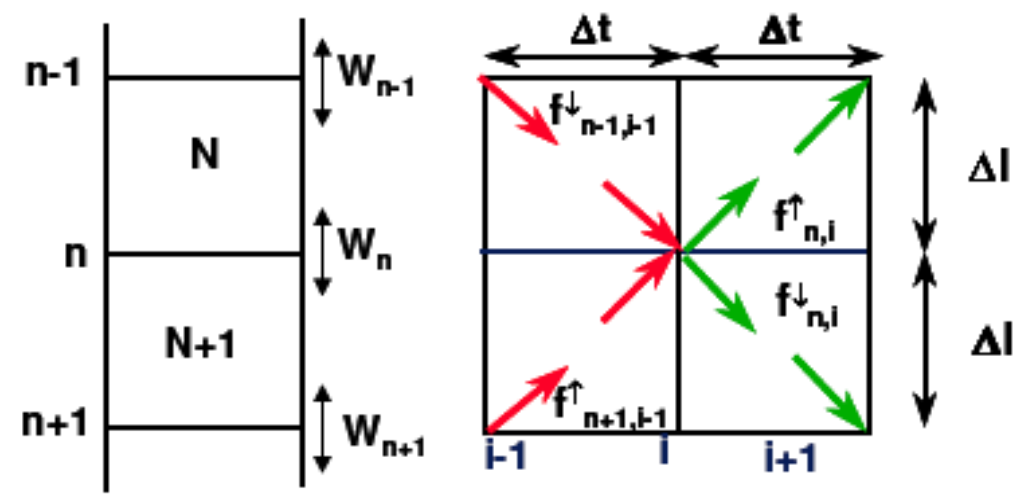

Figura 2-8 Algoritmo TNOWAVE ${ }^{\circledR}$ (Middendorp, 2004)

A Figura 2-9 ilustra a propagação de onda de esforços no método das características.
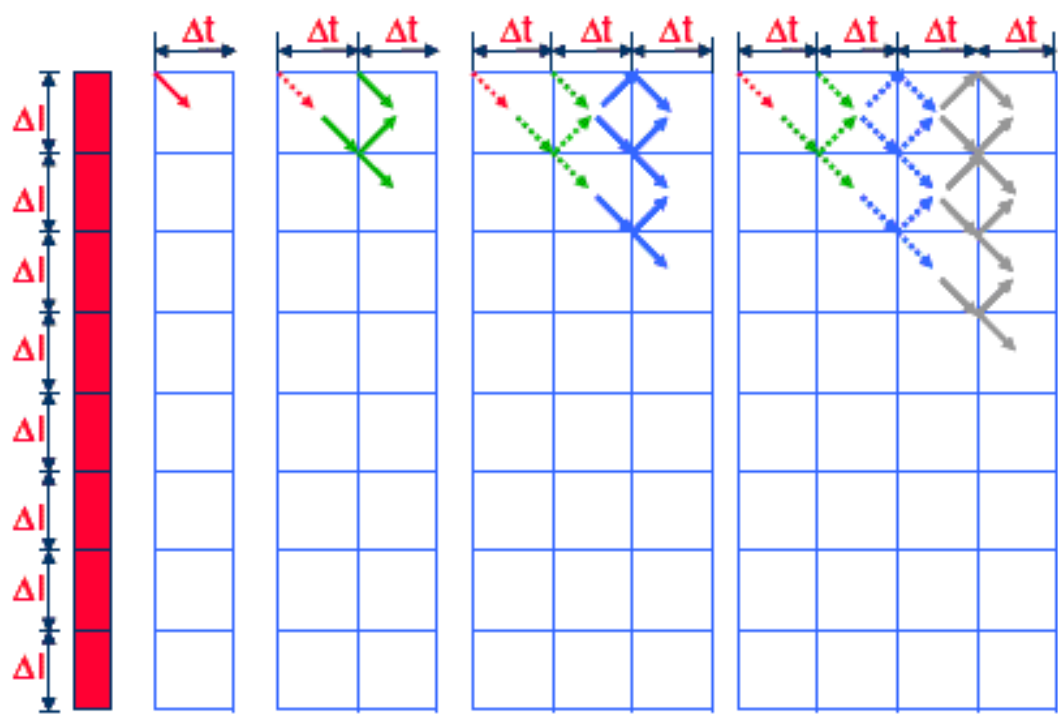

\section{Profundidade}

Figura 2-9 Propagação da onda no método das características (Middendorp, 2004)

$\mathrm{Na}$ atualidade o programa TNOWAVE ${ }^{\circledR}$, ainda baseado no método de características, tem aplicações diversas no campo do ensaio de estacas: estudos de cravabilidade para martelos de impacto (PDPWAVE ${ }^{\circledR}$ ) e martelos vibratórios $\left(\right.$ VDPWAVE $^{\circledR}$ ), comparação de sinais para ensaio de carregamento dinâmico (DLTWAVE ${ }^{\circledR}$ ), no ensaio de integridade de estacas $\left(\right.$ SITWAVE $\left.^{\circledR}\right)$ e para análise do ensaio do Statnamic (STNWAVE). Existem também versões do TNOWAVE utilizadas por empresas fabricantes de martelos de cravação de estacas: IHCWAVE ${ }^{\circledR}$ da IHC de Holanda para martelos hidráulicos, APEWAVE $^{\circledR}$ da APE 
dos Estados Unidos para martelos de impacto, e BERMWAVE ${ }^{\circledR}$ da Berminhammer de Canada (Middendorp, 2004).

\subsubsection{Programa ZWAVE}

Desenvolvido na empresa Vulcan Iron Works e baseado no programa TTI, o programa ZWAVE é um programa da equação de onda baseado em diferenças finitas, concebido para analisar o comportamento de sistemas martelo-estaca com martelos de combustão ou martelos hidráulicos (Warrington, 1988).

O programa ZWAVE ${ }^{\circledR}$ apresenta algumas características principais: um modelo de solo que calcula o amortecimento radial do solo com rigidez constante das molas e quakes calculados a partir dos parâmetros elásticos do solo (ver Figura 2-10). Também possibilita um formato de entrada de dados iterativo (Warrington, 2007).

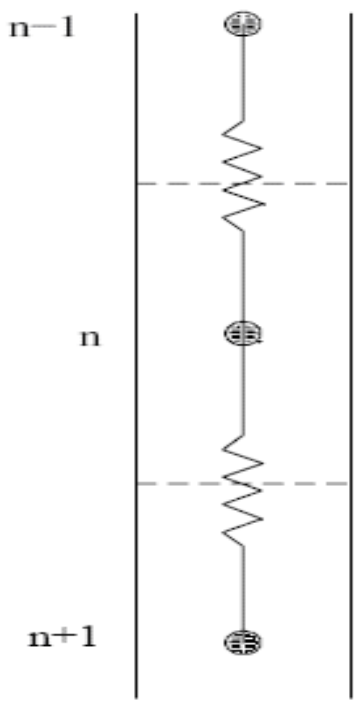

(a) Modelo da estaca

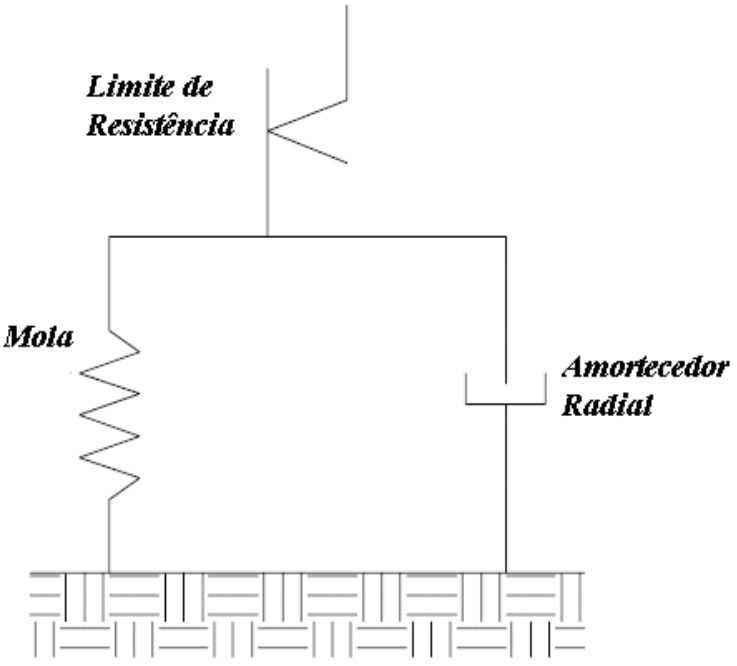

(b) Modelo do solo

Figura 2-10 Características computacionais do ZWAVE ${ }^{\circledR}$ (Warrington, 1988)

\subsubsection{Programa TAMWAVE ${ }^{\circledR}$}

Criado com fins acadêmicos, o programa de equação de onda TAMWAVE ${ }^{\circledR}$ (Texas A\&M Wave) é uma adaptação do programa TTI, cuja rotina permite através de "tentativa e erro" 
determinar o martelo apropriado na previsão do sistema de cravação. O projeto foi desenvolvido durante o período de 2004-2006, e atualmente disponível on-line no site da Vulcam Equipment (VULCANHAMMER.NET, 2007).

Segundo Warrington (2007) o Programa TAMWAVE ${ }^{\circledR}$ utiliza o dado de capacidade de carga da estaca encontrado pelo método de Denis \& Olson ${ }^{11}$ e 12 (1983), no qual o solo é considerado homogêneo e a estaca modelada com secção uniforme, considera-se a distribuição de resistência uniforme para solos coesivos e triangular para solos não-coesivos. O Programa da equação de onda se restringe a martelos de impacto e de combustão externa com cepo (da linha de martelos Vulcan \& Raymond), excluindo da análise martelos diesel sem cepo. Este programa, não considera a mudança da capacidade da estaca após o estaqueamento. Nos resultados, o programa apresenta em forma de tabelas as capacidades da estaca versus a 'resistência de cravação' (ou número de golpes por metro).

\subsection{Medições Dinâmicas (PDA)}

Glambille et $a l^{13}$. (1938) apud VULCANHAMMER.NET (2007) começou com a instrumentação da cabeça da estaca no momento da cravação, o qual constituiu a primeira utilização dos sinais capturados em campo para determinação da capacidade de carga de estacas, trabalho pelo qual pode ser considerado como o "pai" das medições dinâmicas.

A partir dos anos 1960, Goble fundou a Pile Dynamics, Inc. (PDI), a companhia que fabrica, entre outras coisas, o PDA (Pile Driving Analyzer). E por outro lado ele com outros socios também fundou a "Goble Rausche Likins \& Associates" (GRL). A PDI gradualmente melhorou a tecnologia do PDA $^{\circledR}$, sempre utilizando os últimos avanços na tecnologia eletrônica e de computadores. Além disso, novos equipamentos foram desenvolvidos e introduzidos no mercado. A GRL, por outro lado, desenvolveu métodos e "softwares" para a

\footnotetext{
${ }^{11}$ DENNIS, N.D., OLSON, R.E. (1983). Axial Capacity of Steel Pipe Piles in Clay. Proc. of the Conference on Geotechnical Practice in Offshore Engineering. New York: American Society of Civil Engineers, pp. 370-388.. ${ }^{12}$ DENNIS, N.D., OLSON, R.E. (1983). Axial Capacity of Steel Pipe Piles in Sand. Proc. of the Conference on Geotechnical Practice in Offshore Engineering. New York: American Society of Civil Engineers, pp. 389402.

${ }^{13}$ GLANVILLE, W.H., G. GRIME, E.N. FOX AND W.W. DAVIES. (1938). "An Investigation of the Stresses in Reinforced Concrete Piles During Driving." Technical Paper No. 20, British Building Research Station, London, England.
} 
análise dos sinais obtidos. Concebido inicialmente como um método para estacas cravadas, o PDA foi gradualmente sendo introduzido também para medição da capacidade de carga de estacas moldadas "in loco" (CAPWAP Manual, 1990).

Para Hannigan et at.(1998), as análises dinâmicas baseadas em sinais de cravação com ajuda do PDA ${ }^{\circledR}$, objetivam principalmente a obtenção:

- Da capacidade de carga da estaca na ocasião do ensaio. Para levar em consideração os efeitos de variação da capacidade com o tempo, as medições são feitas durante uma recravação da estaca.

- Das tensões dinâmicas durante a cravação (ou recravação) da estaca. Para diminuir a possibilidade de dano durante sua instalação ou recravação, é importante que as tensões na estaca sejam mantidas dentro de limites aceitáveis. Em estacas de concreto, as tensões de tração são também importantes.

- Da integridade da estaca, que freqüentemente deve ser verificada durante e após a instalação ou execução da mesma.

- Do desempenho do martelo utilizado na cravação, dado importante para avaliar a produtividade e controle do estaqueamento.

Um equipamento tipo PDA, visa apresentar os sinais de força e velocidade no topo da estaca. A força é obtida por meio de sensores de deformação, cujo sinal é multiplicado pelo módulo de elasticidade do material da estaca, e pela área de seção na região dos sensores. A velocidade é obtida a partir da integração do sinal de acelerômetros. São utilizados dois transdutores de cada tipo, colocados diametralmente opostos, cujos sinais são enviados por cabo até o PDA ${ }^{\circledR}$.

Ambos os transdutores são fixados à estaca por parafusos; colocados em uma seção situada pelo menos um diâmetro e meio abaixo do topo da estaca para atingir a "equalização dos sinais" (Valverde $\left.{ }^{14}, 2006\right)$.

\footnotetext{
${ }^{14}$ VALVERDE, S. Comunicação pessoal. Set. 2006.
} 
O PDA processa os sinais dos sensores e os envia a um conversor analógico-digital. O equipamento é dotado de um micro-computador. Os dados referentes aos parâmetros da estaca, sensibilidade dos sensores, etc. são previamente inseridos pelo operador. O programa interno lê os dados digitalizados dos sensores e obtém a média dos dois sinais de força e a média dos dois sinais de velocidade. É à partir destes dois sinais que o PDA efetua os cálculos, utilizando o método CASE descrito posteriormente. Após cada golpe do martelo, o PDA exibe os valores de interesse, e armazena os sinais obtidos.

\subsubsection{Método CASE}

$\mathrm{O}$ método $\mathrm{CASE}^{\circledR}$ é um método simplificado para determinação da capacidade estática de carga, que consiste em uma solução matemática fechada para calcular a resistência à penetração de uma estaca cravada, a partir de medições de força e velocidade, feitas com instrumentos localizados perto do topo da estaca (Rausche et al., 1985).

A era dos ensaios dinâmicos em estacas, baseados em medições dinâmicas da onda de tensão, começou nos anos 50 no 'Case Institute of Tecnology' em Ohio. O método foi criado com o intuito de avaliar o desempenho do sistema martelo-estaca-solo utilizando medições de campo e processamento de dados em tempo real (Rausche et al., 1985; Hussein \& Goble, 2004)

O método do $\mathrm{CASE}^{\circledR}$, na 'Fase I', foi derivado e apresentado por Goble et al. ${ }^{15}$ (1967) e Goble \& Rausche ${ }^{16}$ (1970) apud Hussein \& Goble (2004), onde a estaca foi modelada como um corpo rígido.

Na Fase II do método CASE ${ }^{\circledR}$, apresentada por Rausche ${ }^{17}$ (1970) apud Hussein \& Goble (2004), e Rausche et al. (1985), considerou-se a estaca como uma barra elástica para avaliar a resposta do solo e desse modo, a capacidade da estaca. Foram algumas consideradas

\footnotetext{
${ }^{15}$ GOBLE, G.G., R.H. SCANLAN AND J.J. TOMKO. (1967). "Dynamic Studies on the Bearing Capacity of Piles." Highway Research Record, No. 167, pp. 46-47, April.

${ }^{16}$ GOBLE, G.G.; RAUSCHE F. (1970). Pile Load Test by Impact Driving. Highway Research Record, No. 333.

17 RAUSCHE, F. (1970). Soil Response from dynamic analysis and measurements on piles. Ph. D. thesis, Case Western Reserve University, Cleveland, Ohio.
} 
hipóteses simplificadoras do sistema estaca-solo sob carregamento axial da estaca: comportamento plástico ideal do solo, estaca idealmente elástica e de secção uniforme,.

A Figura 2-11 descreve essencialmente o método $\mathrm{CASE}^{\circledR}$, e ilustra os pontos de interesse nos sinais de força e velocidade.

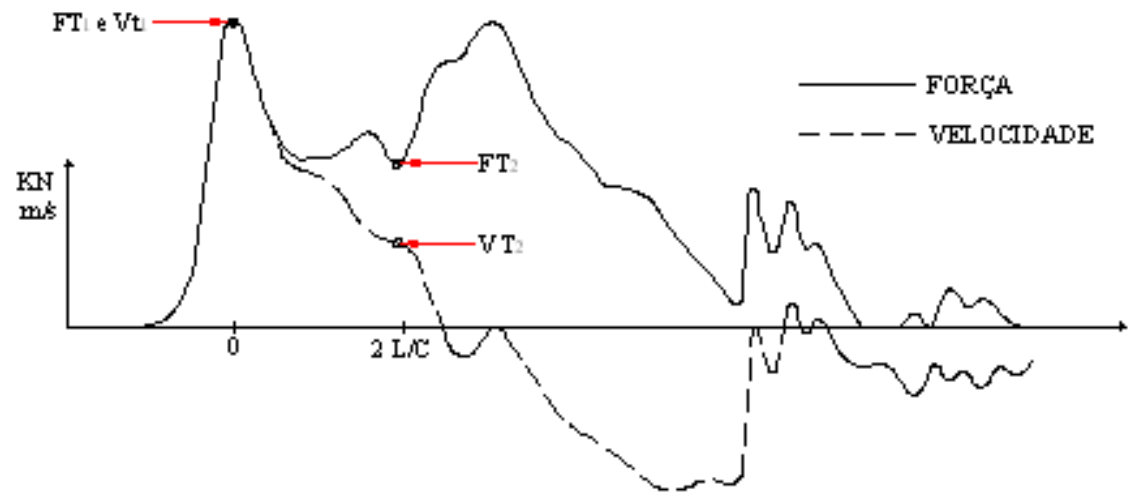

Figura 2-11 Método CASE ${ }^{\circledR}$ Padrão (Hannigan et al., 1998).

A resistência total pode ser calculada como uma função de tempo, utilizando as equações Eq. 2-8 e Eq. 2-9.

$$
\begin{gathered}
\text { Rtotal }=\frac{1}{2}\left[F\left(T_{1}\right)+F\left(T_{1}+\frac{2 . L}{C}\right)\right]+\frac{E \cdot A}{2 \cdot c} \cdot\left[v\left(T_{1}\right)+v\left(T_{1}+\frac{2 . L}{C}\right)\right] \\
\text { R.estâtica }=\text { Rtotal }-J \cdot\left[v\left(T_{1}\right) \cdot \frac{E \cdot A}{c}+F\left(T_{1}\right)-\text { Rtotal }\right]
\end{gathered}
$$

Onde

$F\left(T_{1}\right) \quad=$ Força medida no tempo $\mathrm{T}_{1} ;$

$F\left(T_{1}+\frac{2 . L}{C}\right)=$ Força medida no tempo $\mathrm{T}_{1}$ mais $2 \mathrm{~L} / \mathrm{c}$;

$v\left(T_{1}\right) \quad=$ Velocidade medida no tempo $\mathrm{T}_{1} ;$

$v\left(T_{1}+\frac{2 . L}{C}\right)=$ Velocidade medida no tempo $\mathrm{T}_{1}$ mais $2 \mathrm{~L} / \mathrm{c}$;

E, A = Modulo de elasticidade e secção da estaca; e

c $\quad=$ Velocidade de onda. 
Maiores detalhes sobre a da derivação das equações Eq. 2-8 e Eq. 2-9, podem ser encontrados em Rausche et al. (1985).

O método do CASE apresenta duas variações, a primeira denominada 'Standard CASE Method', onde o valor da resistência estática encontrada, conhecida com o símbolo 'RSP', considera o tempo $\mathrm{T}_{1}$ no primeiro pico de velocidade, ver Figura 2-11, para um determinado valor de fator de amortecimento dinâmico CASE ' $J_{c}$ '. Este método é aplicável quando não se considera deformação elástica do solo, quer dizer para estacas de pouco deslocamento do solo (low displacement piles) e estacas com grandes resistências de fuste (Paikowsky et al., 1994; Hannigan et al., 1998; PDI Engenharia, 2006).

A segunda variação do método original é denominada 'Maximum CASE Method', os valores das resistências estáticas encontradas, conhecido com o símbolo 'RMX', consideram o tempo $\mathrm{T}_{1}$ deslocado do pico de velocidade, ver Figura 2-12, condição identificada pelo programa a partir dos sinais de força e velocidade. Este método considera a máxima deformação elástica do solo, normalmente para resistências de ponta elevadas e em estacas de deslocamento com quakes na ponta altos. Devido à demora da mobilização da resistência de ponta, esse método é válido para estacas maciças ou embuchadas (Paikowsky et al., 1994; Hannigan et al., 1998; PDI Engenharia, 2006).

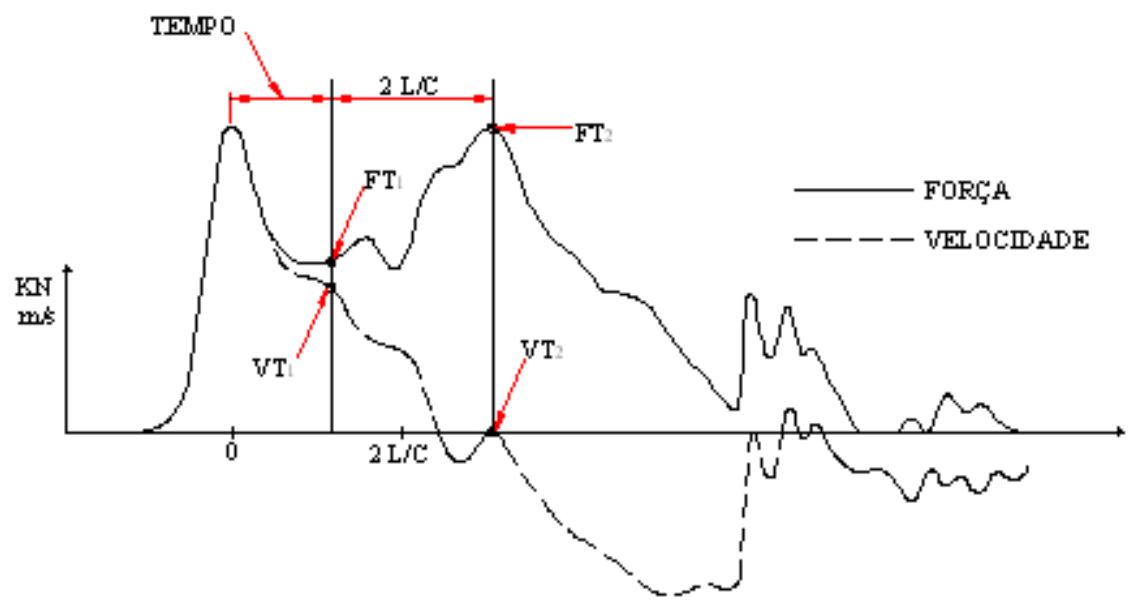

Figura 2-12 Método CASE ${ }^{\circledR}$ Máximo (Hannigan et al., 1998) 
Para Goble et al. (1975), os efeitos dinâmicos produzem uma resistência por amortecimento concentrada perto da ponta da estaca, nesse sentido os valores de fator de amortecimento CASE podem ser determinados em função do tipo de solo correspondente à ponta da estaca. Na Tabela 2-1 apresentam-se os valores de damping CASE.

Tabela 2-1 Fatores de amortecimento para o Método CASE Padrão

\begin{tabular}{|c|c|c|}
\hline $\begin{array}{c}\text { Tipo de solo na ponta da } \\
\text { estaca }\end{array}$ & $\begin{array}{c}\text { Fator de amortecimento } \\
\text { "CASE Damping" } \\
\text { (Goble } \text { et al., 1975) }{ }^{17}\end{array}$ & $\begin{array}{c}\text { Fator de amortecimento } \\
\text { CASE } \\
\text { (Hannigan } \text { et al., 1998) }\end{array}$ \\
\hline Areia limpa & 0,05 a 0,20 & 0,10 a 0,15 \\
Areia siltosa, silte arenoso & 0,15 a 0,30 & 0,15 a 0,25 \\
Silte & 0,20 a 0,45 & 0,25 a 0,40 \\
Silte argiloso & 0,40 a 0,70 & 0,40 a 0,70 \\
Argila & 0,60 a 1,10 & 0,70 a mais \\
\hline
\end{tabular}

Para Valverde $(2006)^{14}$ os valores de fatores de amortecimento de solo usados para o método de CASE, não dependem unicamente do tipo de solo mas também dependeriam do sistema de cravação, e da própria inércia da estaca. Portanto, tal incerteza dos resultados, produto da utilização do método $\mathrm{CASE}^{\circledR}$ em obra, podem ser confirmados utilizando algum procedimento de comparação de sinais que utiliza os sinais de força e velocidade medidas no PDA ${ }^{\circledR}$, p.e. CAPWAP ${ }^{\circledR}$.

Os valores de "damping" utilizados em campo para a estimativa da carga estática mobilizada são preliminares, haja vista que são produto da utilização do método CASE $^{\circledR}$ junto ao PDA ${ }^{\circledR}$, ou da utilização do método de previsão, p.e. WEAP ${ }^{\circledR}$. A estimativa feita em campo da resistência mobilizada e dos outros parâmetros de Smith analisados (quake, damping e Rult) é melhorada com as ferramentas disponíveis em qualquer modelo numérico com procedimento de comparação de sinais que utiliza os sinais de força e velocidade medidas produto do $\mathrm{PDA}^{\circledR}$; p.e. CAPWAP ${ }^{\circledR}$

${ }^{14}$ VALVERDE, S. Comunicação pessoal. Set. 2006. 


\subsection{Análise Dinâmica com Medições Dinâmicas}

Uma análise dinâmica para determinação de carga estática a partir de procedimentos de monitoramento de estacas utiliza modelos numéricos que aproximam a interação estaca-solo mediante a simulação computacional de um evento medido durante o ensaio. Tal modelo tenta descrever o fenômeno da mobilização da resistência do solo promovido pelo golpe da cravação, a resistência lateral do fuste, a resistência de ponta, a mobilização da resistência viscosa e a resistência por radiação do solo (Goble \& Likins, 1996; Charue, 2004).

O principal objetivo do método da análise de sinais de cravação mediante a comparação de sinais é ajustar os parâmetros que caracterizam o modelo estaca-solo. A escolha de tais parâmetros obedece a um critério de comparação de sinais. Quando o critério é atingido, considera-se que o modelo descreve o modelo estaca-solo e que o objetivo foi satisfeito (Goble \& Likins, 1996).

O critério de comparação de sinais comumente utilizado por numerosos procedimentos, listados abaixo, utiliza como dados de entrada e controle os sinais de força e velocidade obtidos no topo da estaca em função do tempo, produto do PDA ${ }^{\circledR}$ (Charue, 2004).

Para Charue (2004), o procedimento de comparação de sinais utilizado por diversos métodos segue um roteiro com as etapas similares:

a) Escolha da condição de contorno do modelo; pode ser o sinal de força ou velocidade.

b) O operador utilizando a condição de contorno, calcula a resposta do sistema estaca-solo de acordo com a sua experiência. Calcula-se a velocidade (se a condição de contorno é a força) ou a força ( se a condição de contorno e a velocidade) em função dos parâmetros do modelo.

c) O sinal calculado e o sinal medido (não a condição de contorno) são comparados e com um critério de qualidade determina o ajuste entre ambos os sinais.

d) Se a comparação é suficiente, o procedimento termina e os parâmetros encontrados configuram o modelo estaca-solo para o ensaio dinâmico. 
e) Se o critério de qualidade não satisfaz os requerimentos de conformidade, os parâmetros do modelo são re-estimados, e uma nova análise deverá ser efetuada para melhorar o critério de qualidade na comparação de sinais.

\subsubsection{Análise CAPWAP ${ }^{\circledR}$}

Goble et al. ${ }^{18}$ (1970), Rausche ${ }^{13}$ (1970) apud Hussein \& Goble (2004), Rausche et a., 1972 e, Goble et al. (1975) apresentaram um método analítico semelhante ao desenvolvido para a análise de equação de onda, chamado CAPWAP ${ }^{\circledR}$ (CAse Pile Wave Analysis Program) que substituiu o modelo da energia liberada pela queda do martelo na teoria da equação de onda (p. e. método GRLWEAP ${ }^{\circledR}$ ), pela utilização das medições feitas dos sinais de forças e velocidade coletadas no topo da estaca (Hannigan, et at.,1998; Rausche et al., 2000)

No CAPWAP ${ }^{\circledR}$, uma estaca é simulada matematicamente pelo modelo mecânico de Smith (1960), o qual representa a interação estaca-solo. O modelo admitido para o solo possui para cada ponto três incógnitas agindo em um só trecho da discretização da estaca (Niyama, 1983; Liang \& Zhou, 1997; Gonçalves et al., 1999).

1. Resistência estática unitária última (Rult);

2. Deformação elástica máxima (quake: Q); e

3. Constante de amortecimento (damping: J).

O CAPWAP® utiliza os registros da variação com o tempo de duas grandezas independentes, a força e a velocidade na região dos sensores, obtidos pelo PDA. Os dados da estaca são conhecidos, e os parâmetros do solo são inicialmente assumidos. O programa resolve a equação da onda, utilizando como condição de contorno uma das variáveis (por exemplo, a velocidade), para obtenção da outra variável da qual se possui um registro (no mesmo exemplo, a força). Os sinais medidos e calculados são comparados, e o modelo do solo é iterativamente modificado, até que a mais perfeita coincidência possível dos dois seja alcançada. Para solução da equação da onda é utilizado o algoritmo inicialmente proposto

\footnotetext{
${ }^{18}$ GOBLE, G. G., LIKINS, G, AND RAUSCHE, F., 1970. Dynamic Studies on the Bearing Capacity of Piles Phase III, Report No. 48. Division of Solid Mechanics, Structures, and Mechanical Design. Case Western Reserve University.
} 
por E.A.L. Smith (1960), atualmente bastante aprimorado a partir da extensa experiência existente. (Rausche et al., 2000; PDI Engenharia, 2006). A Figura 2-13 esquematiza o modo de iteração do programa, relativo aos parâmetros de Smith (Rult, $Q$ e $J$ ).

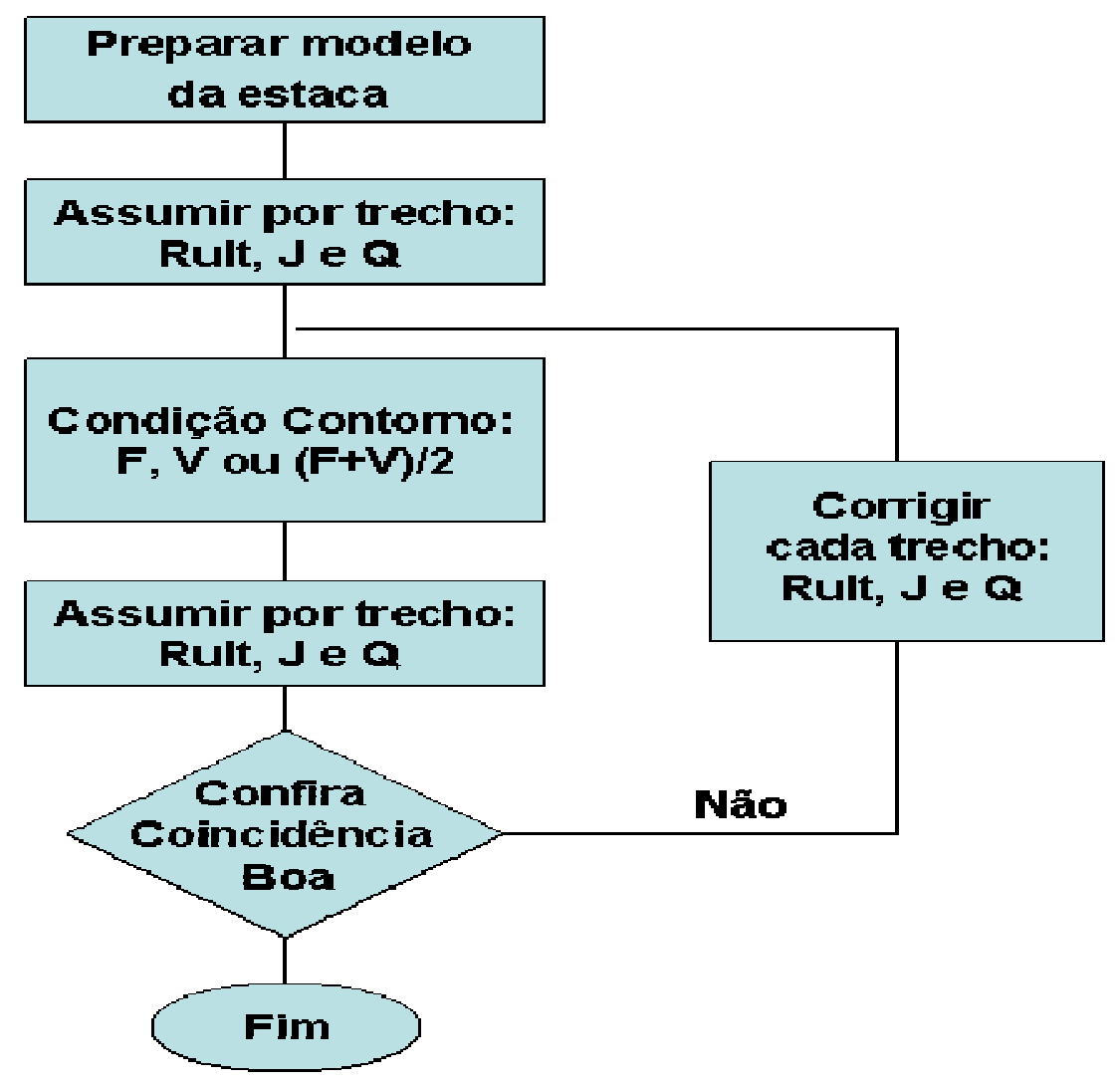

Figura 2-13 Fluxograma do CAPWAP ${ }^{\circledR}$ (Gonçalves et al., 1999)

Atualmente o CAPWAP ${ }^{\circledR}$, foi melhorado a partir do modelo mecânico de Smith (1960), com recursos adicionais da representação do conjunto interativo estaca-solo, tais como: a descontinuidade entre a ponta da estaca e o solo subjacente ('gap' da ponta), considerações de amortecimento radial e análise de tensões residuais na estaca (Gonçalves, et al., 1999).

\subsubsection{Análise TNOWAVE ${ }^{\circledR}$ (Módulo DLTWAVE ${ }^{\circledR}$ )}

Na Holanda a empresa TNO, depois de liberar o programa da equação de onda TNOWAVE $^{\circledR}$ em 1978, continuou pesquisando os parâmetros dinâmicos utilizados para modelar o solo estabelecendo técnicas de comparação de sinais baseado no método das características ampliado, desse modo, em 1982 foi liberado o modulo DLTWAVE ${ }^{\circledR}$ da 
TNO, com técnicas similares ao CAPWAP ${ }^{\circledR}$, que utiliza como adquiridor de dados o PDA. (Middendorp, 2004).

O DLTWAVE ${ }^{\circledR}$ é uma aplicação utilizada para determinar a capacidade de carga e o comportamento da carga estática do deslocamento da estaca. O golpe de um ensaio de carga dinâmico é introduzido no topo da estaca ao modelo e os sinais são calculados na cabeça da estaca. Uma comparação é feita entre sinais calculados e medidos. Os parâmetros do modelo de solo são iterativamente atualizados até atingir boa semelhança entre sinais medidos e calculados. O comportamento carga vs. deslocamento é obtido automaticamente, calculado a partir do modelo de solo (DLTWAVE Specifications, 2007).

O modelo de solo TNOWAVE $^{\circledR}$ segue a aproximação de Smith (1960) com duas alternativas: com um termo estático elasto-plástico e um termo dinâmico linearmente dependente da velocidade; ou um modelo mais complexo que permite modelar a energia dissipada no solo por radiação (Charue, 2004), o comportamento histerético do solo também pode ser levado em conta (DLTWAVE Specifications, 2007).

\subsubsection{Análise SIMBAT ${ }^{\circledR}$}

Para Paquet (1988), Dali \& Heritier (1992) e $\operatorname{Stain}^{19}$ (1992) apud Charue (2004), O programa SIMBAT $^{\circledR}$ é um procedimento utilizado para determinar a curva equivalente da prova de carga estática versus deslocamento, usando uma seqüência completa de golpes de um ensaio de carregamento dinâmico para transmitir diferentes níveis de energia. Nos métodos clássicos de análise de ensaios dinâmicos, somente é preciso um golpe para estudar o comportamento dinâmico da estaca.

O SIMBAT $^{\circledR}$ está baseado no fato de que com deformações altas a relação resistência dinâmica / resistência estática é mais alta que com índices baixos de deformação. Deste modo, uma seqüência de golpes é fornecida à estaca de modo que um vasto intervalo de índices de deformação é explorado com o objetivo de projetar a resistência dinâmica versus

\footnotetext{
${ }^{19}$ STAIN D. (1992). SIMBAT - a dynamic load test for bored piles. In Piling: European practice and worldwide trends. Tomas Telford, London, 1992, pp 198-205.
} 
a penetração por golpe para índices diferentes de deformação. A resistência dinâmica deveria corresponder ao índice de deformação zero (Charue, 2004).

Para Charue (2004), no método SIMBAT ${ }^{\circledR}$ a resistência dinâmica é calculada pela teoria clássica da equação de onda usando a fórmula $\operatorname{CASE}^{\circledR}$ (Eq. 2-8 e Eq. 2-9), a simulação feita no programa pode ser utilizada para verificar se ocorre a ruptura durante o retorno na onda. Considera-se a ruptura se a resistência calculada do modelo corresponde com a do método $\mathrm{CASE}^{\circledR}$; atingida a ruptura na estaca-solo se valida o modelo de interação estaca-solo da Figura 2-14

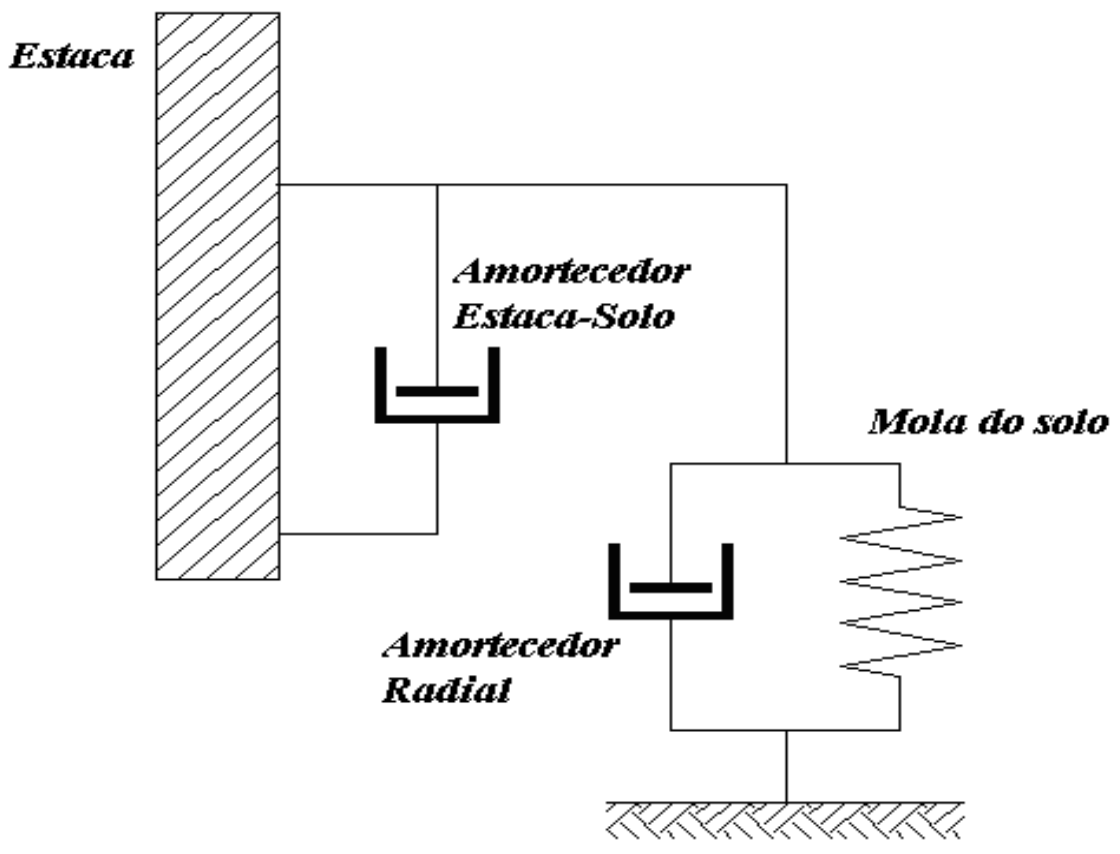

Figura 2-14 Modelo da estaca-solo no programa SIMBAT ${ }^{\circledR}$ (Charue, 2004)

O modelo da estaca-solo adotado para o programa SIMBAT ${ }^{\circledR}$ distingue o comportamento da interface estaca-solo e do solo propriamente dito. Os três meios (estaca, interface e solo) têm movimentação própria e a reação associada é ligada a este movimento.

A metodologia utilizada pelo programa $\operatorname{SIMBAT}^{\circledR}$ é a seguinte:

- Aquisição de sinais (diversos golpes);

- Separação de forças (transmitidas e refletidas);

- Medições das reações dinâmicas de solo;

- Análise da regressão dos golpes para calcular os parâmetros do sistema estaca-solo; 
- Extração da resistência estática da resistência dinâmica;

- Tomar em conta o encurtamento da estaca e projetar a curva carga-recalque;

- Confirmar com uma simulação computacional usando o modelo explicado (acima) para verificar a hipótese, e para calcular a distribuição da resistência do solo. Uma curva hiperbólica recalque-carga total.

\subsubsection{Análise KWAVE ${ }^{\circledR}$}

O programa KWAVE ${ }^{\circledR}$ desenvolvido no Japão (Matsumoto \& Takei, 1991) leva em conta a propagação de onda no solo dentro da estaca circular vazada, também a influência da resistência de fuste no interior do solo dentro. O modelo do solo para o fuste e a ponta da estaca segue o modelo apresentado na Figura 2-15.

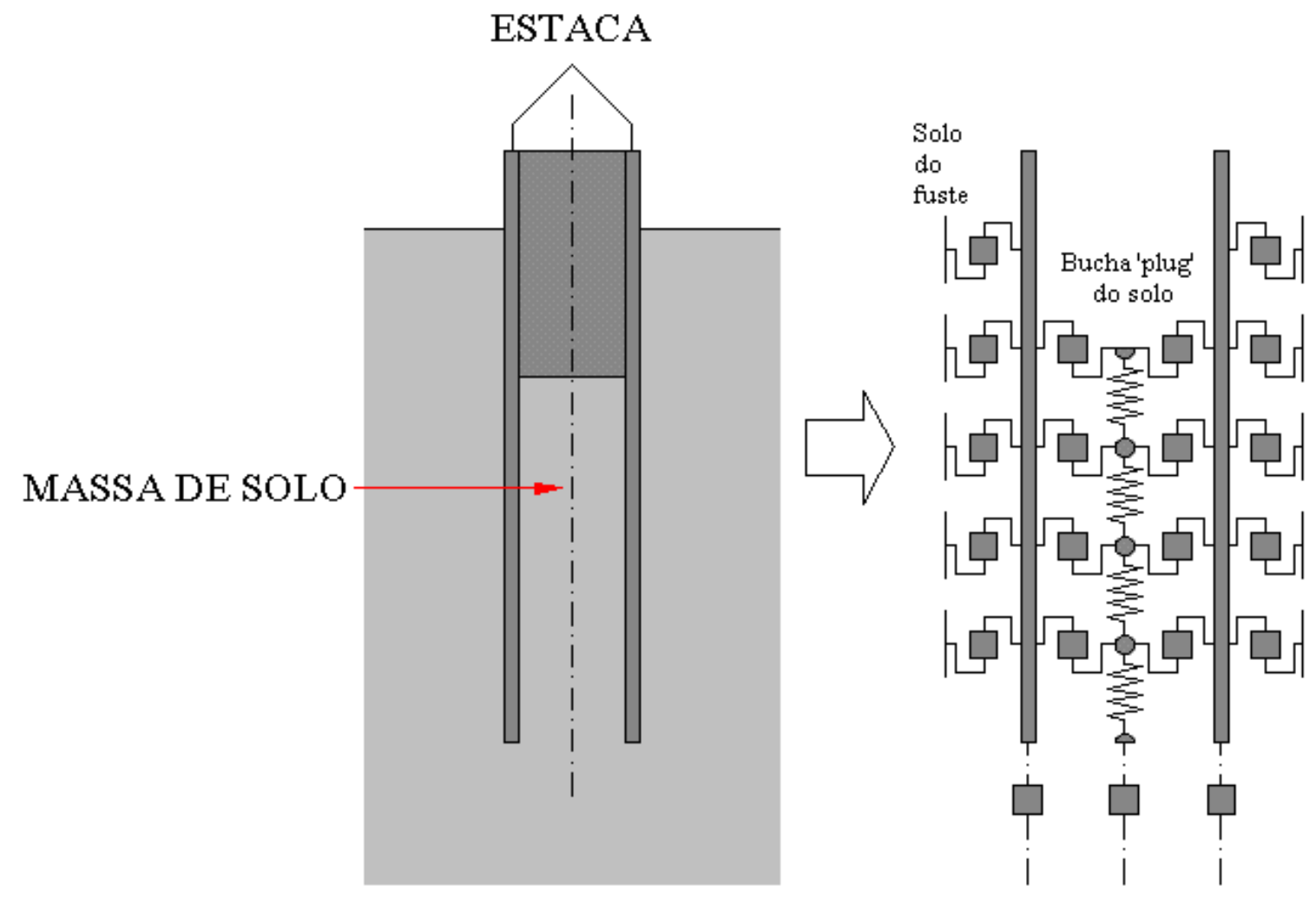

Figura 2-15 Modelo de solo KWAVE ${ }^{\circledR}$ para tubo de aço circular (Matsumoto et al., 1996)

Os valores constantes de rigidez de mola, constantes de amortecimento por radiação, os parâmetros de amortecimento e a massa de solo para o fuste e a ponta, são determinados a 
partir de ensaios de solo, tanto como o módulo cisalhante, a relação de Poisson e a densidade de solo (Matsumoto et al., 1996). O processo de comparação de sinais utiliza a onda de esforços transmitidos como dato de entrada para a resolução do retroanálise.

\subsubsection{Análise NUSUM-UCL}

A estaca e o solo são descritos como um modelo discretizado, ver Figura 2-16. Este modelo permite uma descrição dos campos cinéticos e dinâmicos da estaca ou do solo nas vizinhanças diretas da estacas durante uma solicitação transitória. Um dos sinais obtidos em campo, de força ou velocidade, é colocado como condição de contorno. O procedimento de comparação de sinais está dado por meio de um algoritmo baseado em diferenças finitas, onde pode ser calculado ao longo do tempo o estado relativo de todas as partes do modelo (tensões, forças, deslocamentos, velocidade e acelerações).
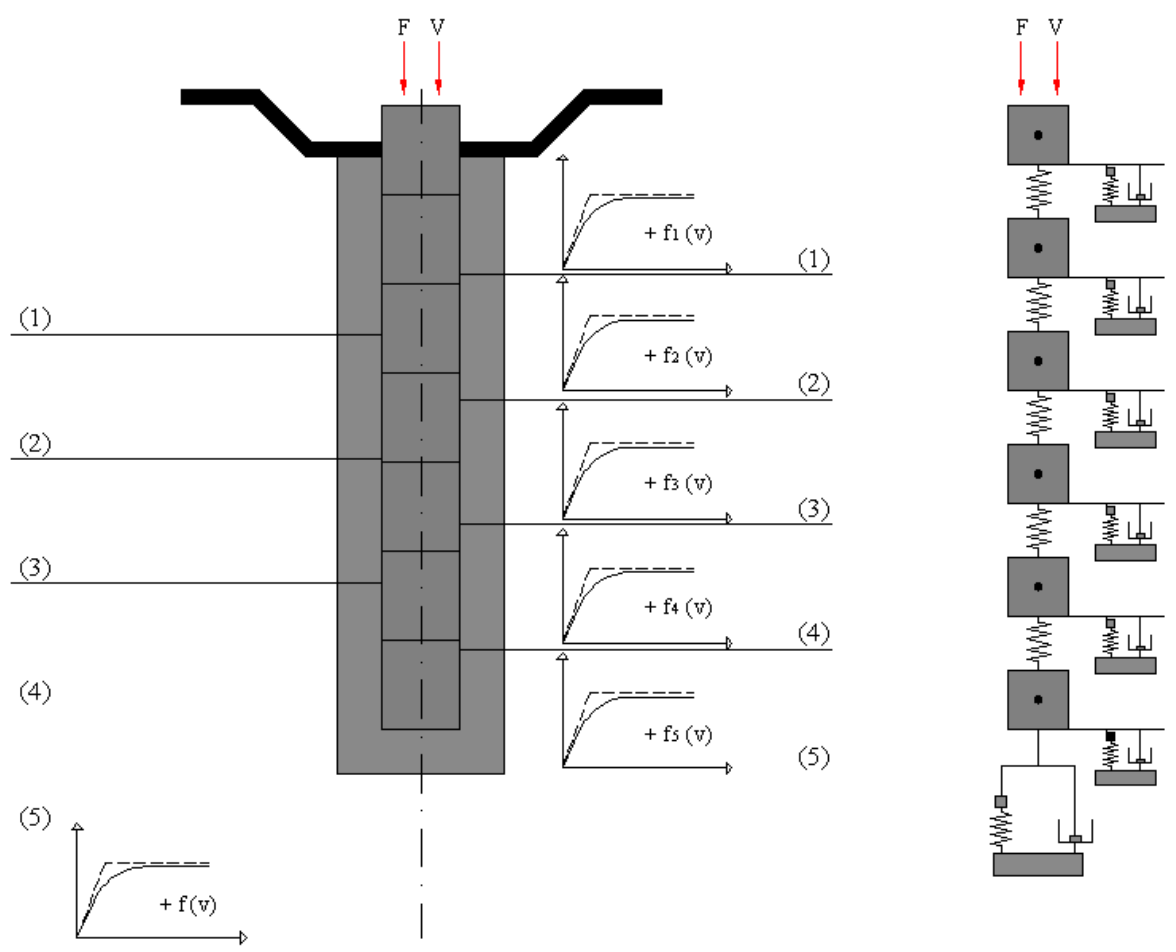

Figura 2-16 Modelo de solo NUSUM-UCL (Charue, 2004)

O modelo de estaca/solo leva em conta o efeito de índice de carga relativo ao damping de radiação e o efeito viscoso. Pode considerar também relações esforço-deformação elasto- 
plásticas ou hiperbólicas dada por Holeyman $(1984)^{20}$ para modelar as resistências do fuste e da ponta da estaca. $\mathrm{O}$ modelo permite levar em conta o atrito entre a estaca e o solo. $\mathrm{O}$ procedimento para encontrar a melhor solução está baseado na comparação de sinais automática que utiliza um algoritmo de trabalho baseado na sensibilidade dos parâmetros (Charue, 2004).

Como parte final desta seção, apresenta-se a Tabela 2-2 para sumariar as principais vantagens e desvantagens dos métodos dinâmicos apresentados.

Tabela 2-2 Métodos Dinâmicos para avaliar a capacidade de carga: vantagens, desvantagens e comentários (Modificada de Paikowsky \& Stenersen, 2000)

\begin{tabular}{|c|c|c|c|c|}
\hline Categoria & Método & Vantagens & Desvantagens & Comentário \\
\hline $\begin{array}{c}\text { Sem } \\
\text { Medições } \\
\text { Dinâmicas }\end{array}$ & $\begin{array}{c}\text { Métodos: } \\
\text { GRLWEAP, } \\
\text { TNOWAVE, } \\
\text { TTI- } \\
\text { MICROWAVE, } \\
\ldots\end{array}$ & 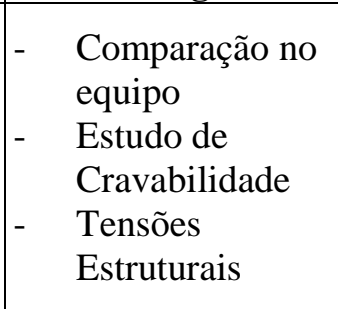 & $\begin{array}{ll}\text { - } & \text { Análise não } \\
\text { única } \\
\text { - Desempenho } \\
\text { dependente das } \\
\text { condições de } \\
\text { campo }\end{array}$ & 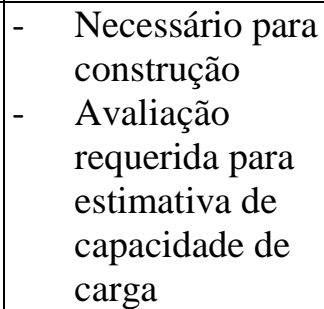 \\
\hline \multirow[t]{2}{*}{$\begin{array}{c}\text { Com } \\
\text { Medições } \\
\text { Dinâmicas }\end{array}$} & $\begin{array}{l}\text { Método } \\
\text { CASE }^{\circledR}\end{array}$ & $\begin{array}{ll}\text { - } & \text { Análise } \\
\text { Simplificada } \\
\text { - } \\
\text { Método } \\
\text { utilizado em } \\
\text { campo }\end{array}$ & 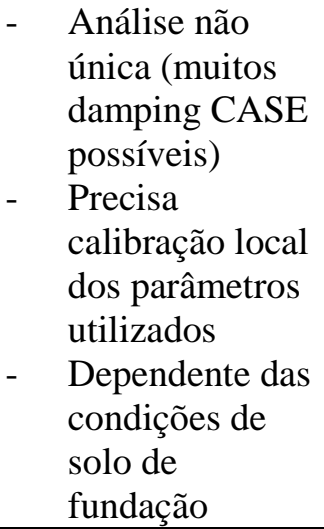 & 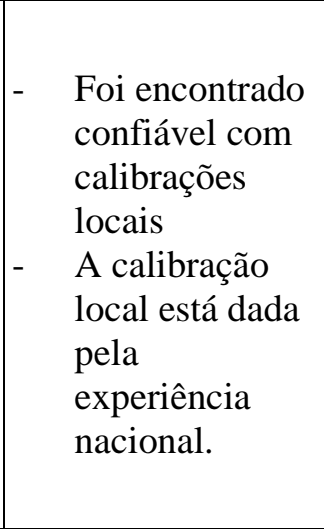 \\
\hline & $\begin{array}{c}\text { Análise de } \\
\text { Comparação de } \\
\text { Sinais: } \\
\text { CAPWAP, } \\
\text { DLTWAVE, } \\
\ldots\end{array}$ & 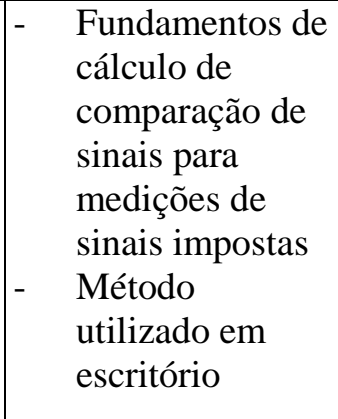 & $\begin{array}{ll}\text { - } & \text { Forças de solo } \\
\text { estáticas } \\
\text { - } & \text { Custoso } \\
\text { - } & \text { Precisa de } \\
& \text { pessoal } \\
& \text { qualificado para } \\
& \text { análise }\end{array}$ & $\begin{array}{l}\text { Análise } \\
\text { Simplificada } \\
\text { (para simulação } \\
\text { do evento } \\
\text { dinâmico, só } \\
\text { considera sinais } \\
\text { de cravação: } \\
\text { força e } \\
\text { velocidade) }\end{array}$ \\
\hline
\end{tabular}

${ }^{20}$ HOLEYMAN, A., 1984. Contribution à l'étude du comportement transitoire non-linéaire des pieux pendant leur battage. Tese de Doutorado, Université Libre de Bruxelles, 584p. 
Ressaltando o tema da adequação nacional dos parâmetros especificados, por exemplo, na utilização do método CASE tem-se alguns valores de damping que são recomendados pelos desenvolvedores do método (ver Tabela 2-1), mas a sua utilização em locais diferentes dos desenvolvidos, exige certa experiência do operador.

Originalmente os parâmetros recomendados nos métodos de análise dinâmicos obedecem a solos sob climas temperados e características geotécnicas diferentes que não refletem a realidade local. Uma calibração nacional ou internacional poderia referir-se à adequação dos parâmetros que originalmente serviram para a validação do método. Segundo Coelho ${ }^{21}$ (2006), essa adequação ou calibração nacional no Brasil, já pode ter acontecido devido à ampla experiência nacional. Nesse sentido, Niyama (1983) apresenta uma revisão histórica das análises dinâmicas no Brasil.

\subsection{Incertezas dos parâmetros do modelo de Smith}

Segundo Hannigan et al. (1998), os maiores erros na seleção de parâmetros de solo na predição de valores de capacidade última da estaca a partir de ensaios dinâmicos usualmente são observados quando as resistências do solo têm sido inapropriadamente consideradas ou calculadas. Os outros parâmetros dinâmicos, damping e quake, são igual de importantes (Svinkin, 1997).

Para Paikowsky et al.(1994), Paikowsky \& Stenersen (2000) e Charue (2004), os parâmetros empíricos de Smith incluem muitos aspectos do comportamento do sistema estaca-solo que acontecem durante o evento dinâmico. Esse comportamento se manifesta tanto dentro do sistema estaca-solo como na interface propriamente dita, ou no solo que circunda a estaca. A seguir listam-se tais fatores:

- A inércia do solo e o nível de acoplamento entre os dois sistemas;

- O excesso de poro pressões geradas no solo devido à cravação;

- O comportamento não drenado da interação estaca-solo durante carregamento dinâmico;

\footnotetext{
${ }^{21}$ COELHO, G. (IPT). Comunicação pessoal. Nov. 2006.
} 
- Os diferentes mecanismos de ruptura durante os eventos de carga estáticos e dinâmicos;

- As perdas de energia devido ao intrínseco comportamento viscoso dos solos;

- As perdas histeréticas de energia do solo devido ao comportamento carregamentodescarregamento.

Os três parâmetros analisados na presente pesquisa apresentam variabilidades que determinam o comportamento do solo nos métodos baseados na teoria da equação da onda. A seguir apresenta-se uma descrição da variabilidade de cada um dos parâmetros do modelo de Smith (1960).

\subsubsection{Incertezas da Resistência Estática de Carga Última}

A resistência estática unitária define-se como a parcela não temporária nem instantânea mobilizada logo apôs do golpe do martelo. Diferente do que acontece com a parcela dinâmica mobilizada, esta parcela contribui diretamente para a capacidade de carga da estaca. Dependendo da localização do trecho analisado tem-se: resistência estática última

$(R u l t)$ de fuste $=\sum q_{f i} \cdot \Delta z_{i} \cdot U$, e resistência estática última $(R u l t)$ de ponta $=q_{p} \cdot A_{p}$. Onde: $q_{f}=$ resistência estática unitária de fuste, do segmento $i$ da estaca, $q_{p}=$ resistência estática de ponta da estaca, $A_{f}=\Delta z_{i} \cdot U=$ área lateral do segmento $\Delta z_{i}$ da estaca, e perímetro $U$, e $A_{p}=$ área da ponta da estaca.

Pode-se apreciar no cálculo da resistência última da estaca a partir da teoria da equação da onda, uma incerteza intrínseca, aquela que não é redutível, inerente ao próprio caráter aleatório do fenômeno da mobilização de resistência do solo, fenômeno reconhecido e aproveitado no caráter probabilista dessa pesquisa.

\subsubsection{Quake}

Segundo a Figura 2-3 (idealização do modelo de Smith, 1960), tem-se que o quake é o máximo deslocamento elástico do solo, antes de mobilizar a máxima resistência estática. 
Podendo mobilizar tanto a resistência estática de fuste, para os trechos ao longo da estaca, ou da ponta, respectivamente.

Outro fato importante é somente a medição dinâmica que pode revelar, com precisão, as grandezas dos valores de quake da estaca (Hannigan et al., 1998). Em campo, são de uso comum procedimentos de controle baseados na utilização da nega e o repique. O repique constitui a parcela elástica do deslocamento máximo da estaca; e a nega vem a ser o deslocamento permanente da estaca, ambos decorrentes da aplicação do golpe do martelo (NBR-6122, 1996).

O repique elástico, visto a partir do ponto de vista da equação de onda, é o deslocamento temporário de um determinado ponto da estaca em função do tempo em que a onda de tensão provocada por uma solicitação dinâmica propaga-se axialmente através da mesma; desta forma, os deslocamentos máximos em quaisquer pontos ocorrerão em instantes de tempos diferentes, em função da resultante da superposição das ondas atuantes ao longo da estaca, durante o tempo de propagação (De Rosa, 2000).

A Figura 2-17 explica os deslocamentos que acontecem no sistema estaca-solo após a cabeça da estaca ter sido atingida pelo golpe de um martelo; onde: $\mathrm{S}=$ deslocamento permanente ('nega'); C2 = deslocamento elástico do topo da estaca ('repique'); C3 = deslocamento elástico do solo ('quake'); e $\mathrm{L}=$ comprimento total da estaca. $\mathrm{Na}$ nomenclatura CASE, $D M X=S+K$, onde, $\mathrm{K}=$ deformação elástica da estaca e do solo (C2 $+\mathrm{C} 3)$ que vem a ser o deslocamento total da estaca.

Seguindo-se o modelo elasto-plástico (vide Figura 2-17) tem-se inicialmente a deformação elástica do solo (C3) até se atingir o valor máximo, denominado 'quake', seguido da ruptura. Assim, admite-se que a deformação da estaca atinge um valor máximo junto com o pico da deformação elástica do solo. Na ruptura os deslocamentos da estaca são predominantemente devidos à deformação plástica (permanente) do solo da ponta. 


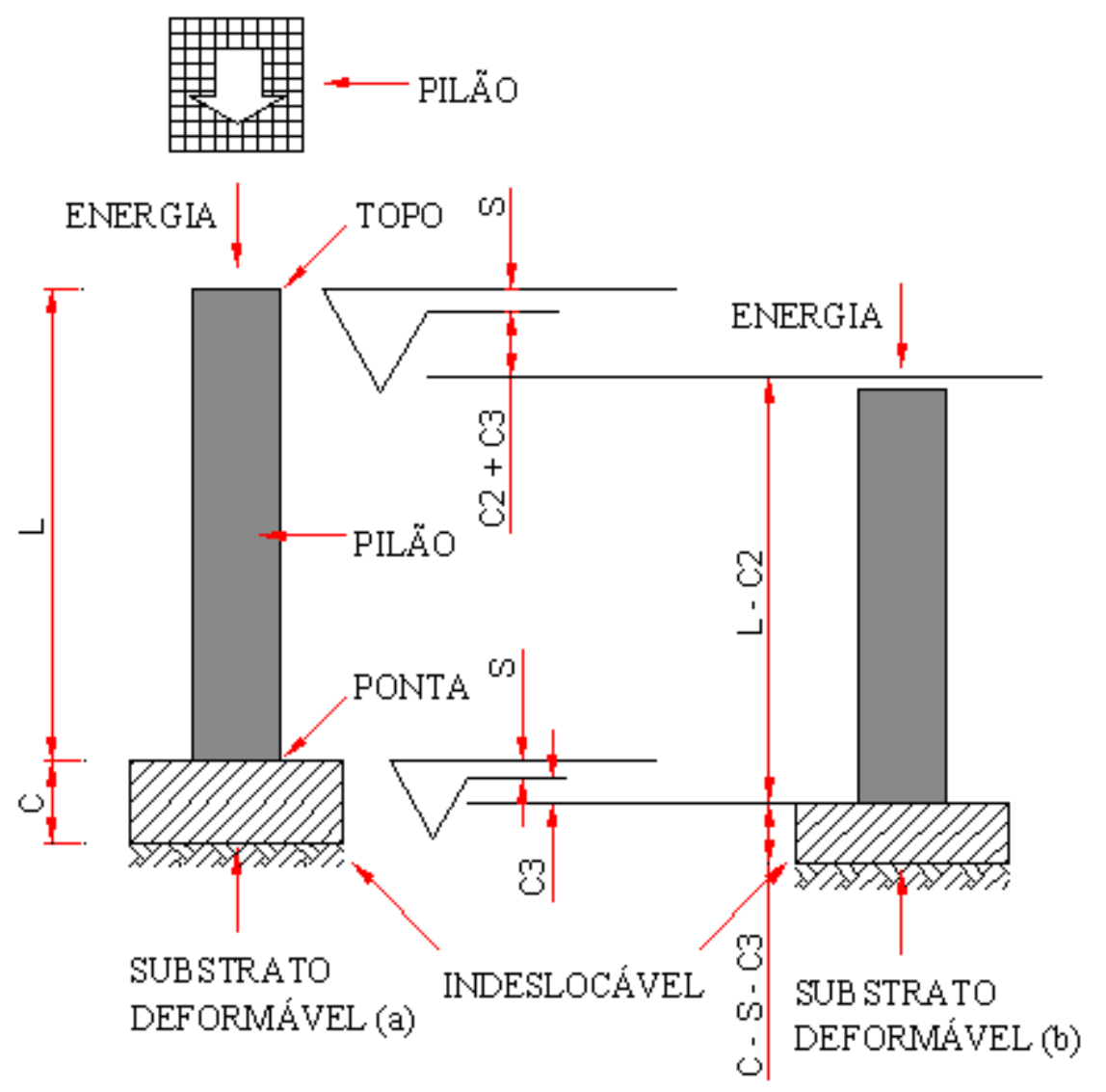

Figura 2-17 Posição do topo e da base da estaca antes do golpe (a) e, (b) os deslocamentos máximos após o golpe (Aoki, 1991)

O Manual de usuário do GRLWEAP ${ }^{\circledR}$ (GRLWEAP Manual, 2003) recomenda os seguintes valores de quake:

- Quake de fuste, ao longo do fuste usualmente utiliza-se 2,5 mm.

- Quake da ponta, usualmente utiliza-se o valor dado por $b / 120(\mathrm{~mm})$, onde $b$ é o diâmetro efetivo da estaca ou largo da ponta da estaca.

\subsubsection{Incertezas do Fator de Amortecimento: damping}

Para Zagottis (1976), a viscosidade é um fenômeno característico dos líquidos; enquanto que para os sólidos, a viscosidade deve se entender como um fenômeno de aparecimento de deformações não imediatas, ou seja, de deformações que não aparecem simultaneamente 
com as tensões correspondentes, não permanecendo constantes ao longo do tempo mesmo que as tensões correspondentes o sejam.

O parâmetro damping do solo tem um efeito importante na análise dinâmica devido ao fato de representar a resistência viscosa na modelagem do comportamento dinâmico do solo. (Paikowsky \& Stenersen, 2000).

$\mathrm{Na}$ possibilidade da viscosidade estar associada intrinsecamente com as propriedades do solo, valores altos de viscosidade seriam esperados para solos coesivos e valores baixos de viscosidade para solos não-coesivos. Seguindo essa lógica, dada uma determinada velocidade, altos valores de viscosidade estarão associados, com maiores resistências dinâmicas e, também, pode-se ter maior dificuldade para definir rigorosamente a resistência estática (Paikowsky \& Stenersen, 2000).

Na prática comum da engenharia de fundações (Hannigan et al. 1998; Svinkin, 1997), utilizam-se as seguintes definições das considerações de amortecimento ou damping:

\section{Damping padrão Smith,}

Tradicionalmente o modelo de Smith (1960), fica estabelecido, assim:

$$
R_{T}=R_{S}\left(1+j_{S} \cdot v\right)
$$

Onde $R_{T}$ é a resistência total, $R_{S}$ é o valor da resistência estática, e $j_{S}$ é a Constante de amortecimento de Smith, de dimensões inversas a velocidade: tempo por longitude.

\section{Damping viscoso}

O modelo de Smith torna-se viscoso quando a resistência estática é igual à resistência última (Goble, 2000).

$$
R_{T}=R_{S}=j_{V} \cdot v
$$


Onde $R_{T}$ é a resistência total, $R_{S}$ o valor da resistência estática, e $j_{V}$ a constante de amortecimento viscoso. Tal modelo considera o comportamento do solo como viscoso linear, quer dizer, que a resistência última é proporcional à velocidade da estaca. Consideram-se como unidades do damping viscoso: força por velocidade

\section{Damping CASE}

Está baseado no amortecimento viscoso, definido para o método CASE máximo (ver Figura 2-11). Em alguns casos, a constante de damping Smith $\left(J_{S}\right)$ é proporcional à impedância da estaca.

$$
J_{S}=J_{C} \cdot \frac{E \cdot A}{c}
$$

Onde, $E=$ Modulo elástico do material da estaca, $A=$ Área da secção, e $c=$ velocidade de onda no material da estaca.

Outra relação muito útil na teoria de análises dinâmicas é a relação entre o Damping Viscoso e Dampin Smith (CAPWAP Manual, 1990).

$$
J_{V}=J_{S} \cdot \text { Rult }_{i}
$$

Onde, Rult $_{i}=$ Resistência estática última correspondente ao trecho $i$ da estaca analisada.

O manual de usuário do GRLWEAP ${ }^{\circledR}$ (GRLWEAP Manual, 2003) fornece os seguintes valores de damping:

- Damping de fuste, ao longo do fuste, usualmente utiliza-se Damping de Smith de fuste de $0,65 \mathrm{~s} / \mathrm{m}$ para solos não coesivos, e $0,16 \mathrm{~s} / \mathrm{m}$ para solos não coesivos. A aproximação de Smith é preferida, ainda existam os diversos modelos de damping.

- Damping de ponta, comumente utiliza-se 0,50 s/m, não importando o tipo de solo. 
Alguns autores, com o objetivo de classificar o fator de amortecimento ou damping em função do tipo de solo, tentaram correlacionar ensaios de carga dinâmicos com provas de carga estática, desenvolvidas nas mesmas condições, para diferenciar o comportamento das resistências de fuste e de ponta e o comportamento viscoso do solo.

Aoki \& De Mello (1992) apresentaram os resultados de um estudo desenvolvido em dados dinâmicos de ensaios de recravação em estacas vazadas de concreto cravadas em areia densa. Os golpes de cravação caracterizaram alturas diferentes (a partir de 0,2 a 2,6m) e, portanto, energias de cravação maiores. No estudo observou-se que a mobilização de resistência estática última ao longo do fuste como da ponta da estaca evolui com o acréscimo de energia transmitida. Observou-se, também, que em relação aos parâmetros de Smith: o valor de 'quake' (de fuste e ponta) não é um valor constante do solo, mas evolui com o acréscimo de energia transmitida. Por outro lado, os valores associados com o fator de amortecimento exibiram uma evolução de redução dos valores de damping da ponta com o aumento da altura de queda do martelo.

Paikowsky et al. (1994), analisaram 372 casos de ensaios de carga dinâmicos e conseguiram resumir os valores necessários de coeficientes de damping Smith para obter a melhor comparação de sinais, 'best match',22, entre os sinais calculados de força ou velocidade das análises CAPWAP. Os valores de damping foram classificados em função do tipo de solo da ponta e do fuste. Os autores concluíram após as análises estatísticas, que não existe correlação entre o tipo de solo e os parâmetros de damping utilizados. A dispersão de valores de $\mathrm{J}_{\mathrm{s}}$ resultou muito grande. Outros autores tentaram correlacionar os dados da cravação dinâmica com os parâmetros de damping utilizados nas análises de equação de onda (utilizando o programa CAPWAP), como se detalha a seguir:

Likins et al. (1996) desenvolveram um estudo de correlação sobre 82 estacas sob carregamento estático e dinâmico, utilizando a base de dados GRL. Eles consideraram a

\footnotetext{
${ }^{22} \mathrm{O}$ valor de "MQN" é um indicador da qualidade utilizado pelo programa computacional CAPWAP, que avalia a comparação de sinais entre um sinal calculado e outro obtido em campo, 'best match', de força ou velocidade, respectivamente. No ANEXO E, ao final do presente trabalho, apresenta-se alguns comentários sobre as formulações para o cálculo do MQN.
} 
possibilidade de que a constante de amortecimento de Smith diminui quando o tamanho dos grãos do solo aumenta. Também concluíram que os valores de quake de fuste aproximam-se a 2,5mm, como se esperava. Thendean et al. (1996) utilizou o mesmo tipo de correlações e a mesma base de dados da GRL, e mais uma vez os valores de damping Smith apresentaram uma grande dispersão. 


\section{FUNDAMENTOS DA EQUAÇÃO DE ONDA APLICADA À CRAVAÇÃO DE ESTACAS}

\subsection{Introdução}

No presente capítulo apresenta-se os fundamentos básicos da mecânica de propagação da onda aplicada à cravação de estacas e a sua relação com as metodologias analíticas empregadas para interpretação dos seus resultados.

O fenômeno da propagação de onda é um tanto complexo, bem como sua formulação. Entretanto, ressalta-se os aspectos mais práticos de sua aplicação onde sua formulação matemática é abordada de forma simplificada.

Visando uma revisão bibliográfica que atendesse os objetivos da presente pesquisa, no presente capítulo podem-se citar como fontes de referência diretas: Niyama (1983), CAPWAP Manual (1990), Coelho (1997), Gonçalves et al. (1999), De Rosa (2000), e Charue (2004).

\subsection{Proporcionalidade}

Considera-se uma estaca uniforme com propriedades lineares, carregada em uma extremidade por uma força $F$, decorrente do impacto do martelo no topo da mesma, no tempo $t$. Também, quando um comprimento, $d L$, seja considerado este será entendido como uma distância curta; $d t$ será considerado como acréscimo curto de tempo. (ver Figura 3-1). 


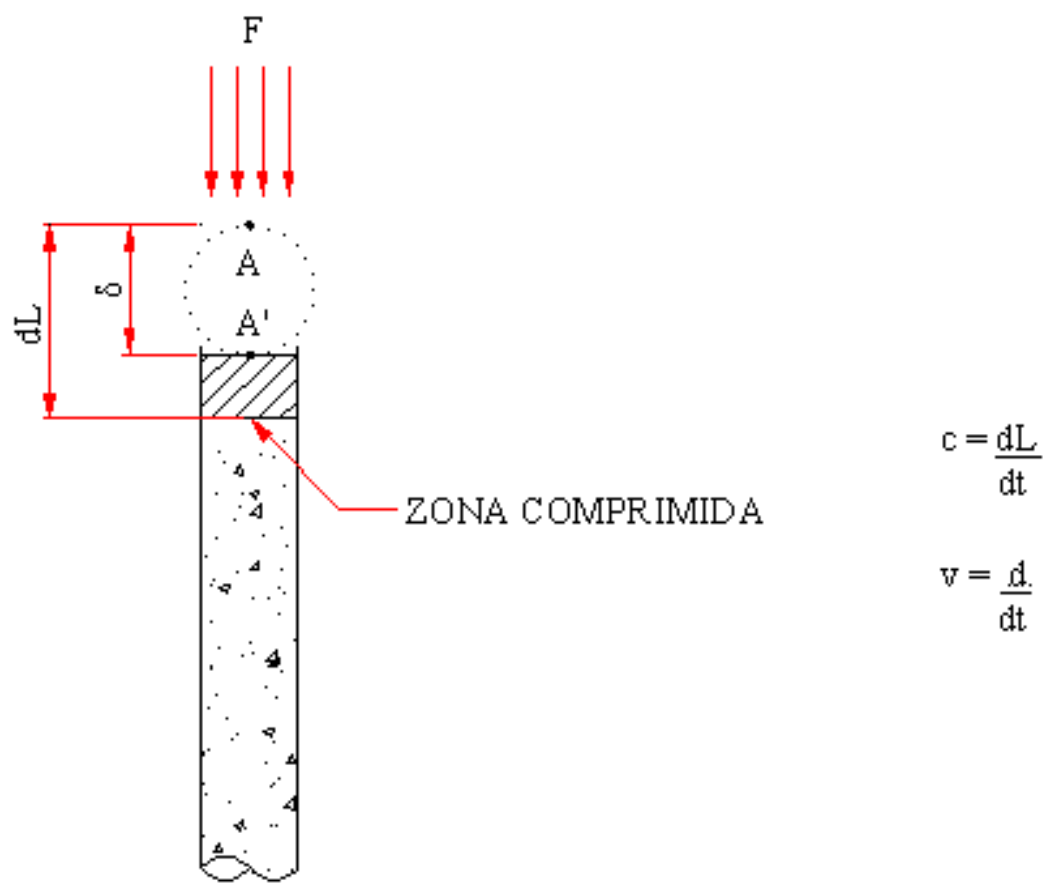

Figura 3-1 Deformação do Elemento $d l$ (Niyama, 1983)

Num curto espaço de tempo $d t$ depois do impacto do martelo no topo da estaca, seu primeiro elemento $d l$ é comprimido, ocasionando sua deformação, $\varepsilon$. Essa deformação gera, num tempo posterior, uma força de compressão que age no elemento seguinte, que é comprimido e se deforma, deformando também os elementos subseqüentes. Esse efeito em cadeia dos elementos da estaca que se deformam pela ação da força $F$, gera uma onda de compressão que se propaga com uma velocidade $c$.

A deformação da zona comprimida, no caso, coincide com o deslocamento do topo da estaca que devido à compressão da estaca, o ponto A move-se para a posição A'. Deste modo obtêm-se:

$$
\begin{gathered}
c=\frac{d L}{d t} \\
v=\frac{\delta}{d t} \\
\varepsilon=\frac{\delta}{d L}
\end{gathered}
$$


Das equações Eq. 3-1, Eq. 3-2 e Eq. 3-3 resulta:

$$
\varepsilon=\frac{v}{c}
$$

Considerando a força de compressão $F=\varepsilon$.A.E (onde, $A$, seção transversal e $E$, módulo de elasticidade do material da estaca), pela lei de Hooke tem-se a relação:

$$
F=\frac{E \cdot A}{c} \cdot v
$$

Refere-se freqüentemente à constante de proporcionalidade $E A / c$ como a impedância $Z$, fator que correlaciona a força $F$ e a velocidade $v$, quando a onda de tensão se propaga numa direção.

$$
Z=\frac{E \cdot A}{c}
$$

\subsection{Velocidade de Onda}

Aplicando-se a segunda Lei de Newton a força de compressão, $F=m . a$, para $d L$, e considerando que a força de deformação é igual à força de inércia, pode-se obter:

$$
\begin{gathered}
a=\frac{d v}{d t} \\
F=\rho . A \cdot d L \cdot \frac{d v}{d t}
\end{gathered}
$$

Onde $\rho$ é a densidade específica do material da estaca.

Desta forma, mistura-se as Eq. 3-5, Eq. 3-7 e Eq. 3-8, e considera-se a hipótese de solo estacionário (ou seja $v_{\text {inicial }}=0$, assim $v_{\text {final }}=v$ ), resulta:

$$
c^{2}=\frac{E}{\rho}
$$

Assim observa-se que a velocidade de onda $c$ é função das propriedades do material da estaca. A Tabela 3-1, indica as propriedades da estaca segundo a Eq. 3-9. Dessa forma, pode-se dizer que a velocidade de onda, $c$, é a velocidade com que as zonas de compressão 
ou tração se movem ao longo da estaca e, a velocidade da partícula, $v$, é a velocidade com que as partículas se movem quando a onda se propaga.

Tabela 3-1 Velocidades recomendadas de onda segundo as propriedades da estaca (CAPWAP Manual, 1990)

Módulo de Elasticidade Densidade Específica Velocidade de Onda (c)

\begin{tabular}{cccc} 
Material & $\begin{array}{c}\mathrm{SI} \\
\mathrm{MPa}\end{array}$ & $\begin{array}{c}\mathrm{SI} \\
\mathrm{KN} / \mathrm{m}^{3}\end{array}$ & $\begin{array}{c}\mathrm{SI} \\
\mathrm{m} / \mathrm{s}\end{array}$ \\
\hline Aço & 210000 & 78,0 & 5140 \\
Concreto & 40000 & 24,0 & 4040 \\
Madera & 16000 & 8,0 & 4430
\end{tabular}

Para estacas não uniformes, representa-se a impedância, como a massa da estaca através da qual a onda de tensão se propaga por unidade de tempo.

$$
Z=\frac{c . m}{L}
$$

Onde $m$ e $L$ são respectivamente a massa e o comprimento da estaca.

\subsection{Equação geral da onda}

Considerando-se um segmento da estaca, conforme Figura 3-2, e segundo as leis de Newton e de Hooke, pelo equilíbrio dinâmico de um segmento da estaca em qualquer instante, a propagação de onda pode ser expressa através de equação diferencial (ver Eq. 3-12). 


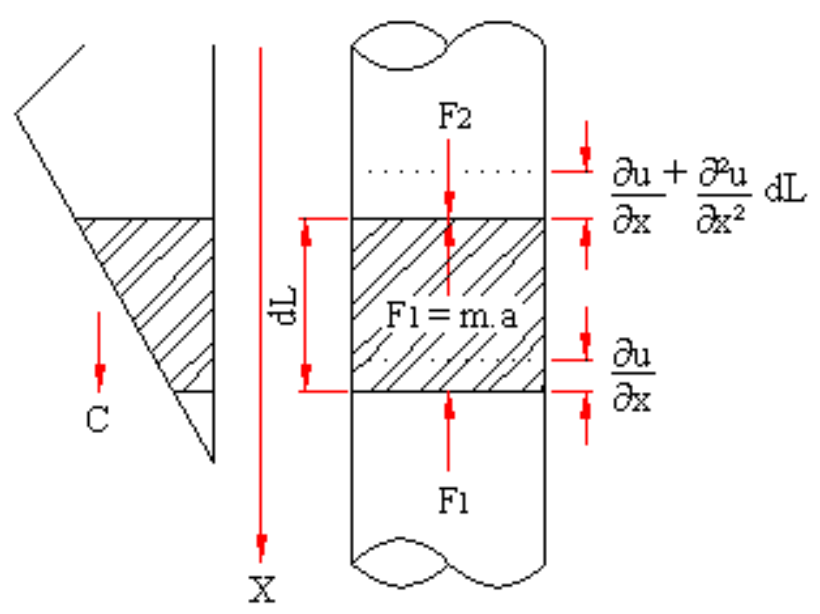

Figura 3-2 Deformações do elemento da estaca devido à Propagação de Onda (Niyama, 1983)

Pelo equilíbrio de forças: $F_{2}-F_{1}-m \cdot a=0$, ou

$E . A .\left(\frac{\partial u}{\partial x}+\frac{\partial^{2} u}{\partial x^{2}} \cdot d L\right)-E . A \cdot\left(\frac{\partial^{2} u}{\partial x^{2}} \cdot d L\right)-\rho \cdot A \cdot d L \cdot \frac{\partial^{2} u}{\partial t^{2}}=0$

Eq. 3-11

Tem-se a equação geral do movimento da onda unidimensional, Eq. 3-12, conhecida como "equação de onda", que representa o deslocamento $u$ de uma partícula, situada a uma distância $x$ do topo da estaca, depois de decorrido um tempo $t$ após a aplicação do golpe do martelo.

$$
c^{2} \frac{\partial^{2} u}{\partial x_{s}^{2}}=\frac{\partial^{2} u}{\partial t^{2}}
$$

Derivada para uma corda vibrante por D'Alembert ${ }^{23}$ a equação de onda é aplicada ao problema da cravação de estacas, no caso hipotético quando os deslocamentos e a resistência de fuste $\left(f_{s}\right)$ da estaca são nulos. A solução geral desta equação diferencial de segunda ordem é dada pela Eq. -13 .

$$
u(x, t)=f(x-c . t)+g(x+c . t)
$$

\footnotetext{
${ }^{23}$ D'Alembert (1717-1783)
} 
Onde: $u(x, t)=$ deslocamento longitudinal do segmento infinitesimal no tempo $t$.

As duas funções $f$ e $g$ arbitradas correspondem a duas ondas se propagando com a mesma velocidade $c$, mas em direções contrárias. Assim, observa-se que as ondas $f$ e $g$, apenas se deslocam inalteráveis no tempo.

Paikowsky \& Whitman (1990) modificaram a equação básica (Eq. 3-12), incluindo a resistência de fuste ao longo da estaca, $f_{s}$. Desse modo, o deslocamento $u$ em cada segmento da estaca pode ser usado para calcular esforços de tensão e compressão dentro da estaca, bem como a resistência lateral desenvolvida no solo. A Eq. 3-14 mostra a equação modificada de onda:

$$
E \cdot \frac{\partial^{2} u}{\partial x^{2}}-\frac{S}{A} f_{s}=\rho \frac{\partial^{2} u}{\partial t^{2}}
$$

Onde: $A, S=$ área da estaca e perímetro, respectivamente.

A partir da solução da Eq. 3-13 utilizam-se notações simplificadas para denotar ondas descendentes e ascendentes, por meio de flechas que indicam o sentido de propagação ao longo da estaca em obediência a um determinado referencial; ver Eq. 3-15

$$
u(x, t)=f(x-c . t)+g(x+c . t)=u \downarrow+u \uparrow
$$

A partir desta solução podem-se obter também as funções força e velocidade de partícula:

$$
\begin{gathered}
F(x, t)=-E \cdot A \cdot \frac{\partial u}{\partial x}=F \downarrow+F \uparrow \\
v(x, t)=\frac{\partial u}{\partial x}=v \downarrow+v \uparrow
\end{gathered}
$$

Deve-se lembrar que a onda descendente inicial gerada pelo impacto do martelo é formada por forças compressivas que ocasionam velocidades proporcionais de partículas descendentes. 


\subsection{Influência da Variação de Impedância da Estaca}

Suponha uma estaca com certa descontinuidade a uma profundidade $X$ de seu comprimento $L$ (Figura 2-3) e que abaixo da seção $a$ - $a$, suas características estejam alteradas, de tal modo que os segmentos superiores e inferiores, tenham impedâncias $Z_{\text {sup }}$ e $Z_{\text {inf }}$, respectivamente.

Quando a onda de tensão inicial $\left(\mathrm{F}_{\text {sup }} \downarrow, \mathrm{v}_{\text {sup }} \downarrow\right)$ chega à seção a-a, ela será parcialmente transmitida $\left(F_{i n f \downarrow} \downarrow, v_{i n f} \downarrow\right)$ e parcialmente refletida $\left(\mathrm{F}_{\text {sup }} \uparrow, \mathrm{v}_{\text {sup }} \uparrow\right)$. As forças e as velocidades estão em equilíbrio acima e abaixo da descontinuidade, logo:

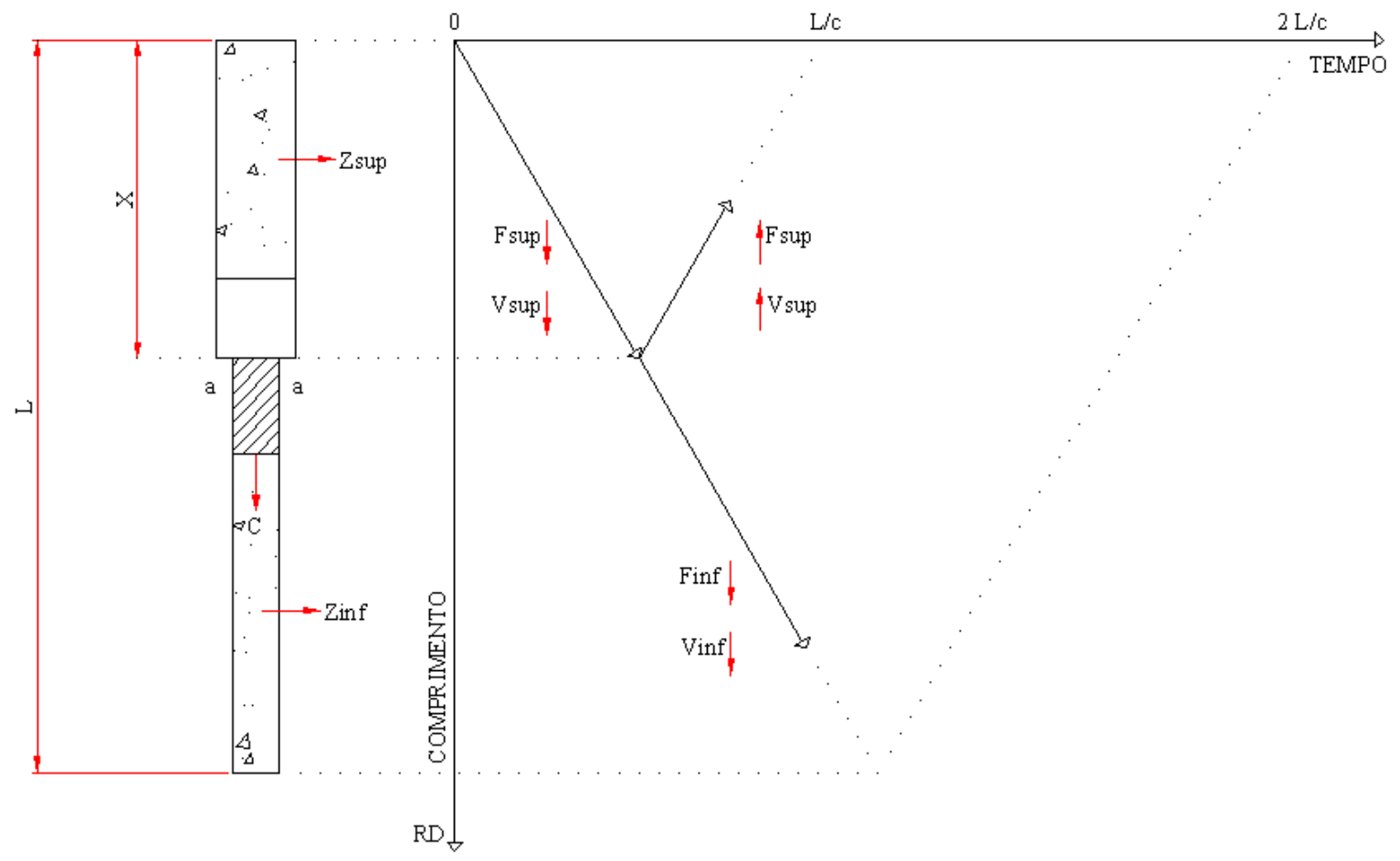

Figura 3-3 Propagação da Onda de Tensão (Niyama, 1983)

Equação de Continuidade:

$$
v_{\text {sup }}=v_{\text {impacto }} \downarrow+v_{\text {refletida }} \uparrow=v_{\text {inf }} \downarrow
$$

\section{Equação de Equilíbrio:}

$F_{\text {sup }}=Z_{\text {sup }} \cdot v_{\text {impacto }} \downarrow-Z_{\text {sup }} \cdot v_{\text {refletida }} \uparrow=Z_{\text {inf }} \cdot v_{\text {inf }} \downarrow$ 
Resolvendo simultaneamente a Eq. 3-18 e Eq. 3-19, obtêm-se a força e a velocidade transmitidas respectivamente.

$$
v_{\text {inf }} \downarrow=\frac{2 . Z_{\text {sup }}}{Z_{\text {inf }}+Z_{\text {sup }}} \cdot v_{\text {impacto }} \downarrow
$$

$\mathrm{e}$

$$
F_{\text {inf }} \downarrow=\frac{2 . Z_{\text {inf }}}{Z_{\text {inf }}+Z_{\text {sup }}} \cdot F_{\text {impacto }} \downarrow
$$

Substituindo-se $F_{\text {inf } \downarrow} \downarrow$ na Eq. 3-19 e $v_{\text {inf }} \downarrow$ na Eq. 3-18, encontra-se a força e a velocidade refletidas respectivamente:

$$
v_{\text {refletida }} \uparrow=\frac{Z_{\text {sup }}-Z_{\text {inf }}}{Z_{\text {inf }}+Z_{\text {sup }}} \cdot v_{\text {impacto }} \downarrow
$$

$\mathrm{e}$

$$
F_{\text {refletida }} \uparrow=\frac{Z_{\text {inf }}-Z_{\text {sup }}}{Z_{\text {inf }}+Z_{\text {sup }}} \cdot F_{\text {impacto }} \downarrow
$$

Na Tabela 3-2, apresenta-se os resultados da Eq. 3-22 e Eq. 3-23, dependendo da relação entre $Z_{\text {inf }}$ e $Z_{\text {sup }}$. Tais condições extremas podem ocorrer devido a descontinuidade. Se a estaca tiver seção uniforme $\left(Z_{\text {sup }}=Z_{\text {inf }}\right)$, a onda transmitida será igual à onda inicial e não haverá onda refletida.

Tabela 3-2 Ondas refletidas pela Descontinuidade da Estaca

\begin{tabular}{|c|c|c|c|}
\cline { 2 - 4 } \multicolumn{1}{c|}{} & $\mathrm{Z}_{\text {sup }}=\mathrm{Z}_{\text {inf }}$ & $\mathrm{Z}_{\text {sup }} \gg>\mathrm{Z}_{\text {inf }}$ & $\mathrm{Z}_{\text {sup }}<<\mathrm{Z}_{\text {inf }}$ \\
\hline$v_{\text {refletida }} \uparrow=\frac{Z_{\text {sup }}-Z_{\text {inf }}}{Z_{\text {inf }}+Z_{\text {sup }} \cdot v_{\text {impacto }} \downarrow}$ & 0 & $\mathrm{v}_{\text {impacto }} \downarrow$ & $-\mathrm{v}_{\text {impacto }}$ \\
\hline$F_{\text {refletida }} \uparrow=\frac{Z_{\text {inf }}-Z_{\text {sup }}}{Z_{\text {inf }}+Z_{\text {sup }}} \cdot F_{\text {impacto }} \downarrow$ & 0 & $-\mathrm{F}_{\text {impacto }} \downarrow$ & $\mathrm{F}_{\text {impacto }}$ \\
\hline Onda refletida & 0 & Tração & Compressão \\
\hline
\end{tabular}

Entretanto, se houver uma redução na seção da estaca $\left(Z_{\text {sup }}>Z_{\text {inf }}\right)$, uma onda de tração refletida será sobreposta à onda inicial, fazendo com que haja uma redução no valor da força 
e um aumento no valor da velocidade no topo da estaca depois do tempo $t=2 x / c$ (Figura 31). Estas mudanças das propriedades ao longo da estaca, que geram a onda refletida de tração, podem ser atribuídas a falhas nas emendas ou defeitos na fabricação das estacas. Se a falha for grande o bastante, a onda inicial será totalmente refletida (ver Tabela 3-2) caracterizando a ruptura estrutural da seção da estaca.

Caso contrario, se $Z_{s u p}<Z_{\text {inf }}$, a onda refletida será de compressão, resultando numa redução da velocidade e aumento da força quando medidas no topo da estaca. Uma mudança súbita na espessura da parede da estaca ou um efeito de 'bucha' (plug) na ponta podem ser responsáveis pelo surgimento da onda de compressão refletida.

\subsection{Influência do Comportamento da Estaca}

Depois de um tempo $L / c$, a onda de impacto atinge a ponta da estaca. As características da onda refletida e da onda transmitida ao solo dependem das condições de contorno abaixo da ponta. Duas condições limites que podem ocorrer: a resistência na ponta ser nula, ou seja, a ponta se encontrar livre, ou o deslocamento da ponta ser nulo, ou seja, a ponta se encontrar engastada (vide Figura 3-4).

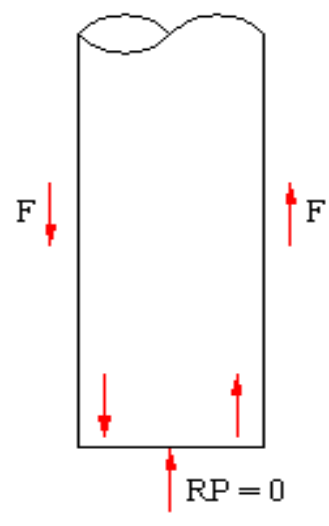

A) PONTA

LIVRE

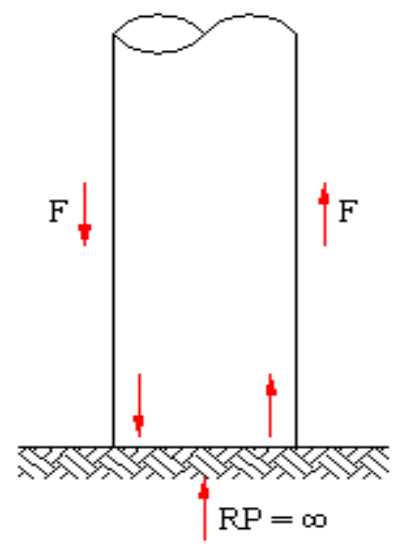

B) PONTA ENGASTADA

Figura 3-4 Condições de Contorno na Ponta da Estaca (Niyama, 1983) 
Se a extremidade da estaca encontra-se livre, permitindo que a ponta da estaca se desloque, a onda de compressão descendente é somada ao efeito causado pela onda de tração ascendente, efeito que também comprime as partículas da ponta da estaca para baixo. Assim sendo, a superposição desse efeito (ondas de tração e compressão) na ponta da estaca acaba duplicando a velocidade das partículas na base da mesma, como é ilustrado na Figura 3-5. Tal efeito é um caso especial da Eq. 3-20 e Eq. 3-21 para $Z_{\text {inf }}=0$, portanto tem-se:

$$
v_{\text {inf }} \downarrow=2 \cdot v_{\text {impacto }} \downarrow
$$

$\mathrm{e}$

$$
F_{\text {inf }} \downarrow=0
$$

\section{A) PONTA \\ LIVRE}

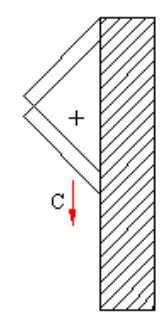

PONTA

(1)

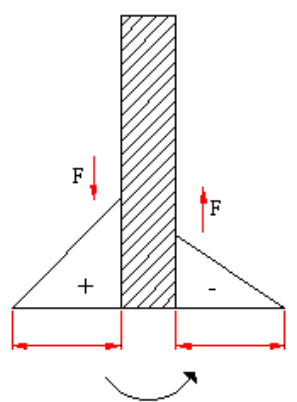

(2)

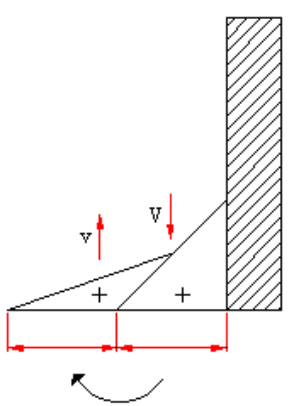

B) PONTA

ENGASTADA

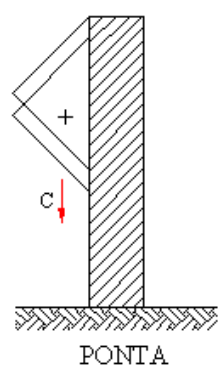

(1)

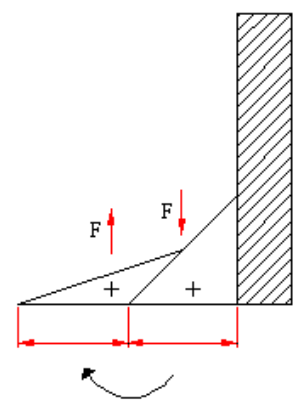

(2)
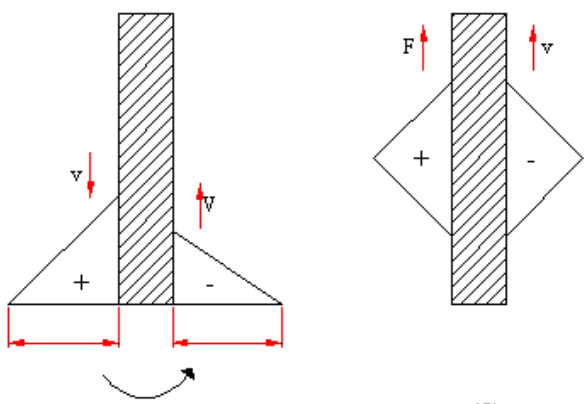

(3)

Figura 3-5 Reflexões das Ondas de Força e Velocidade na Ponta da Estaca (Niyama, 1983) 
E no caso da segunda suposição, para ponta engastada, a onda refletida é uma onda de compressão com a velocidade das partículas negativas, o que provocará uma duplicação da força na ponta da estaca e uma perda da velocidade pela superposição da onda de impacto inicial, como é ilustrado na Figura 3-5. Tal efeito é um caso especial da Eq. 3-20 e Eq. 3-21 para $Z_{\text {inf }}=\infty$; portanto tem-se:

$$
v_{\text {inf }} \downarrow=0
$$

e

$$
F_{\text {inf }} \downarrow=2 . F_{\text {impacto }} \downarrow
$$

\subsection{Conceito Geral de Onda}

Suponha-se que duas ondas viajam através da estaca: uma onda ascendente e outra descendente nas quais se encontram superpostas duas ondas de forças e velocidades de

partículas ascendentes 'asc' e descendentes 'des'. Considerando-se positivas as forças compressivas e as velocidades de partícula descendentes, as proporcionalidades podem ser expressas através das equações:

$$
\begin{gathered}
F_{d e s}=Z \cdot v_{d e s} \\
F_{a s c}=-Z \cdot v_{a s c}
\end{gathered}
$$

Calculam-se a força e a velocidade em um ponto onde as ondas ascendentes e descendentes de forças e velocidades se encontram.

$$
\begin{gathered}
F=F_{d e s}+F_{a s c} \\
v=v_{d e s}+v_{a s c}
\end{gathered}
$$

e depois de substituir a relação de proporcionalidade da Eq. 3-28 dentro da Eq. 3-31, tem-se:

$$
Z . v=F_{d e s}-F_{\text {asc }}
$$

Após da adição ou subtração, a Eq. 3-32 com Eq. 3-30, respectivamente, é possível expressar $F_{d e s}$ e $F_{a s c}$ de força em termos da profundidade ' $x$ ' e do tempo ' $t$ '. Desse modo, podem-se identificar isoladamente as amplitudes das ondas descendentes e ascendentes. 


$$
\begin{aligned}
& F_{d e s}(x, t)=\frac{(F(x, t)+Z \cdot v(x, t))}{2} \\
& F_{a s c}(x, t)=\frac{(F(x, t)-Z \cdot v(x, t))}{2}
\end{aligned}
$$

\subsection{Efeito do atrito Lateral}

Se uma força de resistência do fuste $W$ começa a agir no tempo $t=x / c$ em algum ponto intermediário $x$, ao longo da estaca, enquanto a onda inicial $\left(F_{\text {sup }} \downarrow, v_{\text {sup }} \downarrow\right)$ se propaga, são geradas duas ondas conforme ilustrado na Figura 3-6, tendo cada qual uma magnitude de W/2. Para satisfazer o equilíbrio e a continuidade, a onda ascendente está em compressão e a onda descendente em tração. Neste modelo simplificado, considera-se que a força $W$ tem comportamento rígido-plástico.

Pela condição de equilíbrio:

$$
\begin{gathered}
F_{(1)}=W+F_{(2)} \\
F_{1} \downarrow+F_{1} \uparrow=W+F_{2} \downarrow
\end{gathered}
$$
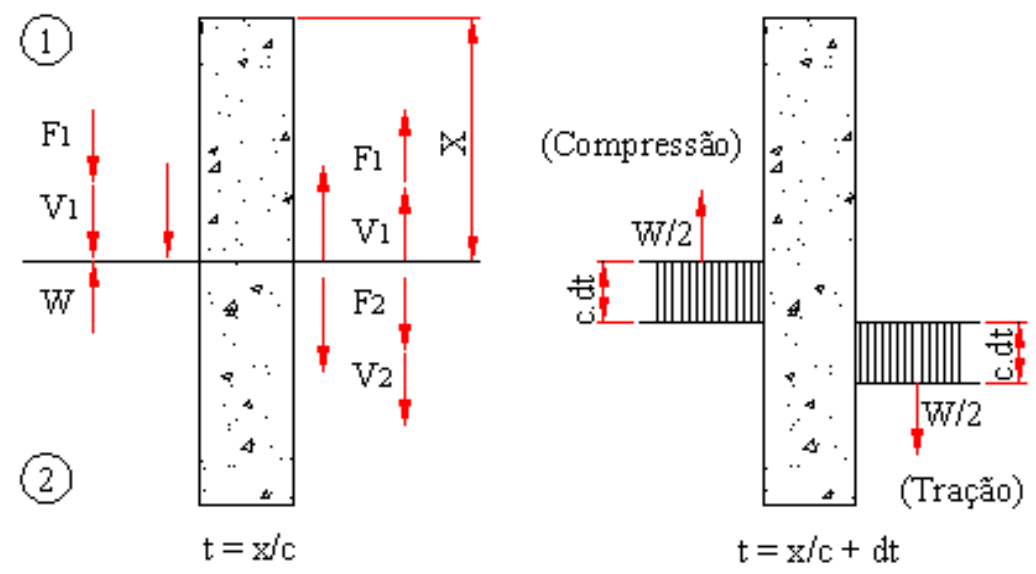

Figura 3-6 Ilustração das Ondas Geradas num Ponto Intermediário da Estaca (Niyama, 1983) 
Pela condição de continuidade:

$$
\begin{gathered}
v_{(1)}=v_{(2)} \\
v_{1} \downarrow+v_{1} \uparrow=v_{2} \downarrow \\
\frac{1}{Z}\left(F_{1} \downarrow-F_{1} \uparrow\right)=\left(F_{2} \downarrow\right) \frac{1}{Z} \\
F_{1} \downarrow-F_{1} \uparrow=F_{2} \downarrow
\end{gathered}
$$

Eq. 3-38

Eq. 3-39

Eq. 3-40

Da Eq. 3-36 e da Eq. 3-40, obtem-se:

$$
F_{1} \uparrow=\frac{W}{2} \uparrow
$$

Da Eq. 3-41 encontra-se a velocidade das partículas (ver Eq. 3-42), a qual é dirigida para cima (negativa) na onda ascendente para manter a continuidade. Essa onda alcança o topo no tempo $t=2 x / c$.

$$
V_{1} \uparrow=\frac{W . Z}{2} \uparrow
$$

Na Figura 3-7, Berruijt (2005) representa esquematicamente a reflexão e transmissão de ondas em uma estaca com seção uniforme e atrito lateral.
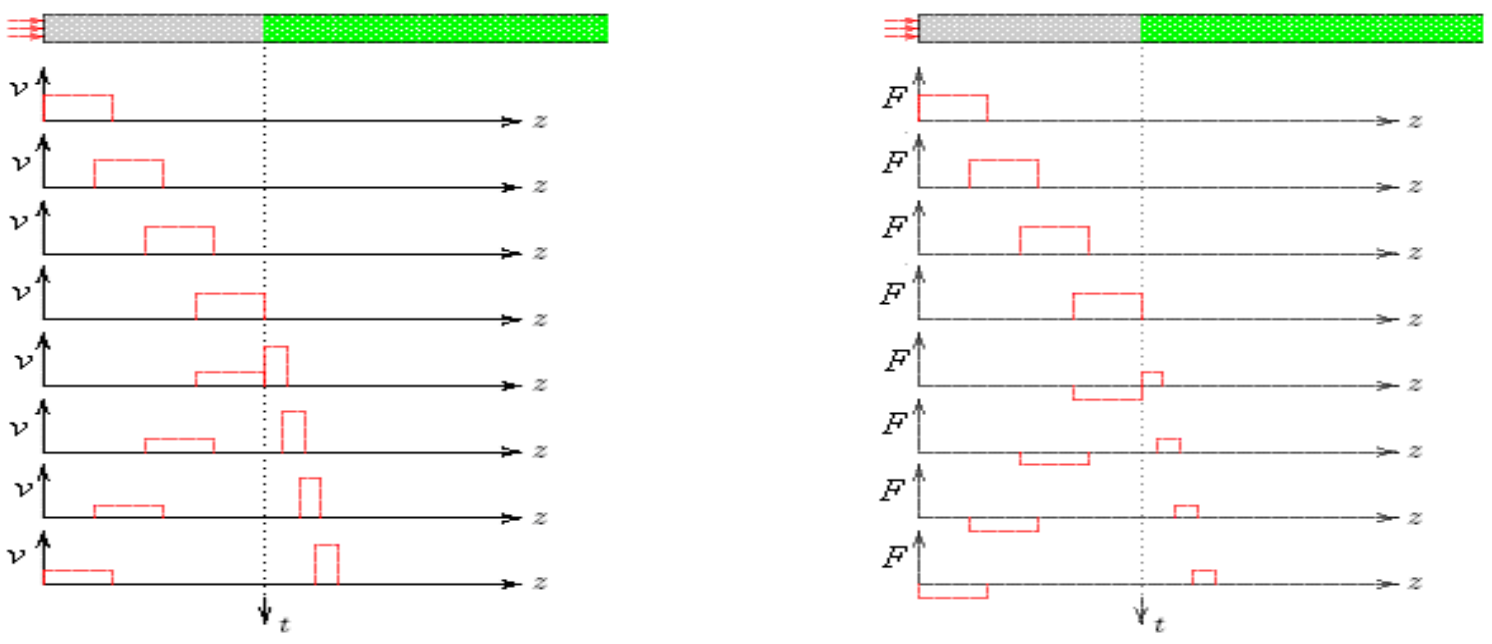

Figura 3-7 Reflexão e Transmissão de Ondas de Impacto (Berruijt, 2005) 
A resistência de ponta que começa a ser mobilizada na base da estaca no tempo $t=L / c$ é resultante da chegada de onda de impacto inicial e somatório da todas as ondas de tração geradas pelo atrito lateral ao longo da estaca. Esse processo de mobilização da resistência de ponta gera uma onda refletida que chega ao topo da estaca com intensidade $R$, uma vez que para cada força de atrito existente a onda ascendente gera novas ondas de intensidade $W / 2$ com sinais contrários aos descritos para onda descendente, conforme ilustrado na Figura 3-8.

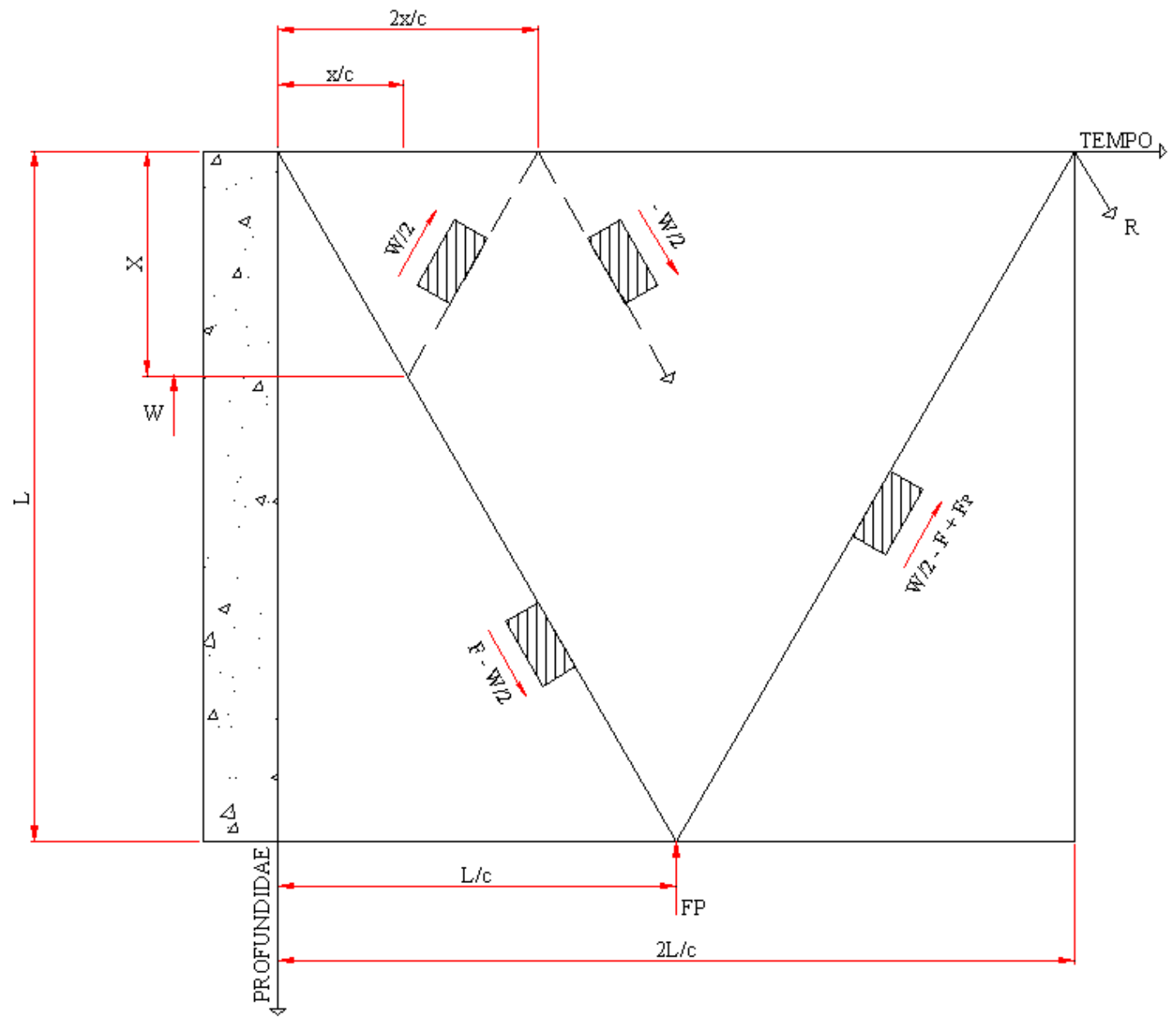

Figura 3-8 Diagrama de Trajetórias das Ondas (Niyama, 1983)

Através de um registro contínuo no tempo, das grandezas de força e velocidade num ponto da estaca junto à cabeça, o resultado seria um par de curvas como é apresentado na Figura 39. Nesta figura pode-se observar que é mantida a proporcionalidade entre força e velocidade através da impedância $Z$, até que comecem a chegar às ondas refletidas de cada uma das singularidades, no caso representadas por atritos laterais unitários Wi. As duas curvas 
começam a afastar-se e a distância entre elas, medidas na vertical, será o somatório dos atritos laterais até uma posição $x$ qualquer.

Para o tempo $t=2 L / c$, a diferença entre as curvas $F$ e Z.v, antes da chegada da onda refletida na ponta, representa o atrito lateral total atuante na estaca (vide Figura 3-9).

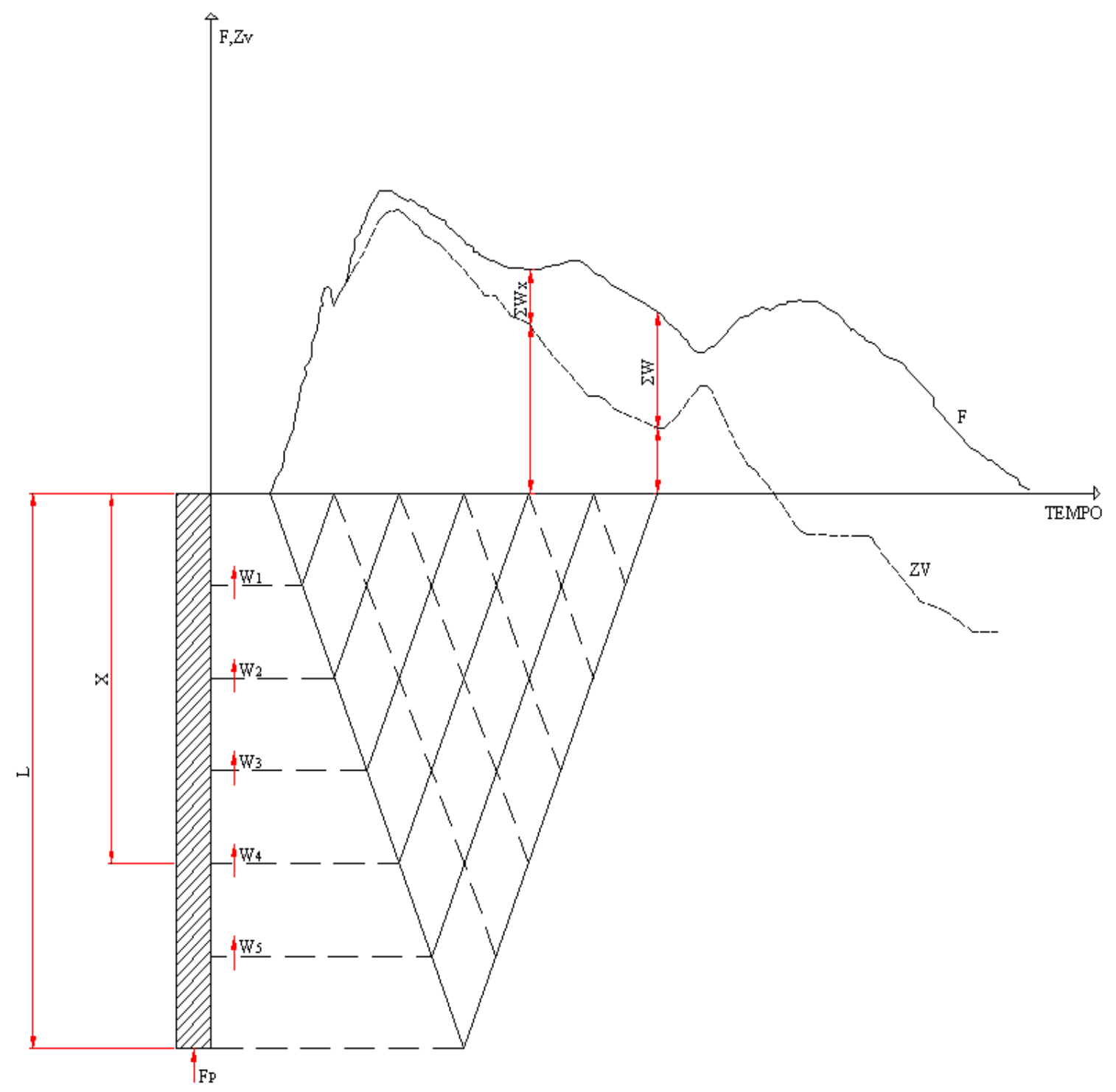

Figura 3-9 Registro típico das curvas de Força e Velocidade (Niyama, 1983) 


\subsection{Comentários sobre as Hipóteses adotadas no presente Capítulo}

Como já foi mencionado, a força e a velocidade são proporcionais a um termo conhecido como a impedância da estaca, mas esta relação é somente verdadeira quando não existe reação (forças de atrito) no fuste, e quando o material e a seção da estaca são constantes. No caso que o solo apresente reações, ondas de força e velocidade, refletidas e transmitidas, influenciarão na relação da impedância, como resultado da interação de todas as ondas geradas ao longo da estaca.

A reação do solo é representada pela diferença de comportamento entre as ondas refletidas e transmitidas (ver Eq. 3-33 e Eq. 3-34).

A distribuição de resistência ao longo do fuste da estaca pode ser interpretada a partir do tempo desenvolvido para uma onda refletida a $2 L / c$. Passado esse tempo, as onda refletidas são resultantes da interação de várias ondas que geralmente são difíceis de interpretar devido ao fato de atuarem efeitos misturados ao integrar efeitos de variáveis dependentes do tempo e da profundidade (Holeyman, 1992).

O ensaio de carga dinâmico, que visa avaliar a capacidade de carga de estacas, pode ser efetuado em tubulões, estaca de hélice continua, estacas moldadas in situ ou estacas cravadas. Por tanto, os comentários em relação à mobilização das resistências de fuste e da ponta, se restringem a estacas cravadas de concreto cravadas e pré-fabricadas:

Considera-se que a resistência de fuste pode ser determinada, se uma resistência constante (Resistência estática última) é ativada (ou mobilizada) durante certo período de tempo. Dependendo do caso, adota-se que as resistências de fuste, são rapidamente mobilizadas, sendo que um golpe no topo da estaca (no ensaio dinâmico) pode ativar a resistência lateral em cada trecho da estaca. Desse modo, um comportamento rígido-plástico representa o comportamento desta parcela de resistência de solo.

Para Charue (2004), também dependendo do caso, a mesma hipótese da mobilização de resistências consideradaa para o fuste não pode ser aplicável para entender o comportamento 
da resistência de ponta, devido a que o golpe que atinge a cabeça da estaca de um ensaio de carga dinâmico, muitas vezes não consegue mobilizar a resistência última de carga correspondente à ponta. Conseqüentemente para esse caso de estacas, a estimativa da parcela correspondente à resistência de ponta a partir de ensaios de carga dinâmicos está em função das hipóteses utilizadas nos procedimentos de análises de sinais de cravação, ou seja, dos programas para análise e tratamento de sinais de cravação, p.e. CAPWAP ou DLTWAVE. 


\section{ASPECTOS TEÓRICOS SOBRE A ATUALIZAÇÃO BAYESIANA DOS \\ PARÂMETROS DO MODELO DE SMITH}

\subsection{Introdução}

Um programa de análise de sinais de cravação (p.e. CAPWAP ou DLTWAVE), resolve a equação da onda, utilizando como condição de contorno um dos sinais obtidos em campo (p. e., sinal de velocidade) e junto a uma configuração de parâmetros do modelo (incluídos os parâmetros de Smith), consegue calcular o outro sinal (p. e., sinal de força), por tanto, tanto o sinal medido e calculado são comparados, se não apresenta boa concordância, o modelo de solo é iterativamente mudado até que o ajuste obtido seja o melhor possível (PDI Engenharia, 2006).

Nesse procedimento iterativo de mudança do modelo do solo, caracterizado pela adequação empírica e/ou automática dos parâmetros do modelo de Smith, faz-se necessária considerar as incertezas envolvidas nesse processo para atualizar os parâmetros de Smith.

Nos tópicos seguintes são apresentados os fundamentos teóricos da metodologia de atualização bayesiana aplicado ao caso dos parâmetros de Smith.

\subsection{Generalidades sobre Probabilidades}

Sob uma definição menos formal do ponto de vista matemático ${ }^{24}$, uma variável aleatória é uma variável que não pode ser predita com exatidão devido a vários fatores, entre eles: variabilidade natural, erros de medida, dados insuficientes, ou imperfeições no modelo. $\mathrm{Na}$ teoria de probabilidades, os resultados de experimentos são descritos como variáveis

\footnotetext{
${ }^{24}$ Sob uma definição mais rigorosa, uma variável aleatória é uma função que associa valores numéricos aos resultados de um experimento aleatório (Benjamim \& Cornell, 1970).
} 
aleatórias ou quantidades incertas para se observar. Portanto, é aceitável que uma variável aleatória possa variar entre um intervalo possível de valores. (Harr, 1987; Phoon et al, 1995)

Em geral, alguns dos valores adotados pelas variáveis aleatórias têm maior possibilidade de ocorrência que os outros. O intervalo de valores possíveis e as diferentes probabilidades de ocorrência estão representados concisamente por uma função de probabilidades (no caso discreto) ou uma função densidade de probabilidades (no caso contínuo).

A função distribuição de probabilidades define a probabilidade de uma variável aleatória (p.e., $K$ ) assumindo valores menores que alguma constante ' $\mathrm{k}$ ':

$$
F_{K}=\operatorname{Pr} o b(K<k)
$$

Onde $F_{K}(\bullet)$ função distribuição de probabilidades de $K$ e $\operatorname{Pr} o b(\bullet)=$ probabilidade do evento ser efetuado com sucesso. A função densidade de probabilidade é definida como a primeira derivada da função distribuição de probabilidades:

$$
f_{K}(x)=d F_{K}(x) / d x
$$

Onde $f_{K}(\bullet)$ função densidade de probabilidade de $K$ e $x=$ domínio da variável. Deste modo, é suficiente uma das duas funções para especificar uma descrição completa de uma variável aleatória. As funções descritas estão representadas na Figura 4-1.

A função densidade de probabilidade fica definida por duas medidas descritivas:

$$
\begin{gathered}
m_{K}=\int_{-\infty}^{\infty} x f_{K}(x) d x \\
\sigma_{K}^{2}=\int_{-\infty}^{\infty}\left(x-m_{K}\right)^{2} f_{k}(x) d x
\end{gathered}
$$

Onde $m_{k}=$ média do parâmetro $K \mathrm{e}, \sigma_{K}^{2}=$ desvio padrão do parâmetro $K$. 


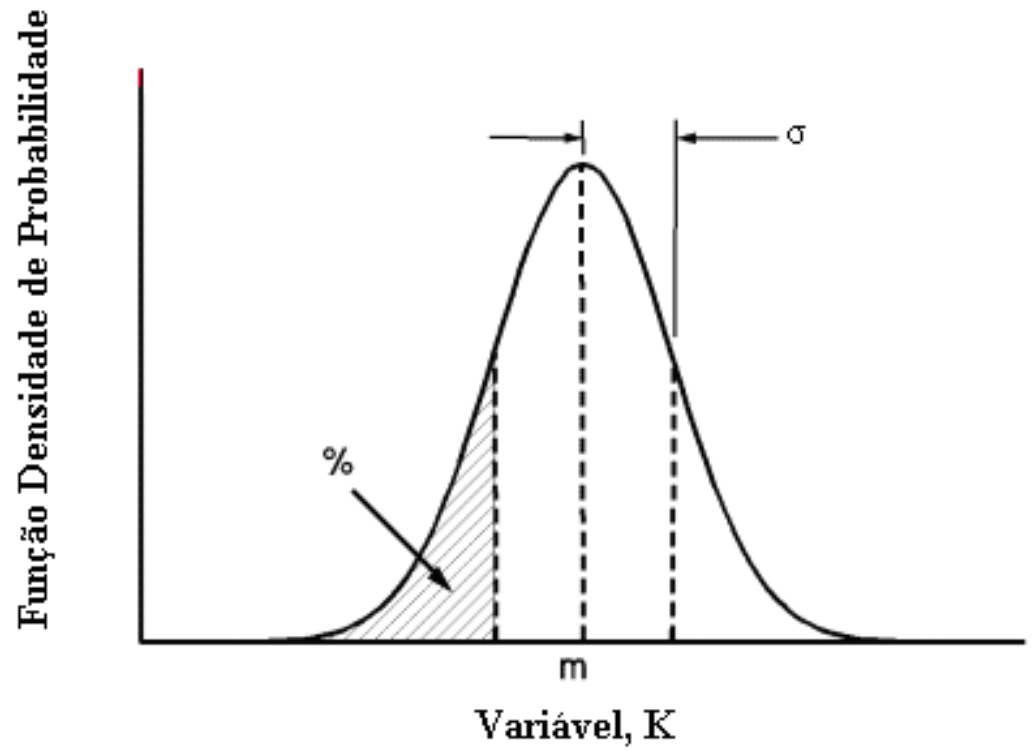

Figura 4-1 Função densidade de probabilidade para uma variável $\mathrm{K}$.

Outro parâmetro comumente utilizado para substituir o desvio padrão é o coeficiente de variação $\left(C O V_{K}\right)$, que relaciona diretamente o desvio padrão e a média, tendo a vantagem de ser adimensional, representando a variabilidade em termos percentuais. Tal parâmetro vem definido por:

$$
\operatorname{COV}_{K}=\frac{\sigma_{K}}{m_{K}}
$$

Se os conceitos de uma variável são ampliados para duas variáveis, a covariância, $\operatorname{Cov}(X, Y)$ representa um outro tipo de segundo momento possível de ser utilizado na caracterização da função de distribuição conjunta dessas variáveis. A covariância vem definida formalmente por:

$$
\operatorname{Cov}(X, Y)=E\left[\left(X-m_{X}\right) \cdot\left(Y-m_{Y}\right)\right]
$$

Uma medida derivada da covariância e que representa o grau de interdependência linear entre duas variáveis aleatórias é o coeficiente de correlação, $\rho_{X Y}$, que varia no intervalo $-1 \leq \rho_{X Y} \leq+1$ e vem conceituado por: 


$$
\rho_{X Y}=\frac{\operatorname{Cov}(X, Y)}{s_{X} s_{Y}}
$$

\subsection{Hipótese de Independência dos Parâmetros de Smith.}

Adotou-se uma hipótese básica entre os parâmetros de Smith: a independência entre cada um deles. Tal independência estatística terá que ser refletida nas análises de sensibilidade ('paramétricas') produto das análises dinâmicas posteriores (p.e, CAPWAP ou DLTWAVE).

Em relação com o tema da independência Liang \& Zhou (1997), utilizaram a base de dados de Paikowsky et al. (1994) para estudar a natureza estatística dos parâmetros de Smith, incluindo o valor médio, o desvio padrão e as funções de probabilidade de cada parâmetro e a correlação entre eles, particularmente entre: quake e damping. Para pesquisar a correlação entre os parâmetros de Smith utilizou-se o coeficiente de correlação para duas variáveis (vide Eq. 4-7).

Liang \& Zhou (1997) aceitaram a matriz de coeficientes de correlação, apresentada na Tabela 4-1, a partir do fato de que a correlação entre os dois parâmetros de Smith analisados foram muito pequenas. Tal conclusão além de ser questionável, só ressalta o fato de que existem restrições nos resultados encontrados, devido a que a base de dados utilizada (Paikowsky et al. 1994) foi obtida a partir de diversas análises CAPWAP, e não em função de um estudo das propriedades de cada tipo de solo.

Na presente pesquisa admite-se que os coeficientes de correlação, entre os parâmetros de Smith (J, $Q$ e Rult) do modelo de Smith e, portanto do modelo do CAPWAP, têm valores muito pequenos, próximo de zero. 
Tabela 4-1 Coeficientes de Correlação para Parâmetros de Smith (Liang \& Zhou, 1997)

\begin{tabular}{|c|c|c|c|c|}
\hline $\begin{array}{c}\text { Parâmetro do } \\
\text { Modelo de } \\
\text { Smith }\end{array}$ & Quake Fuste & Quake Ponta & $\begin{array}{c}\text { Damping } \\
\text { Smith Fuste }\end{array}$ & $\begin{array}{c}\text { Damping } \\
\text { Smith Ponta }\end{array}$ \\
\hline Quake Fuste & 1,0 & 0,32 & 0,06 & 0,03 \\
\hline Quake Ponta & 0,32 & 1,0 & 0,02 & 0,25 \\
\hline $\begin{array}{l}\text { Damping } \\
\text { Smith Fuste }\end{array}$ & 0,06 & 0,02 & 1,0 & 0,37 \\
\hline $\begin{array}{l}\text { Damping } \\
\text { Smith Ponta }\end{array}$ & 0,03 & 0,25 & 0,37 & 1,0 \\
\hline
\end{tabular}

\subsection{Representação do campo estocástico: utilização dos segundos momentos}

Para a definição probabilista de alguma variável aleatória, não sendo possível a definição precisa da descrição completa das leis probabilistas ou das funções de probabilidades que governam o fenômeno aleatório de cada um dos parâmetros, se faz necessário ao menos o conhecimento dos momentos de uma função de distribuição (Hachich, 1981). Relativo ao método dos momentos, para Ang \& Tang (1975) e Magnan (1982) uma primeira estimação do valor esperado e da variância de uma variável aleatória podem servir para determinar os parâmetros de uma distribuição de probabilidades. No caso seja uma distribuição normal (gaussiana) pode-se utilizar a relação seguinte.

\begin{tabular}{cc} 
Parâmetros da distribuição & $\begin{array}{c}\text { Relação com a variável } \\
\text { aleatória }\end{array}$ \\
\hline Média, $m$ & $E[K]=m$ \\
Variância, $\sigma^{2}$ & $\operatorname{Var}[K]=\sigma^{2}$
\end{tabular}

Considerada como variável aleatória, a determinação das medias espaciais (ou valores esperados) de resistência estática últimas (Rult) de fuste e ponta poderão ser definida por alguns métodos que conseguem determinar a resistência estática mobilizada para cada 
segmento discretizado da estaca, p. e., pode-se mencionar os métodos empíricos de Aoki \& Velloso (1975) ou Decourt \& Quaresma (1978).

Já no caso das outras variáveis aleatórias como: o máximo deslocamento elástico (quake) e o fator de amortecimento tipo Smith (damping Smith) a adoção de valores esperados em função exclusivamente do tipo de solo vê-se dificultada pelo fato de não ter um consenso na utilização de tais parâmetros (Paikowsky et al. 1994; Liang \& Zhou, 1997)

Os parâmetros de Smith sendo variáveis definidas para cada elemento discretizado da estaca (conforme Figura 2-3), podem ser descritos por um vetor de variáveis aleatórias que representam a distribuição de valores esperados com a profundidade, ou seja o campo estocástico local por meio de suas funções de valor médio.

$$
m_{K}=E[\underline{K}]=\left[\begin{array}{c}
E\left[\underline{K}_{1}\right] \\
E\left[\underline{K}_{2}\right] \\
\vdots \\
E\left[\underline{K}_{N}\right]
\end{array}\right]
$$

e suas funções de autocovariância.

$$
\operatorname{Cov}[\underline{K}]=\left[\begin{array}{cccc}
\operatorname{Var}\left[\underline{K}_{1}\right] & & & \text { Simétrico } \\
\operatorname{Cov}\left[\underline{K}_{2}, \underline{K}_{1}\right] & \operatorname{Var}\left[\underline{K}_{2}\right] & & \\
\vdots & \vdots & \ddots & \\
\operatorname{Cov}\left[\underline{K}_{N}, \underline{K}_{1}\right] & \operatorname{Cov}\left[\underline{K}_{N}, \underline{K}_{2}\right] & \ldots & \operatorname{Var}\left[\underline{K}_{N}\right]
\end{array}\right]
$$

Sendo: $N$ = Número de segmentos da estaca, e $\underline{K}=$ Parâmetro do modelo de Smith $(R u l t, Q$ ou $J s)$., e $\operatorname{Cov}\left[K_{1}, K_{2}\right]=\rho\left[K_{1}, K_{2}\right] \cdot \sqrt{\operatorname{Var}\left[K_{1}\right] \operatorname{Var}\left[K_{2}\right]}$.

Segundo Hachich (1981) a representação anterior dos primeiros dois momentos, geralmente carrega informação relevante sobre o campo estocástico analisado. Ou seja:

$$
\underline{K} \approx\left\{\underline{m}_{K} ; \operatorname{Cov}[\underline{K}, \underline{K}]\right\}
$$




\subsection{Determinação da Matriz de Covariâncias}

Adota-se que as variáveis de Smith variam continuamente sobre um domínio no espaço, chamado de campo aleatório.Assim, pode-se estabelecer que o domínio de cada variável é constituído por funções contínuas, que seguem processos aleatórios unidimensionais. Isto implica aceitar que o domínio dos parâmetros de Smith atua em uma só dimensão, ou seja, que os fenômenos físicos que acontecem fora do fuste e da ponta da estaca no espaço tridimensional (3-D) são simplificados a uma só dimensão, no sentido de uma reta vertical ao longo da interface da estaca-solo.

Nesta pesquisa, os parâmetros do modelo de Smith são considerados através de médias espaciais do campo estocástico sobre um elemento genérico L, esse elemento pode ser o trecho discretizado da estaca, como ilustra a Figura 4-2.

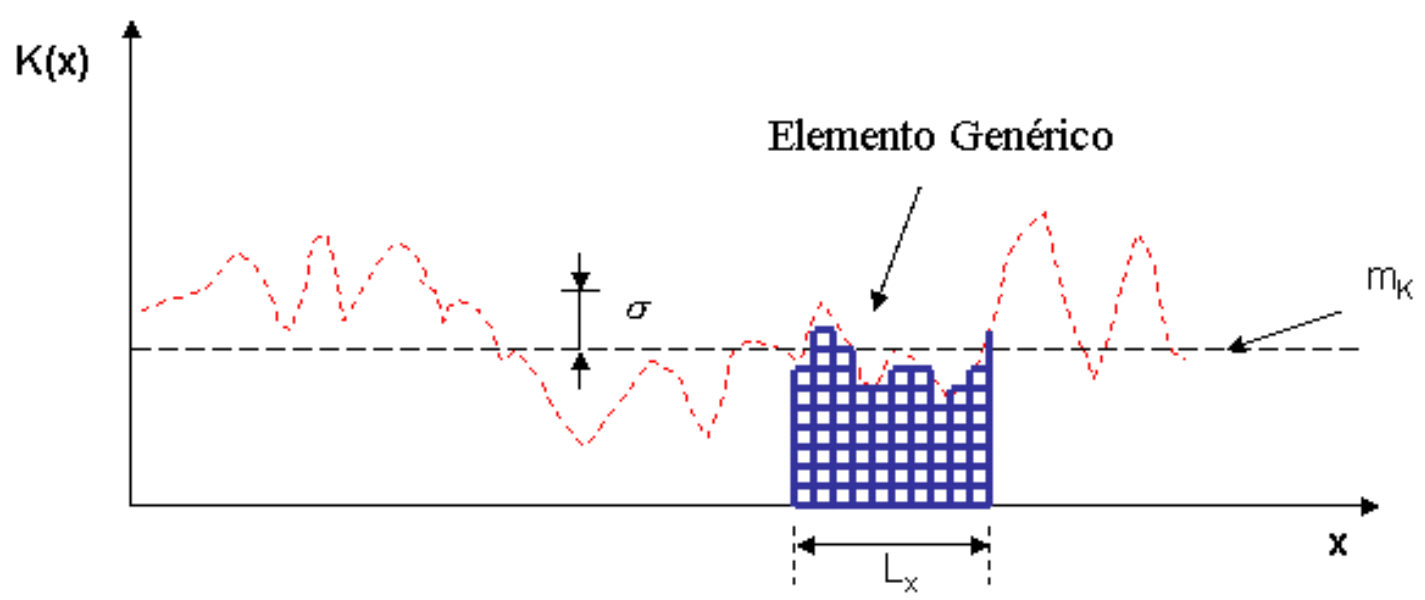

Figura 4-2 Campo estocástico unidimensional da variável $\underline{K}$ (Modificado de Vanmarcke, 1983).

Para o caso da resistência unitária última, o fenômeno físico que acontece radialmente é simplificado a uma dimensão, suposição essa utilizada, por exemplo, nos métodos estáticos empíricos, Aoki-Velloso (1975) e Decourt-Quaresma (1978). Por outro lado, os domínios 
dos parâmetros de quake e de damping, obedecem também a uma simplificação unidimensional, já sejam nos valores do fuste ou da ponta da estaca.

A simplificação feita devida ao entendimento do domínio dos parâmetros analisados do modelo numérico é de fundamental importância para a escolha adequada do modelo analítico na atualização bayesiana.

Para um parâmetro de domínio continuo, $K(x)$, com um processo aleatório estacionário ${ }^{25}$ com média $m_{K}$ e variância $\sigma_{K}^{2}$, como se mostra na Figura 4-2, pode-se obter para cada parâmetro analisado uma família de processos de médias locais, $K_{L}(x)$, para um elemento genérico linear $L$.

$$
K_{L}(x)=\frac{1}{L} \int_{L} K(x) \cdot d x
$$

Utiliza-se a Eq. 4-12 para encontrar a média para um elemento genérico $L$.

$$
m_{K_{T}}==\frac{1}{L_{T}} \int_{L_{T}} K(x) \cdot d x
$$

Sendo que variáveis aleatórias que variam continuamente sobre um espaço definido, neste caso em uma só dimensão se constituem campos aleatórios da mesma dimensão, onde o domínio da variável exibe autocorrelação ou seja a tendência de correlação apresentada entre dois intervalos de valores, chamados de elementos genéricos.

\footnotetext{
${ }^{25}$ Processo aleatório estacionário de segunda ordem (ou fracamente estacionário) é o processo no qual a média permanece constante e a covariância somente dependente da distância de separação entre os pontos amostrados.
} 


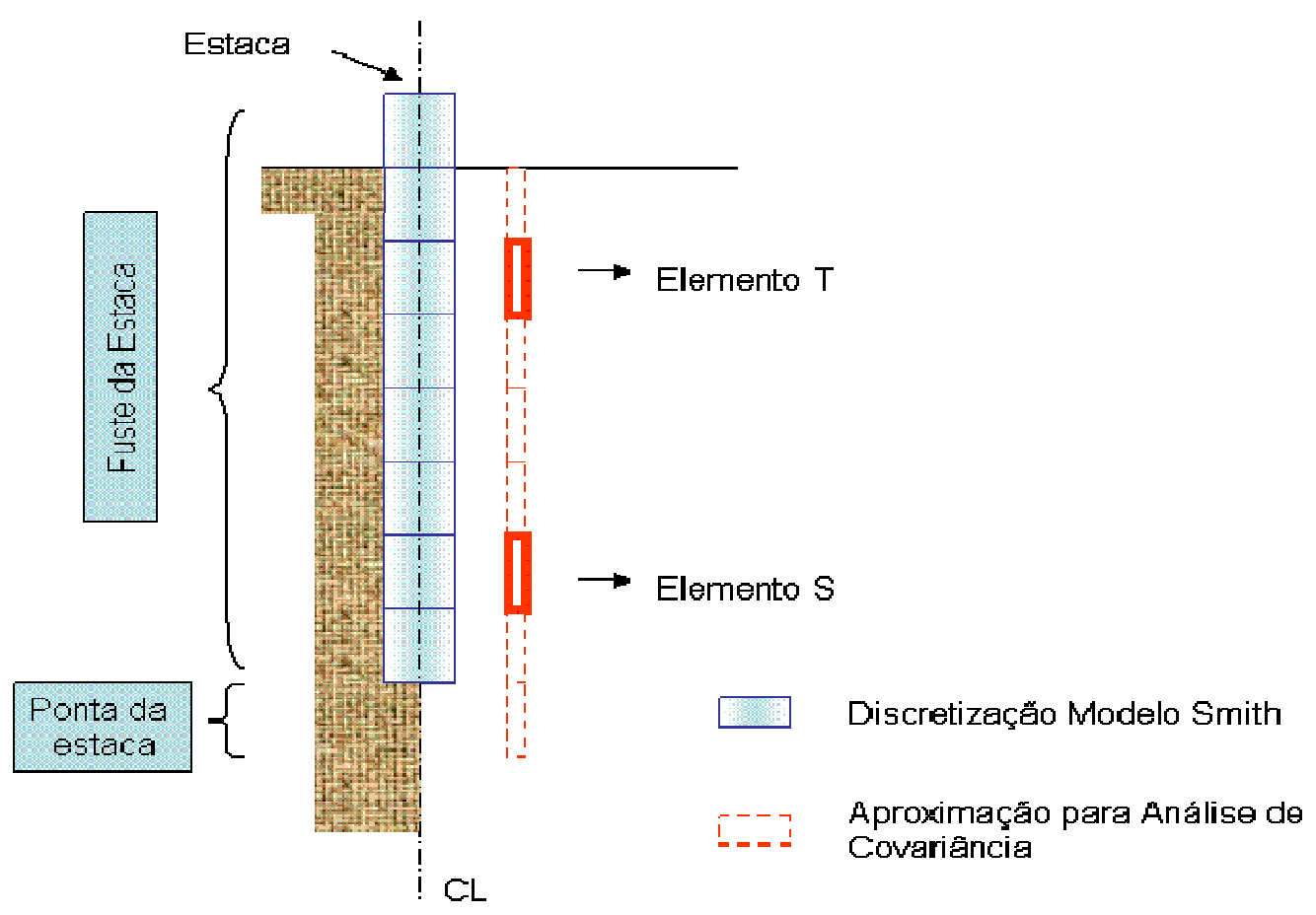

Figura 4-3 Aproximação do sistema estaca-solo para a análise de covariâncias

Define-se a covariância na Eq. 4-13, que correlaciona para um mesmo parâmetro, as médias espaciais de dois elementos genéricos, $L_{S}$ e $L_{T}$ (vide Figura 4-3).

$\operatorname{Cov}\left[K_{L_{S}}, K_{L_{T}}\right]=\frac{1}{L_{T}} \cdot \frac{1}{L_{S}} \int_{L_{T}} \int_{L_{S}} \operatorname{Cov}\left(x_{S}, x_{T}\right) \cdot d x_{S} \cdot d x_{T}$

Onde: $x_{S} \mathrm{e} x_{T}$, são pontos genéricos, dentro dos elementos lineares " $\mathrm{S}$ " e "T", respectivamente.

A Figura 4-3 ilustra a solução fechada da Eq. 4-13 (Vanmarcke, 1983), aplicável em problemas estocásticos que envolvem variáveis aleatórias unidimensionais.

$$
\operatorname{Cov}\left[K_{S}, K_{T}\right]=\frac{\sigma_{K}^{2}}{4 \cdot L_{S} \cdot L_{T}} \sum_{i=1}^{4}(-1)^{i} \cdot \Gamma_{K}^{2}\left(V_{i}\right) \cdot V_{i}^{2}
$$

Onde $\Gamma_{K}^{2}\left(V_{i}\right)$ é a função variância (definida posteriormente) e os significados de $L_{S}, L_{T}$ e $V_{i}$ estão explicados na Figura 4-4. 


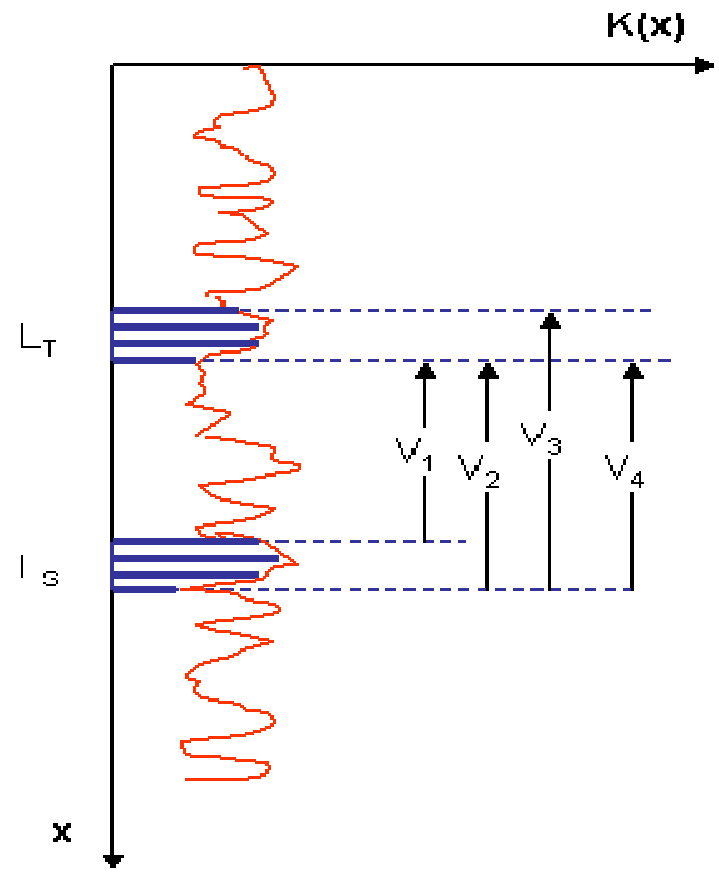

Figura 4-4 Definição dos elementos Vi (Vanmarcke, 1983)

Para Ang \& Tang (1975) se os valores da covariância estão relacionados com os seus valores médios respectivamente, e se a covariância é pequena ou zero a relação é pequena ou nula entre ambos os valores.

A Eq. 4-14 é utilizada para gerar a matriz de coeficientes de correlação entre pares de médias locais (ou integrais locais) da função do parâmetro associado com segmentos diferentes (ou elementos finitos) ao longo do eixo $x$.

Mais detalhes sobre as hipóteses e a derivação do método de integração local de campos aleatórios homogêneos de $n$-dimensões, pode ser encontrado em Vanmarcke (1983, cap. 3). 


\subsection{Determinação da Escala de Flutuação}

A escala de flutuação está relacionada com a distância média entre cruzamentos com a média, ou seja, quanto maior a distância média de cruzamentos com o valor médio, maior a escala de flutuação (Hachich, 2006) ${ }^{26}$.

A escala de flutuação ou distância de correlação (Magnan, 1987; Phoon \& Kulhawy, 1999) é um parâmetro estatístico necessário para descrever a inerente variabilidade do solo. Tal parâmetro fornece um indicativo sobre a distância na qual o domínio do parâmetro analisado apresenta uma relativamente forte correlação. Um método aproximado para determinação da escala de flutuação é apresentado por Vanmarcke (1977) na Eq. 4-15.

$$
d \approx 0,8 \cdot \bar{d}
$$

Onde $d$ = escala vertical de correlação. $\bar{d}=$ distância média entre interseções do domínio do parâmetro e sua correspondente função de valores médios.

Phoon et al. (1995) após uma extensiva revisão bibliográfica de escalas de flutuação para parâmetros geotécnicos comuns apresentaram valores que variam entre $0,5 \mathrm{~m}$ e $10 \mathrm{~m}$ para escalas de flutuação vertical e entre 40 e 60 m para escalas de flutuação horizontal. Já Gimenez (1988) recomenda escalas de flutuação vertical que variam entre 0,5 m a 2,0 m. Inexistem referencias bibliográficas para escalas de flutuação de parâmetros dinâmicos do modelo de Smith ou do modelo do CAPWAP.

Para Vanmarcke (1983, Pág. 327, Cap. 8), pode se quantificar a variabilidade da escala de flutuação por meio de dois estimadores estatísticos: (1) função de autocorrelação, e (2) função de redução da variância.

\footnotetext{
${ }^{26}$ HACHICH, W. 2006, Notas de aula, Estatística e Probabilidades em Engenharia Geotécnica. Disciplina de Pós-graduação. PEF-Escola Politécnica, USP.
} 


\subsection{Determinação da Função de Redução da Variância}

A Função de Redução da Variância, $\Gamma_{K}^{2}(\mathrm{Ls})$, de um elemento linear de dimensões $L_{S}$, é o fator de redução aplicado à variância pontual $\sigma_{K}^{2}$, de maneira a torná-la uma média espacial do campo aleatório sobre o elemento $L_{S}$. O valor da função de variância é 1,0 para $L=0$, e decai ao valor de zero quando $L$ fica maior, assim:

$$
\operatorname{Var}\left[K_{L}\right]=\sigma_{L}^{2}=\Gamma_{L}^{2}(L) \cdot \sigma_{K}^{2}
$$

Segundo Cambou (1975) a média espacial é estimada a partir de um número finito de ensaios, $n$, os quais carregam uma incerteza que causa o decréscimo da variância conforme ao aumento de $n$, e é precisamente essa medida da 'redução' dada pela função de redução da variância,.

Na Eq. 4-17, Vanmarcke (1983, p. 188) define a escala de flutuação em função dos parâmetros do modelo probabilista adotado.

$$
d=\lim _{L \rightarrow \infty} L \cdot \Gamma_{K}^{2}(L)
$$

Onde $\Gamma_{K}^{2}(L)=d / L$, quando $L \rightarrow \infty$; faz com que o $d / L$ seja a assíntota da função variância. A função variância converge rapidamente com a sua assíntota quando L expande.

\subsection{Determinação da Função de Autocorrelação}

A função de redução da variância, $\Gamma_{K}^{2}(L)$, está correlacionada à função de autocorrelação, $\rho(x)$, conforme a Eq. 4-18.

$$
\Gamma_{K}^{2}(L)=\frac{2}{L} \int_{L}\left(1-\frac{t}{L}\right) \cdot \rho_{K}(t) \cdot d t
$$

Segundo Baecher \& Christian (2003, Pág. 251), para que a escala de flutuação exista é necessário que $\rho(t) \rightarrow 0$ e $t \rightarrow \infty$ (ver Figura 4-5). Desse modo, a função de autocorrelação decresce mais rápido que $1 / t$. Neste caso a escala de flutuação pode ser 
calculada resolvendo a integral da função de correlação, ver Eq. 4-19 (ou o momento de $\rho(t)$ relativo à origem) .

$$
d=\int_{-\infty}^{\infty} \rho(t) \cdot d t
$$

Na Tabela 4-2 são listadas as funções de redução da variância para funciones de autocorrelação comuns. Nota-se que cada uma das funciones mencionadas são assintóticas e proporcionais a $1 / L$.

Tabela 4-2 Funções de Redução da Variância para Funções de Autocorrelação 1-D. (Modificado de Vanmarcke, 1983; Baecher \& Christian, 2003).

\begin{tabular}{|c|c|c|c|}
\hline Modelo & $\begin{array}{l}\text { Função de Autocorrrelação } \\
\qquad \rho(t)\end{array}$ & $\begin{array}{l}\text { Função de Redução da Variância } \\
\qquad \Gamma_{K}^{2}(L)\end{array}$ & $\begin{array}{l}\text { Escala de } \\
\text { Flutuação } \\
\qquad d\end{array}$ \\
\hline---- & $\rho(t)= \begin{cases}1 & s e(t=0) \\
0 & s e(t \neq 0)\end{cases}$ & $\Gamma_{K}^{2}(L)= \begin{cases}1 & \text { se. } L=0 \\
0 & \text { se. } L \neq 0\end{cases}$ & $\begin{array}{c}d \\
\text { Eq. 4-20 }\end{array}$ \\
\hline Triangular & $\rho_{K}(t)=\left\{\begin{array}{cc}1-\frac{|t|}{d}, & |t| \leq d \\
0 & |t| \geq d\end{array}\right.$ & $\Gamma_{K}^{2}(L)=\left\{\begin{array}{cc}1-\frac{L}{3 d}, & L \leq d \\
\left(\frac{d}{L}\right) \cdot\left[1-\frac{d}{3 L}\right] & . L \geq d\end{array}\right.$ & $\begin{array}{c}d \\
\text { Eq. } 4-21\end{array}$ \\
\hline Exponencial & $\rho_{K}(t)=\left\{\exp ^{-|t| / a}\right.$ & $\Gamma_{K}^{2}(L)=\left\{2\left(\frac{a}{L}\right)^{2}\left(\frac{L}{a}-1+e^{-L / a}\right)\right.$ & $\begin{array}{c}d=2 . a \\
\text { Eq. } 4-22\end{array}$ \\
\hline $\begin{array}{l}\text { Exponencial } \\
\text { Quadrado } \\
\text { (Gaussiano) }\end{array}$ & $\rho_{K}(t)=\left\{\exp ^{(-|t| / b)^{2}}\right.$ & $=\left\{\left(\frac{b}{L}\right)^{2}\left(\sqrt{\pi} \frac{L}{b} \Phi\left(\frac{L}{d}\right)+e^{-(L / b)^{2}}-1\right.\right.$ & $\begin{array}{l}d=\sqrt{\pi} \cdot b \\
\text { Eq. } 4-23\end{array}$ \\
\hline
\end{tabular}

Onde $t$ é a projeção da distância entre os pontos genéricos dentro do elemento (vide Figura 4-5).

Hachich (1981) utilizou uma função de redução da variância para o caso de campos aleatórios em 2-D. Para a presente pesquisa utilizou-se uma função de redução da variância que correlaciona variáveis continuas unidimensionais (em 1-D). 
De acordo com Vanmarcke (1983), a escolha do modelo de decaimento da correlação não interfere significativamente nos resultados obtidos. Portanto, adotou-se a função de autocorrelação triangular, $\rho_{K}(t)$, que decresce linearmente de 1 a 0 , em função de $|t|$.

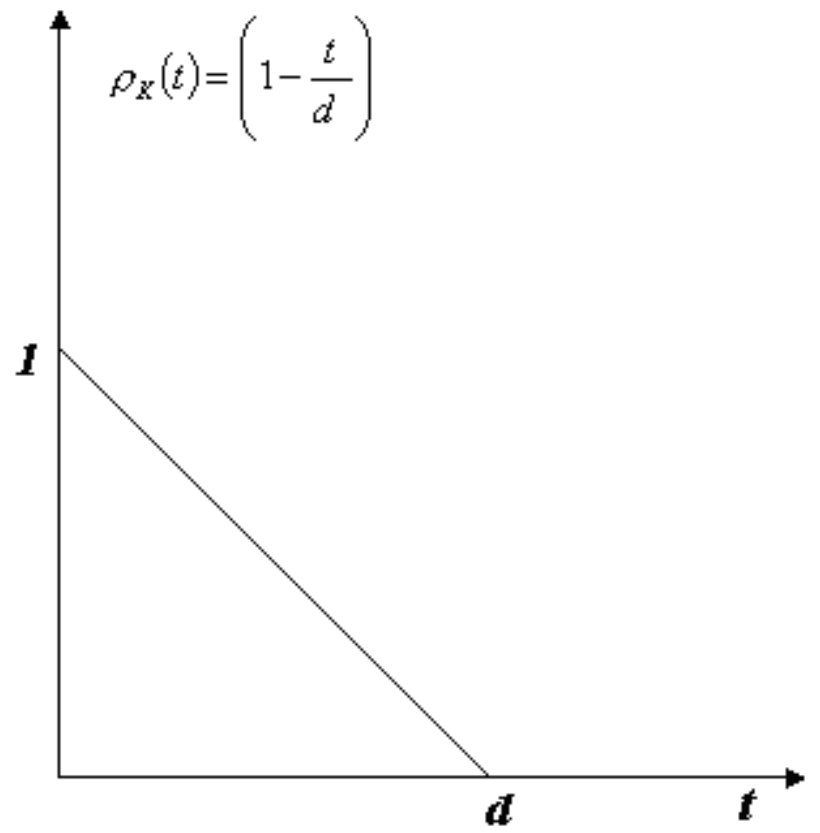

Figura 4-5 Função de correlação triangular $\rho_{K}(t)$.

Substituindo a Eq. 4-22 dentro da Eq. 4-18, Vanmarcke (1983) obteve a função de redução da variância, para $V_{i} \geq 0$ (vide Figura 4-4).

$$
\Gamma_{K}^{2}(V)=\left\{\begin{array}{cc}
1-\frac{V}{3 . d}, & V \leq d, \\
\left(\frac{d}{V}\right)\left[1-\frac{V}{3 . d}\right], & V \geq d .
\end{array}\right.
$$

Substituindo a Eq. 4-24 na Eq. 4-14 e na Eq. 4-16, é possível derivar todos os elementos da matriz de covariâncias para cada parâmetro analisado. 


\subsection{Modelo linear de Observação}

$\mathrm{Na}$ presente pesquisa utilizam-se instrumentos hipotéticos que medem os valores do sinal (de força ou velocidade) calculado por algum programa de análise de sinais de cravação (p. e. CAPWAP $\left.{ }^{\circledR}\right)$.

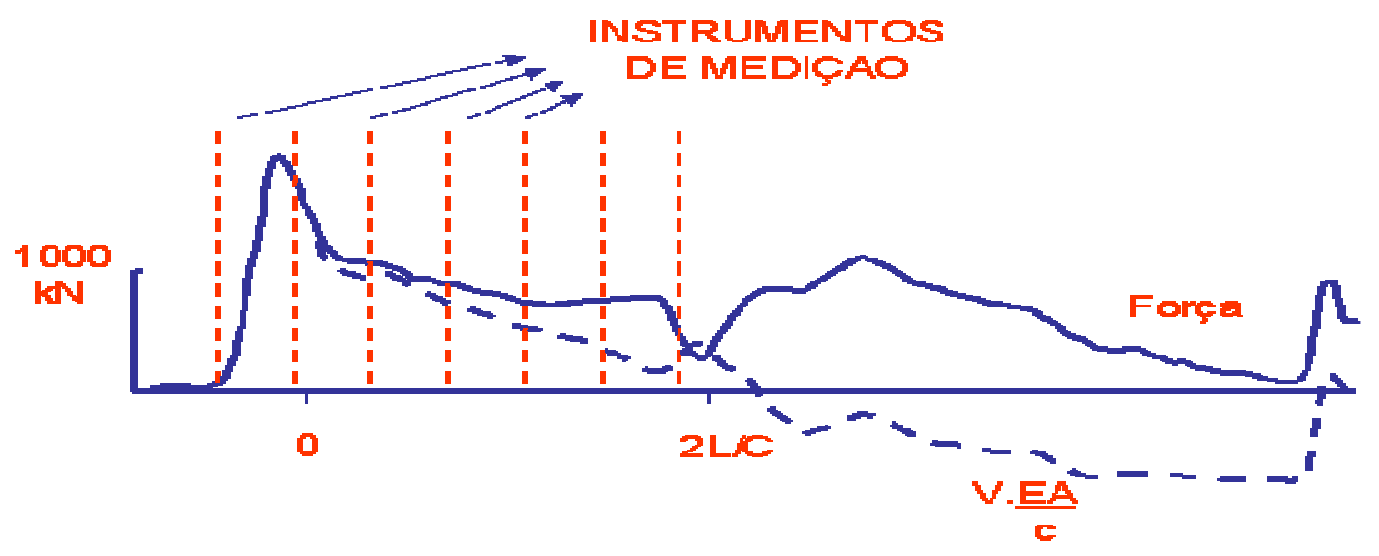

Figura 4-6 Localização dos instrumentos de medição.

Tais observações realizadas nos instrumentos hipotéticos devem necessariamente carregar informação dos parâmetros dinâmicos em questão. Tal relação pode ser inferida diretamente através de um modelo de observação.

Para Hachich (1983) e Phoon et al. (1995), os procedimentos da utilização de um instrumento de medida introduzem uma variabilidade adicional nos valores observados. Já Hachich (1983) menciona que tais variabilidades podem partir da informação carregada pela proximidade dos instrumentos.

Para Hachich (1983) as observações de tais instrumentos hipotéticos anteriormente descritos podem ser afetadas por (a) erros de medida devido às imperfeições do instrumento (erros inerentes ao instrumento ou por causas externas como instalação ou deterioração ao longo prazo) e (b) erros aleatórios que não são explícitos. Utiliza-se um modelo de observação linear, que formaliza e quantifica tais ideais intuitivos. 
A Eq. 4-25, descreve uma equação de calibração do instrumento hipotético que relaciona a quantidade medida (valor do sinal de força ou velocidade calculado) e o valor atual de um parâmetro de Smith (damping, quake ou Rult), em um ponto de observação, $x_{i}$.

$$
Z\left(\underline{x}_{i}\right)=a\left(\underline{x}_{i}\right)+b\left(\underline{x}_{i}\right) \cdot k\left(\underline{x}_{i}\right)+v\left(\underline{x}_{i}\right)
$$

Onde $v\left(\underline{x}_{i}\right)$ é a dispersão aleatória de média não zero das observações, e o significado dos outros símbolos está explicado na curva de calibração do instrumento hipotético da Figura 4-7.

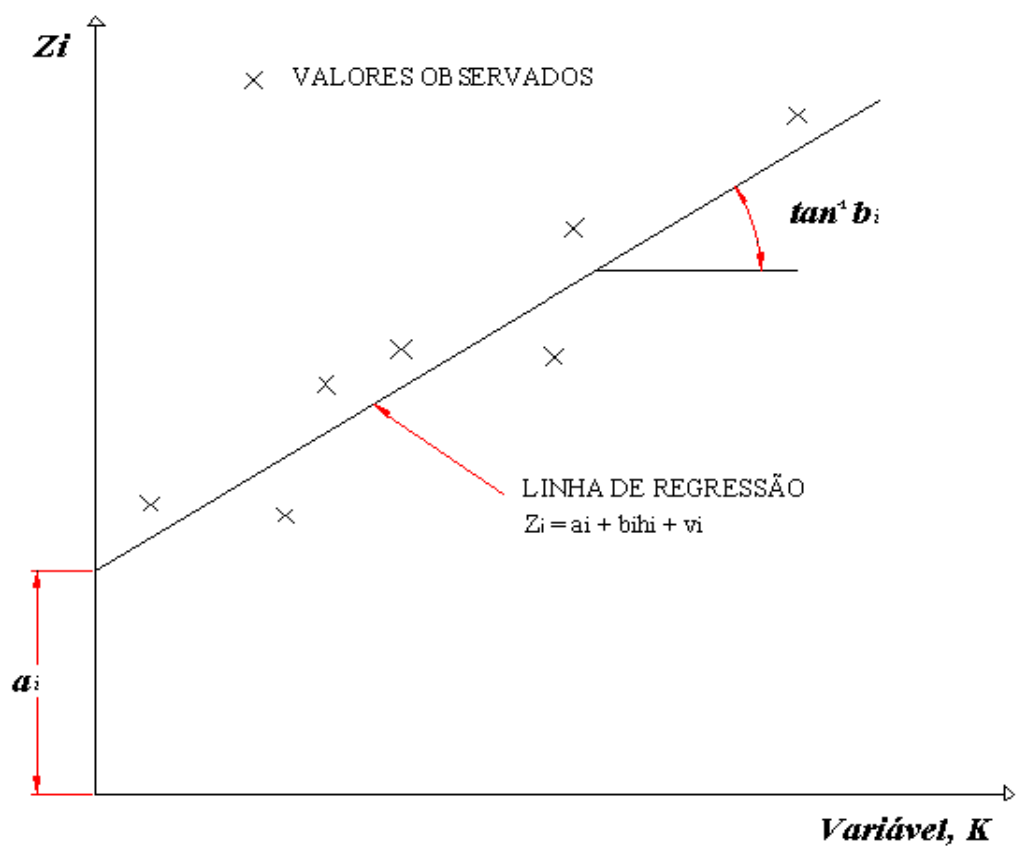

\section{Figura 4-7 Curva de Calibração do instrumento Hipotético}

(Modificado de Hachich, 1981)

Pode-se utilizar o modelo seguinte para descrever as relações entre as variáveis de estado (parâmetros do modelo de Smith) e as observações das leituras no sinal calculado de força ou velocidade. A partir da Eq. 4-25 utiliza-se $\underline{K}$ como um vetor de $n$ variáveis de estado e $\underline{Z}$ um vetor de $p$ observações.

$$
\underline{Z}=\underline{a}+\underline{S} \cdot \underline{K}+\underline{v}
$$


A Eq. 4-26 representa a relação linear com os erros aleatórios adicionados ( $\underline{v})$, onde:

$\underline{Z}=$ Matriz de observações, $\left[p^{*} n\right]$;

$\underline{a}=$ vetor de $p$ parâmetros de interseção; $[p * 1]$

$\underline{S}=$ Matriz de sensibilidade do parâmetro $K,\left[p^{*} n\right]$;

$\underline{K}=$ Vetor do parâmetro analisado, $[n * 1]$;

$\underline{v}=$ vetor de erros de observação dos $p$ instrumentos, $[n * 1]$;

$p=$ Pontos de observação (instrumentos hipotéticos ao longo do sinal analisado);

$n=$ Número de elemento discretizado da estaca (incluído o trecho da ponta); e

$K=$ Parâmetro analisado $(Q, J s$, o Rult $)$.

A matriz de sensibilidade, $\underline{S}$, que relaciona a sensibilidade do sinal no $p$-ésimo instrumento, relativo ao acréscimo ou decréscimo do parâmetro $K$ para os $n$ trechos discretizados da estaca.

$$
S_{p n}=\frac{\partial F_{p}}{\partial K_{n}} \cong \frac{\Delta F_{p}}{\Delta K_{n}}
$$

Onde:

$\Delta F_{p}=$ Mudança de leituras do sinal de força do instrumento $p$ (dependente do parâmetro $n$ ); $\Delta K_{n}=$ Mudança do valor do parâmetro de Smith correspondente ao trecho $n$ da estaca.

\subsection{Teoria da Atualização Bayesiana}

O Teorema herdou o nome de seu precursor, o Reverendo Thomas Bayes, que lançou as bases do método em 1763, republicado em 1958. No entanto, a forma usual do teorema, foi devida à Laplace, em 1782.

Segue-se a explicação dada por Benjamin \& Cornell (1970). Admita-se que os eventos B1, B2,..., Bk do Diagrama de Venn apresentado na figura a seguir, Figura 4-8, formem uma 
partição do espaço amostral $\mathrm{S}$, ou seja, tais eventos são mutuamente excludentes e coletivamente exaustivos.

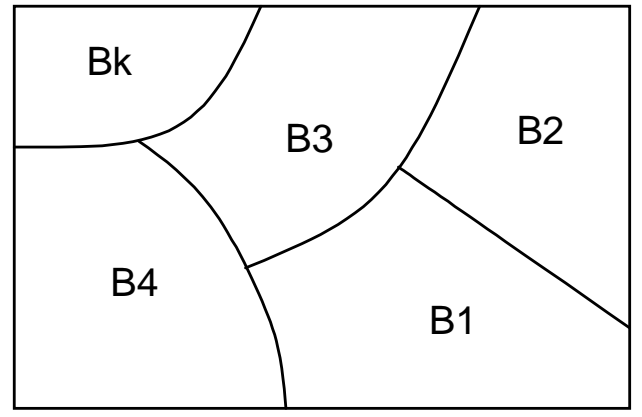

S

Figura 4-8 Partição do espaço amostral S.

Suponha-se ainda que as probabilidades de cada um dos eventos do espaço amostral são conhecidas e denotadas por $\mathrm{P}(\mathrm{Bj}), \mathrm{j}=1, \ldots ., \mathrm{k}$.

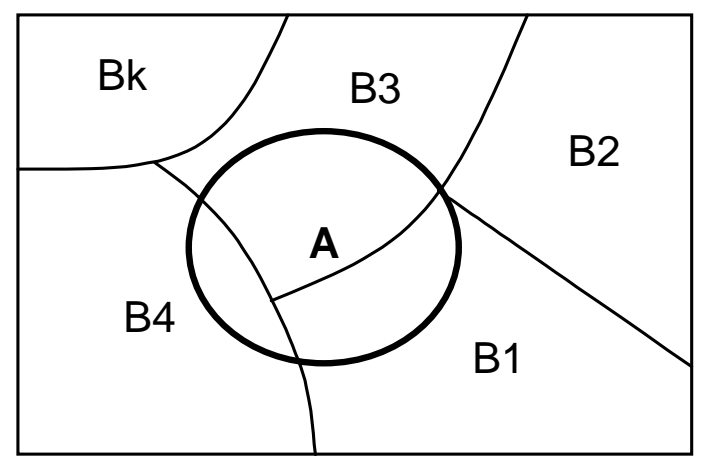

S

Figura 4-9 Ocorrência de um evento A qualquer.

De posse da ocorrência de um evento A qualquer (Figura 4-9), o Teorema de Bayes possibilita recalcular as probabilidades de cada um dos eventos que constitui o espaço amostral, através da seguinte expressão:

$$
P(B i / A)=\frac{P(A / B i) \cdot P(B i)}{\sum_{j=1}^{k} P(A / B j) \cdot P(B j)}
$$

Da formulação acima apresentada, observa-se que as probabilidades anteriores, traduzidas por $\mathrm{P}(\mathrm{Bi})$, são combinadas à informação adicional decorrente da observação do fenômeno, 
representada por $\mathrm{P}(\mathrm{A} / \mathrm{Bi})$, conduzindo a um estado de conhecimento atualizado, posterior à amostragem, representado por $\mathrm{P}(\mathrm{Bi} / \mathrm{A})$. Diz-se, portanto que as probabilidades posteriores, $\mathrm{P}(\mathrm{Bi} / \mathrm{A})$, estão condicionadas à ocorrência de um evento A qualquer.

\subsubsection{Hipóteses para Atualização Bayesiana.}

Para utilizar a teoria da atualização bayesiana é importante ter em conta as hipóteses seguintes que permitiram sua derivação. Como condição básica admite-se que o vetor de variáveis de estado (parâmetros do modelo de Smith), $\underline{K}$, seja conhecido, além das seguintes hipóteses:

1. $\underline{K}$ é $n$ - $\left(\underline{m}^{\prime} ; \underline{C^{\prime}}\right)$, i.e., o vetor $\underline{K}$ segue um campo aleatório normal (Gaussiano), com uma distribuição normal $n$-dimensional com vetor média, $\underline{m}^{\prime}$, e matriz de covariâncias, $\underline{C}^{\prime}$, conhecidas, e função distribuição de probabilidades:

$$
f(\underline{K})=\left[(2 \pi)^{n} \cdot\left|\underline{C^{\prime}}\right|\right]^{\frac{1}{2}} \cdot \exp \left[-\frac{1}{2}\left(\underline{K}-\underline{m^{\prime}}\right)^{T} \cdot\left(\underline{C^{\prime}}\right)^{-1} \cdot\left(\underline{K}-\underline{m^{\prime}}\right)\right]
$$

Sendo $\left|\underline{C}^{\prime}\right|=$ determinante da matriz de covariância, $\underline{C}^{\prime}$.

2. $\underline{v}$ é $p-N(\underline{0} ; \underline{V})$, i.e., $\underline{v}$ é um vetor de erros de média nula com uma distribuição normal p-dimensional, com matriz de covariâncias conhecidas, $\underline{V}$.

3. $E\left[\underline{K} \cdot \underline{v}^{T}\right]=0$, os erros de medida não são linearmente correlacionados com as variáveis de estado.

Sendo o vetor de variáveis de estado conhecido, $\underline{K}$. A partir da Eq. 4-29, para uma probabilidade condicional de $\underline{Z}$, dado $\underline{K}$, é uma translação da distribuição de $\underline{v}$ : 
$f(\underline{Z} \mid \underline{K})=\left[(2 \pi)^{n} \cdot|\underline{\mid V}|\right]^{-\frac{1}{2}} \cdot \exp \left[-\frac{1}{2}(\underline{Z}-\underline{a}-\underline{S} \cdot \underline{K})^{T} \cdot(\underline{V})^{-1} \cdot(\underline{Z}-\underline{a}-\underline{S} \cdot \underline{K})\right]$

i.e., $\underline{Z} \mid \underline{K}$ é $p-N(\underline{a}+\underline{S} . \underline{K} ; \underline{V})$

Segundo Hachich (1981) a Eq. 4-30 pode ser vista de dois modos: como uma função de $\underline{Z}$ significa uma função de probabilidade de $\underline{Z}$, condicional ao conhecimento de $\underline{K}$. Como uma função de $\underline{K}$, para um valor fixo $\underline{Z}$, isto é a função verosimilhança, fundamento da teoria da estimação bayesiana, que expressa a probabilidade de um vetor de observações, $\underline{Z}$, derivar de diferentes valores de variáveis de estado, $\underline{K}$.

Benjamin e Cornell (1970) expõem que a função de verossimilhança, representa a probabilidade de se obter a amostra observada como função do verdadeiro estado da natureza.

\subsubsection{Atualização Bayesiana}

A Eq. 4-31 apresenta o teorema de Bayes em função do problema em questão:

$$
P[\text { estado |amostras }]=\frac{P[\text { estado }] P[\text { amostra } \mid \text { estado }]}{\sum_{\substack{\text { estados } \\ \text { posiveis }}}(P[\text { estado }] P[\text { amostra } \mid \text { estado }])}
$$

Onde:

$P[$ estado $]=$ probabilidade anterior ao experimento de um estado em particular;

$P[$ amostra|estado $]=$ informação fornecida pelo experimento, ou seja, a probabilidade daquela determinada amostra ter sido originada naquele estado em particular;

$P[$ estado $\mid$ amostra $]=$ probabilidade atualizada (posterior) dos parâmetros de Smith, dada uma amostra ou vetor de observações; e

$P[$ amostra $]=$ denominador da Eq. 4-31, probabilidade total da amostra relativa ao estado anterior às observações, constitui-se a constante de normalização. 
Uma expressão similar da Eq. 4-31, em termos de funções de densidade de probabilidades, $f(\bullet)$, e considerando o objetivo de atualizar parâmetros a partir de observações feitas no sinal.

$$
f(\underline{K} \mid \underline{Z})=\frac{f(\underline{K}) \cdot f(\underline{Z} \mid \underline{K})}{f(\underline{Z})}
$$

Considerando ao denominador como uma constante de normalização:

$$
f(\underline{K} \mid \underline{Z}) \propto f(\underline{K}) \cdot f(\underline{Z} \mid \underline{K})
$$

Hachich (1981), a partir do formato da Eq. 4-33, derivou as equações para a obtenção da matriz atualizadas das médias dos parâmetros do modelo $\left(\underline{m}^{\prime \prime}\right)$ e da respectiva matriz atualizada de covariâncias ( $\left.\underline{C}^{\prime \prime}\right)$.

$$
\begin{gathered}
\underline{m}^{\prime \prime}=\underline{m^{\prime}}+\underline{C}^{\prime \prime} \cdot \underline{S}^{T} \cdot\left(\underline{S} \cdot \underline{C}^{\prime} \cdot \underline{S}^{T}+\underline{V}\right)^{-1} \cdot\left(\underline{Z}-\underline{a}-\underline{S} \cdot \underline{m}^{\prime}\right) \\
\underline{C}^{\prime \prime}=\underline{C}^{\prime}+\underline{C}^{\prime} \cdot \underline{S}^{T} \cdot\left(\underline{S} \cdot \underline{C}^{\prime} \cdot \underline{S}^{T}+\underline{V}\right)^{-1} \cdot \underline{S} \cdot \underline{C^{\prime}}
\end{gathered}
$$

Eq. 4-35

Onde:

$\underline{m^{\prime}}=$ Matriz inicial, da variável $\underline{K}$ analisada do modelo, $[n * 1] ;$

$\underline{C}^{\prime}=$ Matriz inicial de covariâncias, $[n * n]$; e

$\underline{V}=$ Matriz de erros de observação, $[p * p]$.

Segundo Hachich (1981), a Eq. 4-34 revela que o vetor de médias posterior é a soma do vetor médio anterior e um termo novo, linear com as observações ou, mais precisamente, com o viés das leituras dos instrumentos $(\underline{Z})$ dos seus valores esperados anteriores $\left(\underline{a}-\underline{S} \cdot \underline{m^{\prime}}\right)$. 


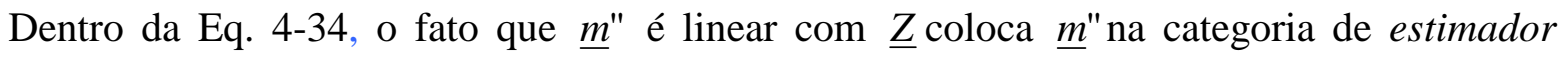
linear, e o fato que $E\left[m^{\prime \prime}\right]=\underline{m}^{\prime}=E[K]$ converte este em um estimador não viesado.

A Eq. 4-35 mostra que $\underline{C}^{\prime \prime}$, a matriz de covariâncias atualizada, é independente de $\underline{Z}$ e pode, ainda, ser calculado antes mesmo de serem feitas as leituras dos instrumentos.

As considerações a respeito das hipóteses adotadas para a derivação das equações que utiliza a retroanálise probabilista pela óptica bayesiana podem ser encontradas em Veneciano \& Faccioli (1975), Hachich (1981) e Vanmarcke (1983).

Segundo a perspectiva ilustrada, a metodologia proposta permite encontrar o campo atualizado de parâmetros $\left(\underline{m}^{\prime \prime}, \underline{C}^{\prime \prime}\right)$ mais compatível com o vetor de observações introduzido, e principalmente permite estabelecer se as hipóteses de trabalho adotadas são coerentes e consistentes (Strufaldi, 2004). 


\section{APLICAÇÃo PRÁtiCA: ATUALIZAÇÃo dOS PARÂMETROS DE SMITH}

\subsection{Detalhes do solo e da estaca cravada}

Os detalhes do perfil do solo do local da cravação e da estaca utilizada estão apresentados na Figura 5-1.

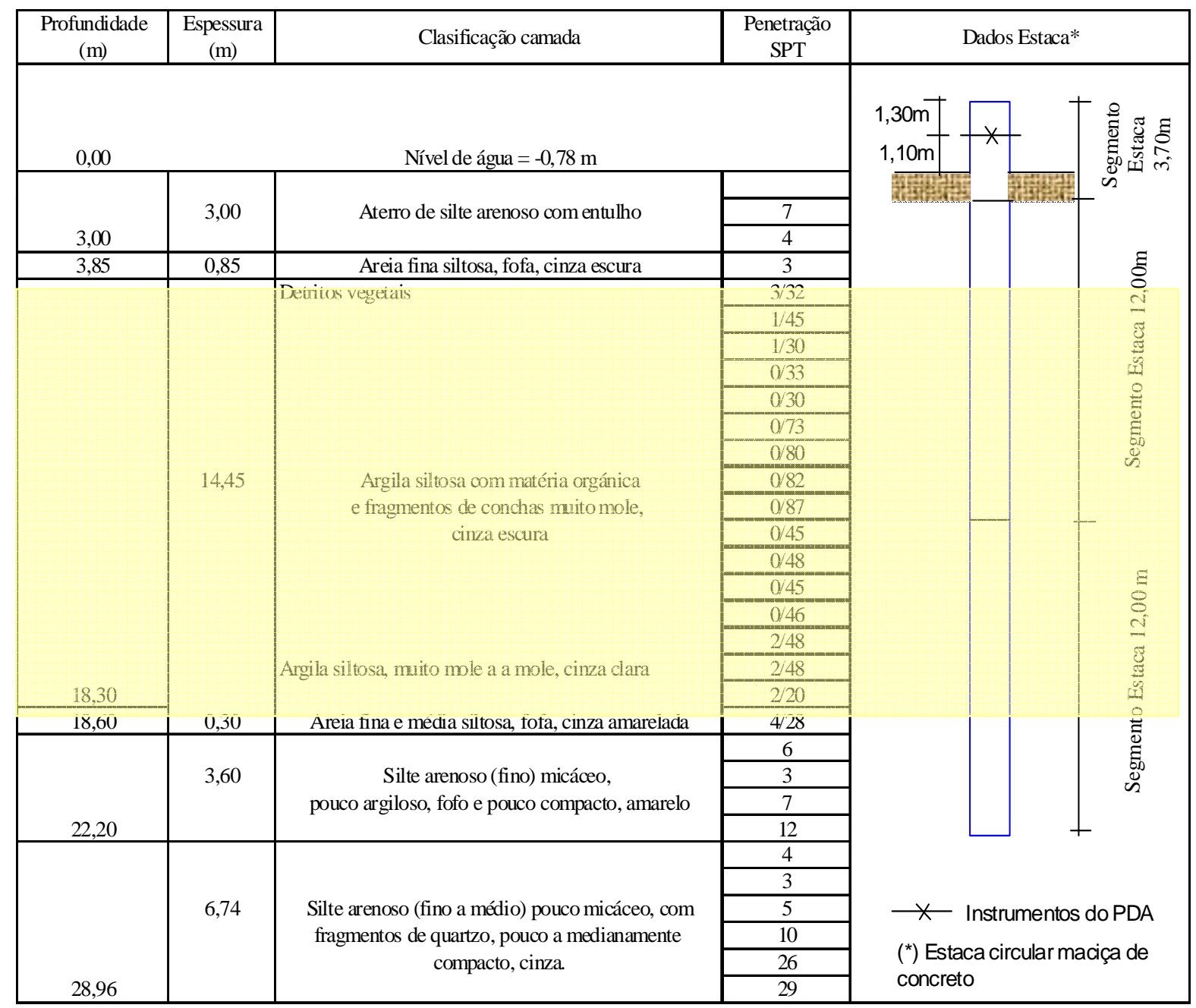

Figura 5-1 Dados do Perfil de Solo e da Estaca Cravada

As características da estaca utilizada estão apresentadas na Tabela 5-1. 
Tabela 5-1 Dados da Estaca utilizada

\begin{tabular}{|llc|}
\hline Diâmetro da estaca & $\varphi=$ & $0,52 \mathrm{~m}$ \\
Comprimento da estaca & $L=$ & $27,7 \mathrm{~m}$ \\
Comprimento da estaca abaixo dos sensores & $L c=$ & $26,4 \mathrm{~m}$ \\
Velocidade de onda (elástica) & $c=$ & $3600 \mathrm{~m} / \mathrm{s}$ \\
Módulo de elasticidade da estaca & $E=$ & $33000 \mathrm{MPa}$ \\
Peso específico & $\rho=$ & $25 \mathrm{kN} / \mathrm{m}^{3}$ \\
\hline
\end{tabular}

\subsection{Análise de Sinais de Cravação para modelo inicial de solo}

Denominou-se análise inicial CAPWAP, à análise dos sinais de cravação realizado no programa CAPWAP ${ }^{\circledR}$ Versão 1996-II. Para tal análise, utilizou-se os parâmetros de Smith da Tabela 5-2 e os sinais de força e velocidade obtidos em campomedidos no PDA. Os valores de Rult foram estimados a partir da utilização do método semi-empírico de Decourt \& Quaresma (1978 e 1982) a partir de valores mostrados no ensaio de SPT. Por outro lado utilizou-se o programa CAPWAP para processar a partir dos dados de Rult para cada trecho da estaca e dos sinais de cravação (descrito anteriormente) um sinal de força calculada que dependia dos valores de damping e quake adotados. Desse modo se encontrou os valores de damping Smith e quake.

\section{Tabela 5-2 Informação dos parâmetros de Smith}

\begin{tabular}{|rrrrr|}
\hline $\begin{array}{c}\text { Profundidade } \\
(\mathrm{m})\end{array}$ & $\begin{array}{c}\text { Segmento } \\
\text { daestaca }\end{array}$ & $\begin{array}{c}\text { Rult } \\
(\mathrm{kN})\end{array}$ & $\begin{array}{r}\mathrm{Q} \\
(\mathrm{mm})\end{array}$ & $\begin{array}{r}J s \\
(\mathrm{~s} / \mathrm{m})\end{array}$ \\
\hline 3 & 1 & 60,1 & 1,576 & 0,581 \\
5 & 2 & 38,2 & 1,576 & 0,581 \\
7,1 & 3 & 57,5 & 1,576 & 0,581 \\
9,2 & 4 & 104,4 & 1,576 & 0,581 \\
11,2 & 5 & 81,9 & 1,576 & 0,581 \\
13,3 & 6 & 2,7 & 1,576 & 0,581 \\
15,3 & 7 & 0 & 1,576 & 0,581 \\
17,4 & 8 & 2,3 & 1,576 & 0,581 \\
19,5 & 9 & 58,1 & 1,576 & 0,581 \\
21,5 & 10 & 92,6 & 1,576 & 0,581 \\
21,5 & 11 & 84,3 & 1,576 & 0,581 \\
23,6 & 12 & 43,4 & 1,576 & 0,581 \\
25,6 & 13 & 5,6 & 1,576 & 0,581 \\
27,7 & 14 & 1219,3 & 0,517 & 15,519 \\
\hline
\end{tabular}


O programa CAPWAP utiliza o $M Q N$ (match quality number) como um estimador de qualidade do procedimento de comparação de sinais (anteriormente descrito no Cap. 3). A derivação deste estimador de qualidade tem sido aprimorada ao longo dos últimos anos. A revisão do cálculo do $M Q N$ está apresentada no ANEXO B.

A Figura 5-2 ilustra o resultado desta primeira análise, e como indicador da proximidade entre as curvas de força calculada e medida, encontrou-se um MQN de 4,71.

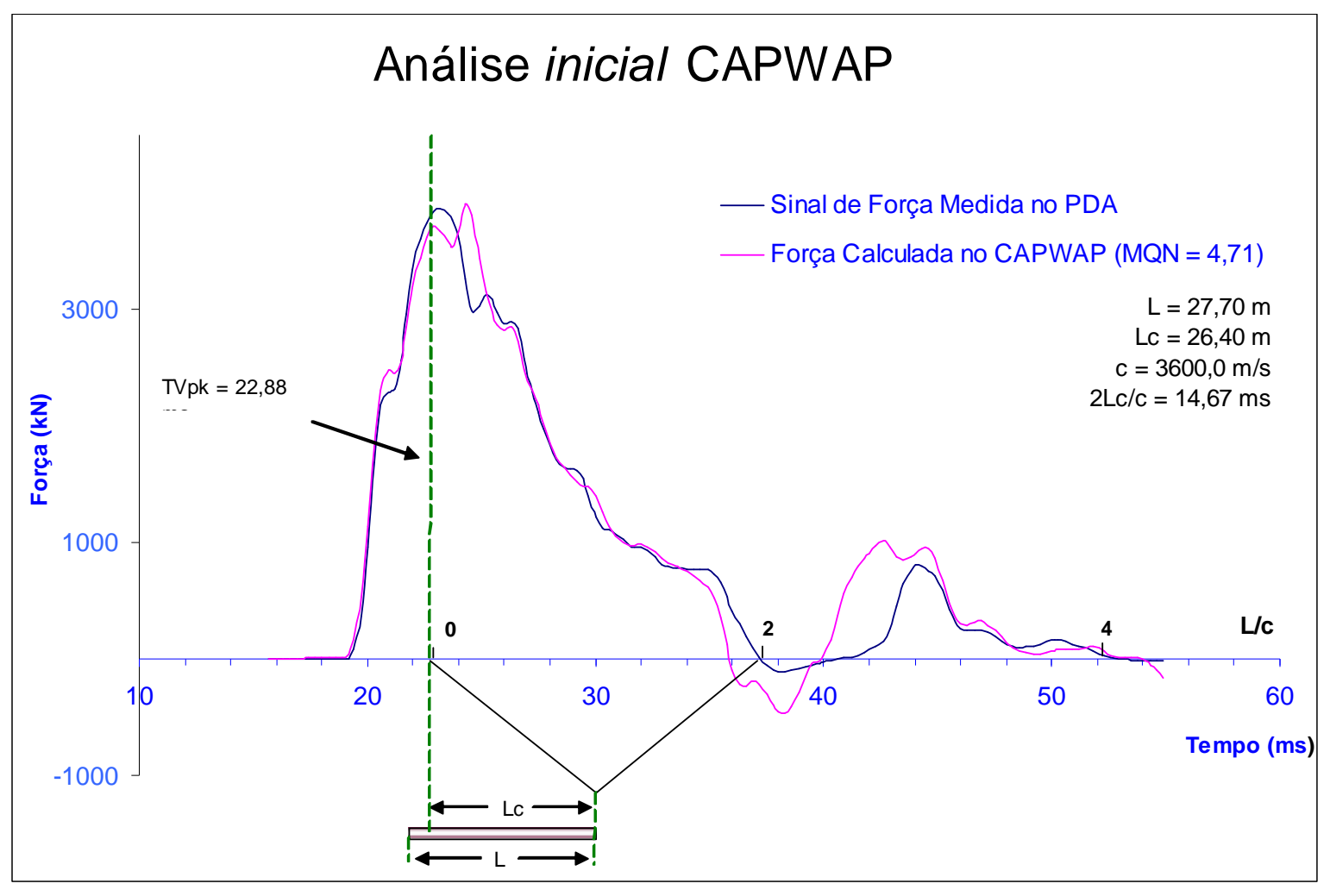

Figura 5-2 Análise CAPWAP inicial, $M Q N=4,71$

Detectou-se dois fatos importantes na 'análise inicial CAPWAP' realizada: (a) dificuldade para aproximar o sinal calculado do medido no trecho da estaca situado a aproximadamente 1,40 m abaixo dos transdutores, onde possivelmente existe uma deficiência ou dano na emenda da estaca, e (b) dificuldade para aproximar o sinal calculado do medido na região da ponta da estaca, onde a análise sugere a existência de uma massa de solo aderida à região da ponta da estaca. Tais detalhes podem ser observados na Figura 5-2 Análise CAPWAP inicial, $M Q N=4,71$. 


\subsection{Cálculo da matriz de sensibilidade}

A análise inicial do CAPWAP ${ }^{\circledR}$, já descrito no item anterior, foi utilizada para a construção da matriz de sensibilidade. Tal matriz objetiva relacionar o valor observado no instrumento hipotético com a mudança de determinado parâmetro de estado (de Smith).

Utilizou-se o intervalo menor do CAPWAP ${ }^{\circledR}$, instrumentos regularmente espaçados a cada $0,3 \mathrm{~ms}$ (milissegundos).

Uma matriz de sensibilidade, $S_{p n}$, deve ter p-filas que correspondem ao número de instrumentos hipotéticos colocados ao longo do eixo do tempo em espaços regulares e $n$ colunas que correspondem ao número de segmentos da estaca.

Um valor da matriz de sensibilidade $S_{p n}$ indica a sensibilidade do sinal de força medida no instrumento $p$ com relação à mudança do parâmetro de Smith do trecho $n$ da estaca. Tal relação está definida na Eq. 4-27 e detalhada na Eq. 5-1.

$$
S_{p n}=\frac{F_{p}\left(K_{n}^{*}\right)-F_{p}\left(K_{n}^{* *}\right)}{K_{n}^{*}-K_{n}^{* *}}
$$

Onde:

$F_{p}=$ Leituras do valor do sinal de força (neste caso) nos instrumentos hipotéticos $p$ espaçados ao longo do eixo do tempo em espaços regulares;

$K_{n}^{*}=$ Valor do parâmetro de Smith correspondente ao trecho $n$ da estaca, calculado na análise inicial do CAPWAP ${ }^{\circledR}$. Valor que permanece constante no cálculo da matriz de sensibilidade;

$F_{p}\left(K_{n}^{*}\right)$ Leitura do valor do sinal de força calculado (p.e., no CAPWAP ${ }^{\circledR}$ ) do instrumento hipotético $p$ função do parâmetro de Smith $K_{n}^{*}$. Leituras que permanecem constantes no cálculo da matriz de sensibilidade;

$K_{n}^{* *}=$ Valor do parâmetro de Smith correspondente ao trecho $n$ da estaca, utilizado como variável nos estudos paramétricos; e 
$F_{p}\left(K_{n}^{*}\right)=$ Leitura do valor do sinal de força calculado (p.e., no CAPWAP ${ }^{\circledR}$ ) do instrumento hipotético $p$ função do parâmetro de Smith do trecho $n$ da estaca, $K_{n}^{* *}$.

Delta. $K=K_{n}^{*}-K_{n}^{* *}=$ Denominador da Eq. 4-27, considerado como o acréscimo o decréscimo do valor constante $K_{n}^{*}$.

O programa CAPWAP possibilita a análise dos sinais de cravação junto com o modelo do solo mediante uma interface iterativa entre o usuário e a entrada de dados, a qual esta sujeita a algumas particularidades, em função do parâmetro analisado, descritas a seguir.

No presente caso, a Figura 5-3 ilustra graficamente os valores da matriz de sensibilidade para o parâmetro quake de Smith

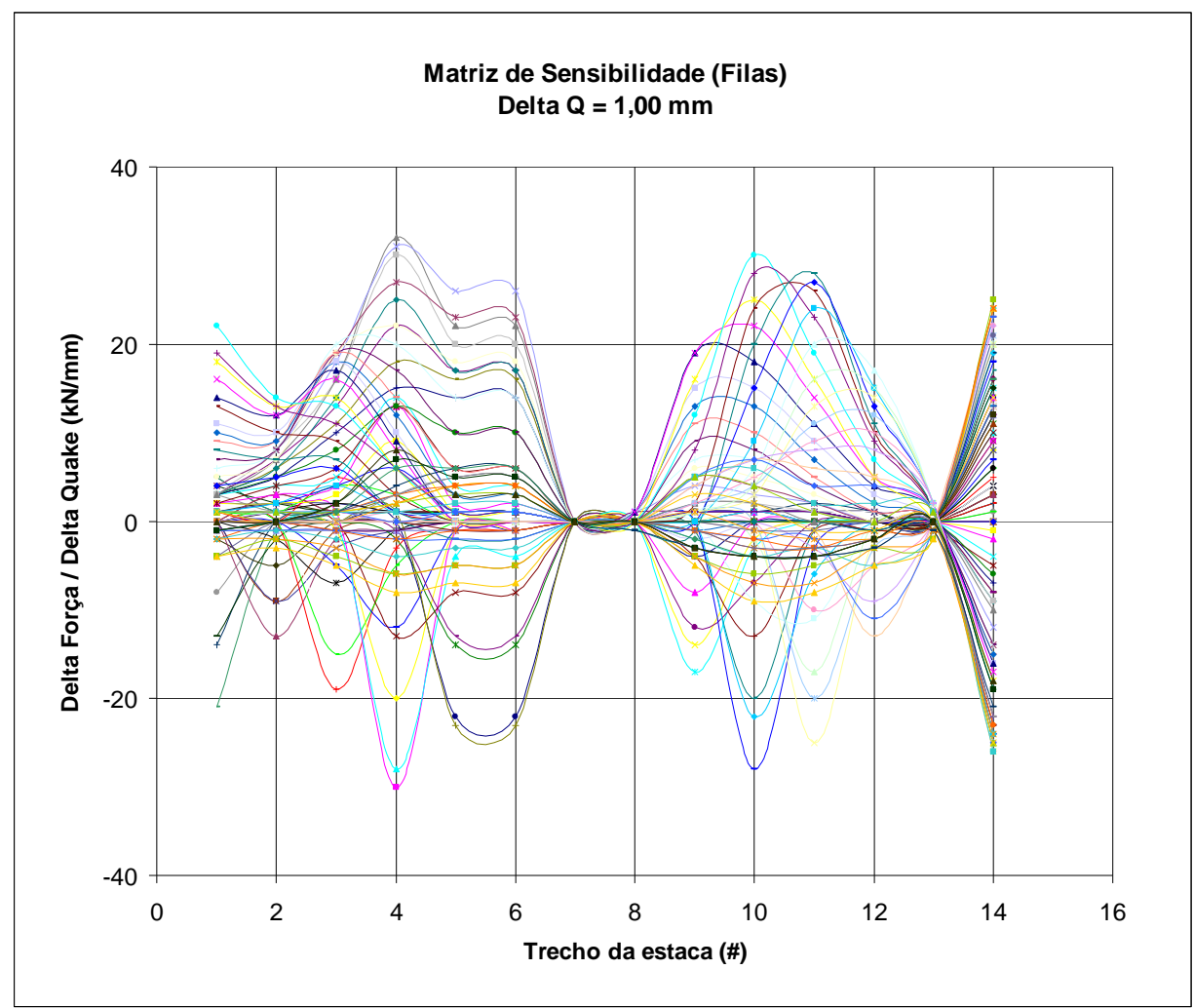

Figura 5-3 Representação gráfica da Matriz de sensibilidade para o parâmetro Quake (Delta $Q=1,00 \mathrm{~mm}$ )

Para realizar a análise se sensibilidade do parâmetro quake de Smith, considerou-se o denominador da Eq. 4-27 como Delta. $Q=Q_{n}^{*}-Q_{n}^{* *}$, e como valores de Delta $Q:-1,0 \mathrm{~mm}$, - 
0,25 mm, 0,25 mm e 1,0 mm. Construindo-se no total 4 matrizes de sensibilidade, ou seja, para $n=14$ elementos da estaca discretizada, e Delta $Q$ de 4 valores, procedeu-se 14 x 4 análises CAPWAP. A matriz de sensibilidade adotada corresponde a um Delta $Q=1,00$ $\mathrm{mm}$.

A análise de sensibilidade do quake, $Q$, apresentou como restrição na escolha dos valores utilizados para Delta $Q$ o fato de que a utilização de valores positivos maiores induzem à não mobilização do último segmento da estaca e, portanto, é necessária uma redução automática do valor de quake de ponta.

No presente caso, a Figura 5-4 ilustra graficamente os valores da matriz de sensibilidade para o parâmetro Rult de Smith.

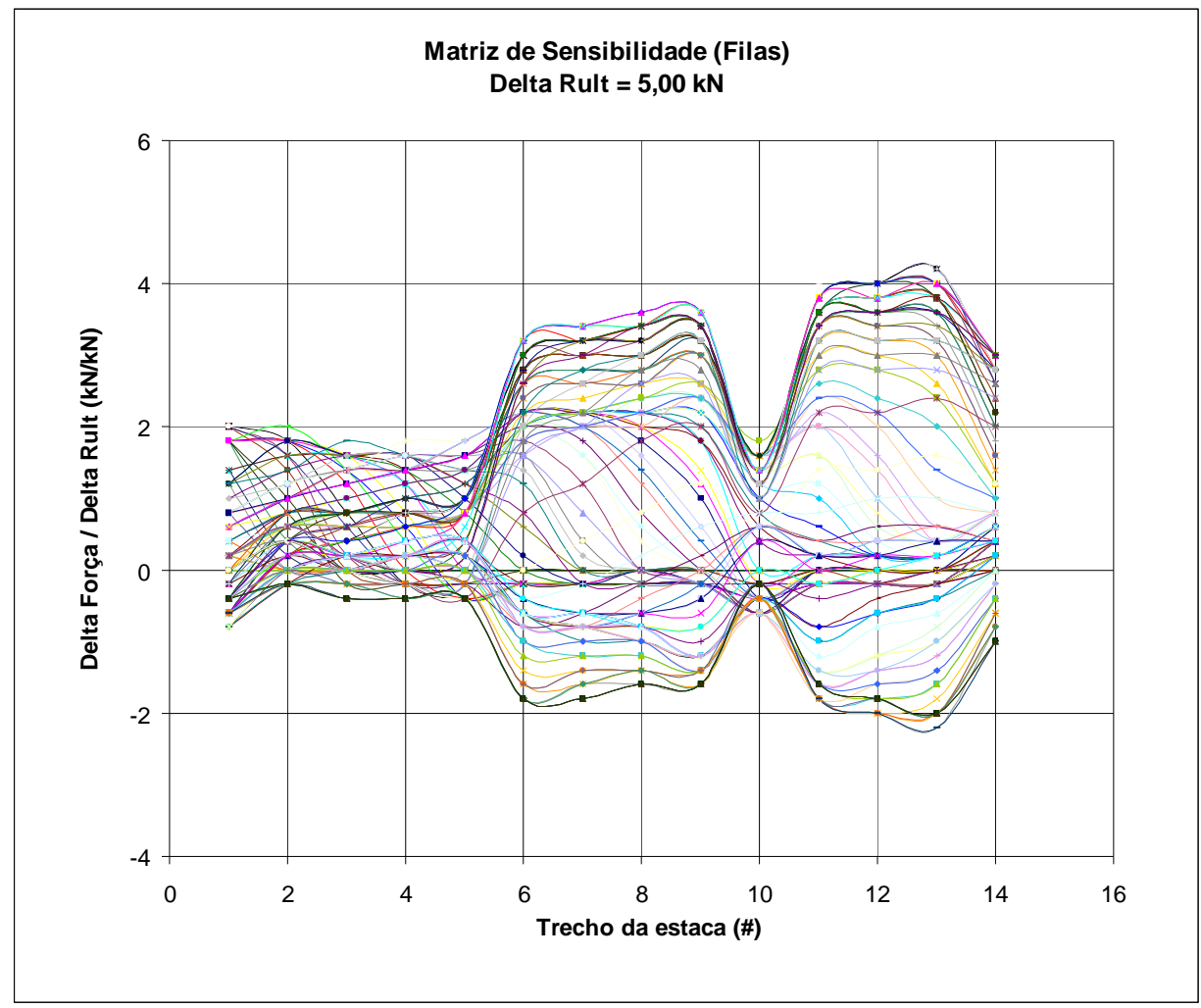

Figura 5-4 Representação gráfica da Matriz de sensibilidade para o parâmetro Rult $($ Delta Rult $=\mathbf{5 , 0 0} \mathrm{kN})$

Para realizar a análise de sensibilidade do parâmetro de resistência estática última ou Rult de Smith, considerou-se o denominador da Eq. 4-27 como Delta.Rult $=$ Rult $_{n}^{*}-$ Rult $_{n}^{* *}$, e como 
valores de Delta Rult: $+5,00 \mathrm{kN}$ e $+15,00 \mathrm{kN}$. Construindo-se no total 2 matrizes de sensibilidade, ou seja, para $n=14$ elementos da estaca, e Delta Rult de 2 valores, calcularam-se 14 x 2 análises CAPWAP. A matriz de sensibilidade adotada corresponde a um Delta Rult $=5,00 \mathrm{kN}$.

A análise de sensibilidade do Rult apresentou duas complicações: (1) Qualquer mudança no valor de Rult em qualquer trecho da estaca (isto dentro da análise CAPWAP $^{\circledR}$ ) deve ser refletido na capacidade de carga total, p.e. se o trecho 2 da estaca é aumentado em $15 \mathrm{kN}$, o valor da resistência total deve ser aumentado em $15 \mathrm{kN}$, isto devido à característica do CAPWAP $^{\circledR}$ de distribuir proporcionalmente alguma mudança dos valores de Rult entre os outros trechos analisados e, (2) Os valores de Delta Rult seguiram outras duas condições: como limite superior, o fato da não mobilização da resistência última do último trecho do modelo CAPWAP ${ }^{\circledR}$ para valores maiores, como consequiência do item anterior e, como limite inferior o fato de ter adotado para o trecho 7 do modelo CAPWAP ${ }^{\circledR}$ um valor de Rult $=0 \mathrm{kN}$, implicava que Delta Rult só podia ser positivo.

No presente caso, a Figura 5-5 ilustra graficamente os valores da matriz de sensibilidade para o parâmetro damping de Smith.

Para realizar a análise de sensibilidade do parâmetro do fator de amortecimento ou damping de Smith $J s$, foi necessário considerar o denominador da Eq. 4-27 como Delta.Js $=J s_{n}^{*}-J s_{n}^{* *}$, e utilizar como valores de Delta $J_{s}:+0,05 \mathrm{~s} / \mathrm{m}$ e $+0,15 \mathrm{~s} / \mathrm{m}$. Construindo-se no total 2 matrizes de sensibilidade, ou seja, para $n=14$ elementos discretizados da estaca, e Delta $J s$ de 2 valores, calcularam-se 14 × 2 análises CAPWAP. A matriz de sensibilidade adotada corresponde a um Delta $J_{s}=0,05 \mathrm{~s} / \mathrm{m}$.

A análise de sensibilidade do damping Smith, $J s$, necessitou das considerações seguintes: (1) A utilização dos fatores de amortecimento em uma análise CAPWAP ${ }^{\circledR}$ comumente implica a adoção de dois valores: damping Smith de fuste e damping Smith de ponta, tal adoção não poderia ser utilizada devido à necessidade de utilizar uma entrada de dados por cada trecho da estaca, que só fica disponível para o damping viscoso, $J v$,.e (2) A metodologia CAPWAP $^{\circledR}$ (CAPWAP Manual, 1990) utiliza a relação entre o damping viscoso e damping 
Smith $J v=J s . R u l t$ (ver Erro! Fonte de referência não encontrada. ) para entrada de fatores de amortecimento adicionais, portanto unicamente se utilizaram valores positivos de Delta Js.

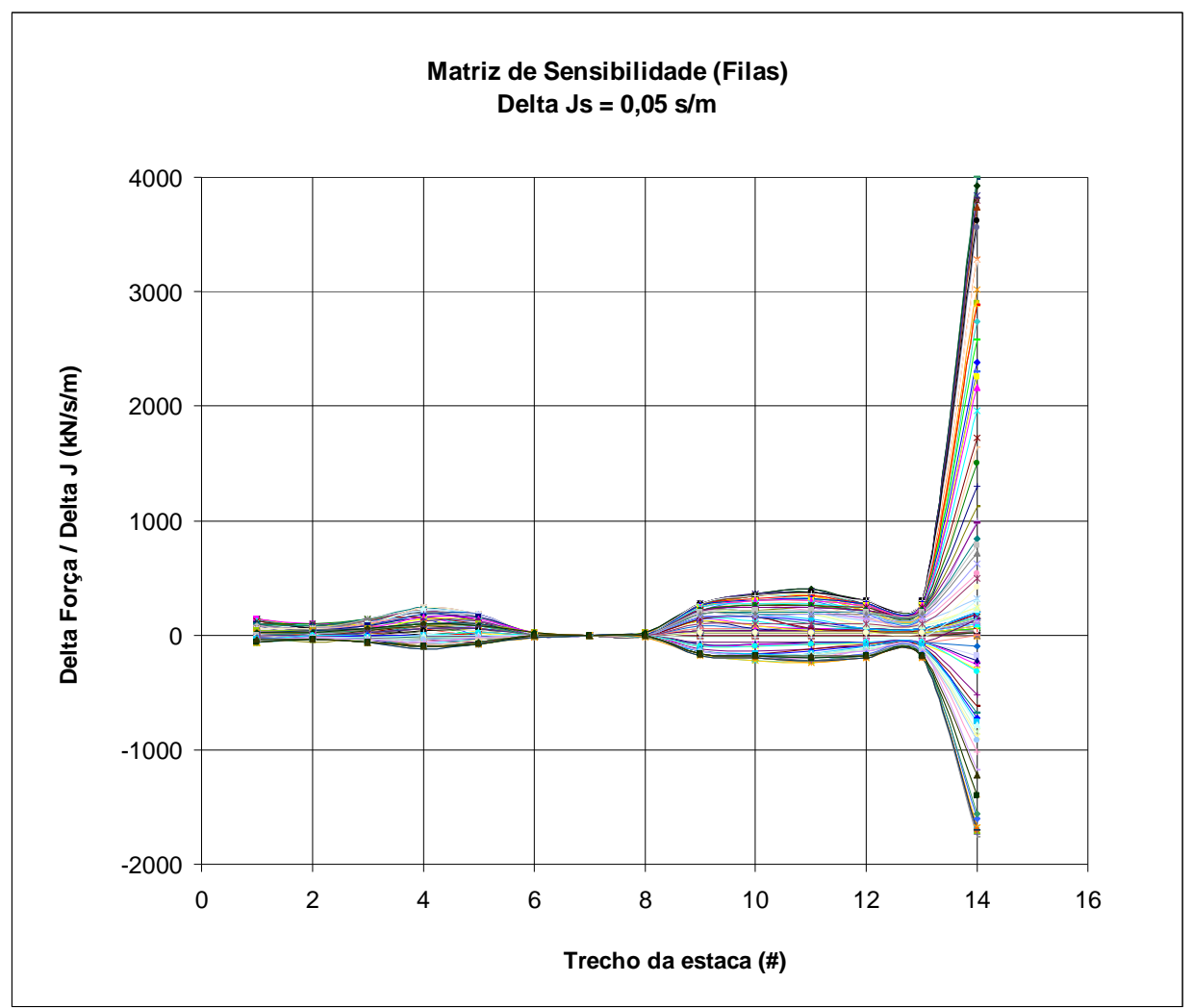

Figura 5-5 Representação gráfica da Matriz de sensibilidade para o parâmetro Damping Smith (Delta $J s=0,05 \mathrm{~s} / \mathrm{m}$ )

\subsection{Estudo da Linearidade do Modelo de Observação}

A adoção das matrizes de sensibilidade de cada um dos parâmetros de Smith analisados deve atender a hipótese de linearidade utilizada na teoria da atualização bayesiana (aplicada posteriormente). As figuras a seguir apresentadas dão suporte à provável linearidade do comportamento dos instrumentos hipotéticos utilizados na presente pesquisa. 

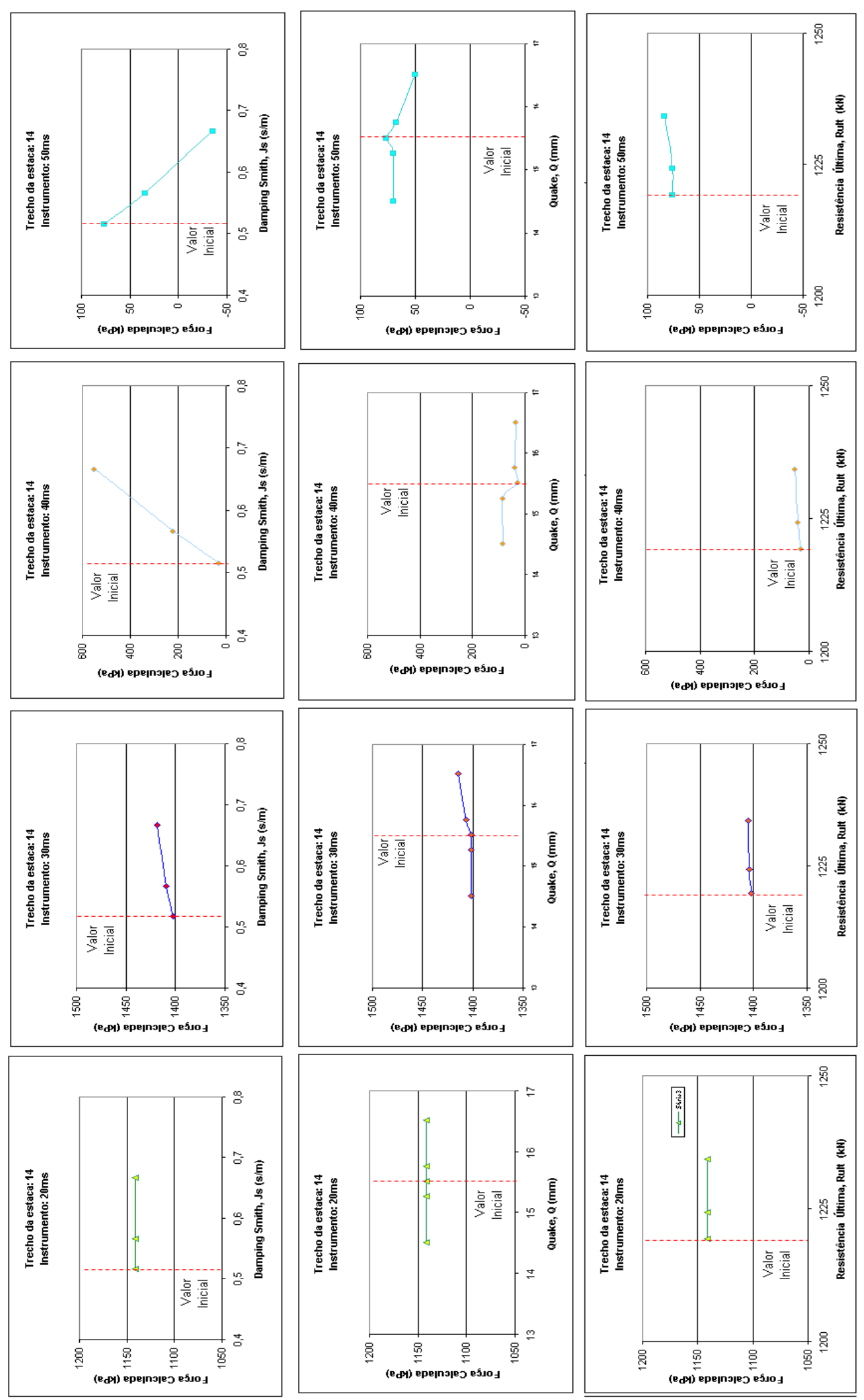

Figura 5-6 Validação do modelo de observação linear para os instrumentos hipotéticos para mudanças de valores da ponta da estaca (trecho 14) 


\subsection{Cálculo da matriz de covariâncias}

A partir dos dados apresentados na Tabela 5-3 e aplicando a teoria de análises de correlação espacial descrita no Capítulo 4, procedeu-se o cálculo das matrizes de covariância (C $\left.{ }^{\prime}\right)$.

Tabela 5-3 Valores médios e variâncias dos Parâmetros de Smith, para o presente caso

\begin{tabular}{|c|c|c|c|c|c|c|c|}
\hline \multicolumn{7}{|c|}{ Valores esperadose variancias dos Parâmetros de Smith } & \multirow[t]{2}{*}{ Esquema da Estaca } \\
\hline$N^{0}$ & $\begin{array}{c}\mathrm{m}^{\prime}(\text { Rutt) } \\
(\mathrm{kN})\end{array}$ & $\begin{array}{c}\text { Var' (Rult) } \\
(\mid \wedge F)\end{array}$ & $\begin{array}{l}\mathrm{m}^{\prime}(\mathrm{Q}) \\
(\mathrm{mm})\end{array}$ & $\begin{array}{c}\text { Var' (Q) } \\
\text { (mmr) }\end{array}$ & $\begin{array}{c}\mathrm{m}^{\prime}(\mathrm{Js}) \\
\text { (sim) }\end{array}$ & $\begin{array}{c}\text { Var' (JS) } \\
\text { (smin) }\end{array}$ & \\
\hline 1 & 601 & 36,12 & 1,576 & 0,025 & 0,581 & 0,003 & 1 \\
\hline 2 & 38,2 & 14,59 & 1,576 & 0,025 & 0,581 & 0,003 & 2 \\
\hline 3 & 57,5 & 33,06 & 1,576 & 0,025 & 0,581 & 0,003 & 3 \\
\hline 4 & 104,4 & 108,99 & 1,576 & 0,025 & 0,581 & 0,003 & 4 \\
\hline 5 & 81,9 & 67,08 & 1,576 & 0,025 & 0,581 & 0,003 & 5 \\
\hline 6 & 2,7 & 0,07 & 1,576 & 0,025 & 0,581 & 0,003 & 6 \\
\hline 7 & 0 & 0,00 & 1,576 & 0,025 & 0,581 & 0,003 & 7 \\
\hline 8 & 2,3 & 0,05 & 1,576 & 0,025 & 0,581 & 0,003 & 8 \\
\hline 9 & 58,1 & 33,76 & 1,576 & 0,025 & 0,581 & 0,003 & 9 \\
\hline 10 & 92,6 & 85.75 & 1,576 & 0,025 & 0,581 & 0,003 & 10 \\
\hline 11 & 84,3 & 71,06 & 1.576 & 0,025 & 0,581 & 0,003 & 11 \\
\hline 12 & 434 & 18,84 & 1,576 & 0,025 & 0,581 & 0,003 & 12 \\
\hline 13 & 5,6 & 0,31 & 1,576 & 0,025 & 0,581 & 0,003 & 13 \\
\hline 14 & 1219,3 & 14866,92 & 15,519 & 2,408 & 0.517 & 0,003 & 14 \\
\hline
\end{tabular}

Para a elaboração da Tabela 5-3, utilizou-se como valores esperados os parâmetros obtidos na análise inicia CAPWAP, e para determinação das variâncias respectivas utilizou-se um coeficiente de variação, $\mathrm{COV}=0,10$, que serve como estimativa da variabilidade da relação do desvio padrão relativo ao seu valor médio adotado.

Além disso, para o cálculo das matrizes de covariâncias, utilizou-se também o comprimento dos segmentos discretizados da estaca, $L_{S}=2,0 \mathrm{~m}$, considerou-se como erro pontual do instrumento $\sigma^{2}=0,25(k N)^{2}$ e se utilizou 3 valores de distâncias de correlação, $\mathrm{d}=0,5,1,0$ e 2,0 m, para cada um dos parâmetros de Smith. Portanto tem-se 3x3 matrizes de covariâncias. Tais matrizes estão apresentadas no ANEXO B.

As matrizes de covariâncias apresentaram a característica singular: a diagonal principal da matriz está formada pelos valores das variâncias do vetor de parâmetros médios (ver Tabela 5-3), portanto tal diagonal não depende da correlação espacial entre trechos diferentes mas 
só da variabilidade do parâmetro em si. Por exemplo, na Tabela 5-4 apresenta-se a matrizes de covariâncias para o parâmetro Rult.

Tabela 5-4 Matriz de covariâncias para Rult com $d=1,0 \mathrm{~m}, L_{S}=2,0 \mathrm{~m}$, e $\sigma^{2}=$ $0,25(\mathbf{k N})^{2}$.

\begin{tabular}{|c|c|c|c|c|c|c|c|c|c|c|c|c|c|c|}
\hline & 1 & 2 & 3 & 4 & 5 & 6 & 7 & 8 & 9 & 10 & 11 & 12 & 13 & 14 \\
\hline 1 & 36,120 & 0,042 & 0 & 0 & 0 & 0 & 0 & 0 & 0 & 0 & 0 & 0 & 0 & 0 \\
\hline 2 & 0,042 & 14,592 & 0,042 & 0 & 0 & 0 & 0 & 0 & 0 & 0 & 0 & 0 & 0 & 0 \\
\hline 3 & 0 & 0,042 & 33,063 & 0,042 & 0 & 0 & 0 & 0 & 0 & 0 & 0 & 0 & 0 & 0 \\
\hline 4 & 0 & 0 & 0,042 & 108,994 & 0,042 & 0 & 0 & 0 & 0 & 0 & 0 & 0 & 0 & 0 \\
\hline 5 & 0 & 0 & 0 & 0,042 & 67,076 & 0,042 & 0 & 0 & 0 & 0 & 0 & 0 & 0 & 0 \\
\hline 6 & 0 & 0 & 0 & 0 & 0,042 & 0,073 & 0,042 & 0 & 0 & 0 & 0 & 0 & 0 & 0 \\
\hline 7 & 0 & 0 & 0 & 0 & 0 & 0,042 & 0,000 & 0,042 & 0 & 0 & 0 & 0 & 0 & 0 \\
\hline 8 & 0 & 0 & 0 & 0 & 0 & 0 & 0,042 & 0,053 & 0,042 & 0 & 0 & 0 & 0 & 0 \\
\hline 9 & 0 & 0 & 0 & 0 & 0 & 0 & 0 & 0,042 & 33,756 & 0,042 & 0 & 0 & 0 & 0 \\
\hline 10 & 0 & 0 & 0 & 0 & 0 & 0 & 0 & 0 & 0,042 & 85,748 & 0,042 & 0 & 0 & 0 \\
\hline 11 & 0 & 0 & 0 & 0 & 0 & 0 & 0 & 0 & 0 & 0,042 & 71,065 & 0,042 & 0 & 0 \\
\hline 12 & 0 & 0 & 0 & 0 & 0 & 0 & 0 & 0 & 0 & 0 & 0,042 & 18,836 & 0,042 & 0 \\
\hline 13 & 0 & 0 & 0 & 0 & 0 & 0 & 0 & 0 & 0 & 0 & 0 & 0,042 & 0,314 & 0,042 \\
\hline 14 & 0 & 0 & 0 & 0 & 0 & 0 & 0 & 0 & 0 & 0 & 0 & 0 & 0,042 & 14866,925 \\
\hline
\end{tabular}

Na matriz de covariâncias apresentada na Tabela 5-5, observa-se que a escala de flutuação influencia somente no cálculo dos elementos que ficam fora da diagonal principal, e que se a escala de flutuação é menor que o comprimento do trecho discretizado $\left(L_{S}\right)$ da estaca, só ocupa um espaço adjacente do lado da variância do parâmetro do trecho em questão.Por exemplo, na Tabela 5-5, avalia-se alguns valores de covariâncias e sua localização dentro da matriz de covariâncias em função da escala de flutuação para um mesmo valor de comprimento discretizado $\left(L_{S}=2,0 \mathrm{~m}\right)$.

Tabela 5-5 Valores adjacentes à diagonal da matriz de covariâncias, para diferentes escalas de flutuação, com $\mathrm{Ls}=2,0 \mathrm{~m}$ e $\sigma^{2}=0,25(\mathrm{kN})^{2}$

\begin{tabular}{|c|c|c|}
\hline $\begin{array}{c}\text { Escala de } \\
\text { flutuação } \\
d(m)\end{array}$ & Cov $(S, S \pm 1)$ & Cov $(S, S \pm 2)$ \\
\hline 0,5 & 0,010 & \multirow{2}{*}{----} \\
1,0 & 0,042 & --- \\
1,5 & 0,094 & --- \\
2,0 & 0,167 & --- \\
2,5 & 0,266 & 0,002 \\
\cline { 2 - 2 } 3,0 & 0,347 & 0,014 \\
\cline { 2 - 2 } 3,0
\end{tabular}




\subsection{Atualização Bayesiana.}

Como apresentado no Capítulo 5, o passo seguinte é a utilização da Eq. 4-34 e Eq. 4-35 para atualização dos valores médios dos parâmetros de Smith, $m^{\prime}(K)$, e os valores das variâncias, $\operatorname{Var}^{\prime}(K)$. A Tabela 5-6 apresenta os parâmetros utilizados.

Tabela 5-6 Resumo dos Parâmetros utilizados na Atualização Bayesiana

\begin{tabular}{|c|c|c|c|c|}
\hline $\begin{array}{l}\text { Disposição dos } \\
\text { Instrumentos em função da } \\
\text { variabilidade dos mesmos }\end{array}$ & $\begin{array}{c}\text { Escala de } \\
\text { flutuação } \\
d(\mathbf{m})\end{array}$ & $\begin{array}{c}\text { Comprimento } \\
\text { do Trecho } \\
\text { Discretizado } \\
L_{S}(\mathrm{~m})\end{array}$ & $\begin{array}{c}\text { Erro pontual } \\
\text { do } \\
\text { Instrumento } \\
\sigma^{2}\left(\mathbf{k N}^{2}\right)\end{array}$ & $\begin{array}{c}\text { Coeficiente de } \\
\text { Variação do Erro } \\
\text { do Instrumento } \\
\text { COVerro (\%) }\end{array}$ \\
\hline $\begin{array}{l}\text { Análise Uniforme } \\
\text { (Ver Figura 5-7) }\end{array}$ & $\begin{array}{l}0,5 \\
\frac{1,0}{2,0}\end{array}$ & $2,0^{27}$ & 0,25 & $\begin{array}{c}5,0 \\
10,0 \\
15,0 \\
20,0\end{array}$ \\
\hline $\begin{array}{l}\text { Análise Pontual } \\
\text { (Ver Figura 5-8) }\end{array}$ & $\begin{array}{l}0,5 \\
\frac{1,0}{2,0}\end{array}$ & $\underline{2,0}$ & $\underline{0,25}$ & $\begin{array}{c}5,0 \\
10,0 \\
15,0 \\
20,0\end{array}$ \\
\hline
\end{tabular}

Uma análise uniforme implica a consideração dos instrumentos hipotéticos dispostos ao longo do eixo do tempo do sinal de força calculada com coeficiente de variação do erro uniforme para todos os instrumentos hipotéticos (vide Figura 5-7), e COVerro variável, segundo a Tabela 5-6. Utilizou-se 4 valores de COVerro, 3 valores de $d$, portanto tem-se 4 x 3 análises uniformes de atualização bayesiana realizados por cada um dos parâmetros de Smith. A análise integral da atualização bayesiana está no ANEXO C.

Uma análise pontual implica a consideração dos instrumentos hipotéticos dispostos ao longo do eixo do tempo do sinal de força calculada com coeficiente de variação do erro constante, COVerro $=5 \%$, para todos os instrumentos exceto para as regiões que apresentam uma variabilidade maior com COVerro variável (vide Figura 5-8), segundo a Tabela 5-6. Neste

\footnotetext{
${ }^{27}$ Para as análises de coavariâncias o comprimento da discretização permanece constante, 2,0m. Já para as análises de sinais (CAPWAP), que foram analisadas previamente, esse comprimento deve corresponder ao especificado, podendo variar em função do programa.
} 


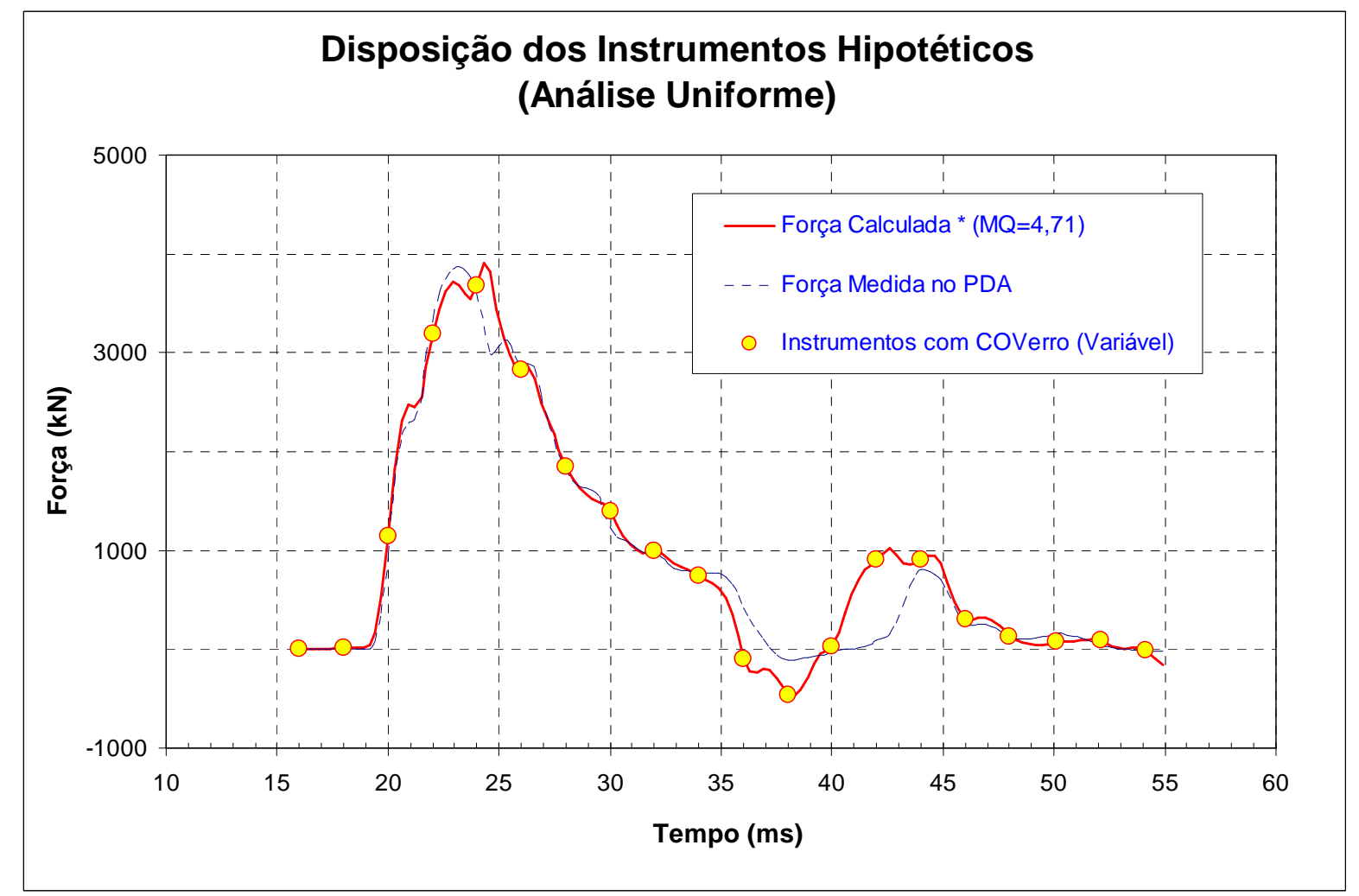

Figura 5-7 Disposição de instrumentos hipotéticos com variabilidade uniforme

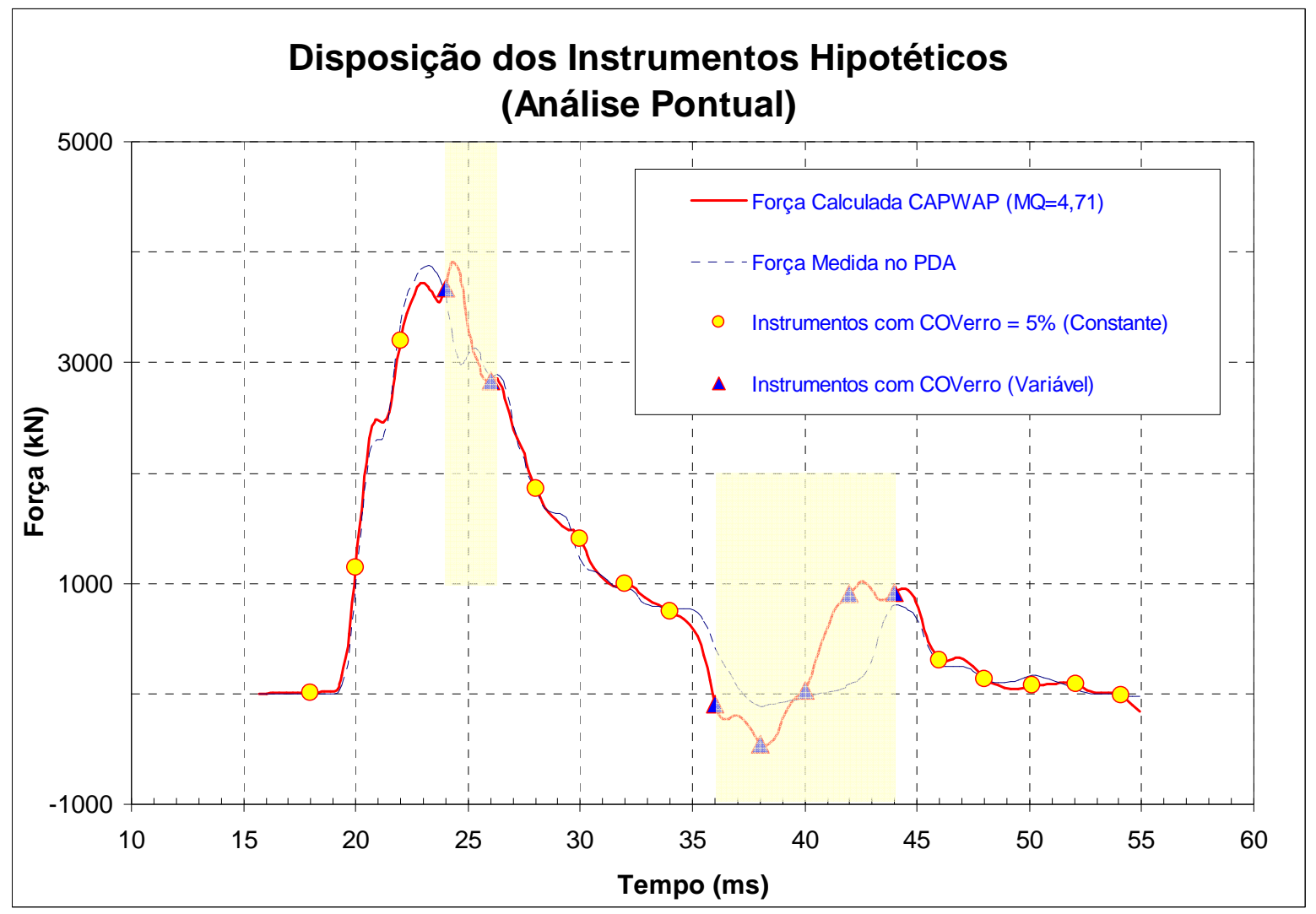

Figura 5-8 Disposição de instrumentos hipotéticos com variabilidade pontual 
caso a região do defeito/dano está entre o tempo de $24 \mathrm{~ms}$ e $26 \mathrm{~ms}$, e na região da ponta, entre o tempo de $36 \mathrm{~ms}$ e $44 \mathrm{~ms}$. Na Figura 5-8 apresenta-se um exemplo de disposição de instrumentos hipotéticos a cada $2 \mathrm{~ms}$.

Em relação à análise pontual, utilizou-se 4 valores de COVerro, 3 valores de $d$, portanto tem-se 4x3 análises pontuais de atualização bayesiana realizadas para cada um dos parâmetros de Smith. A íntegra das análises de atualização bayesiana está apresentada no ANEXO C.

Na Tabela 5-7, Tabela 5-8 e Tabela 5-9, apresenta-se os valores médios, $m$ ” $(K)$, e das variâncias, Var” $(K)$, para os parâmetros de Smith, atualizados sob o enfoque bayesiano, considerando-se ainda $d=1,0 \mathrm{~m}$.

Tabela 5-7 Valores atualizados de resistência estática última $(\mathrm{kN}), \operatorname{com} d=1,0 \mathrm{~m}, L_{S}=$ $2,0 \mathrm{~m}$, e $\sigma^{2}=0,25(\mathrm{kN})^{2}$ vs. diferentes variabilidade de erro dos instrumentos hipotéticos

\begin{tabular}{|c|r|r|r|r|r|}
\cline { 3 - 6 } \multicolumn{2}{c}{} & \multicolumn{4}{c|}{ COVerro (Uniforme) } \\
\cline { 3 - 6 } \multicolumn{2}{c|}{} & \multicolumn{1}{c|}{$5 \%$} & \multicolumn{1}{c|}{$10 \%$} & \multicolumn{1}{c|}{$15 \%$} & \multicolumn{1}{c|}{$20 \%$} \\
\hline $\begin{array}{c}\text { Trecho da } \\
\text { estaca }\end{array}$ & m' (Rult) & m" (Rult) & m" (Rult) & m" (Rult) & m" (Rult) \\
\hline 1 & 60,1 & 101,2 & 134,4 & 167,9 & 203,1 \\
\hline 2 & 38,2 & 5,0 & $-7,7$ & $-23,1$ & $-48,0$ \\
\hline 3 & 57,5 & 131,5 & 168,9 & 195,0 & 214,6 \\
\hline 4 & 104,4 & 101,5 & 86,0 & 61,6 & 25,0 \\
\hline 5 & 81,9 & 45,2 & 12,6 & $-20,5$ & $-61,4$ \\
\hline 6 & 2,7 & 1,9 & 1,8 & 1,6 & 1,5 \\
\hline 7 & 0,0 & $-2,7$ & $-1,1$ & $-1,2$ & $-1,4$ \\
\hline 8 & 2,3 & 1,6 & 1,3 & 1,1 & 0,9 \\
\hline 9 & 58,1 & 69,0 & 84,0 & 109,8 & 149,5 \\
\hline 10 & 92,6 & 72,8 & 9,6 & $-84,7$ & $-224,5$ \\
\hline 11 & 84,3 & 74,5 & 77,7 & 78,5 & 76,3 \\
\hline 12 & 43,4 & 14,4 & $-26,7$ & $-71,8$ & $-124,7$ \\
\hline 13 & 5,6 & 4,9 & 3,3 & 1,6 & $-0,2$ \\
\hline 14 & 1219,3 & 1293,3 & 1385,2 & 1497,2 & 1641,6 \\
\hline
\end{tabular}

\begin{tabular}{|c|r|r|r|r|r|}
\cline { 3 - 6 } \multicolumn{2}{c|}{} & \multicolumn{4}{c|}{ COVerro (Uniforme) $=$} \\
\cline { 3 - 6 } \multicolumn{2}{c|}{} & \multicolumn{1}{c|}{$5 \%$} & \multicolumn{1}{c|}{$10 \%$} & \multicolumn{1}{c|}{$15 \%$} & \multicolumn{1}{c|}{$\mathbf{2 0 \%}$} \\
\hline $\begin{array}{c}\text { Trecho da } \\
\text { estaca }\end{array}$ & Var' (Rult) & Var" (Rult) & Var" (Rult) & Var" (Rult) & Var" (Rult) \\
\hline 1 & 36,1 & 70,5 & 69,3794 & 68,5 & 67,8 \\
\hline 2 & 14,6 & 23,5 & 22,7 & 22,6 & 22,9 \\
\hline 3 & 33,1 & 55,5 & 52,2 & 50,0 & 48,3 \\
\hline 4 & 109,0 & 205,5 & 198,5 & 194,1 & 191,2 \\
\hline 5 & 67,1 & 124,2 & 120,1 & 117,1 & 115,0 \\
\hline 6 & 0,1 & 0,1 & 0,1 & 0,1 & 0,1 \\
\hline 7 & 0,0 & 0,0 & 0,0 & 0,0 & 0,0 \\
\hline 8 & 0,1 & 0,1 & 0,1 & 0,1 & 0,1 \\
\hline 9 & 33,8 & 66,3 & 65,9 & 65,8 & 66,2 \\
\hline 10 & 85,7 & 171,8 & 177,3 & 186,1 & 199,2 \\
\hline 11 & 71,1 & 135,4 & 132,6 & 130,5 & 128,9 \\
\hline 12 & 18,8 & 35,1 & 34,2 & 34,0 & 34,1 \\
\hline 13 & 0,3 & 0,3 & 0,3 & 0,3 & 0,3 \\
\hline 14 & 14866,9 & 29735,0 & 29737,4 & 29741,4 & 29747,6 \\
\hline
\end{tabular}

\begin{tabular}{|c|r|r|r|r|r|}
\cline { 3 - 6 } \multicolumn{2}{c|}{} & \multicolumn{4}{c|}{ COVerro (Pontual) } \\
\cline { 3 - 6 } \multicolumn{2}{c|}{} & \multicolumn{1}{c|}{$5 \%$} & \multicolumn{1}{c|}{$10 \%$} & $15 \%$ & \multicolumn{1}{c|}{$20 \%$} \\
\hline $\begin{array}{c}\text { Trecho da } \\
\text { estaca }\end{array}$ & m' (Rult) & m" (Rult) & m" (Rult) & m" (Rult) & m" (Rult) \\
\hline 1 & 60,1 & 101,2 & 86,1 & 91,6 & 93,0 \\
\hline 2 & 38,2 & 5,0 & 68,0 & 55,4 & 53,4 \\
\hline 3 & 57,5 & 131,5 & 110,6 & 129,0 & 136,4 \\
\hline 4 & 104,4 & 101,5 & 89,6 & 80,5 & 75,3 \\
\hline 5 & 81,9 & 45,2 & 66,5 & 57,1 & 54,3 \\
\hline 6 & 2,7 & 1,9 & 2,5 & 2,4 & 2,4 \\
\hline 7 & 0,0 & $-2,7$ & $-0,2$ & $-0,4$ & $-0,5$ \\
\hline 8 & 2,3 & 1,6 & 2,4 & 2,2 & 2,2 \\
\hline 9 & 58,1 & 69,0 & 49,3 & 55,8 & 57,7 \\
\hline 10 & 92,6 & 72,8 & 111,3 & 96,8 & 92,8 \\
\hline 11 & 84,3 & 74,5 & 77,1 & 74,0 & 72,5 \\
\hline 12 & 43,4 & 14,4 & 29,9 & 24,8 & 23,5 \\
\hline 13 & 5,6 & 4,9 & 7,5 & 6,9 & 6,7 \\
\hline 14 & 1219,3 & 1293,3 & 1250,0 & 1269,0 & 1275,1 \\
\hline
\end{tabular}

\begin{tabular}{|c|r|r|r|r|r|}
\cline { 3 - 6 } \multicolumn{2}{c|}{} & \multicolumn{4}{c|}{ COVerro (Pontual) $=$} \\
\cline { 3 - 6 } \multicolumn{2}{c|}{} & \multicolumn{1}{c|}{$5 \%$} & \multicolumn{1}{c|}{$10 \%$} & \multicolumn{1}{c|}{$15 \%$} & \multicolumn{1}{c|}{$20 \%$} \\
\hline $\begin{array}{c}\text { Trecho da } \\
\text { estaca }\end{array}$ & Var' (Rult) & Var" (Rult) & Var" (Rult) & Var" (Rult) & Var" (Rult) \\
\hline 1 & 36,1 & 70,5 & 69,6 & 69,8 & 69,9 \\
\hline 2 & 14,6 & 23,5 & 15,5 & 18,6 & 19,4 \\
\hline 3 & 33,1 & 55,5 & 52,3 & 53,6 & 53,8 \\
\hline 4 & 109,0 & 205,5 & 205,2 & 204,9 & 204,7 \\
\hline 5 & 67,1 & 124,2 & 123,5 & 124,4 & 124,7 \\
\hline 6 & 0,1 & 0,1 & 0,1 & 0,1 & 0,1 \\
\hline 7 & 0,0 & 0,0 & 0,0 & 0,0 & 0,0 \\
\hline 8 & 0,1 & 0,1 & 0,1 & 0,1 & 0,1 \\
\hline 9 & 33,8 & 66,3 & 65,1 & 65,5 & 65,6 \\
\hline 10 & 85,7 & 171,8 & 165,9 & 167,6 & 168,0 \\
\hline 11 & 71,1 & 135,4 & 135,9 & 136,1 & 136,1 \\
\hline 12 & 18,8 & 35,1 & 34,2 & 34,5 & 34,5 \\
\hline 13 & 0,3 & 0,3 & 0,3 & 0,3 & 0,3 \\
\hline 14 & 14866,9 & 29735,0 & 29726,3 & 29728,6 & 29729,1 \\
\hline
\end{tabular}


Tabela 5-8 Valores atualizados de damping Smith $(\mathrm{s} / \mathrm{m}), \operatorname{com} d=1,0 \mathrm{~m}, L_{S}=2,0 \mathrm{~m}$, e $\sigma^{2}=0,25(\mathrm{kN})^{2}$ vs. diferentes variabilidades dos instrumentos hipotéticos

\begin{tabular}{|c|c|c|c|c|c|}
\cline { 3 - 6 } \multicolumn{2}{c|}{} & \multicolumn{4}{c|}{ COVerro (Uniforme) } \\
\cline { 3 - 6 } \multicolumn{2}{c|}{} & $5 \%$ & $10 \%$ & $15 \%$ & $20 \%$ \\
\hline $\begin{array}{c}\text { Trecho da } \\
\text { estaca }\end{array}$ & m' (Js) & $\mathrm{m} "(\mathrm{Js})$ & $\mathrm{m} "(\mathrm{Js})$ & $\mathrm{m} "(\mathrm{Js})$ & $\mathrm{m}$ " (Js) \\
\hline 1 & 0,581 & 0,913 & 1,329 & 1,812 & 2,351 \\
\hline 2 & 0,581 & 0,081 & $-0,439$ & $-0,959$ & $-1,461$ \\
\hline 3 & 0,581 & 0,620 & 0,507 & 0,246 & $-0,168$ \\
\hline 4 & 0,581 & 0,645 & 0,730 & 0,849 & 1,019 \\
\hline 5 & 0,581 & 0,681 & 0,840 & 1,046 & 1,288 \\
\hline 6 & 0,581 & $-0,015$ & $-0,572$ & $-1,094$ & $-1,582$ \\
\hline 7 & 0,581 & 1,835 & 3,201 & 4,647 & 6,144 \\
\hline 8 & 0,581 & 0,857 & 1,001 & 1,052 & 1,050 \\
\hline 9 & 0,581 & 1,120 & 1,597 & 1,996 & 2,301 \\
\hline 10 & 0,581 & 0,000 & 0,102 & $-0,144$ & $-0,355$ \\
\hline 11 & 0,581 & 0,354 & 0,408 & 0,538 & 0,795 \\
\hline 12 & 0,581 & 0,418 & $-0,216$ & $-0,476$ & $-0,656$ \\
\hline 13 & 0,581 & 0,917 & 0,865 & 0,706 & 0,342 \\
\hline 14 & 0,517 & 0,528 & 0,539 & 0,550 & 0,563 \\
\hline
\end{tabular}

\begin{tabular}{|c|c|c|c|c|c|}
\cline { 3 - 6 } \multicolumn{2}{c|}{} & \multicolumn{4}{c|}{ COVerro (Uniforme) } \\
\cline { 3 - 6 } \multicolumn{2}{c|}{} & $5 \%$ & $10 \%$ & $15 \%$ & $20 \%$ \\
\hline $\begin{array}{c}\text { Trecho da } \\
\text { estaca }\end{array}$ & Var' (Js) & Var" (Js) & Var" (Js) & Var" (Js) & Var" (Js) \\
\hline 1 & 0,003 & 0,006 & 0,006 & 0,005 & 0,005 \\
\hline 2 & 0,003 & 0,006 & 0,005 & 0,004 & 0,003 \\
\hline 3 & 0,003 & 0,005 & 0,003 & 0,000 & $-0,003$ \\
\hline 4 & 0,003 & 0,006 & 0,006 & 0,005 & 0,004 \\
\hline 5 & 0,003 & 0,006 & 0,006 & 0,005 & 0,005 \\
\hline 6 & 0,003 & 0,007 & 0,007 & 0,007 & 0,007 \\
\hline 7 & 0,003 & $-0,018$ & $-0,021$ & $-0,022$ & $-0,023$ \\
\hline 8 & 0,003 & 0,005 & 0,003 & 0,001 & $-0,001$ \\
\hline 9 & 0,003 & 0,007 & 0,006 & 0,006 & 0,006 \\
\hline 10 & 0,003 & 0,006 & 0,006 & 0,006 & 0,006 \\
\hline 11 & 0,003 & 0,005 & 0,004 & 0,003 & 0,002 \\
\hline 12 & 0,003 & $-0,007$ & $-0,009$ & $-0,010$ & $-0,010$ \\
\hline 13 & 0,003 & $-0,007$ & $-0,010$ & $-0,011$ & $-0,012$ \\
\hline 14 & 0,003 & 0,005 & 0,005 & 0,005 & 0,005 \\
\hline
\end{tabular}

\begin{tabular}{|c|c|c|c|c|c|}
\cline { 3 - 6 } \multicolumn{2}{c}{} & \multicolumn{4}{c|}{ COVerro (Pontual) $=$} \\
\cline { 3 - 6 } \multicolumn{2}{c|}{} & $5 \%$ & $10 \%$ & $15 \%$ & $20 \%$ \\
\hline $\begin{array}{c}\text { Trecho da } \\
\text { estaca }\end{array}$ & m' (Js) & $\mathrm{m}$ " (Js) & $\mathrm{m}$ " (Js) & $\mathrm{m} "$ (Js) & $\mathrm{m}$ " (Js) \\
\hline 1 & 0,581 & 0,913 & 3,842 & 0,286 & 0,474 \\
\hline 2 & 0,581 & 0,081 & $-4,023$ & 0,926 & 0,656 \\
\hline 3 & 0,581 & 0,620 & $-3,180$ & 1,469 & 1,224 \\
\hline 4 & 0,581 & 0,645 & 3,472 & 0,029 & 0,204 \\
\hline 5 & 0,581 & 0,681 & $-0,606$ & 0,955 & 0,879 \\
\hline 6 & 0,581 & $-0,015$ & $-5,054$ & 1,049 & 0,721 \\
\hline 7 & 0,581 & 1,835 & 10,834 & $-0,057$ & 0,550 \\
\hline 8 & 0,581 & 0,857 & 2,229 & 0,651 & 0,761 \\
\hline 9 & 0,581 & 1,120 & 4,074 & 0,486 & 0,677 \\
\hline 10 & 0,581 & 0,000 & $-3,371$ & 1,194 & 0,970 \\
\hline 11 & 0,581 & 0,354 & 0,933 & 0,241 & 0,257 \\
\hline 12 & 0,581 & 0,418 & $-5,715$ & 1,369 & 0,995 \\
\hline 13 & 0,581 & 0,917 & 8,645 & $-0,889$ & $-0,408$ \\
\hline 14 & 0,517 & 0,528 & 0,406 & 0,565 & 0,560 \\
\hline
\end{tabular}

\begin{tabular}{|c|c|c|c|c|c|}
\hline & \multicolumn{4}{|c|}{ COVerro $($ Pontual $)=$} \\
\hline & & $5 \%$ & $10 \%$ & $15 \%$ & $20 \%$ \\
\hline $\begin{array}{c}\text { Trecho da } \\
\text { estaca }\end{array}$ & Var' (Js) & Var" (Js) & Var" (Js) & Var" (Js) & Var" (Js) \\
\hline 1 & 0,003 & 0,006 & 0,010 & 0,005 & 0,006 \\
\hline 2 & 0,003 & 0,006 & 0,014 & 0,004 & 0,005 \\
\hline 3 & 0,003 & 0,005 & 0,012 & 0,003 & 0,004 \\
\hline 4 & 0,003 & 0,006 & 0,010 & 0,005 & 0,006 \\
\hline 5 & 0,003 & 0,006 & 0,007 & 0,006 & 0,006 \\
\hline 6 & 0,003 & 0,007 & 0,019 & 0,004 & 0,005 \\
\hline 7 & 0,003 & $-0,018$ & 0,020 & $-0,028$ & $-0,025$ \\
\hline 8 & 0,003 & 0,005 & 0,006 & 0,005 & 0,005 \\
\hline 9 & 0,003 & 0,007 & 0,011 & 0,006 & 0,006 \\
\hline 10 & 0,003 & 0,006 & 0,013 & 0,005 & 0,006 \\
\hline 11 & 0,003 & 0,005 & 0,006 & 0,006 & 0,006 \\
\hline 12 & 0,003 & $-0,007$ & 0,008 & $-0,012$ & $-0,011$ \\
\hline 13 & 0,003 & $-0,007$ & 0,021 & $-0,015$ & $-0,013$ \\
\hline 14 & 0,003 & 0,005 & 0,005 & 0,005 & 0,005 \\
\hline
\end{tabular}


Tabela 5-9 Valores atualizados de quake $(\mathrm{mm}), \operatorname{com} d=1,0 \mathrm{~m}, L_{S}=2,0 \mathrm{~m}$, e $\sigma^{2}=0,25$ $(\mathrm{kN})^{2}$ vs. diferentes variabilidades dos instrumentos hipotéticos

\begin{tabular}{|c|c|c|c|c|c|}
\cline { 3 - 6 } \multicolumn{2}{c|}{} & \multicolumn{4}{c|}{ COVerro (Uniforme) } \\
\cline { 3 - 6 } \multicolumn{2}{c|}{} & $5 \%$ & $10 \%$ & $15 \%$ & $20 \%$ \\
\hline $\begin{array}{c}\text { Trecho da } \\
\text { estaca }\end{array}$ & $\mathrm{m}^{\prime}(\mathrm{Q})$ & $\mathrm{m}^{\prime \prime}(\mathrm{Q})$ & $\mathrm{m} \mathrm{m}^{\prime}(\mathrm{Q})$ & $\mathrm{m}^{\prime \prime}(\mathrm{Q})$ & $\mathrm{m}^{\prime \prime}(\mathrm{Q})$ \\
\hline 1 & 1,576 & 3,301 & 6,943 & $-5,344$ & 0,971 \\
\hline 2 & 1,576 & $-0,022$ & $-1,935$ & $-0,678$ & $-1,283$ \\
\hline 3 & 1,576 & 2,254 & 4,221 & 8,752 & 6,892 \\
\hline 4 & 1,576 & 2,747 & 2,048 & $-0,532$ & 1,994 \\
\hline 5 & 1,576 & 1,064 & 1,827 & 8,725 & 5,882 \\
\hline 6 & 1,576 & 2,731 & 4,828 & $-4,940$ & 0,601 \\
\hline 7 & 1,576 & 0,965 & 0,692 & 0,036 & 1,296 \\
\hline 8 & 1,576 & $-0,716$ & $-14,988$ & 41,446 & 15,179 \\
\hline 9 & 1,576 & 1,130 & 2,085 & $-6,392$ & $-3,221$ \\
\hline 10 & 1,576 & 1,244 & 0,249 & 4,354 & 2,452 \\
\hline 11 & 1,576 & 0,912 & $-2,938$ & 12,024 & 5,066 \\
\hline 12 & 1,576 & 3,443 & 11,674 & $-20,125$ & $-4,854$ \\
\hline 13 & 1,576 & $-0,717$ & $-12,777$ & 38,614 & 15,587 \\
\hline 14 & 15,519 & 15,746 & 16,180 & 15,683 & 16,315 \\
\hline
\end{tabular}

\begin{tabular}{|c|c|c|c|c|c|}
\hline & \multicolumn{4}{|c|}{ COVerro (Uniforme) = } \\
\hline & & $5 \%$ & $10 \%$ & $15 \%$ & $20 \%$ \\
\hline $\begin{array}{c}\text { Trecho da } \\
\text { estaca }\end{array}$ & $\operatorname{Var}^{\prime}(\mathrm{Q})$ & Var" (Q) & Var" (Q) & Var" (Q) & Var" (Q) \\
\hline 1 & 0,025 & 0,033 & 0,007 & 0,105 & 0,055 \\
\hline 2 & 0,025 & 0,059 & 0,134 & 0,113 & 0,111 \\
\hline 3 & 0,025 & $-0,051$ & 0,323 & 0,168 & 0,132 \\
\hline 4 & 0,025 & $-0,036$ & 0,292 & 0,154 & 0,122 \\
\hline 5 & 0,025 & 0,015 & 0,285 & 0,192 & 0,156 \\
\hline 6 & 0,025 & 0,046 & 0,086 & 0,122 & 0,080 \\
\hline 7 & 0,025 & $-0,038$ & 0,088 & 0,054 & 0,049 \\
\hline 8 & 0,025 & $-0,233$ & $-0,587$ & 1,282 & 0,336 \\
\hline 9 & 0,025 & 0,029 & 0,002 & 0,008 & $-0,069$ \\
\hline 10 & 0,025 & 0,032 & 0,009 & $-0,012$ & $-0,079$ \\
\hline 11 & 0,025 & 0,027 & 0,003 & 0,105 & $-0,005$ \\
\hline 12 & 0,025 & $-0,005$ & $-0,122$ & 0,479 & 0,162 \\
\hline 13 & 0,025 & $-0,258$ & $-0,468$ & 1,062 & 0,330 \\
\hline 14 & 2,408 & 4,816 & 4,815 & 4,815 & 4,815 \\
\hline
\end{tabular}

\begin{tabular}{|c|c|c|r|r|r|}
\cline { 3 - 6 } \multicolumn{2}{c|}{} & \multicolumn{4}{c|}{ COVerro (Pontual) $=$} \\
\cline { 3 - 6 } \multicolumn{2}{c|}{} & \multicolumn{5}{c|}{$5 \%$} & $10 \%$ & $15 \%$ & $20 \%$ \\
\hline $\begin{array}{c}\text { Trecho da } \\
\text { estaca }\end{array}$ & $\mathrm{m}^{\prime}(\mathrm{Q})$ & $\mathrm{m} "(\mathrm{Q})$ & $\mathrm{m} "(\mathrm{Q})$ & $\mathrm{m} "(\mathrm{Q})$ & $\mathrm{m} "(\mathrm{Q})$ \\
\hline 1 & 1,576 & 3,301 & 1,810 & 3,089 & 2,998 \\
\hline 2 & 1,576 & $-0,022$ & 1,040 & 0,999 & 1,542 \\
\hline 3 & 1,576 & 2,254 & 3,000 & 0,093 & $-0,771$ \\
\hline 4 & 1,576 & 2,747 & 2,000 & 5,370 & 6,284 \\
\hline 5 & 1,576 & 1,064 & 2,410 & $-0,976$ & $-1,717$ \\
\hline 6 & 1,576 & 2,731 & 1,710 & 3,460 & 3,736 \\
\hline 7 & 1,576 & 0,965 & 1,440 & 1,858 & 2,168 \\
\hline 8 & 1,576 & $-0,716$ & 2,860 & 0,854 & 1,242 \\
\hline 9 & 1,576 & 1,130 & 0,210 & 1,029 & 1,019 \\
\hline 10 & 1,576 & 1,244 & 2,170 & 1,177 & 1,150 \\
\hline 11 & 1,576 & 0,912 & 0,650 & 1,485 & 1,613 \\
\hline 12 & 1,576 & 3,443 & 2,700 & 2,590 & 2,418 \\
\hline 13 & 1,576 & $-0,717$ & 2,580 & 0,871 & 1,252 \\
\hline 14 & 15,519 & 15,746 & 15,760 & 15,729 & 15,718 \\
\hline
\end{tabular}

\begin{tabular}{|c|c|c|c|c|c|}
\cline { 3 - 6 } \multicolumn{2}{c|}{} & \multicolumn{4}{c|}{ COVerro (Pontual) $=$} \\
\cline { 3 - 6 } \multicolumn{2}{c|}{} & \multicolumn{5}{c}{$5 \%$} & $10 \%$ & $15 \%$ & $20 \%$ \\
\hline $\begin{array}{c}\text { Trecho da } \\
\text { estaca }\end{array}$ & Var' (Q) $^{\prime}$ & Var" (Q) & Var" (Q) & Var" (Q) & Var" (Q) \\
\hline 1 & 0,025 & 0,033 & 0,044 & 0,049 & 0,0525 \\
\hline 2 & 0,025 & 0,059 & 0,067 & 0,051 & 0,039 \\
\hline 3 & 0,025 & $-0,051$ & 0,060 & $-0,168$ & $-0,208$ \\
\hline 4 & 0,025 & $-0,036$ & 0,056 & $-0,150$ & $-0,187$ \\
\hline 5 & 0,025 & 0,015 & 0,050 & $-0,064$ & $-0,088$ \\
\hline 6 & 0,025 & 0,046 & 0,030 & 0,040 & 0,039 \\
\hline 7 & 0,025 & $-0,038$ & 0,061 & $-0,044$ & $-0,047$ \\
\hline 8 & 0,025 & $-0,233$ & 0,019 & $-0,190$ & $-0,191$ \\
\hline 9 & 0,025 & 0,029 & 0,017 & 0,030 & 0,030 \\
\hline 10 & 0,025 & 0,032 & 0,017 & 0,033 & 0,033 \\
\hline 11 & 0,025 & 0,027 & 0,017 & 0,031 & 0,031 \\
\hline 12 & 0,025 & $-0,005$ & 0,026 & 0,010 & 0,011 \\
\hline 13 & 0,025 & $-0,258$ & 0,067 & $-0,223$ & $-0,224$ \\
\hline 14 & 2,408 & 4,816 & 4,816 & 4,816 & 4,816 \\
\hline
\end{tabular}

\subsection{Análise de Sensibilidade do MQN}

A partir dos valores atualizados dos parâmetros de Smith encontrados na seção anterior, fazse necessário utilizar tais valores atualizados dentro de análise CAPWAP ${ }^{\circledR}$. Tais análises se encontram na íntegra apresentadas no ANEXO C.

Na Tabela 5-10, apresenta-se os valores do match quality number (MQN) encontrados nas análises CAPWAP ${ }^{\circledR}$ a partir dos valores dos parâmetros de Smith atualizados, $m$ ” $(K)$, a partir da variabilidade do erro dos instrumentos hipotéticos utilizados, para $d=1,0 \mathrm{~m}$. Tais resultados são apresentados na Figura 5-9. 
O MQN foi o medidor da qualidade da comparação de sinais calculado e medido para cada configuração adotada.

Tabela 5-10 Valores do MQN versus a variabilidade do erro dos instrumentos hipotéticos (COVerro), para d $=1,0 \mathrm{~m}, \mathrm{Ls}=2,0 \mathrm{~m}$ e $\sigma^{2}=0,25(\mathrm{kN})^{2}$

\begin{tabular}{|c|c|c|c|c|c|}
\hline $\begin{array}{l}\text { Disposição dos } \\
\text { Instrumentos em } \\
\text { função do } \\
\text { variabilidade dos } \\
\text { mesmos }\end{array}$ & $\begin{array}{c}\text { Escala de } \\
\text { flutuação } \\
d(\mathrm{~m})\end{array}$ & $\begin{array}{c}\text { Comprimento } \\
\text { do Trecho } \\
\text { Discretizado }^{27} \\
L_{S}(\mathrm{~m})\end{array}$ & $\begin{array}{c}\text { Erro } \\
\text { pontual do } \\
\text { Instrumento } \\
\sigma^{2}\left(\mathbf{k N}^{2}\right)\end{array}$ & $\begin{array}{c}\text { Coeficiente } \\
\text { de Variação } \\
\text { do Erro do } \\
\text { Instrumento } \\
\text { COVerro } \\
(\%)\end{array}$ & $\begin{array}{c}\text { Número de } \\
\text { Match } \\
\text { Quality } \\
\text { (MQN) }\end{array}$ \\
\hline $\begin{array}{l}\text { Análise Uniforme } \\
\text { (Ver Figura 5-7) }\end{array}$ & 1,0 & 2,0 & 0,25 & $\begin{array}{r}5,0 \\
10,0 \\
15,0 \\
20,0\end{array}$ & $\begin{array}{r}* 5,31 \\
5,91 \\
8,34 \\
14,93\end{array}$ \\
\hline $\begin{array}{l}\text { Análise Pontual } \\
\text { (Ver Figura 5-8) }\end{array}$ & 1,0 & $\underline{2,0}$ & $\underline{0,25}$ & $\begin{array}{r}5,0 \\
10,0 \\
15,0 \\
20,0\end{array}$ & $\begin{array}{r}* 5,31 \\
10,20 \\
6,27 \\
5,52\end{array}$ \\
\hline
\end{tabular}

(*) Análise CAPWAP que serve para ambos os análises: uniforme e pontual.

Os resultados das 07 análises CAPWAP (01 análise se repete para ambos os análises), apresentados na Tabela 5-10, são expostos na Figura 5-9. 


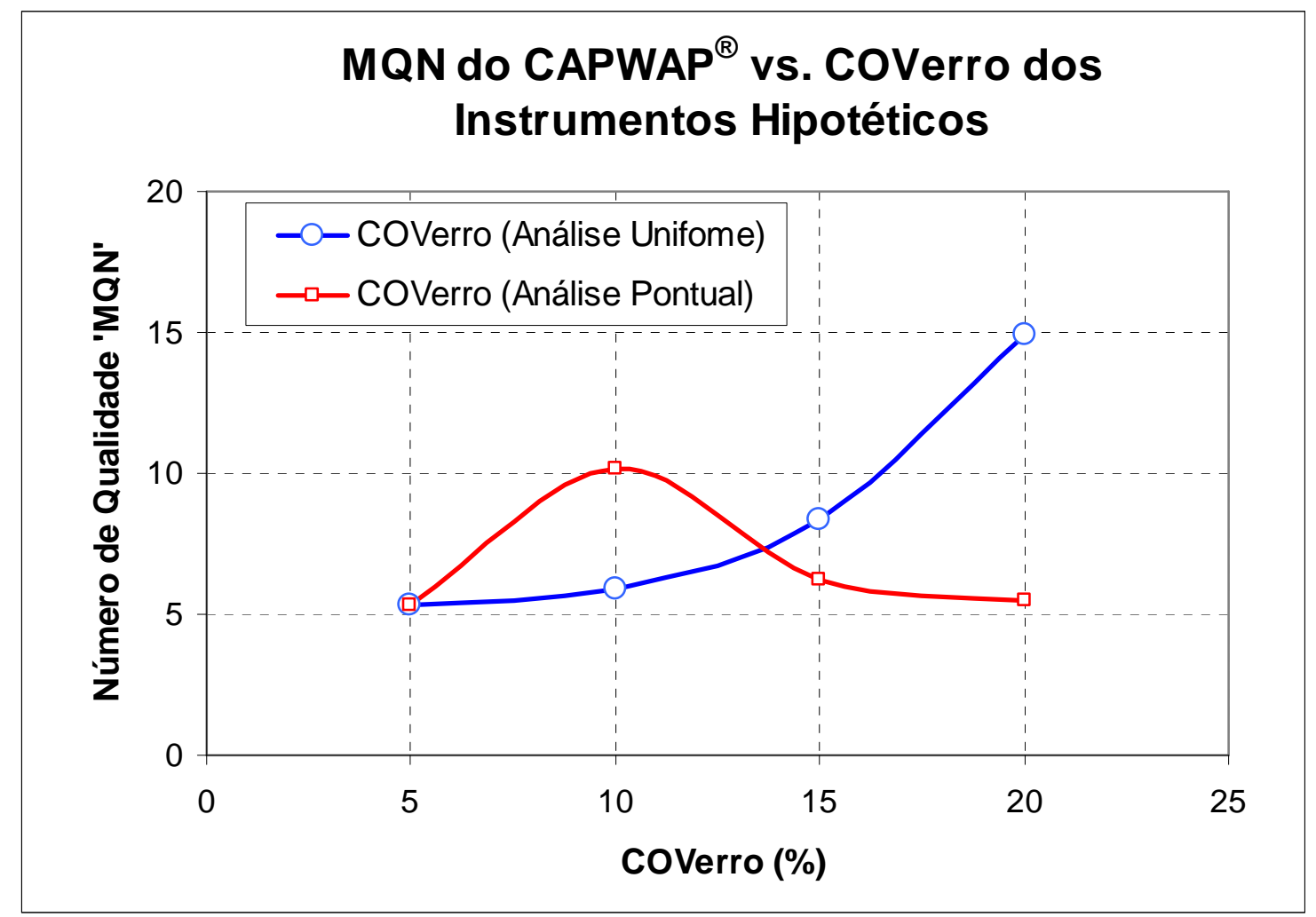

Figura 5-9 Curva de comparação do MQN da Análise CAPWAP e a variabilidade dos instrumentos hipotéticos

Na Figura 5-9, observa-se os resultados para os dois tipos de análises: uniforme e pontual. Para as análises uniformes, observa-se que com uma consideração de maior variabilidade dos erros dos instrumentos hipotéticos na atualização bayesiana, os números MQN das análises de confirmação CAPWAP ${ }^{\circledR}$ também são maiores. Tal comportamento da análise uniforme confirmou até certo ponto o fato de que fornecer maior intervalo de dispersão do erro dos instrumentos podia apresentar uma menor qualidade de comparação de sinais ou maior MQN.

Por outro lado, para as análises pontuais, observa-se que se as considerações de maior variabilidade na atualização bayesiana para os instrumentos localizados (1) na emenda da estaca no primeiro elemento discretizado da estaca e, (2) na ponta da estaca, apresentam uma diminuição dos números de MQN nas análises de confirmação CAPWAP ${ }^{\circledR}$. Tal comportamento das análises pontuais indica que para valores altos de variabilidade do erro (20\%) dos instrumentos, o número MQN se aproxima a uma análise com variabilidade 
pequena $(5 \%)$ com considerações das incertezas dos instrumentos localizados nas regiões em questão.

\subsection{Análise de Resultados}

$\mathrm{Na}$ etapa inicial da pesquisa, aplicou-se a metodologia mostrada na presente pesquisa a uma estaca hipotética com um modelo de solo adotado. Desenvolveu-se a atualização dos parâmetros de Smith a partir de sinais de cravação 'simuladas' sob o enfoque da solução de onda de Smith $(1955,1960)$. Tal solução de onda considerou parâmetros do sistema de cravação e do sistema estaca-solo. Tal simulação dos sinais de cravação possibilitou a adoção de um sinal de velocidade no trecho dos instrumentos como 'sinal medido em campo'. Vários instrumentos hipotéticos foram distribuídos ao longo do eixo do tempo espaçados regularmente. Observou nessas condições certa linearidade no modelo de observação.

Já na parte final da pesquisa para aplicação da teoria da atualização bayesiana aplicada à cravação de estacas utilizou-se sinais de cravação medidos em campo e processados no PDA $^{\circledR}$. Foi utilizado o Programa CAPWAP ${ }^{\circledR}$ (versão 1996-II) para realizar as análises inicial, de sensibilidade e de confirmação. Utilizou-se o sinal de força medido para a aplicação da teoria probabilista.

Para determinação dos parâmetros quake do modelo de Smith, os valores médios mais prováveis foram produto da análise inicial CAPWAP a partir dos sinais de força e velocidade obtidos em campo. Em um procedimento típico de Comparação de Sinais, considera-se somente dois valores de quake: um valor de quake lateral para todos os trechos discretizados da estaca e um quake de ponta, conforme é apresentado na folha dos resultados da análise inicial CAPWAP na Tabela C-11 do ANEXO C. Para construir as matrizes de sensibilidade do parâmetro no CAPWAP ${ }^{\circledR}$, aproveitou-se da capacidade de entrada de dados do quake para cada trecho da estaca, como já descrito anteriormente. O procedimento utilizado para a atualização bayesiana do quake mostrou-se eficiente (conforme apresentado na Tabela de valores atualizados do parâmetro, ver ANEXO C, Tabela C-8), mostrando valores negativos em alguns trechos da estaca para escalas de flutuação diferentes de 
d=0,5m. Para efetuar a análise CAPWAP de confirmação com os valores atualizados de quake, utilizou-se os valores correspondentes à escala de flutuação de $d=1,0 m$ e corrigiu-se alguns valores negativos com valores mínimos aceitáveis para as análises CAPWAP de confirmação (conforme apresentado no ANEXO C).

Para determinação dos parâmetros de damping do modelo de Smith, os valores médios mais prováveis foram produto da análise inicial CAPWAP. Em um procedimento típico de Comparação de Sinais, considera-se somente dois valores de damping Smith para caracterizar o amortecimento do solo: o damping Smith lateral e damping Smith de ponta, conforme é apresentado na folha dos resultados da análise inicial CAPWAP na Tabela C-11 do ANEXO C. Para construir as matrizes de sensibilidade do damping no CAPWAP, aproveitou-se da capacidade de entrada de dados do damping viscoso para cada trecho da estaca. O Procedimento utilizado para a atualização bayesiana do damping Smith mostrou-se eficiente (conforme apresentado na Tabela de valores atualizados do parâmetro Damping Smith, ver ANEXO C), mostrando valores negativos em alguns trechos da estaca para as três escalas de flutuação avaliadas $(\mathrm{d}=0,5 \mathrm{~m}, 1,0 \mathrm{~m}$ e 2,0m). Para efetuar a análise CAPWAP de confirmação com os valores atualizados de Damping Smith, utilizou-se os valores correspondente à escala de flutuação de $\mathrm{d}=1,0 \mathrm{~m}$. Corrigiu-se os valores negativos com valores aceitáveis para efetuar as análises CAPWAP ${ }^{\circledR}$ de confirmação (conforme apresentado no ANEXO C).

Para o cálculo dos parâmetros de resistência estática última do modelo de Smith, os valores médios mais prováveis devem ser determinados anteriormente à análise inicial CAPWAP, neste caso, utilizou-se o método semi-empírico de Decourt-Quaresma. Tais resultados permitiram adotar os valores médios mais prováveis como entrada de dados para a análise CAPWAP conforme é apresentado no ANEXO C. Para construir as matrizes de sensibilidade do Rult no CAPWAP, aproveitou-se da capacidade de entrada de dados da resistência estática unitária última para cada trecho da estaca. O Procedimento utilizado para a atualização bayesiana do resistência estática unitária última mostrou-se eficiente (conforme apresentado na Tabela de valores atualizados da resistência estática unitária última, ver ANEXO C), mostrando valores negativos no trecho 07 da estaca, onde o valor médio era zero, para as três escalas de flutuação avaliadas $(\mathrm{d}=0,5 \mathrm{~m}, 1,0 \mathrm{~m}$ e $2,0 \mathrm{~m})$. Para 
efetuar a análise CAPWAP de confirmação com os valores atualizados de resistência estática unitária última, utilizou-se os valores correspondentes à escalas de flutuação de $\mathrm{d}=1,0 \mathrm{~m}$, sendo corrigido o valor negativo da tabela com um valor aceitável, $0,1 \mathrm{kN}$; valor que serviu para efetuar as análises CAPWAP $^{\circledR}$ de confirmação (conforme apresentado no ANEXO C).

O valores negativos encontrados após realizadas as análises de atualização bayesiana dos parâmetros em questão, podem ser produto de algumas causas mencionadas a seguir: (1) aos procedimentos matemáticos do modelo probabilista utilizado para a atualização bayesiana dos parâmetros, e (2) aos parâmetros adotados como valores médios mais prováveis (valores muito baixos no caso do Rult).

Para a construção das matrizes de sensibilidade, revisou-se a relação das observações no sinal de força (neste caso) para valores diferentes de parâmetros de Smith. Tais análises permitiram validar o modelo linear de observação postulado, ver Figura 5-6. Tal linearidade da relação entre as observações e os parâmetros em questão também facilita a escolha da matriz de sensibilidade utilizada para a aplicação da metodologia proposta.

O procedimento de comparação de sinais da análise entre um sinal medido e calculado (seja força ou velocidade) está sujeito a produzir resultados físicamente coerentes e com parâmetros dentro dos limites razoáveis. Na análise dinâmica CAPWAP realizada na presente pesquisa observou-se duas dificuldades:

1. Detectou-se defeito/dano aproximadamente no primeiro elemento discretizado da estaca refletindo-se no sinal medido de cravação.

2. Detectou-se a possibilidade de formação uma massa de solo na ponta ('bucha') já que a análise CAPWAP sugeriu a existência de uma massa de solo aderida à ponta da estaca, inobstante tratar-se de uma estaca maciça de concreto. Pode ser que a estaca, ao passar pelo estrato de solo mole, propiciou a formação de uma massa de solo na ponta, a qual se influenciou no golpe analisado.

Foram avaliadas as incertezas nas observações (sinais) por meio de um vetor de erros de observação, formado por coeficientes de variação, denominados de COVerro, ou como 
porcentagens dos valores médios das observações. Tais incertezas nas observações foram consideradas de dois modos: o primeiro que considerava as incertezas uniformes em todos os instrumentos, e outra que considerava as incertezas pontuais, ou seja em função das regiões que apresentaram maior incerteza para comparação de sinais (ver Figura 5-9).

\begin{abstract}
Alguns resultados das análises CAPWAP, produto tanto das análises de sensibilidade ou das análises de confirmação após a atualização bayesiana, acusaram falta de mobilização da resistência de ponta, portanto foi preciso utilizar a opção do CAPWAP de redução automática do quake de ponta para reduzir a resistência última da estaca . No ANEXO A, apresenta-se o resultado das análises de sensibilidade realizados no CAPWAP mostrando quais análises precisaram da opção de redução automática do quake.
\end{abstract}




\section{CONCLUSÕES E PESQUISAS FUTURAS}

Este trabalho apresenta uma metodologia para atualização bayesiana dos parâmetros de Smith, levando em conta não só os sinais registrados, mas também a informação geotécnicaprobabilista prévia sobre estes parâmetros. A partir de um conjunto de hipóteses de trabalho coincidentes com as hipóteses de projeto, adaptou-se um modelo de comportamento dos sinais de cravação em relação aos parâmetros de Smith inserido no Software de análise de sinais, p.e. CAPWAP ou DLTWAVE.

\subsection{Conclusões}

Deste modo, a partir dos resultados obtidos tanto na etapa de qualificação e na etapa final da pesquisa foram alcançadas as seguintes conclusões:

- O modelo de Smith $(1955,1960)$, se utilizado para fins de análise das variáveis, faz com que as incertezas do modelo do martelo (sistema de cravação) sejam inseridas dentro do modelo estaca-solo, ou seja, dentro dos parâmetros de Smith. Portanto, a variabilidade dos parâmetros de Smith vê-se afetada por incertezas que dificultam as análises paramétricas necessárias para uma atualização bayesiana dos parâmetros de Smith. No software de análise de sinais, a consideração do modelo de martelo (sistema de cravação) que é substituída pelos sinais de cravação obtidos em campa, é possível isolar de melhor modo as incertezas de cada um dos parâmetros de Smith.

- O tratamento paramétrico de cada um dos parâmetros de Smith permitiu a construção das matrizes de sensibilidade, que relacionam cada parâmetro a cada observação, mostradas nas Figura 5-3, Figura 5-4 e Figura 5-5.

- A metodologia proposta mostrou-se uma ferramenta útil para a avaliação do comportamento dos parâmetros do modelo do solo utilizando-se dados de instrumentação hipoteticamente instalada (vide Figura 5-7 e Figura 5-8). Com tal 
aplicação foi possível atualizar os domínios dos parâmetros de Smith sob a ótica bayesiana. Tal Atualização permitiu aos parâmetros afetados por incerteza maior ter um ajuste proporcionalmente maior de acordo com as observações (vide Tabela 5-7, Tabela 5-8 e Tabela 5-9).

- O máximo deslocamento elástico (quake), o fator de amortecimento (damping) e a resistência estática última, de cada trecho da estaca, foram considerados como variáveis aleatórias com distribuições prévias estimadas (vide Tabela 5-3). Devido à adoção do vetor de valores médios mais prováveis e da uma matriz de covariâncias foi possível a aplicação do método de primeira ordem e momentos de ordem 2 (FOSM) no procedimento de atualização bayesiana.

- A utilização do modelo linear de observação permitiu utilizar as observações feitas nos instrumentos hipotéticos localizados ao longo do eixo do tempo em espaços regulares no sinal calculado de força, para correlacioná-las com os parâmetros do modelo, neste caso os parâmetros de Smith. Tal correlação apresentou de fato certa linearidade em vários trechos analisados (p.e. no trecho da ponta, ver Figura 5-6). Deste modo validou-se o modelo linear de observação adotado para a aplicação da teoria de atualização bayesiana usada na presente pesquisa.

- Os valores dos parâmetros atualizados variam de acordo com a variância admitida para cada um deles, com a combinação de escalas de flutuação vertical, discretização da estaca, disposição dos instrumentos hipotéticos e imprecisão admitida para cada um deles. Para efeitos computacionais utilizou-se, o valor mínimo estabelecido pelo CAPWAP, espaços regulares de $0,3 \mathrm{~ms}$ para. Por meio da Tabela 5-5, observa-se que existe alguma correlação cruzada entre trechos de estaca diferentes se a escala de flutuação é maior que o elemento discretizado da estaca.

- A qualidade dos resultados obtidos medida pelo 'MQN' ou indicador de qualidade, na falta de melhor indicador (vide Figura 5-9), sugere que o processo de atualização bayesiana, neste caso específico e para estes dados, não levou a resultados significativamente diferentes daqueles obtidos com processo usual do CAPWAP. 
Finalmente, confirmou-se o fato de que a metodologia utilizada neste trabalho pode ser aplicada a diferentes tipos de fenômenos na engenharia geotécnica, dependendo dos diferentes tipos de instrumentos utilizados e do desempenho dos mesmos.

\subsection{Pesquisas Futuras}

Como sugestões para pesquisas futuras sobre a retroanálise probabilista visando a atualização dos parâmetros de Smith a partir de observações feitas no sinal de cravação calculado destacam-se:

- Um estudo da atualização bayesiana dos parâmetros de Smith relativo ao número de instrumentos hipotéticos dispostos em intervalos, regulares ou não, ao longo do eixo do tempo no sinal calculado analisado. Este estudo deveria ser combinado com o desenvolvimento de indicadores de ajuste similares ao MQN mas adaptados especificamente ao processo proposto.

- Aplicar a metodologia proposta a outros casos de obra, com diferentes perfis de subsolo, com diferentes tipos de estacas: moldadas in situ, hélice continua, tubuloes e para estacas cravadas, com diferentes equipamentos de cravação, nos dois momentos da cravação: no final da cravação ('end of driving', EOD) como no inicio da recravação ('beginning of restrike', BOR), que vise à comparação de resultados.

- Refinar o procedimento para estimativa de variabilidades de cada um dos parâmetros de Smith, ou seja, melhorar o procedimento da estimativa de valores médios e desvios padrões dos parâmetros de Smith a partir das propriedades geotécnicas de determinado perfil de subsolo, investigando a eventual correlação entre eles (ver item 4.3) 


\section{REFERÊNCIAS}

ANG, A.; TANG, W. H. Probability concepts in engineering planning and design. New York: J. Wiley, 1975. v. 1, 399 p.

AOKI, N. Carga admissível de estacas através de ensaios dinâmicos. In: SEMINÁRIO DE ENGENHARIA DE FUNDAÇÕES ESPECIAIS, 2., 1991, São Paulo. Anais... São Paulo: ABEF: ABMS, Núcleo Regional de São Paulo, 1991. v. 2.

AOKI, N.; DE MELLO, V. F. B. Dynamic loading test curvs. In: INTERNATIONAL CONFERENCE ON THE APPLICATION OF THE STRESS-WAVE THEORY TO PILES, 4., 1992, The Hague, The Netherlands. Proceedings... Rotterdam; Brookfield: A.A. Balkema, 1992. p. 525-530.

AOKI, N.; VELLOSO, D. A. An approximate method to estimate the bearing capacity of piles. In: PANAMERICAN CONFERENCE OF SOIL MECHANICS AND FOUNDATION ENGINEERING (PAMCSMFE), 5., 1975, Buenos Aires. Proceedings... Buenos Aires, 1975. p. 367-376.

BAECHER, G. B.; CHRISTIAN, J. T. Reliability and statistics in geotechnical engineering. Chichester, West Sussex, England; Hoboken, NJ: J. Wiley, c2003. xii, 605 p.

BENJAMIN, J. R.; CORNELL, C. A. Probability, statistics and decision for civil engineers. New York: McGraw-Hill, [1970]. xiv, 684 p.

BERRUIJT, A. Soil mechanics. The Neterlands: Delft University of Technology, 2001. Disponível em: <http://vulcanhammer.net/geotechnical/SoilMechBook.pdf >. Acesso em: jan 2008.

BILFINGER, W. Critérios de segurança de fundações em estacas cravadas com consideração de controles executivos. 2002. 2 v. Tese (Doutorado) - Escola Politécnica, Universidade de São Paulo, São Paulo, 2002. 
BOWLES, J. E. Analytical and computer methods in foundation engineering. New York: McGraw-Hill, 1974. 519 p.

CAMBOU, B. Applications of firs order uncertainty analysis in the finite elements method in linear elasticity. In: International Conference On Applications Of Statistics And Probability To Soil And Strutural Engineering, 2., Aachen, 1975. Proceedings. Essen: Deutche Gessellschaft fiir Erd. Und Grundbau, 1976. p. 67-81.

CASTILLO, E.; ALONSO, E.E. Probabilistic versus deterministic modelling: Filling a gap. In $11^{\text {th }}$ International Conference on Soil Mechanics and Foundations, San Francisco, volume 1, 813-818, 1983.

CAPWAP Manual. Cleveland, Ohio: Grl \& Associates, 1990.

CHARUE, N. Loading rate effects on pile load-displacement behaviour derived from back-analysis of two load testing procedures. 2004. Tese (Doutorado) - Université Catholique de Louvain, Belgium. 2004.

CHELLIS, R. D. Pile foundations. $2^{\text {nd }}$ ed. New York: McGraw-Hill, 1961. 704 p.

COELHO, G. Previsão do fator de set-up para avaliação da capacidade de carga de estacas cravadas em ensaios de carregamento dinâmico. 1997. 162 p. Dissertação (Mestrado) - Escola Politécnica, Universidade de São Paulo, São Paulo, 1997.

DALI, B.; HERITIER, B. A new way for the dynamic static equivalence load. In: INTERNATIONAL CONFERENCE ON THE APPLICATION OF THE STRESS-WAVE THEORY TO PILES, 4., 1992, The Hague, The Netherlands. Proceedings... Rotterdam; Brookfield: A.A. Balkema, 1992. p. 551-556.

DE ROSA, R. L. Proposição de modificação das fórmulas dinâmicas de cravação de Chellis e de Uto et al. a partir de resultados do método Case. 2000. 197 p. Dissertação (Mestrado) - Escola Politécnica, Universidade de São Paulo, São Paulo, 2000.

DÉCOURT, L.; QUARESMA, A. R. Capacidade de carga de estacas a partir de valores de SPT. In: CONGRESSO BRASILEIRO DE MECÂNICA DOS SOLOS E ENGENHARIA DE FUNDAÇÕES (COBRAMSEF), 6., 1978, Rio de Janeiro. Anais... Rio de Janeiro: ABMS, 1978. p. 45-54. 
DLTWAVE SPECIFICATIONS. Wave equation program signal matching for PDA and DLT. Waddinxveen, The Netherlands: Profound B.V., 2007. Disponível em:

<http://www.profound.nl/downloads/techspec/prof_DLTWAVE.pdf>. Acesso em: jan. 2008.

GIMENES, E.A. Contribuição à obenção de parâmetros estatísticos de medições geotécnicas irregularmente espaçadas. 1988. 72 p. Dissertação (Mestrado) - Escola Politécnica, Universidade de São Paulo, São Paulo, 1988.

GOBLE, G. G. Some wave mechanics applications. In: INTERNATIONAL

CONFERENCE ON THE APPLICATION OF STRESS-WAVE THEORY TO PILES, 6. 2000, Rotterdam. Proceedings... Rotterdam: Balkema, 2000. p. 3-9.

GOBLE, G.G.; LIKINS, G.; RAUSCHE, F. Bearing capacity of piles form dynamic measurements. Cleveland, Ohio: Department of Civil Engineering, Case Western Reserve University, 1975. Final Report. OHIO-DOT-05-75. Disponível em:

<http://www.pile.com/Reference/BearingCapacity1975/main.pdf>. Acesso em: jan. 2007.

GOBLE, G. G.; RAUSCHE, F. Wave equation analysis of piling driving: WEAP program. Washington: Federal Highway Administration; Springfield, Va.: Available through the National Technical Information Service, 1976. 4 v. Disponível em:

<http://www.vulcanhammer.net/wave/FHWA-IP-76-14.pdf>. Acesso em: maio 2007

GOBLE, G. G.; RAUSCHE, F. Wave equation analysis of piling driving: WEAP program. Washington, DC: Federal Highway Administration, 1986. v. 1-4. Disponível em: <http://www.vulcanhammer.info/drivability/WEAP86.pdf >. Acesso em: dia fev. 2008.

GOBLE, G. G.; LIKINS, G. E. On the application of PDA dynamic pile testing. In: INTERNATIONAL CONFERENCE ON THE APPLICATION OF STRESSWAVE THEORY TO PILES, 1996, Orlando, FL. Proceedings... Orlando, FL, 1996. p. 263-273.

GONÇALVES, C.; ANDREO, C. S.; BERNARDES, G. P. Ensaios de carregamento dinâmico. Guarulhos: Estacas Benaton, 1999. 269 p.

GRLWEAP Manual. Pile dynamics. Cleveland, Ohio. 2003.

HACHICH, W. C. Sobre a segurança nos projetos de geotecnia. 1978. 1 v. Dissertação (Mestrado) - Escola Politécnica, Universidade de São Paulo, São Paulo, 1978. 
HACHICH, W. C. Seepage-related reliablity of embankment dams. 1981. 164 p. Tese (Doutorado) - Massachusetts Institute of Technology, Cambridge, 1981

HACHICH, W. C.; VANMARCKE, E. H. Probabilistic updating of pore pressure fields. Journal of Geotechnical Engineering, New York, v. 109, n. 3, p. 373-387, Mar. 1983.

HACHICH, W. C. Modelos matemáticos e probabilistas em engenharia geotécnica: uma sistematização na forma de sonata. 1998. 55 p. Tese (Livre Docência) - Escola Politécnica, Universidade de São Paulo, São Paulo, 1998.

HANNIGAN, P. J.; GOBLE, G. G.; THENDEAN, G.; LIKINS, G. E. Design and construction of driven pile foundations. Washington, DC: Federal Highway Administration, 1998. 2 v. (Publication $n^{\circ}$ FHWA H1-96-033). Disponível em: $<$ http://www.fhwa.dot.gov/engineering/geotech/library_arc.cfm?sortheader=NTIS_PubNo\& pub_number=42>. Acesso em: 24 jul. 2006.

HARR, M. E. Reliability-based design in civil engineering. New York: McGraw-Hill, 1987. x, $290 \mathrm{p}$.

HOLEYMAN, A. Keynote lecture: technology of pile dynamic testing. In:

INTERNATIONAL CONFERENCE ON THE APPLICATION OF THE STRESS-WAVE THEORY TO PILES, 4., 1992, The Hague, The Netherlands. Proceedings... Rotterdam; Brookfield: A.A. Balkema, 1992. p. 195-215.

HUSSEIN, M. H.; GOBLE, G. G. A brief history of the application of stress-wave theory to piles. In: DiMAGGIO, J. A.; HUSSEIN, M. H. (Ed.). Current practices and future trends in deep foundations. Reston, VA: American Society of Civil Engineers, 2004. p. 186-201. (Geotechnical Special Publication, n. 125). Disponível em:

<http://www.pile.com/Reference/ggg2004/11-Hussein.pdf>. Acesso em: 24 jul. 2006.

JAYNES, E. T. Probability theory: the logic of science. Cambridge: Cambridge University Press, 1996. Disponível em: <http://omega.albany.edu:8008/JaynesBook.html>. Acesso em: 24 jul. 2006.

LEDESMA, A.; GENS, A.; ALONSO, E. E. Probabilistic back analysis using a maximun likelihood aproach. In: INTERNATIONAL CONFERENCE ON SOIL MECHANICS AND FOUNDATION ENGINEERING, 12., 1989, Rio de Janeiro. Proceedings... Rotterdam: Balkema, 1989. p. 849-852. 
LIKINS, G., RAUSCHE, F., THENDEAN, G.; SVINKIN, M. R. CAPWAP correlations studies. In: INTERNATIONAL CONFERENCE ON THE APPLICATION OF STRESSWAVE THEORY TO PILES, 5., 1996, Orlando, USA. Proceedings... Gainesville, FL: University of Florida, 1996. p. 447-464.

LIANG, R. Y.; ZHOU, J. Probability method applied to dynamic pile-driving control. Journal of Geotechnical and Geoenvironmental Engineering, New York, v. 123, n. 2, p.137-144, 1997.

LOWERY, L. L.; HIRSCH, T. J.; EDWARDS, T. C.; COYLE, H. M.; SAMSON JR, C. H. Pile driving analysis: state of the art. College Station: Texas Transportation Institute, Texas A \& M University, 1969. Texas Transportation Institute Research Report 33-13. Disponível em: 〈http://www.vulcanhammer.info/drivability/TTI-33-13.pdf>. Acesso em: fev. 2008.

LOWERY, L. L. Pile driving analysis by the wave equation. Texas: Department of Civil Engineering, 1993. Disponível em:

<http://www.vulcanhammer.net/download/mwmanwrd.pdf>. Acesso em: fev. 2008.

MAGNAN, J. P. Les méthodes statistiques et probabilistes en mécanique des sols. Paris [France]: Presses de l'école nationale des ponts et chaussées, 1982. 203 p.

MANUAL ABEF. Manual de especificação de produtos e procedimentos ABEF. ASSOCIAÇÃO BRASILEIRA DE EMPRESAS DE ENGENHARIA DE FUNDAÇÕES E GEOTECNIA).. 2. ed. São Paulo, 2002. 282 p.

MATSUO, M.; SUGAI, M.; NAKATA, S.; KOSEKI, T. A method of evaluation of the bearing capacity of steel pipe piles by dynamic displacement wave of pile tops. In:

INTERNATIONAL CONFERENCE ON SOIL MECHANICS AND FOUNDATION ENGINEERING, 12., 1989, Rio de Janeiro. Proceedings... Rotterdam; Brookfield, Vt.: A.A. Balkema, 1989. v. 1, p. 13-16.

MATSUMOTO, T.; TAKEI, M. Effect of soil plug on behavior of driven pipe pile. Soils and Foundations, Tokyo, v. 31, n. 2, p. 14-34, 1991.

MATSUMOTO T.; NISHIMURA, S. Wave propagation phenomena in statnamic tests of a steel pipe pile. In: INTERNATIONAL CONFERENCE ON THE APPLICATION OF STRESS-WAVE THEORY TO PILES, 5., 1996, Orlando, USA. Proceedings... Gainesville, FL: University of Florida, 1996. p. 1015- 1030. 
MIDDENDORP, P. Thirty years of experience with stress wave simulation applications based on method of characteristics (TNOWAVE). In: INTERNATIONAL CONFERENCE ON THE APPLICATION OF STRESS-WAVE THEORY TO PILES, 7., 2004, Kuala Lumpur, Malaysia. Proceedings... Lumpur, Malaysia, 2004. Disponível em: <http://www.profound-usa.com/information/downloads/SW2004_Paper_Middendorp.pdf>. Acesso em: jun. 2007.

NBR 13208: estacas: ensaio de carregamento dinâmico. Rio de Janeiro: Associação Brasileira de Normas Técnicas, [2007]. 12 p.

NBR 6122: projeto e execução de fundações. Rio de Janeiro: Associação Brasileira de Normas Técnicas, 1996. 33 p.

NIYAMA, S. Medições dinâmicas na cravação de estacas: fundamentos, instrumentação e aplicações práticas. 1983. 1 v. Dissertação (Mestrado) - Escola Politécnica, Universidade de São Paulo, São Paulo, 1983.

NIYAMA, S.; AOKY, N.; CHAMECKI, P. R. Verificação de desempenho. In: HACHICH, W. et al. Fundações: teoria e prática. 2 ed. São Paulo: Pini, 1998.

PAIKOWSKY, S. G.; WHITMAN, R. V. The effects of plugging on pile performance and a design. Canadian Geotechnical Journal, Ottawa, CA, v. 27, n. 3, p. 429-440, Aug. 1990.

PAIKOWSKY, S. G.; REGAN, J. E.; McDONELL, J. J. A simplified field method for capacity evaluation of driven piles. Washington, DC: Federal Highway Administration, 1994. 291 p. (Publication n. FHWA-RD-94-042).

PAIKOWSKY, S. G.; STENERSEN, K. L. The performance of the dynamic methods, their controlling parameters and deep foundation specifications. In: INTERNATIONAL CONFERENCE ON THE APPLICATION OF STRESS-WAVE THEORY TO PILES, 6. 2000, São Paulo, Brazil. Proceedings... Rotterdam: Balkema, 2000. p. 281-304.

PAQUET, J. Checking bearing capacity of dynamic loading: choice of methodology. In: INTERNATIONAL CONFERENCE ON THE APPLICATION OF STRESS-WAVE THEORY TO PILES, 3., 1988, Ottawa. Proceedings... Vancouver, B.C.: BiTech Publishers, 1988. p. 383-398. 
PDI Engenharia. Rio de Janeiro, 2006. Texto anexado aos Relatórios Técnicos de Ensaios Dinâmicos Versão 2006.

PECK, R. B. Advantages and limitations of the observational method in applied soil mechanics. Geotechnique, London, v. 19, n. 2, p. 171-187, jun. 1969. Ninth Rankine Lecture.

PHOON, K-K.; KULHAWY, F. H.; GRIGORIU, M. D. Reliability-based design of foundations for transmission line structures. Palo Alto, CA: Electric Power Research Institute, 1995. 380 p. Report TR-105000. Disponível em:

<http://www.eng.nus.edu.sg/civil/people/cvepkk/reliability.html >. Acesso em: 10 jan. 2008.

PHOON, K-K.; KULHAWY, F. H. Characterization of geotechnical variability. Canadian Geotechnical Journal, Ottawa, Canada. v. 36, n. 4, Aug. 1999.

POULOS, H. G.; DAVIS, E. H. Elastic solutions for soil and rock mechanics. New York; London: J. Wiley, 1974. xi, 411 p. (Series in soil engineering).

RAUSCHE, F.; MOSES, F.; GOBLE, G. G. Soil resistance predictions from pile dynamics. Journal of the Soil Mechanics and Foundations Division, New York, v. 98, n. SM9, p. 917-937, Sept. 1972.

RAUSCHE, F.; GOBLE, G.; LIKINS, G. Dynamic determination of pile capacity. Journal of Geotechnical Engineering, New York, v. 111, n. 3, p. 367-383, 1985. Disponível em: <http://www.pile.com/Reference/ggg2004/24-Rausche-Classic2.pdf>. Acesso em: jan. 2008.

RAUSCHE, F.; GOBLE, G. G.; LIKINS, G. E. Recent WEAP developments. In: INTERNATIONAL CONFERENCE ON THE APPLICATION OF STRESS-WAVE THEORY TO PILES, 3., 1988, Ottawa, Canada. Proceedings... Ottawa, Canada, 1988. p. 164-173.

RAUSCHE, F.; ROBINSON, B.; LIANG, L. Automatic signal matching with CAPWAP. In: INTERNATIONAL CONFERENCE ON THE APPLICATION OF STRESS-WAVE THEORY TO PILES, 6., 2000, São Paulo, Brazil. Proceedings... Rotterdam: Balkema, 2000. p. 53-58.

RAUSCHE, F.; LIANG, L.; ALLIN, R.; RANCMAN, D. Applications and correlations of the wave equation analysis program GRLWEAP. In: INTERNATIONAL CONFERENCE 
ON THE APPLICATION OF STRESSWAVE THEORY TO PILES, 7., 2004.

Proceedings... Petaling Jaya, Selangor, Malaysia, 2004. p. 107-123.

SAMSON, C. H.; HIRSCH, T. L.; LOWERY, L. L. Computer study of dynamic behavior of piling. Journal of the Structural Division, New York, v. 89, n. ST4, paper 3608, Aug. 1963.

SMITH, E. A. L. Impact and longitudinal wave transmission. Transactions, New York, v. 77, p 963-973, Aug. 1955.

SMITH, E. A. L. Pile driving analysis by the wave equation. Journal of Soil Mechanics and Foundations Division, New York, v. 86, p. 35-61, Aug. 1960.

STRUFALDI, E. G. B. Retroanálise probabilista: aplicação prática de análise de percolação em uma barragem de terra. 2004. 82 p. Dissertação (Mestrado) - Escola Politécnica, Universidade de São Paulo, São Paulo, 2004.

SVINKIN, M. R. Time-dependent capacity of piles in clayey soils by dynamic methods. In: INTERNATIONAL CONFERENCE ON SOIL MECHANICS AND FOUNDATION ENGINEERING, 14., 1997, Hamburg, Germany. Proceedings... Hamburg, Germany, 1997. v. 2, p. 1045-1048.

THENDEAN G.; RAUSCHE F.; SVINKIN, M. R.; LIKINS, G. Wave equation correlation studies. In: INTERNATIONAL CONFERENCE ON THE APPLICATION OF THE STRESS-WAVE THEORY TO PILES, 5., 1996, Orlando, Florida. Proceedings... Gainesville, FL: University of Florida, 1996. p. 144-162.

TERZAGHI, K. Theoretical soil mechanics. New York: John Wiley \& Sons, 1943. 510 p.

UTO, K.; FUYUKI, M.; SAKURAI, M. An equation for the dynamic bearing capacity of a pile base on wave theory. In: INTERNATIONAL ON PENETRABILITY AND DRIVABILITY OF PILES, 1985, San Francisco. Proceedings... Japan: Japanese Society of Soil Mechanics and Foundation Engineering, 1985. v. 2, p. 95-100.

VANMARCKE, E. Probabilistic modeling of soil profiles. Journal of the Geotechnical Engineering Division, New York, v. 103, n. GT11, p. 1227-1246, 1977. Proc. Paper 13364. 
VANMARCKE, E. Random fields, analysis and synthesis. Cambridge, Mass.: MIT Press, c1983. xii, 382 p.

VENEZIANO, D.; FACCIOLI, E. Bayesian design of optimal experiments for estimation of soil properties. In: International Conference On Applications Of Statistics And Probability To Soil And Strutural Engineering, 2., Aachen, 1975. Proceedings. Essen: Deutche Gessellschaft fiir Erd. Und Grundbau, 1976. p. 191-213

VULCAMHAMMER.NET. Geotechnical anda marine engineering on-line library. 2007. Disponível em: http://www.vulcanhammer.net. Acesso em: fev. 2008.

WARRINGTON, DON C. A new type of wave equation analysis program: ZWAVE. In: INTERNATIONAL CONFERENCE ON THE APPLICATION OF STRESS-WAVE THEORY TO PILES, 3., 1988, Ottawa, Ontario. Proceedings... Vancouver, B.C.: BiTech Publishers, 1988. Disponível em:

<http://www.vulcanhammer.net/download/STRESS88.pdf>. Acesso em: fev. 2008.

WARRINGTON, DON C. A pile design analyzer for academic use: TAMWAVE. Pile Buck. March 2007. Disponível em: <http://www.vulcanhammer.net/soils/Pile-DrivingAnalyser.pdf>. Acesso em: fev. 2008.

WOOD, D. M. Geotechnical modeling. New York: Spon Press, 2004. 488 p.

ZAGOTTIS, D. L. de. Os modelos matemáticos no projeto estrutural de barragens: relato geral do tema II. In: SEMINÁRIO NACIONAL DE GRANDES BARRAGENS, 11, 1976, Fortaleza. Anais... Fortaleza: [s.n.], 1976. p. 1-100. 


\section{ANEXO A - Folhas Resumo da Análise de Sensibilidade realizada no CAPWAP ${ }^{\circledR}$}

Tabela A-1 Resultados das Análises CAPWAP da Análise de Sensibilidade do parâmetro Quake (Q)

\begin{tabular}{|l|c|c|}
\hline Arquivo & Quake $(\mathrm{mm})$ & $\mathrm{MQN} Q$ \\
\hline Q1 - B & 0,576 & 4,62 \\
\cline { 2 - 3 } Q1 - E & 1,326 & 4,70 \\
\hline Q1 - F & 1,576 & 4,71 \\
\hline Q1 - G & 1,826 & 4,73 \\
\cline { 2 - 3 } Q1 - I & 2,576 & 4,75 \\
\hline
\end{tabular}

\begin{tabular}{|ll|c|c|}
\hline \multicolumn{2}{|l|}{ Arquivo } & Quake $(\mathrm{mm})$ & MQN Q \\
\hline Q2- & B & 0,576 & 4,65 \\
\cline { 2 - 4 } Q2- & E & 1,326 & 4,70 \\
\hline Q2- & F & 1,576 & 4,71 \\
\hline Q2- & G & 1,826 & 4,73 \\
\cline { 2 - 3 } Q2- & I & 2,576 & 4,75 \\
\hline
\end{tabular}

\begin{tabular}{|l|c|c|}
\hline Arquivo & Quake $(\mathrm{mm})$ & $\mathrm{MQN} \mathrm{Q}$ \\
\hline Q3 - B & 0,576 & 4,67 \\
\cline { 2 - 3 } Q3- E & 1,326 & 4,70 \\
\hline Q3- F & 1,576 & 4,71 \\
\hline Q3- G & 1,826 & 4,73 \\
\cline { 2 - 3 } Q3 - I & 2,576 & 4,77 \\
\hline
\end{tabular}

\begin{tabular}{|ll|c|c|}
\hline \multicolumn{2}{|c|}{ Arquivo } & Quake $(\mathrm{mm})$ & MQN $Q$ \\
\hline Q4- & B & 0,576 & 4,60 \\
\cline { 3 - 4 } Q4- & E & 1,326 & 4,69 \\
\hline Q4- & F & 1,576 & 4,71 \\
\hline Q4- & G & 1,826 & 4,74 \\
\cline { 2 - 3 } Q4- & I & 2,576 & 4,82 \\
\hline
\end{tabular}

\begin{tabular}{|l|c|c|}
\hline Arquivo & Quake $(\mathrm{mm})$ & MQN $Q$ \\
\hline Q5- B & 0,576 & 4,64 \\
\cline { 2 - 3 } Q5- E & 1,326 & 4,70 \\
\hline Q5- F & 1,576 & 4,71 \\
\hline Q5- G & 1,826 & 4,73 \\
\cline { 2 - 3 } Q5 - I & 2,576 & 4,76 \\
\hline
\end{tabular}

\begin{tabular}{|ll|c|c|}
\hline \multicolumn{2}{|l|}{ Arquivo } & Quake $(\mathrm{mm})$ & $\mathrm{MQN} \mathrm{Q}$ \\
\hline Q6- & B & 0,576 & 4,71 \\
\cline { 2 - 4 } Q6- & E & 1,326 & 4,71 \\
\hline Q6- & F & 1,576 & 4,71 \\
\hline Q6- & G & 1,826 & 4,72 \\
\cline { 2 - 3 } Q6- & I & 2,576 & 4,72 \\
\hline
\end{tabular}

\begin{tabular}{|l|c|c|}
\hline Arquivo & Quake $(\mathrm{mm})$ & MQN Q \\
\hline Q7- B & 0,576 & 4,71 \\
\cline { 2 - 3 } Q7- E & 1,326 & 4,71 \\
\hline Q7- F & 1,576 & 4,71 \\
\hline Q7- G & 1,826 & 4,71 \\
\cline { 2 - 3 } Q7- I & 2,576 & 4,71 \\
\hline
\end{tabular}

\begin{tabular}{|ll|c|c|}
\hline \multicolumn{2}{|c|}{ Arquivo } & Quake (m m) & MQN Q \\
\hline Q8- & B & 0,576 & 4,71 \\
\cline { 3 - 4 } Q8- & E & 1,326 & 4,71 \\
\hline Q8- & F & 1,576 & 4,71 \\
\hline Q8- & G & 1,826 & 4,72 \\
\cline { 2 - 3 } Q8- & I & 2,576 & 4,72 \\
\hline
\end{tabular}

\begin{tabular}{|l|c|c|}
\hline Arquivo & Quake $(\mathrm{mm})$ & MQN Q \\
\hline Q9- B & 0,576 & 4,68 \\
\cline { 2 - 3 } Q9- E & 1,326 & 4,71 \\
\hline Q9- F & 1,576 & 4,71 \\
\hline Q9- G & 1,826 & 4,72 \\
\cline { 2 - 3 } Q9- I & 2,576 & 4,74 \\
\hline
\end{tabular}

\begin{tabular}{|l|c|c|}
\hline Arquivo & Quake $(\mathrm{mm})$ & MQN Q \\
\hline Q10- B & 0,576 & $4,68^{*}$ \\
\cline { 2 - 3 } Q10- E & 1,326 & 4,71 \\
\hline Q10- F & 1,576 & 4,71 \\
\hline Q10- G & 1,826 & 4,72 \\
\cline { 2 - 3 } Q10- I & 2,576 & 4,75 \\
\hline
\end{tabular}

\begin{tabular}{|l|c|c|}
\hline Arquivo & Quake $(\mathrm{mm})$ & MQN Q \\
\hline Q11 B & 0,576 & $4,68^{*}$ \\
\cline { 2 - 3 } Q11 E & 1,326 & 4,71 \\
\hline Q11 F & 1,576 & 4,71 \\
\hline Q11 G & 1,826 & 4,72 \\
\cline { 2 - 3 } Q11 I & 2,576 & 4,73 \\
\hline
\end{tabular}

\begin{tabular}{|l|c|c|}
\hline Arquivo & Quake $(\mathrm{mm})$ & MQN $Q$ \\
\hline Q12- B & 0,576 & 4,70 \\
\cline { 2 - 3 } Q12- E & 1,326 & 4,71 \\
\hline Q12- F & 1,576 & 4,71 \\
\hline Q12- G & 1,826 & 4,72 \\
\cline { 2 - 3 } Q12- I & 2,576 & 4,72 \\
\hline
\end{tabular}

\begin{tabular}{|l|c|c|}
\hline Arquivo & Quake $(\mathrm{mm})$ & MQN Q \\
\hline Q13 B & 0,576 & 4,71 \\
\cline { 2 - 3 } Q13 E & 1,326 & 4,72 \\
\hline Q13 F & 1,576 & 4,71 \\
\hline Q13 G & 1,826 & 4,71 \\
\cline { 2 - 3 } Q13 I & 2,576 & 4,71 \\
\hline
\end{tabular}

\begin{tabular}{|l|c|c|}
\hline Arquivo & Quake $(\mathrm{mm})$ & MQN Q \\
\hline Q14- B & 14,519 & 4,88 \\
\cline { 2 - 3 } Q14- E & 15,269 & 4,76 \\
\hline Q14- F & 15,519 & 4,71 \\
\hline Q14- G & 15,769 & $4,66^{*}$ \\
\cline { 2 - 3 } Q14- I & 16,519 & $4,67^{*}$ \\
\hline
\end{tabular}

( ${ }^{*}$ Análises C APW AP com redução automática do quake da ponta. 
Tabela A-2 Resultados das Análises CAPWAP da Análise de Sensibilidade do parâmetro Rult $(\mathbf{Q})$

\begin{tabular}{|l|c|c|}
\hline Arquivo & Rult (kN) & MQN Rult \\
\hline Rult1- F & 60,1 & 4,71 \\
\hline Rult1- G & 65,1 & 4,71 \\
\hline Rult1- H & 75,1 & 4,72 \\
\hline Rult1- I & 95,1 & 4,77 \\
\hline Rult1- J & 145,1 & 4,98 \\
\hline
\end{tabular}

\begin{tabular}{|l|c|c|}
\hline Arquivo & Rult (kN) & MQN Rult \\
\hline Rult3- F & 57,5 & 4,71 \\
\hline Rult3- G & 62,5 & 4,71 \\
\hline Rult3- H & 72,5 & 4,70 \\
\hline Rult3- I & 92,5 & 4,72 \\
\hline Rult3- J & 142,5 & 4,89 \\
\hline
\end{tabular}

\begin{tabular}{|l|c|c|}
\hline Arquivo & Rult (kN) & MQN Rult \\
\hline Rult5- F & 81,9 & 4,71 \\
\hline Rult5- G & 86,9 & 4,71 \\
\hline Rult5- H & 96,9 & $4,71^{*}$ \\
\hline Rult5- I & 116,9 & --- \\
\hline Rult5- J & 166,9 & --- \\
\hline
\end{tabular}

\begin{tabular}{|l|c|c|}
\hline Arquivo & Rult (kN) & MQN Rult \\
\hline Rult7- F & 0 & 4,71 \\
\hline Rult7- G & 5 & $4,71^{*}$ \\
\hline Rult7- H & 15 & $4,71^{*}$ \\
\hline Rult7- I & 35 & --- \\
\hline Rult7- J & 85 & --- \\
\hline
\end{tabular}

\begin{tabular}{|l|c|c|}
\hline Arquivo & Rult (kN) & MQN Rult \\
\hline Rult9- F & 58,1 & 4,71 \\
\hline Rult9- G & 63,1 & $4,71^{*}$ \\
\hline Rult9- H & 73,1 & $4,71^{*}$ \\
\hline Rult9- I & 93,1 & --- \\
\hline Rult9- J & 143,1 & --- \\
\hline
\end{tabular}

\begin{tabular}{|l|c|c|}
\hline Arquivo & Rult (kN) & MQN Rult \\
\hline Rult11- F & 84,3 & $4,71^{*}$ \\
\hline Rult11- G & 89,3 & $4,70^{*}$ \\
\hline Rult11- H & 99,3 & $4,69^{*}$ \\
\hline Rult11- I & 119,3 & --- \\
\hline Rult11-J & 169,3 & --- \\
\hline
\end{tabular}

\begin{tabular}{|l|c|c|}
\hline Arquivo & Rult (kN) & MQN Rult \\
\hline Rult13- F & 5,6 & 4,71 \\
\hline Rult13- G & 10,6 & $4,72^{*}$ \\
\hline Rult13- H & 20,6 & $4,75^{*}$ \\
\hline Rult13- I & 40,6 & --- \\
\hline Rult13- J & 90,6 & --- \\
\hline
\end{tabular}

\begin{tabular}{|ll|c|c|}
\hline Arquivo & Rult (kN) & MQN Rult \\
\hline Rult2- & F & 38,2 & 4,71 \\
\hline Rult2- & G & 43,2 & 4,71 \\
\hline Rult2- & H & 53,2 & 4,72 \\
\hline Rult2- & I & 73,2 & 4,75 \\
\hline Rult2- & J & 123,2 & 4,96 \\
\hline
\end{tabular}

\begin{tabular}{|ll|c|c|}
\hline \multicolumn{2}{|l|}{ Arquivo } & Rult (kN) & MQN Rult \\
\hline Rult4- & F & 104,4 & 4,71 \\
\hline Rult4- & G & 109,4 & 4,71 \\
\hline Rult4- & H & 119,4 & 4,71 \\
\hline Rult4- & I & 139,4 & $4,72^{*}$ \\
\hline Rult4- & J & 189,4 & $4,87^{*}$ \\
\hline
\end{tabular}

\begin{tabular}{|ll|c|c|}
\hline Arquivo & Rult (kN) & MQN Rult \\
\hline Rult6- & F & 2,7 & 4,71 \\
\hline Rult6- & G & 7,7 & $4,71^{*}$ \\
\hline Rult6- & H & 17,7 & $4,71^{*}$ \\
\hline Rult6- & I & 37,7 & --- \\
\hline Rult6- & J & 87,7 & --- \\
\hline
\end{tabular}

\begin{tabular}{|ll|c|c|}
\hline Arquivo & Rult (kN) & MQN Rult \\
\hline Rult8- & F & 2,3 & 4,71 \\
\hline Rult8- & G & 7,3 & $4,71^{*}$ \\
\hline Rult8- & H & 17,3 & $4,71^{*}$ \\
\hline Rult8- & I & 37,3 & --- \\
\hline Rult8- & J & 87,3 & --- \\
\hline
\end{tabular}

\begin{tabular}{|l|c|c|}
\hline Arquivo & Rult (kN) & MQN Rult \\
\hline Rult10- F & 92,6 & 4,71 \\
\hline Rult10- G & 97,6 & $4,71^{*}$ \\
\hline Rult10- H & 107,6 & $4,70^{*}$ \\
\hline Rult10- I & 127,6 & --- \\
\hline Rult10- J & 177,6 & --- \\
\hline
\end{tabular}

\begin{tabular}{|l|c|c|}
\hline Arquivo & Rult (kN) & MQN Rult \\
\hline Rult12- F & 43,4 & 4,71 \\
\hline Rult12- G & 48,4 & $4,71^{*}$ \\
\hline Rult12- H & 58,4 & $4,71^{*}$ \\
\hline Rult12- I & 78,4 & --- \\
\hline Rult12- J & 128,4 & --- \\
\hline
\end{tabular}

\begin{tabular}{|l|c|c|}
\hline Arquivo & Rult (kN) & MQN Rult \\
\hline Rult14- F & 1219,3 & 4,71 \\
\hline Rult14- G & 1224,3 & $4,72^{\star}$ \\
\hline Rult14- H & 1234,3 & $4,75^{\star}$ \\
\hline Rult14- I & 1254,3 & --- \\
\hline Rult14- J & 1304,3 & --- \\
\hline
\end{tabular}

(*) Análises CAPWAP com redução automática do quake da ponta. 
Tabela A-3 Resultados das Análises CAPWAP da Análise de Sensibilidade do parâmetro Damping (Q)

\begin{tabular}{|c|c|c|c|c|c|}
\hline \multicolumn{2}{|l|}{ D 1} & \multicolumn{3}{|c|}{ Rult 1 = } & $\mathrm{kN}$ \\
\hline Arquivo & $\mathrm{Js}$ & Jv & DJv & Match J & Dfor \\
\hline $\begin{array}{ll}J 1 & A\end{array}$ & 0,581 & 35 & 0,0 & 4,71 & 89,7 \\
\hline & 0,631 & 38 & 3,0 & 4,70 & 97,40 \\
\hline J1 & & 44 & 9,0 & 4,68 & 112,80 \\
\hline J1 D & 0,831 & 50 & 15,0 & 4,66 & 128,20 \\
\hline
\end{tabular}

\begin{tabular}{|c|c|c|c|c|c|}
\hline \multicolumn{2}{|l|}{ D 3} & \multicolumn{2}{|c|}{ Rult 3 = } & \multicolumn{2}{|c|}{$57,5 \mathrm{kN}$} \\
\hline Arquivo & $\mathrm{Js}$ & $\mathrm{JV}$ & DJv & Match J & Dfor \\
\hline \begin{tabular}{|l|l|}
$J 3$ & $A$ \\
\end{tabular} & 0,581 & $\overline{33,41}$ & 0,0 & 4,71 & 82,1 \\
\hline $\begin{array}{ll}J 3 & B\end{array}$ & 0,631 & 36,28 & 2,9 & 4,70 & 82,10 \\
\hline J3 & 0,73 & 42,0 & 8,6 & 4,68 & 103,00 \\
\hline D & 0,831 & 47,78 & 14,4 & $4,67^{*}$ & 117,10 \\
\hline
\end{tabular}

\begin{tabular}{|c|c|c|c|c|c|}
\hline \multicolumn{2}{|l|}{ D 5} & \multicolumn{2}{|c|}{ Rult $5=$} & \multicolumn{2}{|c|}{$81,9 \quad \mathrm{kN}$} \\
\hline Arquivo & $\mathrm{Js}$ & $\mathrm{Jv}$ & DJV & Match J & Dfor \\
\hline $\begin{array}{ll}\text { J5 } & A \\
\end{array}$ & 0,581 & 47,58 & 0,0 & 4,71 & 115,6 \\
\hline & 0,631 & 51,68 & 4,1 & 4,69 & 125,40 \\
\hline J5 & & 59,87 & 12,3 & $4,68^{*}$ & 144,80 \\
\hline J5 & 0,831 & 68,06 & 20,5 & $-\ldots$ & ---- \\
\hline
\end{tabular}

\begin{tabular}{|c|c|c|c|c|c|}
\hline \multicolumn{2}{|l|}{ D 7} & \multicolumn{2}{|c|}{ Rult $7=$} & 0 & N \\
\hline Arquivo & $\mathrm{Js}$ & $\mathrm{Jv}$ & DJv & Match J & Dfor \\
\hline $\begin{array}{|ll|}J 7 & A \\
\end{array}$ & 0,581 & 0 & 0,0 & 4,71 & 0 \\
\hline J7 & 0,631 & 0 & 0,0 & 4,71 & 0,00 \\
\hline J7 & 0,731 & 0 & 0,0 & 4,71 & 0,00 \\
\hline J7 & 0,831 & 0 & 0,0 & - & \\
\hline
\end{tabular}

\begin{tabular}{|c|c|c|c|c|c|}
\hline \multicolumn{2}{|l|}{ D 9} & \multicolumn{4}{|c|}{ Rult 9 $=58,1 \mathrm{kN}$} \\
\hline Arquivo & Js & $\mathrm{Jv}$ & DJv & Match J & Dfor \\
\hline $\begin{array}{ll}J 9 & A \\
\end{array}$ & $\overline{0,581}$ & 33,76 & $\overline{0,0}$ & 4,71 & 79,4 \\
\hline & 0,631 & 36,66 & 2,9 & $4,69^{\star}$ & 86,20 \\
\hline J9 & 0,731 & 42,47 & 8,7 & $4,66^{*}$ & 99,60 \\
\hline D & 0,831 & 48,28 & 14,5 & --- & $-\cdots$ \\
\hline
\end{tabular}

\begin{tabular}{|c|c|c|c|c|c|}
\hline \multicolumn{2}{|l|}{ D 11} & \multicolumn{2}{|c|}{ Rult 11= } & \multicolumn{2}{|c|}{$84,3 \quad \mathrm{kN}$} \\
\hline Arquivo & Js & $\mathrm{Jv}$ & DJv & Match J & Dfor \\
\hline $\mathrm{J} 11$ A & 0,581 & 48,98 & 0,0 & 4,71 & 131,5 \\
\hline J11 B & 0,631 & 53,19 & 4,2 & 4,68 & 142,60 \\
\hline J11 C & & 61,62 & 12,6 & 4,62 & 164,50 \\
\hline J11 D & 0,831 & 70,05 & 21,1 & --- & --- \\
\hline
\end{tabular}

\begin{tabular}{|c|c|c|c|c|c|}
\hline \multicolumn{2}{|l|}{ D 13} & \multicolumn{2}{|c|}{ Rult $13=$} & 5.6 & $\mathrm{NN}$ \\
\hline Arquivo & Js & JV & DJv & Match J & Dfor \\
\hline$J 13 A$ & 0,581 & 3,254 & 0,0 & 4,71 & 8,71 \\
\hline J13 B & 0,631 & 3,534 & 0,3 & 4,71 & 9,50 \\
\hline J13 C & 0,731 & 4,094 & 0,8 & 4,71 & 10,80 \\
\hline J13 D & 0,831 & 4,654 & 1,4 & $\overline{----}$ & ---- \\
\hline
\end{tabular}

\begin{tabular}{|c|c|c|c|c|c|}
\hline \multicolumn{2}{|l|}{ D 2} & \multicolumn{3}{|c|}{ Rult $2=38,2$} & $\mathrm{kN}$ \\
\hline Arquivo & $\mathrm{Js}$ & Jv & DJv & Match J & Dfor \\
\hline & 0,581 & 22,19 & $\overline{0,0}$ & 4,71 & 55,4 \\
\hline$\sqrt{\mathrm{J} 2}$ & $\overline{0,631}$ & 24,1 & 1,9 & 4,70 & 60,20 \\
\hline $\mathrm{J} 2$ & & 27,92 & 5,7 & 4,69 & 69,60 \\
\hline $\mathrm{J} 2$ & 0,831 & 31,74 & 9,6 & 4,67 & 79,10 \\
\hline
\end{tabular}

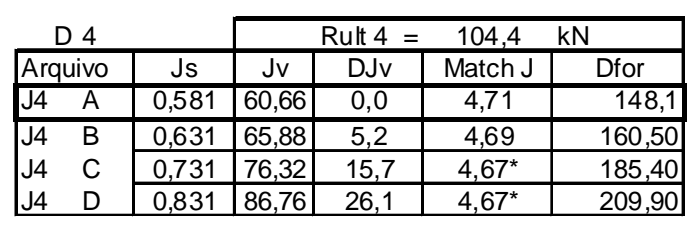

\begin{tabular}{|c|c|c|c|c|c|}
\hline \multicolumn{2}{|l|}{ D 6} & \multicolumn{3}{|c|}{ Rult $6=$} & $\mathrm{kN}$ \\
\hline Arquivo & $\mathrm{Js}$ & Jv & DJv & Match J & Dfor \\
\hline \begin{tabular}{|ll}
$J 6$ & $A$ \\
\end{tabular} & 0,581 & 1,6 & 0,0 & 4,71 & 3,8 \\
\hline$\sqrt{6} 6$ & 0,631 & 1,7 & 0,1 & 4,71 & 4,00 \\
\hline J6 & & 2,0 & 0,4 & 4,71 & 4,70 \\
\hline J6 & 0,831 & $\overline{2,2}$ & 0,7 & ---- & ---- \\
\hline
\end{tabular}

\begin{tabular}{|c|c|c|c|c|c|}
\hline \multicolumn{2}{|l|}{ D 8} & \multicolumn{3}{|c|}{ Rult 8 = } & $\mathrm{kN}$ \\
\hline Arquivo & $\mathrm{Js}$ & $\mathrm{Jv}$ & DJv & Match J & Dfor \\
\hline$\sqrt{\mathrm{J} 8} \mathrm{~A}$ & 0,581 & 1,34 & $\overline{0,0}$ & 4,71 & 3 \\
\hline J8 & 0,631 & 1,45 & $\overline{0,1}$ & 4,71 & 3,20 \\
\hline J8 & 0,731 & 1,68 & 0,3 & 4,71 & 3,70 \\
\hline J8 & 0,831 & 1,91 & 0,6 & $-\cdots$ & -..- \\
\hline
\end{tabular}

\begin{tabular}{|c|c|c|c|c|c|}
\hline \multicolumn{2}{|l|}{ D 10} & \multicolumn{2}{|c|}{ Rult 10 } & 92,6 & $\overline{\mathrm{kN}}$ \\
\hline Arquivo & Js & JV & DJV & Match J & Dfor \\
\hline$J 10$ A & 0,581 & 53,8 & $\overline{0,0}$ & 4,71 & 141,5 \\
\hline $\mathrm{J10} B$ & 0,631 & 58,43 & 4,6 & $4,68^{*}$ & 152,30 \\
\hline J10 C & 0,731 & 67,69 & 13,9 & $4,62^{*}$ & 177,10 \\
\hline $\mathrm{J} 10 \mathrm{D}$ & 0,831 & 76,95 & 23,2 & $-\cdots$ & ---- \\
\hline
\end{tabular}

\begin{tabular}{|c|c|c|c|c|c|}
\hline \multicolumn{2}{|l|}{ D 12} & \multicolumn{3}{|c|}{ Rult $12=$} & $\mathrm{kN}$ \\
\hline Arquivo & Js & Jv & DJv & Match J & Dfor \\
\hline J12 A & 0,581 & 25,22 & $\overline{0,0}$ & 25 & 67,6 \\
\hline J12 B & 0,631 & 27,39 & $\overline{2,2}$ & $4,69^{*}$ & 73,50 \\
\hline J12 C & 0,731 & 31,73 & 6,5 & $4,67^{*}$ & 84,80 \\
\hline J12 D & 0,831 & 36.07 & 10,9 & 0 & \\
\hline
\end{tabular}

\begin{tabular}{|c|c|c|c|c|c|}
\hline \multicolumn{2}{|l|}{ D 14} & \multicolumn{4}{|c|}{ Rult 14 $=1219,3 \mathrm{kN}$} \\
\hline Arquivo & Js & $\mathrm{Jv}$ & DJv & $\overline{\text { Match J }}$ & Dfor \\
\hline $\mathrm{J} 14 \mathrm{~A}$ & 0,517 & $\overline{630,4}$ & 0,0 & 4,71 & 1675,5 \\
\hline J14 B & 0,567 & 691,3 & 61,0 & 4,72 & 1789,40 \\
\hline J14 C & 0,667 & 813,3 & 182,9 & 5,83 & 1997,50 \\
\hline J14 D & 0,767 & 935,2 & 304,8 & --- & ---- \\
\hline
\end{tabular}

$\left({ }^{*}\right)$ Análises CAPWAP com redução automática do quake da ponta. Dfor $=$ fator de damping viscoso adicional

$\mathrm{Jv}=$ Damping viscoso

$\mathrm{Js}=$ damping Smith 


\section{ANEXO B - Matrizes de Covariâncias para as Análises de Atualização Bayesiana}

Tabela B-1 Matriz de covariâncias para Rult com $d=1,0 \mathrm{~m}, L_{S}=2,0 \mathrm{~m}$, e $\sigma^{2}=$ $0,25(\mathbf{k N})^{2}$.

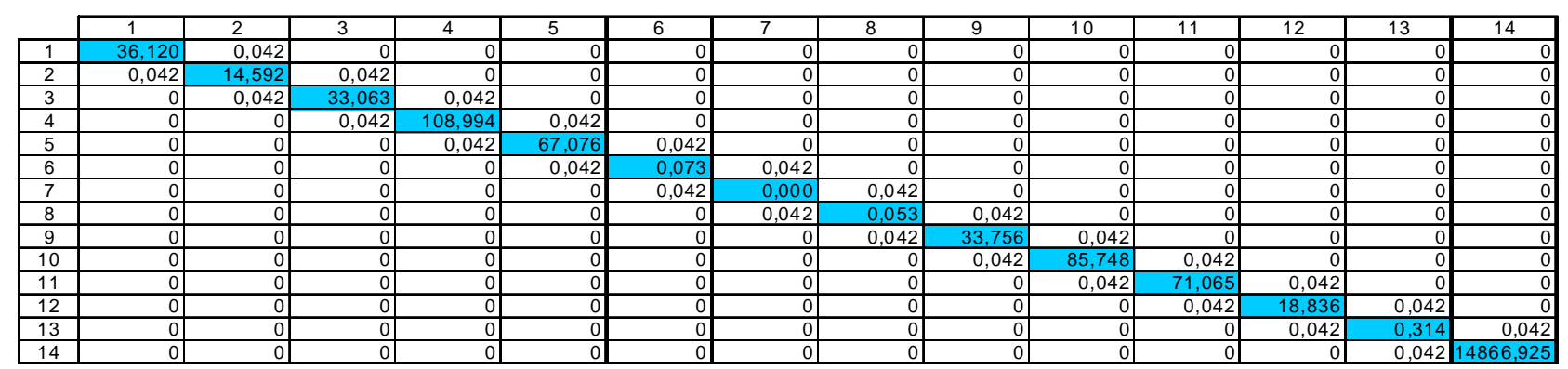

Tabela B-2 Matriz de covariâncias para Quake com $d=1,0 \mathrm{~m}, L_{S}=2,0 \mathrm{~m}$, e $\sigma^{2}=$ $0,25(\mathbf{k N})^{2}$.

\begin{tabular}{|c|c|c|c|c|c|c|c|c|c|c|c|c|c|c|}
\hline & 1 & 2 & 3 & 4 & 5 & 6 & 7 & 8 & 9 & 10 & 11 & 12 & 13 & 14 \\
\hline 1 & 0,025 & 0,042 & 0 & 0 & 0 & 0 & 0 & 0 & 0 & 0 & 0 & 0 & 0 & 0 \\
\hline 2 & 0,042 & 0,025 & 0,042 & 0 & 0 & 0 & 0 & 0 & 0 & 0 & 0 & 0 & 0 & 0 \\
\hline 3 & 0 & 0,042 & 0,025 & 0,042 & 0 & 0 & 0 & 0 & 0 & 0 & 0 & 0 & 0 & 0 \\
\hline 4 & 0 & 0 & 0,042 & 0,025 & 0,042 & 0 & 0 & 0 & 0 & 0 & 0 & 0 & 0 & 0 \\
\hline 5 & 0 & 0 & 0 & 0,042 & 0,025 & 0,042 & 0 & 0 & 0 & 0 & 0 & 0 & 0 & 0 \\
\hline 6 & 0 & 0 & 0 & 0 & 0,042 & 0,025 & 0,042 & 0 & 0 & 0 & 0 & 0 & 0 & 0 \\
\hline 7 & 0 & 0 & 0 & 0 & 0 & 0,042 & 0,025 & 0,042 & 0 & 0 & 0 & 0 & 0 & 0 \\
\hline 8 & 0 & 0 & 0 & 0 & 0 & 0 & 0,042 & 0,025 & 0,042 & 0 & 0 & 0 & 0 & 0 \\
\hline 9 & 0 & 0 & 0 & 0 & 0 & 0 & 0 & 0,042 & 0,025 & 0,042 & 0 & 0 & 0 & 0 \\
\hline 10 & 0 & 0 & 0 & 0 & 0 & 0 & 0 & 0 & 0,042 & 0,025 & 0,042 & 0 & 0 & 0 \\
\hline 11 & 0 & 0 & 0 & 0 & 0 & 0 & 0 & 0 & 0 & 0,042 & 0,025 & 0,042 & 0 & 0 \\
\hline 12 & 0 & 0 & 0 & 0 & 0 & 0 & 0 & 0 & 0 & 0 & 0,042 & 0,025 & 0,042 & 0 \\
\hline 13 & 0 & 0 & 0 & 0 & 0 & 0 & 0 & 0 & 0 & 0 & 0 & 0,042 & 0,025 & 0,042 \\
\hline 14 & 0 & 0 & 0 & 0 & 0 & 0 & 0 & 0 & 0 & 0 & 0 & 0 & 0,042 & 2,408 \\
\hline
\end{tabular}

Tabela B-3 Matriz de covariâncias para Damping com $d=1,0 \mathrm{~m}, L_{S}=2,0 \mathrm{~m}$, e $\sigma^{2}=$ $0,25(\mathbf{k N})^{2}$.

\begin{tabular}{|c|c|c|c|c|c|c|c|c|c|c|c|c|c|c|}
\hline & 1 & 2 & 3 & 4 & 5 & 6 & 7 & 8 & 9 & 10 & 11 & 12 & 13 & 14 \\
\hline 1 & 0,0034 & 0,0417 & 0 & 0 & 0 & 0 & 0 & 0 & 0 & 0 & 0 & 0 & 0 & 0 \\
\hline 2 & 0,0417 & 0,0034 & 0,0417 & 0 & 0 & 0 & 0 & 0 & 0 & 0 & 0 & 0 & 0 & 0 \\
\hline 3 & 0 & 0,0417 & 0,003 & 0,0417 & 0 & 0 & 0 & 0 & 0 & 0 & 0 & 0 & 0 & \\
\hline 4 & 0 & 0 & 0,0417 & 0,0034 & 0,0417 & 0 & 0 & 0 & 0 & 0 & 0 & 0 & 0 & 0 \\
\hline 5 & 0 & 0 & 0 & 0,0417 & 0,0034 & 0,0417 & 0 & 0 & 0 & 0 & 0 & 0 & 0 & 0 \\
\hline 6 & 0 & 0 & 0 & 0 & 0,0417 & 0,0034 & 0,0417 & 0 & 0 & 0 & 0 & 0 & 0 & 0 \\
\hline 7 & 0 & 0 & 0 & 0 & 0 & 0,0417 & 0,0034 & 0,0417 & 0 & 0 & 0 & 0 & 0 & 0 \\
\hline 8 & 0 & 0 & 0 & 0 & 0 & 0 & 0,0417 & 0,0034 & 0,0417 & 0 & 0 & 0 & 0 & 0 \\
\hline 9 & 0 & 0 & 0 & 0 & 0 & 0 & 0 & 0,0417 & 0,0034 & 0,0417 & 0 & 0 & 0 & 0 \\
\hline$\frac{5}{10}$ & 0 & 0 & 0 & 0 & 0 & 0 & 0 & 0 & 0,0417 & 0,0034 & 0,0417 & 0 & 0 & 0 \\
\hline 11 & 0 & 0 & 0 & 0 & 0 & 0 & 0 & 0 & 0 & 0,0417 & 0,0034 & 0,0417 & 0 & 0 \\
\hline 12 & 0 & 0 & 0 & 0 & 0 & 0 & 0 & 0 & 0 & 0 & 0,0417 & 0,0034 & 0,0417 & 0 \\
\hline 13 & 0 & 0 & $\mathrm{c}$ & 0 & 0 & 0 & 0 & 0 & 0 & 0 & 0 & 0,0417 & 0,0034 & 0,0417 \\
\hline 14 & 0 & 0 & 0 & 0 & 0 & 0 & 0 & 0 & 0 & 0 & 0 & 0 & 0,0417 & 0,0027 \\
\hline
\end{tabular}




\section{ANEXO C - Resultados da Atualização Bayesiana e das Análises CAPWAP de Confirmação}

Tabela C-1 Parâmetros de Smith atualizados para uma Análise Uniforme e Pontual com COVerro $=5 \%, L_{S}=2,0 \mathrm{~m}$ e $\sigma^{2}=0,25(\mathrm{kN})^{2}$

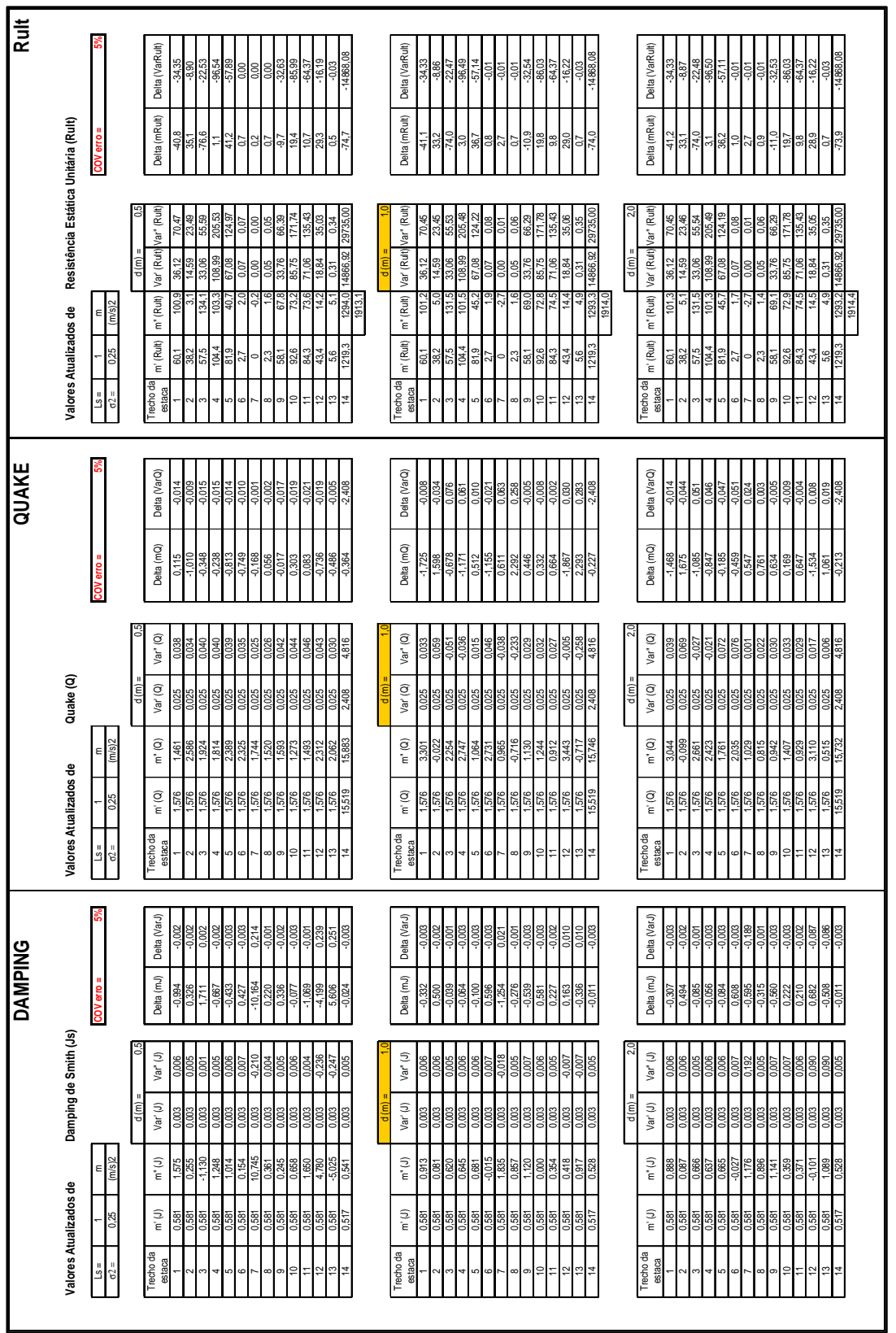


Tabela C-2 Parâmetros de Smith atualizados para uma Análise Uniforme com COVerro $=10 \%, L_{S}=2,0 \mathrm{~m}$ e $\sigma^{2}=0,25(\mathrm{kN})^{2}$

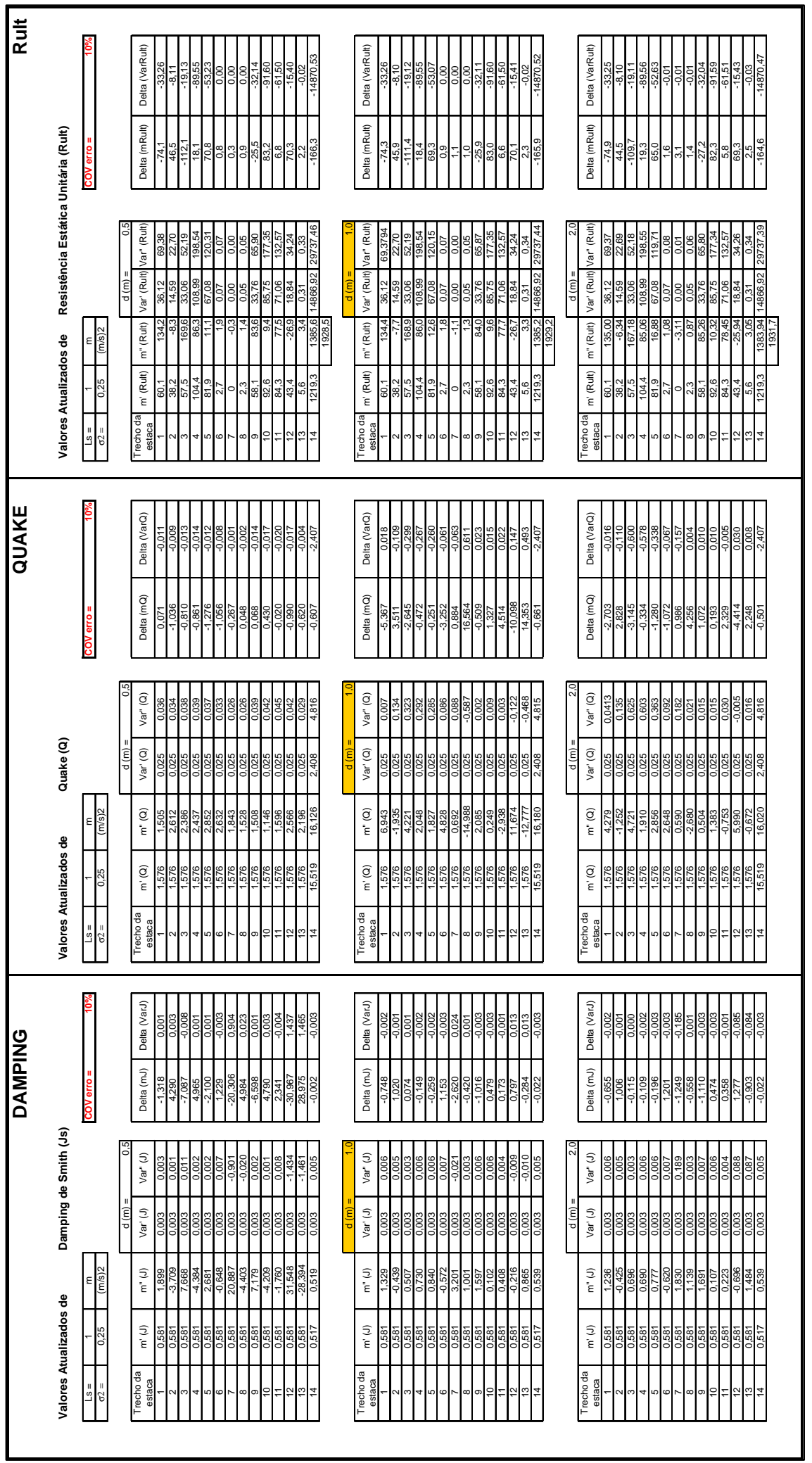


Tabela C-3 Parâmetros de Smith atualizados para uma Análise Uniforme com COVerro $=15 \%, L_{S}=2,0 \mathrm{~m}$ e $\sigma^{2}=0,25(\mathrm{kN})^{2}$

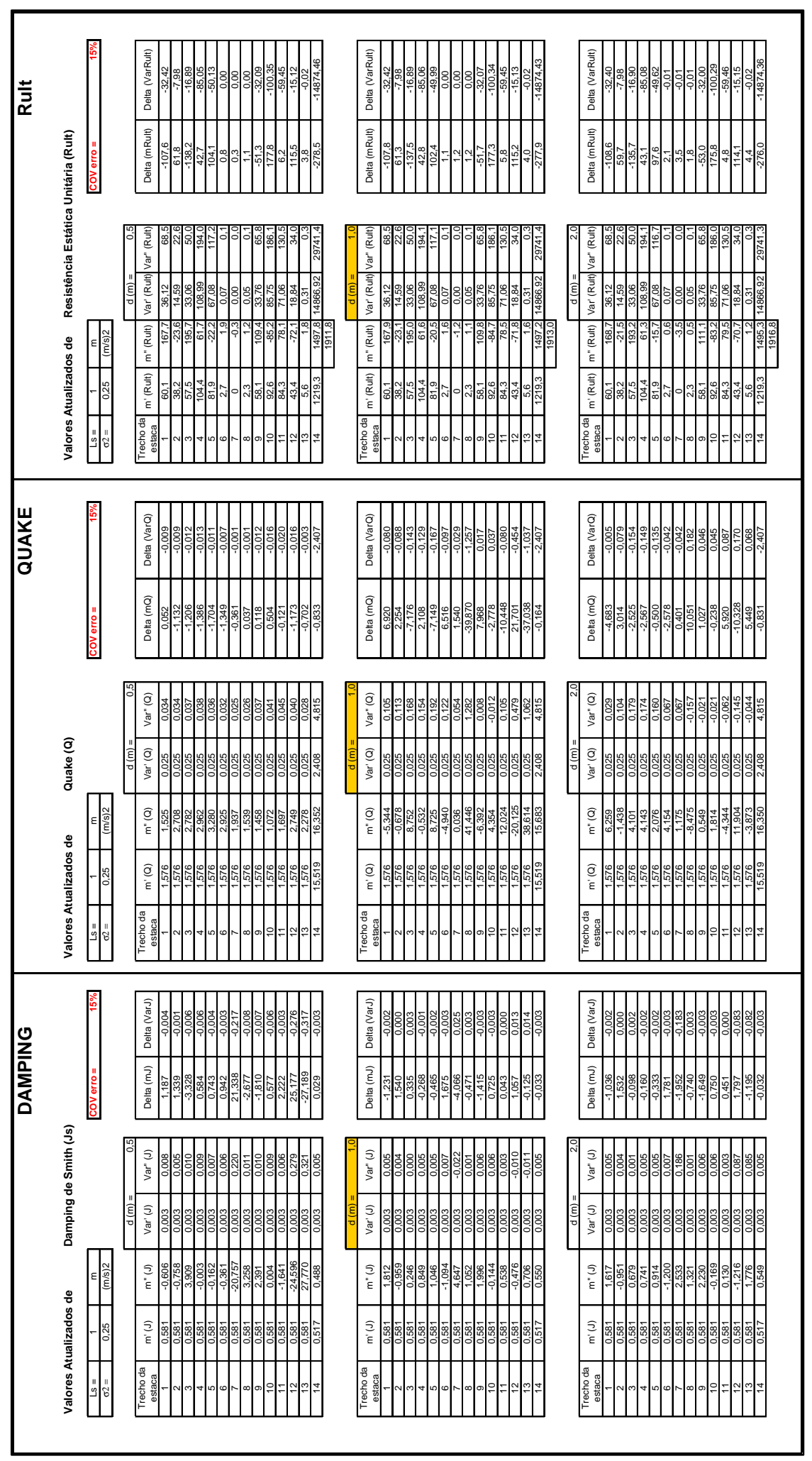


Tabela C-4 Parâmetros de Smith atualizados para uma Análise Uniforme com COVerro $=20 \%, L_{S}=2,0 \mathrm{~m}$ e $\sigma^{2}=0,25(\mathrm{kN})^{2}$

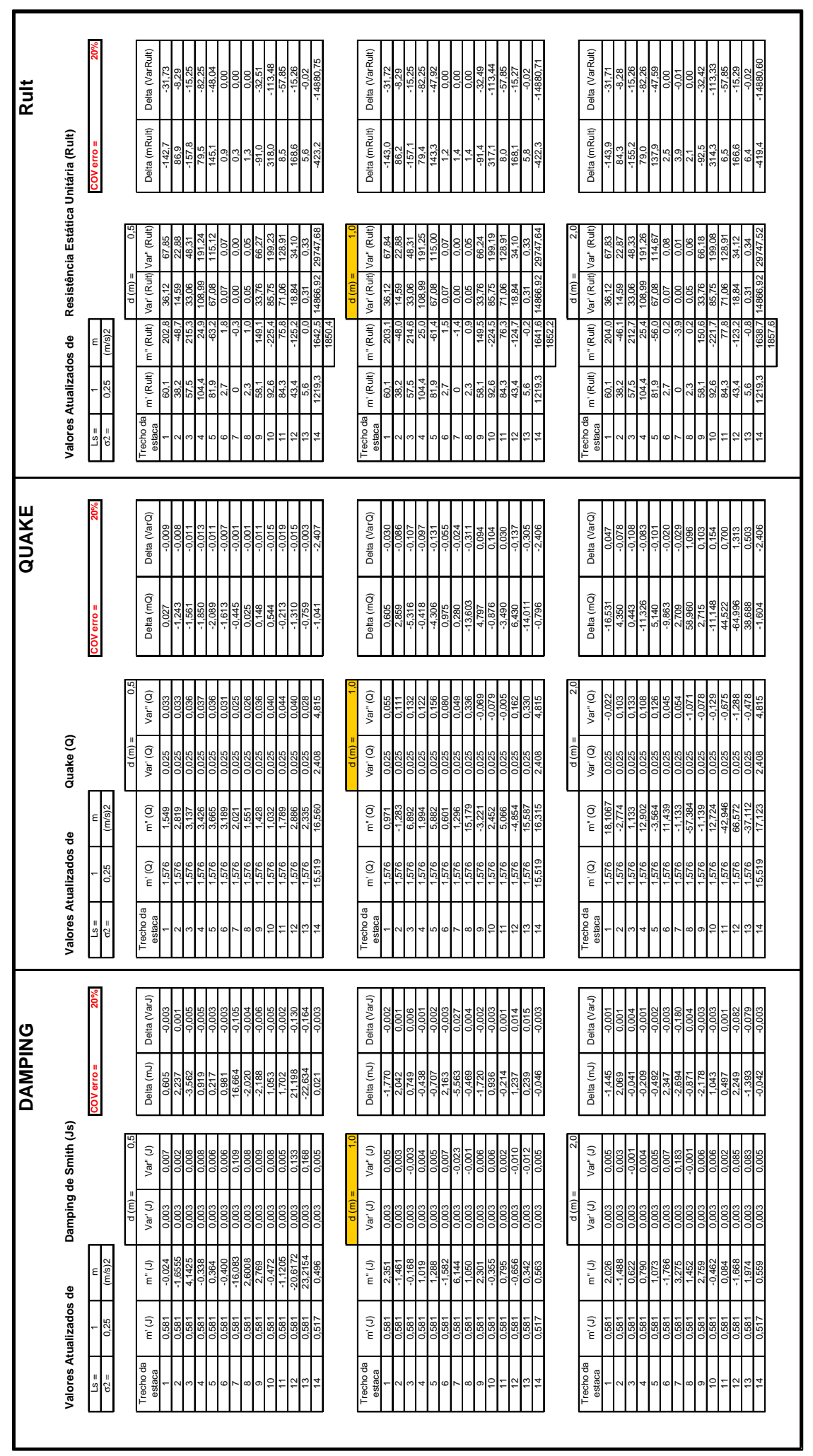


Tabela C-5 Parâmetros de Smith atualizados para uma Análise Pontual com COVerro $=10 \%, L_{S}=2,0 \mathrm{~m}$ e $\sigma^{2}=0,25(\mathrm{kN})^{2}$

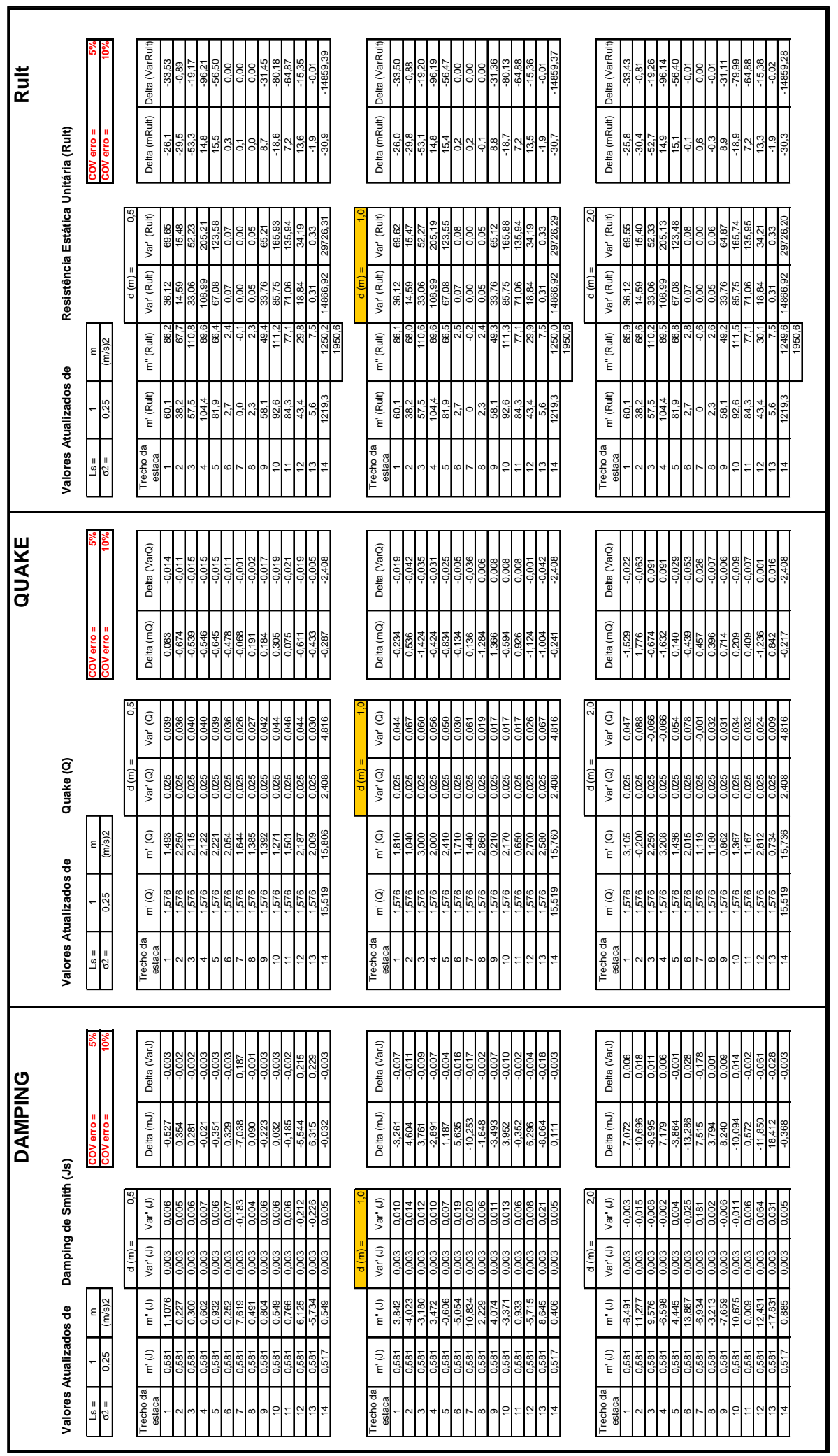


Tabela C-6 Parâmetros de Smith atualizados para uma Análise Pontual com COVerro $=15 \%, L_{S}=2,0 \mathrm{me} \sigma^{2}=0,25(\mathrm{kN})^{2}$

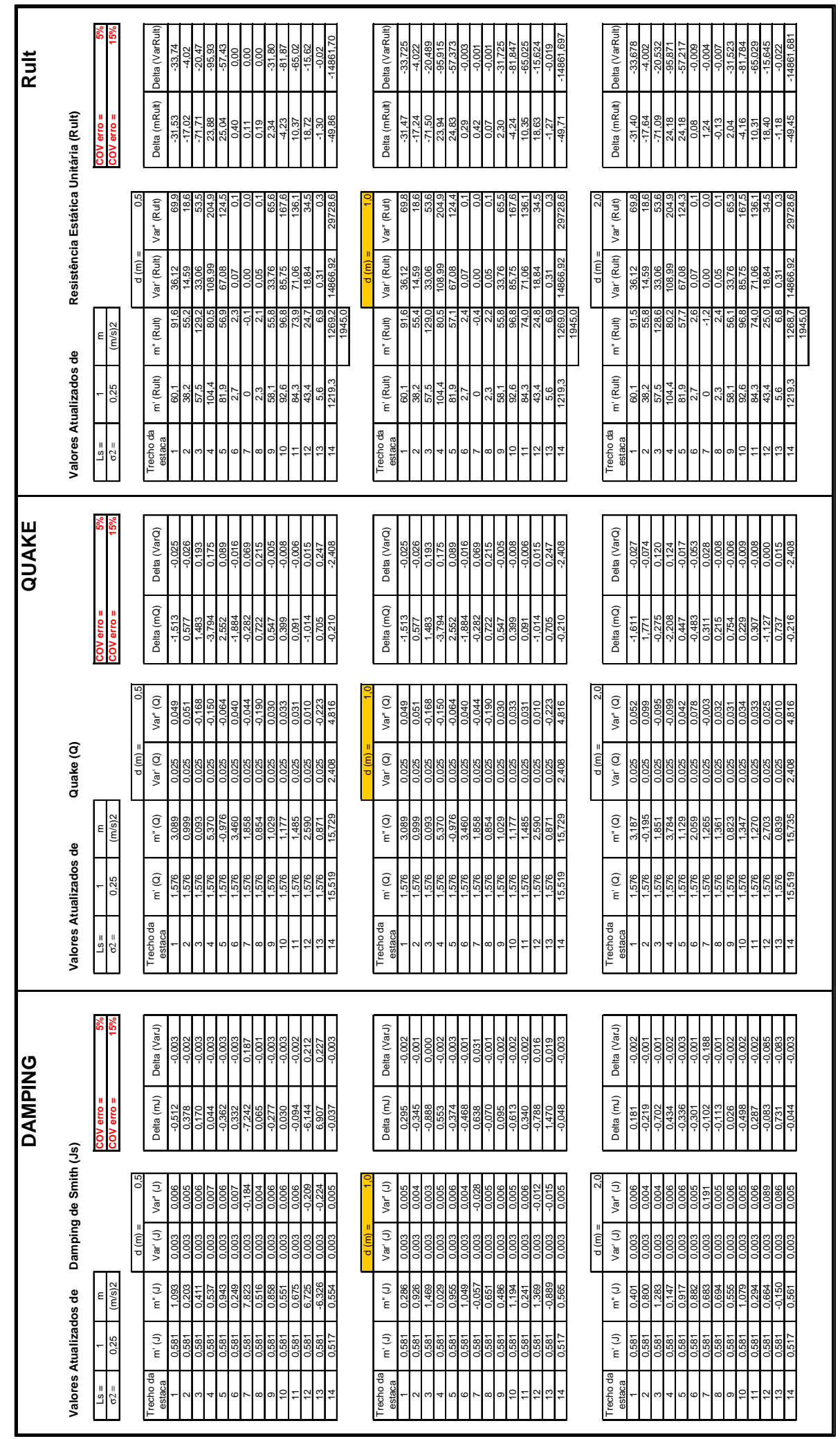


Tabela C-7 Parâmetros de Smith atualizados para uma Análise Pontual com COVerro $=20 \%, L_{S}=2,0 \mathrm{me} \sigma^{2}=0,25(\mathrm{kN})^{2}$

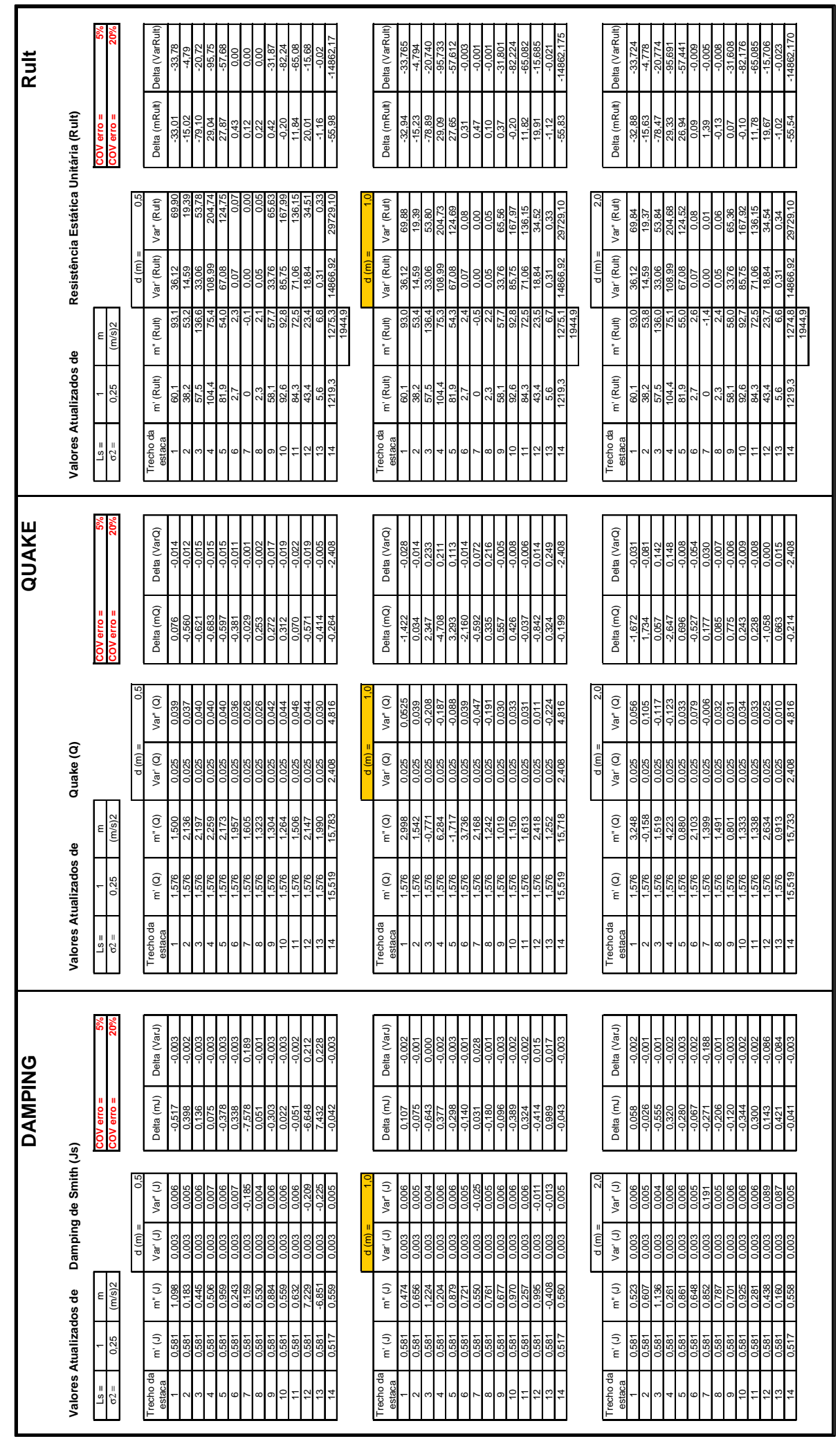


Tabela C-8 Valores atualizados de quake $(\mathrm{mm}), \operatorname{com} d=1,0 \mathrm{~m}, L_{S}=2,0 \mathrm{~m}$, e $\sigma^{2}=0,25$ $(\mathbf{k N})^{2}$ e valores utilizados nas análises CAPWAP ${ }^{\circledR}$

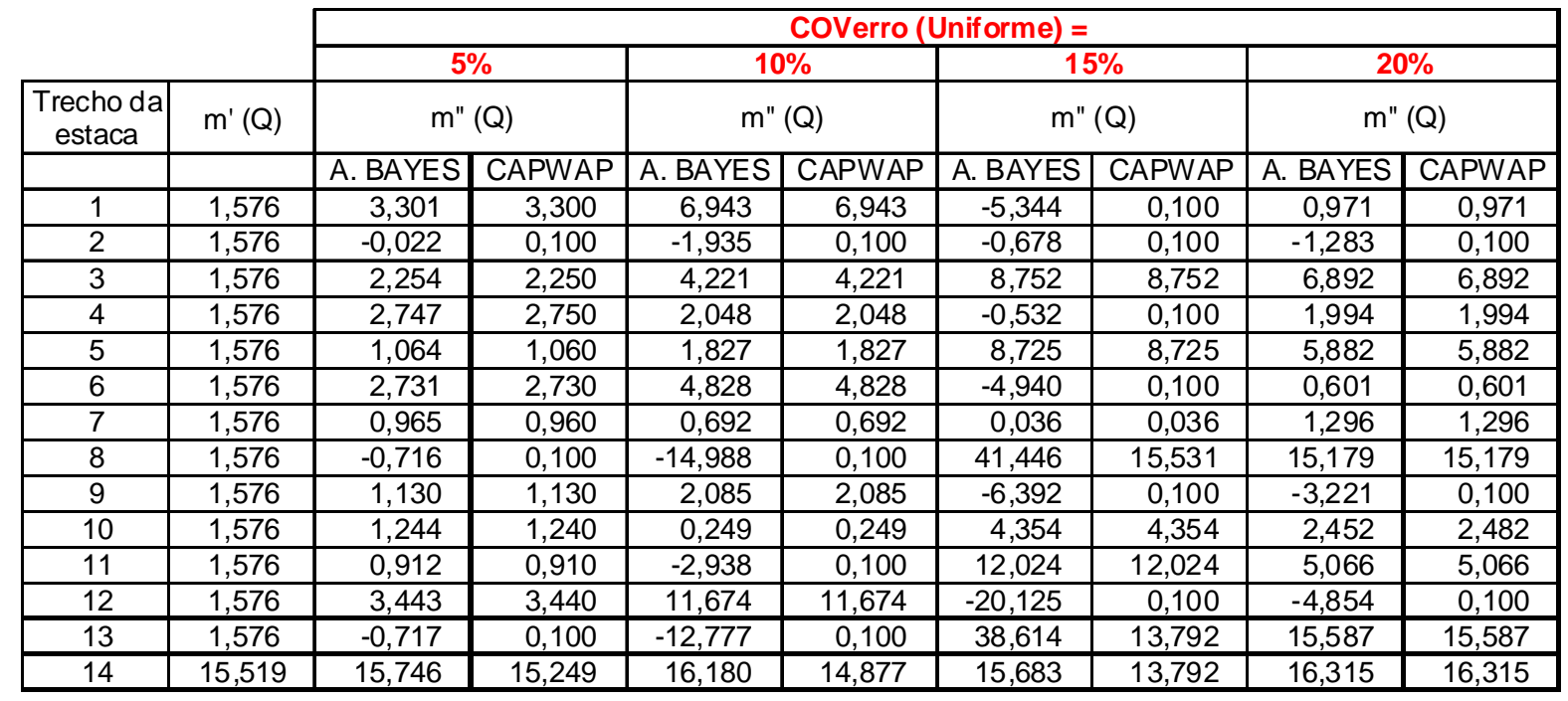

\begin{tabular}{|c|c|c|c|c|c|c|c|c|c|}
\hline & \multicolumn{8}{|c|}{ COVerro (Pontual) $=$} \\
\hline & & \multicolumn{2}{|c|}{$5 \%$} & \multicolumn{2}{|c|}{$10 \%$} & \multicolumn{2}{|l|}{$15 \%$} & \multicolumn{2}{|l|}{$20 \%$} \\
\hline \multirow{2}{*}{$\begin{array}{c}\text { Trecho da } \\
\text { estaca }\end{array}$} & \multirow{2}{*}{ m' (Js) } & \multicolumn{2}{|c|}{ m" (Q) } & \multicolumn{2}{|c|}{ m" (Q) } & \multicolumn{2}{|c|}{ m" (Q) } & \multicolumn{2}{|c|}{ m" (Q) } \\
\hline & & A. BAYES & CAPWAP & A. BAYES & CAPWAP & A. BAYES & CAPWAP & A. BAYES & CAPWAP \\
\hline 1 & 1,576 & 3,301 & 3,300 & 3,166 & 3,166 & 3,089 & 3,089 & 2,998 & 2,998 \\
\hline 2 & 1,576 & $-0,022$ & 0,100 & 1,040 & 0,435 & 0,999 & 0,999 & 1,542 & 1,542 \\
\hline 3 & 1,576 & 2,254 & 2,250 & 3,000 & 1,130 & 0,093 & 0,093 & $-0,771$ & 0,100 \\
\hline 4 & 1,576 & 2,747 & 2,750 & 2,000 & 4,210 & 5,370 & 5,370 & 6,284 & 6,284 \\
\hline 5 & 1,576 & 1,064 & 1,060 & 2,410 & 0,100 & $-0,976$ & 0,100 & $-1,717$ & 0,100 \\
\hline 6 & 1,576 & 2,731 & 2,730 & 1,710 & 3,104 & 3,460 & 3,460 & 3,736 & 3,736 \\
\hline 7 & 1,576 & 0,965 & 0,960 & 1,440 & 1,463 & 1,858 & 1,858 & 2,168 & 2,168 \\
\hline 8 & 1,576 & $-0,716$ & 0,100 & 2,860 & 0,331 & 0,854 & 0,854 & 1,242 & 1,242 \\
\hline 9 & 1,576 & 1,130 & 1,130 & 0,210 & 1,059 & 1,029 & 1,029 & 1,019 & 1,019 \\
\hline 10 & 1,576 & 1,244 & 1,240 & 2,170 & 1,209 & 1,177 & 1,177 & 1,150 & 1,150 \\
\hline 11 & 1,576 & 0,912 & 0,910 & 0,650 & 1,301 & 1,485 & 1,485 & 1,613 & 1,613 \\
\hline 12 & 1,576 & 3,443 & 3,440 & 2,700 & 2,842 & 2,590 & 2,590 & 2,418 & 2,418 \\
\hline 13 & 1,576 & $-0,717$ & 0,100 & 2,580 & 0,344 & 0,871 & 0,871 & 1,252 & 1,252 \\
\hline 14 & 15,519 & 15,746 & 15,249 & 15,760 & 14,619 & 15,729 & 14,628 & 15,718 & 14,851 \\
\hline
\end{tabular}


Tabela C-9 Valores atualizados de damping Smith $(\mathrm{s} / \mathrm{m}), \operatorname{com} d=1,0 \mathrm{~m}, L_{S}=2,0 \mathrm{~m}$, e $\sigma^{2}=0,25(\mathbf{k N})^{2}$ e valores utilizados nas análises CAPWAP ${ }^{\circledR}$

\begin{tabular}{|c|c|c|c|c|c|c|c|c|c|}
\hline & \multicolumn{8}{|c|}{ COVerro (Uniforme) = } \\
\hline & & \multicolumn{2}{|c|}{$5 \%$} & \multicolumn{2}{|c|}{$10 \%$} & \multicolumn{2}{|l|}{$15 \%$} & \multicolumn{2}{|l|}{$20 \%$} \\
\hline \multirow{2}{*}{$\begin{array}{c}\text { Trecho da } \\
\text { estaca }\end{array}$} & \multirow{2}{*}{ m' (Js) } & \multicolumn{2}{|c|}{ m" (Js) } & \multicolumn{2}{|c|}{ m" (Js) } & \multicolumn{2}{|c|}{ m" (Js) } & \multicolumn{2}{|c|}{ m" (Js) } \\
\hline & & A. BAYES & CAPWAP & A. BAYES & CAPWAP & A. BAYES & CAPWAP & A. BAYES & CAPWAP \\
\hline 1 & 0,581 & 0,913 & 0,864 & 1,329 & 1,329 & 1,812 & 1,812 & 2,351 & 2,351 \\
\hline 2 & 0,581 & 0,081 & 0,078 & $-0,439$ & 0,160 & $-0,959$ & 0,160 & $-1,461$ & 0,160 \\
\hline 3 & 0,581 & 0,620 & 0,658 & 0,507 & 0,507 & 0,246 & 0,246 & $-0,168$ & 0,080 \\
\hline 4 & 0,581 & 0,645 & 0,627 & 0,730 & 0,730 & 0,849 & 0,849 & 1,019 & 1,019 \\
\hline 5 & 0,581 & 0,681 & 0,645 & 0,840 & 0,840 & 1,046 & 1,080 & 1,288 & 1,380 \\
\hline 6 & 0,581 & $-0,015$ & 0,076 & $-0,572$ & 0,102 & $-1,094$ & 0,097 & $-1,582$ & 0,102 \\
\hline 7 & 0,581 & 1,835 & 1,693 & 3,201 & 3,280 & 4,647 & 2,080 & 6,144 & 6,180 \\
\hline 8 & 0,581 & 0,857 & 0,916 & 1,001 & 1,003 & 1,052 & 1,041 & 1,050 & 0,080 \\
\hline 9 & 0,581 & 1,120 & 1,114 & 1,597 & 1,597 & 1,996 & 1,996 & 2,301 & 2,307 \\
\hline 10 & 0,581 & 0,000 & 0,359 & 0,102 & 0,099 & $-0,144$ & 0,160 & $-0,355$ & 0,160 \\
\hline 11 & 0,581 & 0,354 & 0,357 & 0,408 & 0,408 & 0,538 & 0,538 & 0,795 & 0,795 \\
\hline 12 & 0,581 & 0,418 & 0,071 & $-0,216$ & 0,160 & $-0,476$ & 0,160 & $-0,656$ & 0,160 \\
\hline 13 & 0,581 & 0,917 & 0,887 & 0,865 & 0,853 & 0,706 & 0,815 & 0,342 & 0,099 \\
\hline 14 & 0,517 & 0,528 & 0,534 & 0,539 & 0,586 & 0,550 & 0,625 & 0,563 & 0,726 \\
\hline
\end{tabular}

\begin{tabular}{|c|c|c|c|c|c|c|c|c|c|}
\hline & \multicolumn{8}{|c|}{ COVerro (Pontual) $=$} \\
\hline & & \multicolumn{2}{|c|}{$5 \%$} & \multicolumn{2}{|c|}{$10 \%$} & \multicolumn{2}{|l|}{$15 \%$} & \multicolumn{2}{|l|}{$20 \%$} \\
\hline \multirow{2}{*}{$\begin{array}{c}\text { Trecho da } \\
\text { estaca }\end{array}$} & \multirow{2}{*}{ m' (Js) } & \multicolumn{2}{|c|}{ m" (Js) } & \multicolumn{2}{|c|}{ m" (Js) } & \multicolumn{2}{|c|}{ m" (Js) } & \multicolumn{2}{|c|}{ m" (Js) } \\
\hline & & A. BAYES & CAPWAP & A. BAYES & CAPWAP & A. BAYES & CAPWAP & A. BAYES & CAPWAP \\
\hline 1 & 0,581 & 0,913 & 0,864 & 3,842 & 3,842 & 0,286 & 0,286 & 0,474 & 0,431 \\
\hline 2 & 0,581 & 0,081 & 0,078 & $-4,023$ & 0,080 & 0,926 & 0,927 & 0,656 & 0,606 \\
\hline 3 & 0,581 & 0,620 & 0,658 & $-3,180$ & 0,080 & 1,469 & 1,469 & 1,224 & 1,154 \\
\hline 4 & 0,581 & 0,645 & 0,627 & 3,472 & 3,472 & 0,029 & 0,800 & 0,204 & 0,170 \\
\hline 5 & 0,581 & 0,681 & 0,645 & $-0,606$ & 0,080 & 0,955 & 0,954 & 0,879 & 0,821 \\
\hline 6 & 0,581 & $-0,015$ & 0,076 & $-5,054$ & 0,080 & 1,049 & 1,038 & 0,721 & 0,669 \\
\hline 7 & 0,581 & 1,835 & 1,693 & 10,834 & 1,080 & $-0,057$ & 0,160 & 0,550 & 0,504 \\
\hline 8 & 0,581 & 0,857 & 0,916 & 2,229 & 2,205 & 0,651 & 0,625 & 0,761 & 0,705 \\
\hline 9 & 0,581 & 1,120 & 1,114 & 4,074 & 4,074 & 0,486 & 0,485 & 0,677 & 0,626 \\
\hline 10 & 0,581 & 0,000 & 0,359 & $\begin{array}{ll}-3,371 \\
\end{array}$ & 0,080 & 1,194 & 1,195 & 0,970 & 0,909 \\
\hline 11 & 0,581 & 0,354 & 0,357 & 0,933 & 0,932 & 0,241 & 0,241 & 0,257 & 0,221 \\
\hline 12 & 0,581 & 0,418 & 0,071 & $-5,715$ & 0,080 & 1,369 & 1,368 & 0,995 & 0,933 \\
\hline 13 & 0,581 & 0,917 & 0,887 & 8,645 & 8,640 & $-0,889$ & 0,080 & $-0,408$ & 0,052 \\
\hline 14 & 0,517 & 0,528 & 0,534 & 0,406 & 0,437 & 0,565 & 0,608 & 0,560 & 0,560 \\
\hline
\end{tabular}


Tabela C-10 Valores atualizados de Resistência Estática última $(\mathrm{kN}), \operatorname{com} d=1,0 \mathrm{~m}, L_{S}$ $=2,0 \mathrm{~m}, \mathrm{e} \sigma^{2}=0,25(\mathrm{kN})^{2}$ e valores utilizados nas análises CAPWAP ${ }^{\circledR}$

\begin{tabular}{|c|c|c|c|c|c|c|c|c|c|}
\hline & \multicolumn{8}{|c|}{ COVerro (Uniforme) = } \\
\hline & & \multirow{2}{*}{\multicolumn{2}{|c|}{$\frac{5 \%}{\mathrm{~m} " \text { (Rult) }}$}} & \multirow{2}{*}{\multicolumn{2}{|c|}{$\begin{array}{c}10 \% \\
\text { m" (Rult) }\end{array}$}} & \multirow{2}{*}{\multicolumn{2}{|c|}{$\begin{array}{l}15 \% \\
\mathrm{~m}^{\prime \prime} \text { (Rult) }\end{array}$}} & \multirow{2}{*}{\multicolumn{2}{|c|}{$\begin{array}{l}20 \% \\
\text { m" (Rult) }\end{array}$}} \\
\hline \multirow{2}{*}{$\begin{array}{c}\text { Trecho da } \\
\text { estaca }\end{array}$} & \multirow{2}{*}{ m' (Rult) } & & & & & & & & \\
\hline & & A. BAYES & CAPWAP & A. BAYES & CAPWAP & A. BAYES & CAPWAP & A. BAYES & CAPWAP \\
\hline 1 & 60,1 & 101,2 & 103,4 & 134,4 & 134,4 & 167,9 & 167,9 & 203,1 & 203,1 \\
\hline 2 & 38,2 & 5,0 & 5,1 & $-7,7$ & 0,1 & $-23,1$ & 0,1 & $-48,0$ & 0,1 \\
\hline 3 & 57,5 & 131,5 & 134,4 & 168,9 & 168,9 & 195,0 & 195,0 & 214,6 & 215,3 \\
\hline 4 & 104,4 & 101,5 & 103,7 & 86,0 & 86,0 & 61,6 & 61,6 & 25,0 & 24,9 \\
\hline 5 & 81,9 & 45,2 & 46,0 & 12,6 & 12,6 & $-20,5$ & 0,1 & $-61,4$ & 0,1 \\
\hline 6 & 2,7 & 1,9 & 1,9 & 1,8 & 1,8 & 1,6 & 1,6 & 1,5 & 1,8 \\
\hline 7 & 0 & $-2,7$ & 0,1 & $-1,1$ & $\overline{0,1}$ & $-1,2$ & 0,1 & $-1,4$ & 0,1 \\
\hline 8 & 2,3 & 1,6 & 1,6 & 1,3 & 1,3 & 1,1 & 1,1 & 0,9 & 1,0 \\
\hline 9 & 58,1 & 69,0 & 70,4 & 84,0 & 84,0 & 109,8 & 109,8 & 149,5 & 149,1 \\
\hline 10 & 92,6 & 72,8 & 74,3 & 9,6 & 9,6 & $-84,7$ & 0,1 & $-224,5$ & 0,1 \\
\hline 11 & 84,3 & 74,5 & 76,1 & 77,7 & 77,7 & 78,5 & 78,5 & 76,3 & 75,8 \\
\hline 12 & 43,4 & 14,4 & 14,7 & $-26,7$ & 0,1 & $-71,8$ & 0,1 & $-124,7$ & 0,1 \\
\hline 13 & 5,6 & 4,9 & 5,1 & 3,3 & 3,3 & 1,6 & 1,4 & $-0,2$ & 0,0 \\
\hline 14 & 1219,3 & 1293,3 & 1279,7 & 1385,2 & 1273,6 & 1497,2 & 1316,7 & 1641,6 & 1274,1 \\
\hline
\end{tabular}

\begin{tabular}{|c|c|c|c|c|c|c|c|c|c|}
\hline & \multicolumn{8}{|c|}{ COVerro $($ Pontual $)=$} \\
\hline & & \multicolumn{2}{|c|}{$5 \%$} & \multirow{2}{*}{\multicolumn{2}{|c|}{$\begin{array}{c}10 \% \\
\mathrm{~m} " \text { (Rult) }\end{array}$}} & \multicolumn{2}{|l|}{$15 \%$} & \multicolumn{2}{|l|}{$20 \%$} \\
\hline \multirow{2}{*}{$\begin{array}{c}\text { Trecho da } \\
\text { estaca }\end{array}$} & \multirow{2}{*}{ m' (Rult) } & \multicolumn{2}{|c|}{ m" (Rult) } & & & \multicolumn{2}{|c|}{ m" (Rult) } & \multicolumn{2}{|c|}{ m" (Rult) } \\
\hline & & A. BAYES & CAPWAP & A. BAYES & CAPWAP & A. BAYES & CAPWAP & A. BAYES & CAPWAP \\
\hline 1 & 60,1 & 101,2 & 103,4 & 86,1 & 86,1 & 91,6 & 91,6 & 93,0 & 96,5 \\
\hline 2 & 38,2 & 5,0 & 5,1 & 68,0 & 68,0 & 55,4 & 55,4 & 53,4 & 55,4 \\
\hline 3 & 57,5 & 131,5 & 134,4 & 110,6 & 110,6 & 129,0 & 129,0 & 136,4 & 141,5 \\
\hline 4 & 104,4 & 101,5 & 103,7 & 89,6 & 89,6 & 80,5 & 80,5 & 75,3 & 78,1 \\
\hline 5 & 81,9 & 45,2 & 46,0 & 66,5 & 66,5 & 57,1 & 57,1 & 54,3 & 56,3 \\
\hline 6 & 2,7 & 1,9 & 1,9 & 2,5 & 2,5 & 2,4 & 2,4 & 2,4 & 2,5 \\
\hline 7 & 0 & $-2,7$ & 0,1 & $-0,2$ & 0,1 & $-0,4$ & 0,1 & $-0,5$ & 0,1 \\
\hline 8 & 2,3 & 1,6 & 1,6 & 2,4 & 2,4 & 2,2 & 2,2 & 2,2 & 2,3 \\
\hline 9 & 58,1 & 69,0 & 70,4 & 49,3 & 49,3 & 55,8 & 55,8 & 57,7 & 59,9 \\
\hline 10 & 92,6 & 72,8 & 74,3 & 111,3 & 111,3 & 96,8 & 96,8 & 92,8 & 96,3 \\
\hline 11 & 84,3 & 74,5 & 76,1 & 77,1 & 77,1 & 74,0 & 74,0 & 72,5 & 75,2 \\
\hline 12 & 43,4 & 14,4 & 14,7 & 29,9 & 29,9 & 24,8 & 24,8 & 23,5 & 24,4 \\
\hline 13 & 5,6 & 4,9 & 5,1 & 7,5 & 7,5 & 6,9 & 6,9 & 6,7 & 7,0 \\
\hline 14 & 1219,3 & 1293,3 & 1279,7 & 1250,0 & 1161,1 & 1269,0 & 1180,1 & 1275,1 & 1250,0 \\
\hline
\end{tabular}


Tabela C-11 Análises inicial CAPWAP ${ }^{\circledR}(\mathrm{MQN}=4,71)$

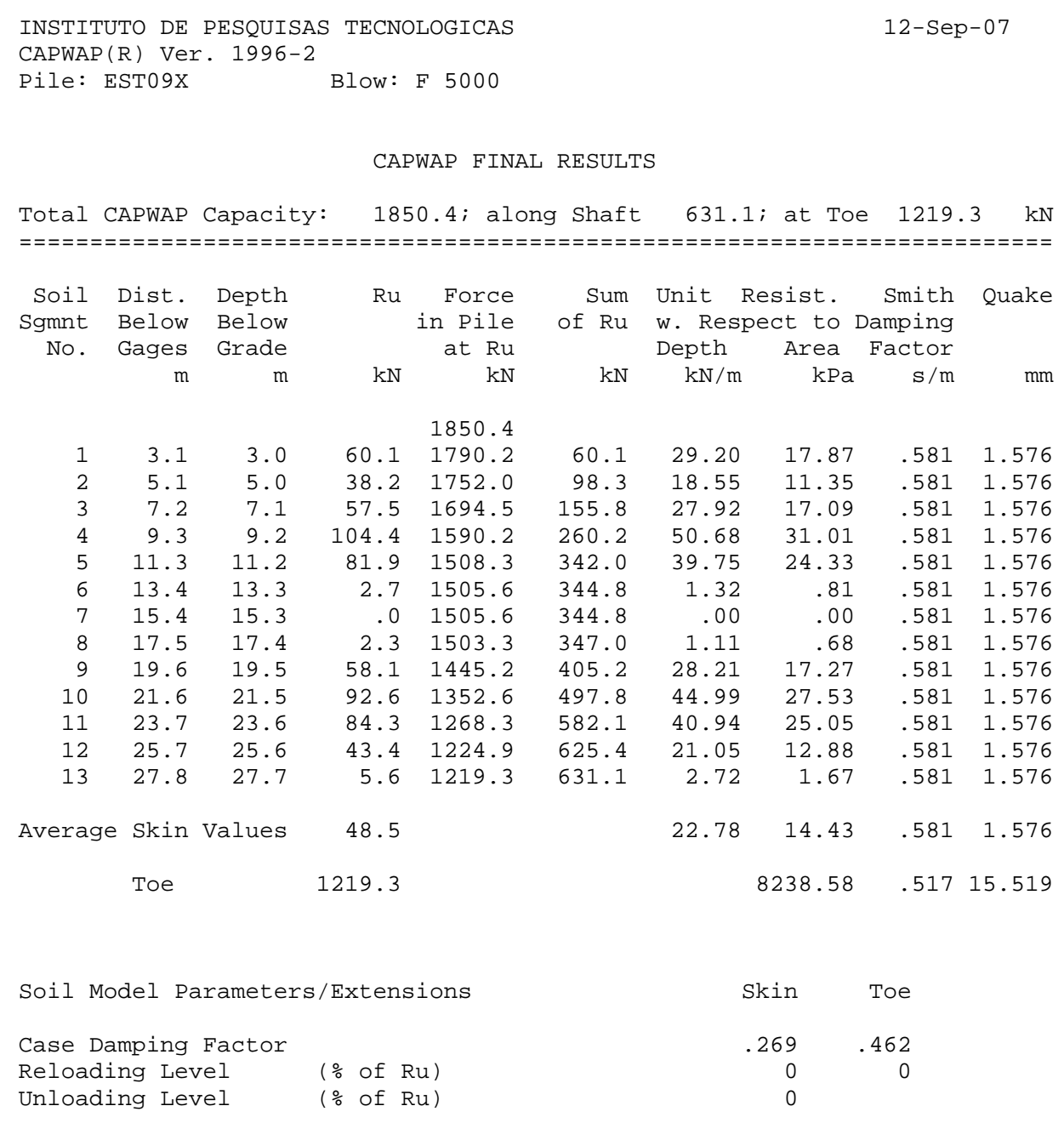


Tabela C-12 Análises CAPWAP ${ }^{\circledR}$ de confirmação com parâmetros de Smith atualizados para uma Análise Uniforme e Pontual com COVerro $=5 \%, L_{S}=2,0 \mathrm{~m} \mathrm{e}$ $\sigma^{2}=0,25(\mathrm{kN})^{2} d=1,0 \mathrm{~m}(\mathrm{MQN}=\mathbf{5 , 3 1})$

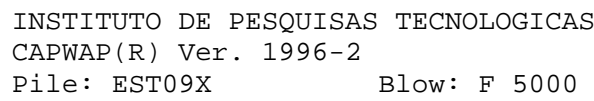

CAPWAP FINAL RESULTS

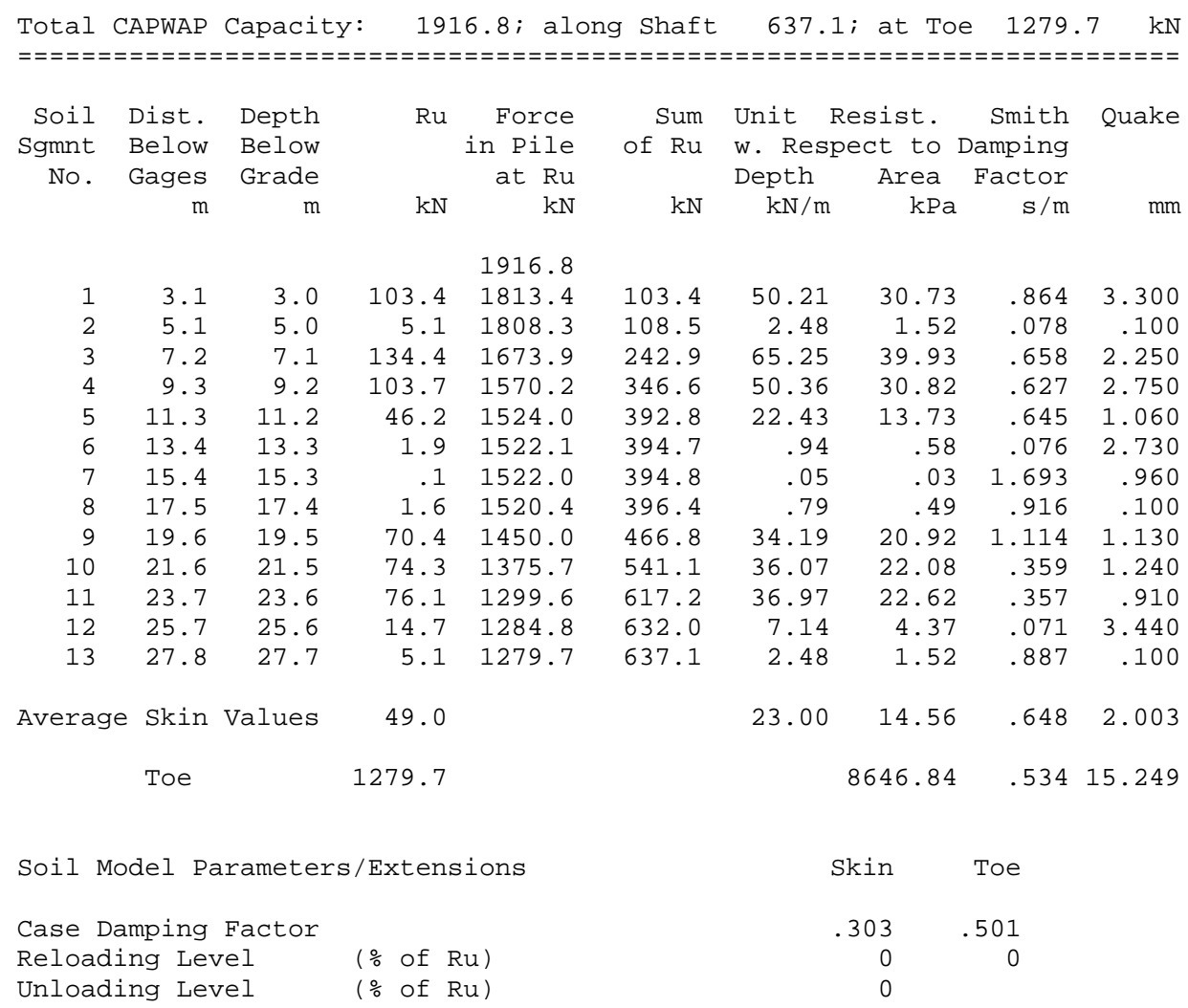


Tabela C-13 Análises CAPWAP ${ }^{\circledR}$ de confirmação com parâmetros de Smith atualizados para uma Análise Uniforme com COVerro $=10 \%, L_{S}=2,0 \mathrm{~m}$ e $\sigma^{2}=0,25$ $(\mathrm{kN})^{2} d=1,0 \mathrm{~m}(\mathrm{MQN}=\mathbf{5 , 9 1})$

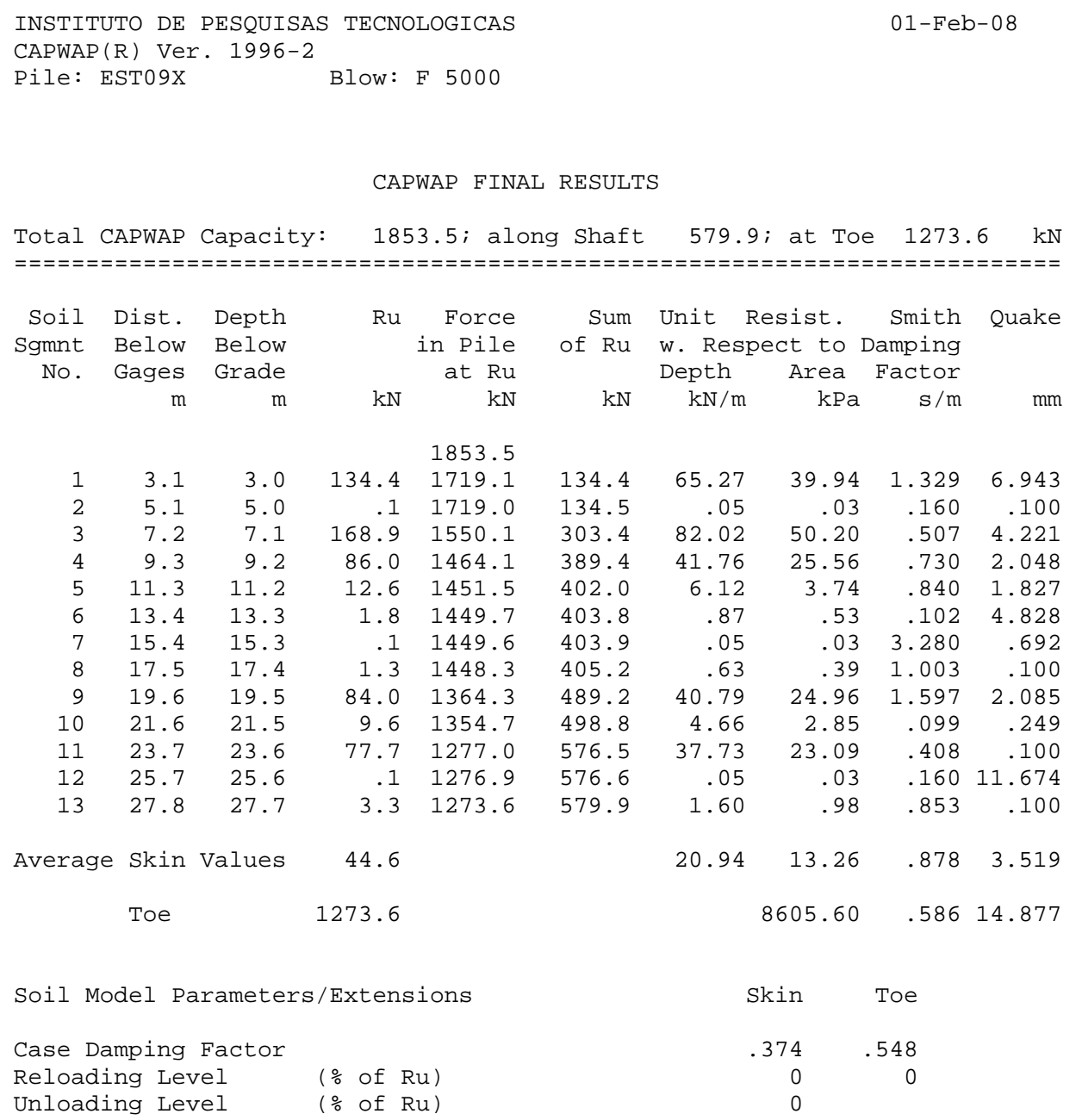


Tabela C-14 Análises CAPWAP ${ }^{\circledR}$ de confirmação com parâmetros de Smith atualizados para uma Análise Uniforme com COVerro $=15 \%, L_{S}=2,0 \mathrm{~m}$ e $\sigma^{2}=0,25$ $(\mathrm{kN})^{2} d=1,0 \mathrm{~m}(\mathrm{MQN}=\mathbf{8 , 3 4})$

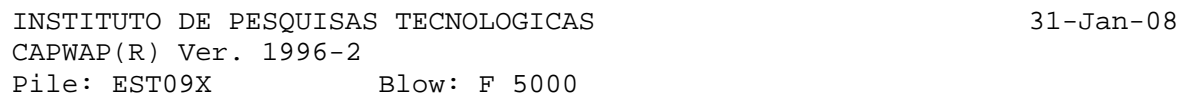

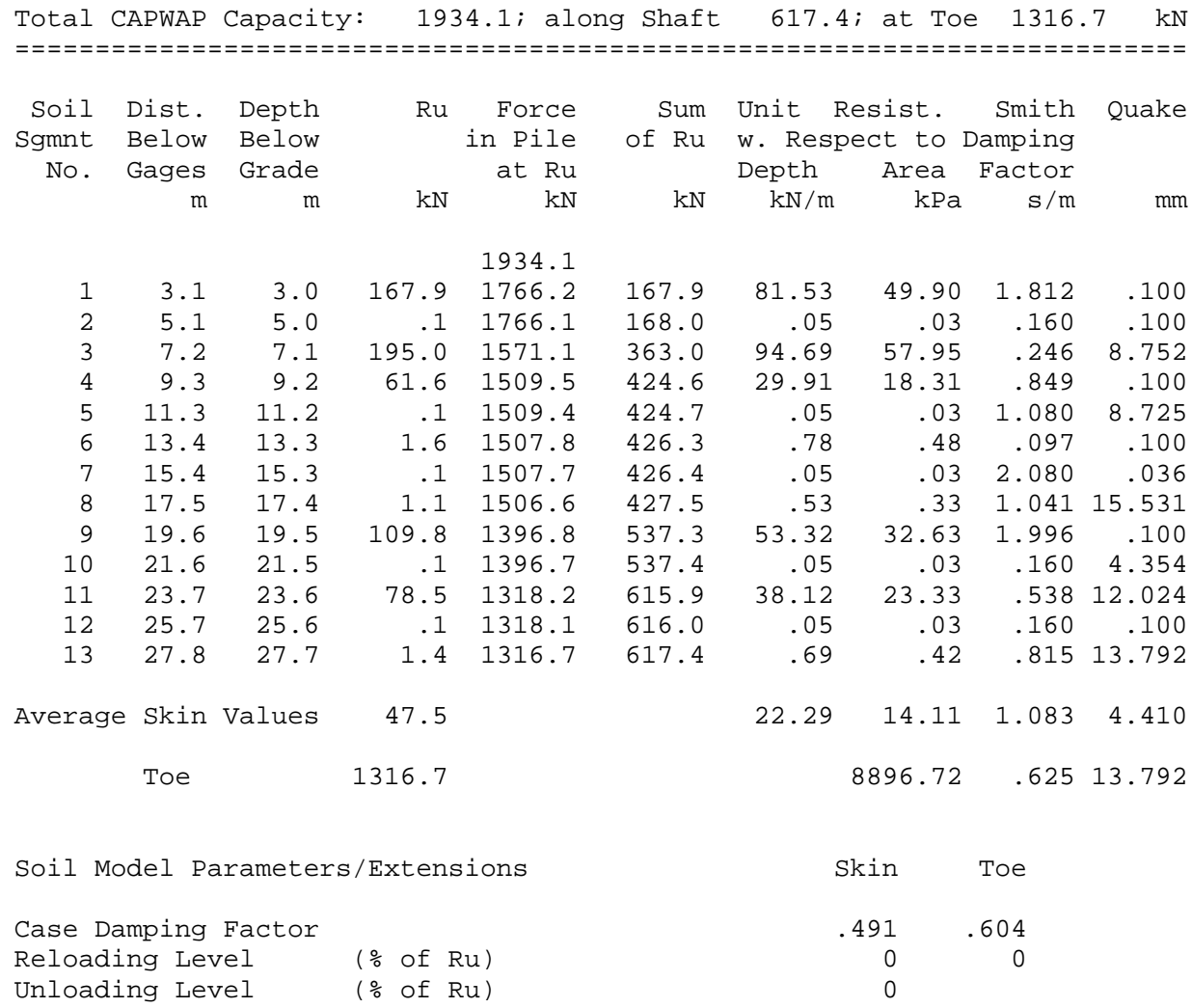


Tabela C-15 Análises CAPWAP ${ }^{\circledR}$ de confirmação com parâmetros de Smith atualizados para uma Análise Uniforme com COVerro $=20 \%, L_{S}=2,0 \mathrm{~m}$ e $\sigma^{2}=\mathbf{0 , 2 5}$ $(\mathrm{kN})^{2} d=1,0 \mathrm{~m}(\mathrm{MQN}=14,93)$

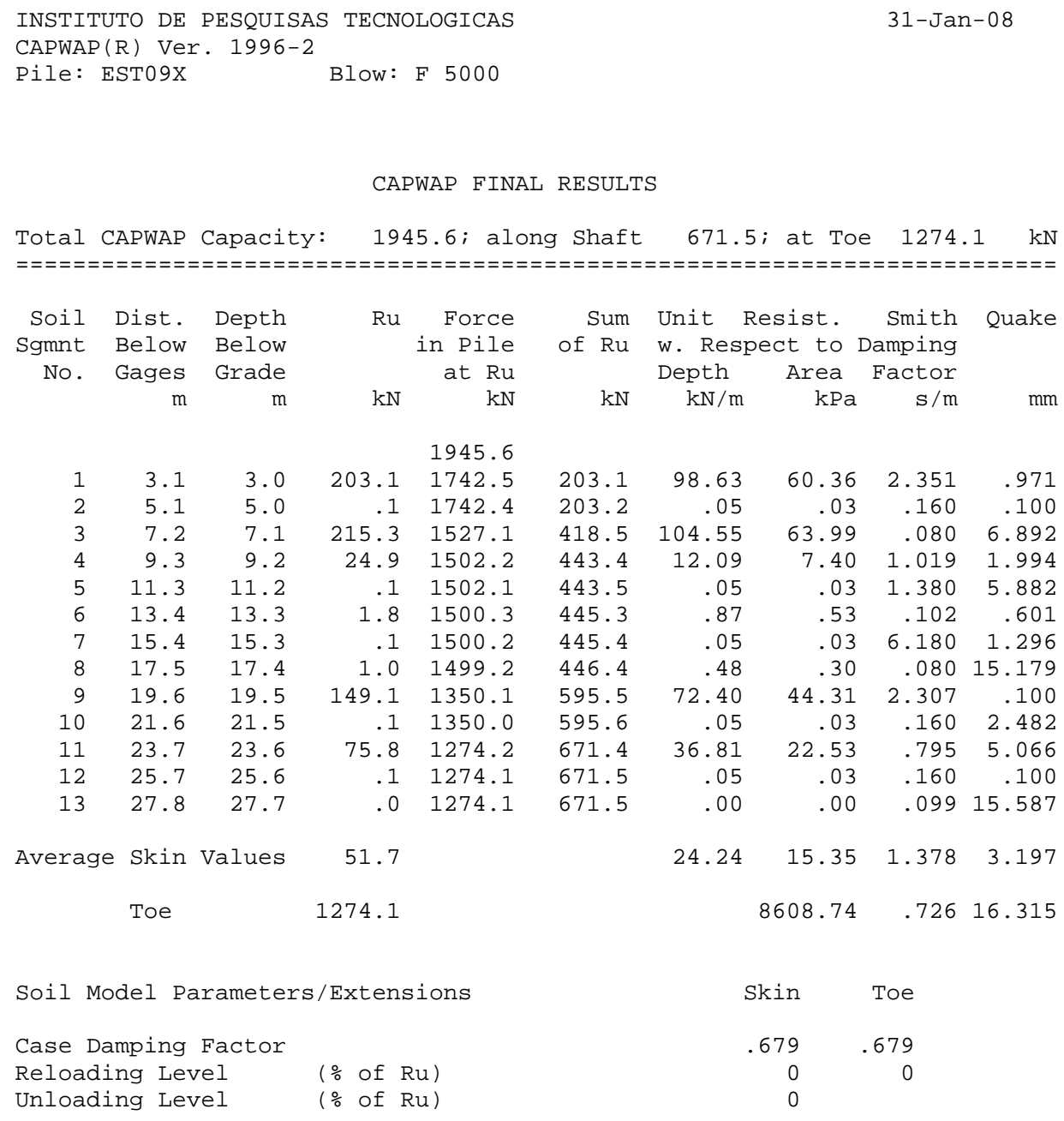


Tabela C-16 Análises CAPWAP ${ }^{\circledR}$ de confirmação com parâmetros de Smith atualizados para uma Análise Pontual com COVerro $=10 \%, L_{S}=2,0 \mathrm{~m}$ e $\sigma^{2}=\mathbf{0 , 2 5}$ $(\mathrm{kN})^{2} d=1,0 \mathrm{~m}(\mathrm{MQN}=10,12)$

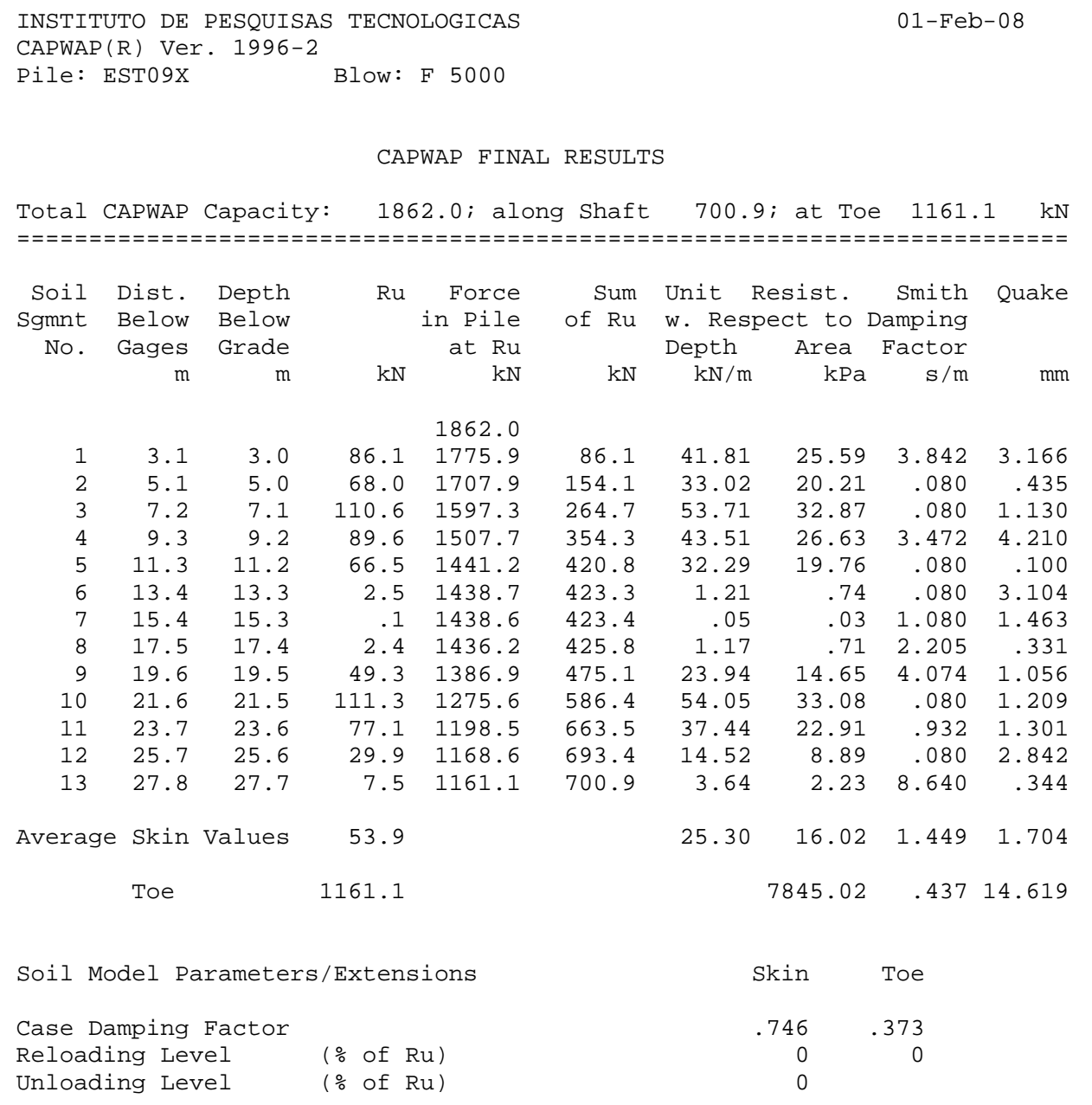


Tabela C-17 Análises CAPWAP ${ }^{\circledR}$ de confirmação com parâmetros de Smith atualizados para uma Análise Pontual com COVerro $=15 \%, L_{S}=2,0 \mathrm{~m}$ e $\sigma^{2}=0,25$ $(\mathrm{kN})^{2} d=1,0 \mathrm{~m}(\mathrm{MQN}=6,27)$

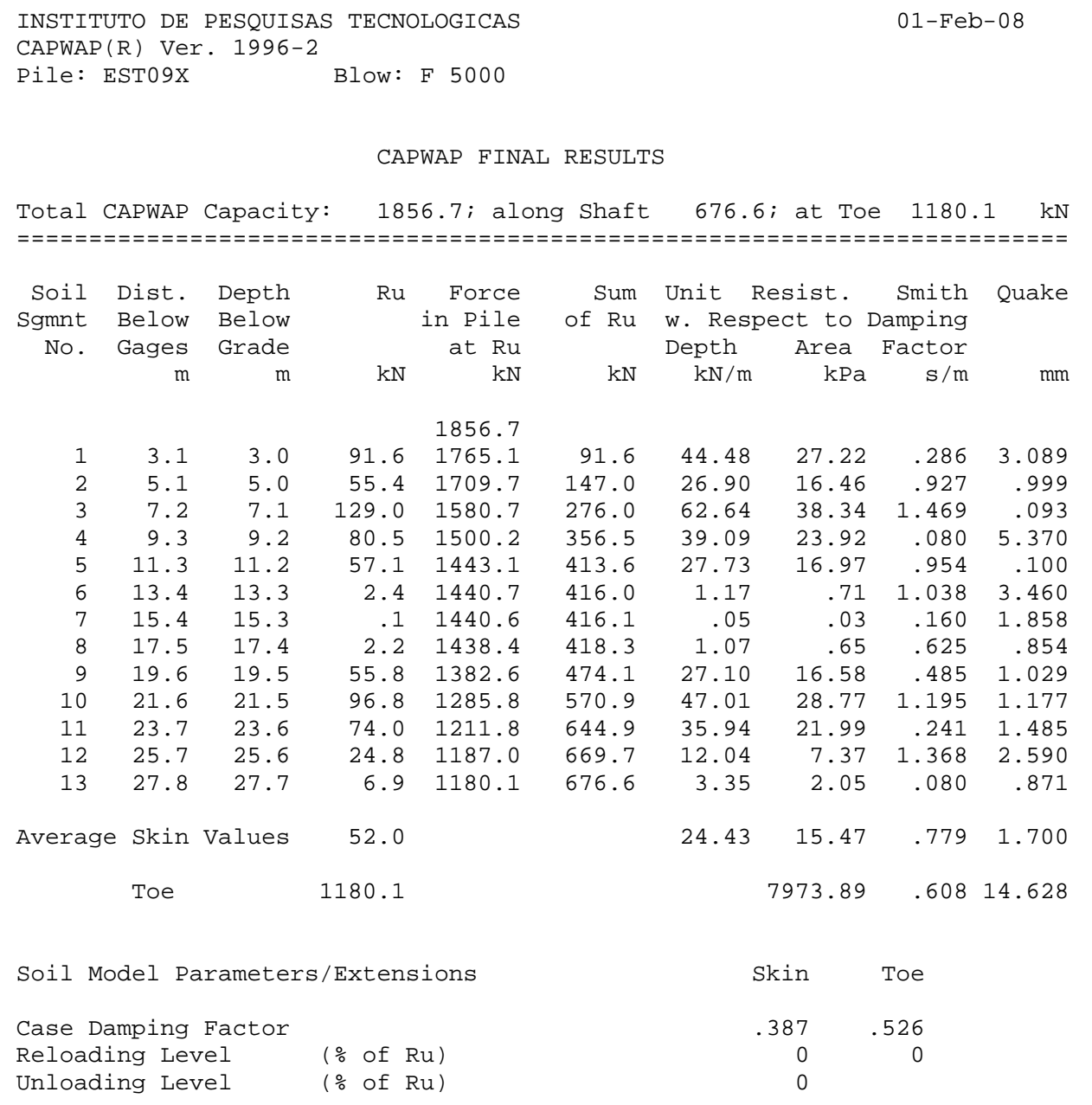


Tabela C-18 Análises CAPWAP ${ }^{\circledR}$ de confirmação com parâmetros de Smith atualizados para uma Análise Pontual com COVerro $=20 \%, L_{S}=2,0 \mathrm{~m}$ e $\sigma^{2}=\mathbf{0 , 2 5}$ $(\mathrm{kN})^{2} d=1,0 \mathrm{~m}(\mathrm{MQN}=5,68)$

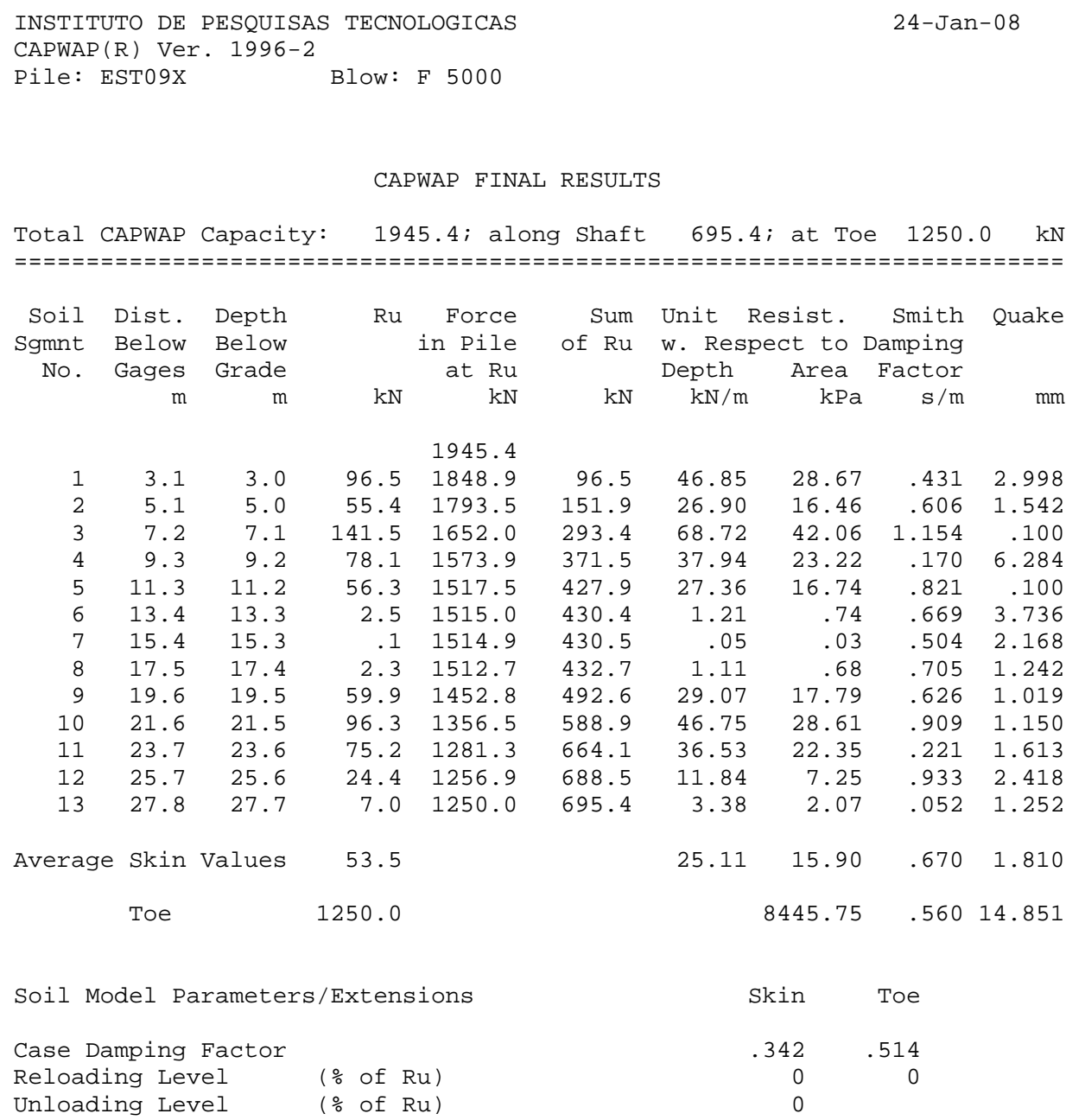




\section{ANEXOS D - Influência dos ‘outros' Parâmetros nas Análises CAPWAP}

O texto apresentado a continuação é uma tradução livre do Manual CAPWAP (1990).

\section{Variáveis do Modelo CAPWAP ${ }^{\circledR}$}

Uma estaca é divida em $\mathrm{N}_{\mathrm{p}}$ segmentos. $\mathrm{O}$ atrito lateral é discretizado em $\mathrm{N}_{\mathrm{s}}$ forças resistentes. Usualmente as forças de resistência lateral (atrito) são representadas a cada dois metros do trecho abaixo da superfície de solo. Uma força adicional representa o suporte de ponta da estaca.

Desse modo, com três variáveis desconhecidas para cada força resistente, existe um total de 3. $\left(N_{S}+1\right)$ incógnitas. Em alguns casos, os valores de quake lateral e damping Smith lateral tipo são iguais. Neste caso os valores de damping viscoso são proporcionais aos valores das resistências estáticas. Assim, existem $\mathrm{N}_{\mathrm{S}}+1$ incógnitas $\mathrm{R}_{\mathrm{ui}}$ valores e 2 incógnitas entre dampings e quakes, tem-se $\left(\mathrm{N}_{\mathrm{s}}+5\right)$.

A extensão do modelo de solo CAPWAP ${ }^{\circledR}$ e outras duas incógnitas para os quakes de descarregamento (unloading quakes) de fuste e de ponta, uma para o nível de descarregamento, duas para os níveis de ré-carregamento, três para a opção de damping de ponta, 'gap', e 'plug' (bucha). Quatro variáveis são disponíveis para damping radial, e mais uma opção incógnita para a análise de tensões residuais. O número total de incógnitas acumula, $\mathrm{N}_{\mathrm{s}}+18$.

As forças de resistência laterais podem ser diretamente determinadas a partir da análise da primeira porção do sinal entre o tempo de impacto e o tempo da primeira onda de retorno. As outras 17 incógnitas têm que ser determinadas em função da porção final do sinal analisada. A Tabela D.1 lista todas as variáveis e opções, suas unidades e alguns intervalos admitidos e recomendados para começar com as análises. 
Para maior explicação da utilização de cada uma das variáveis listadas abaixo, pode-se revisar o Manual CAPWAP.

Tabelas D-1 Variáveis CAPWAP ${ }^{\circledR}$, versão 1996-II (Unidades SI) (CAPWAP Manual, 1990)

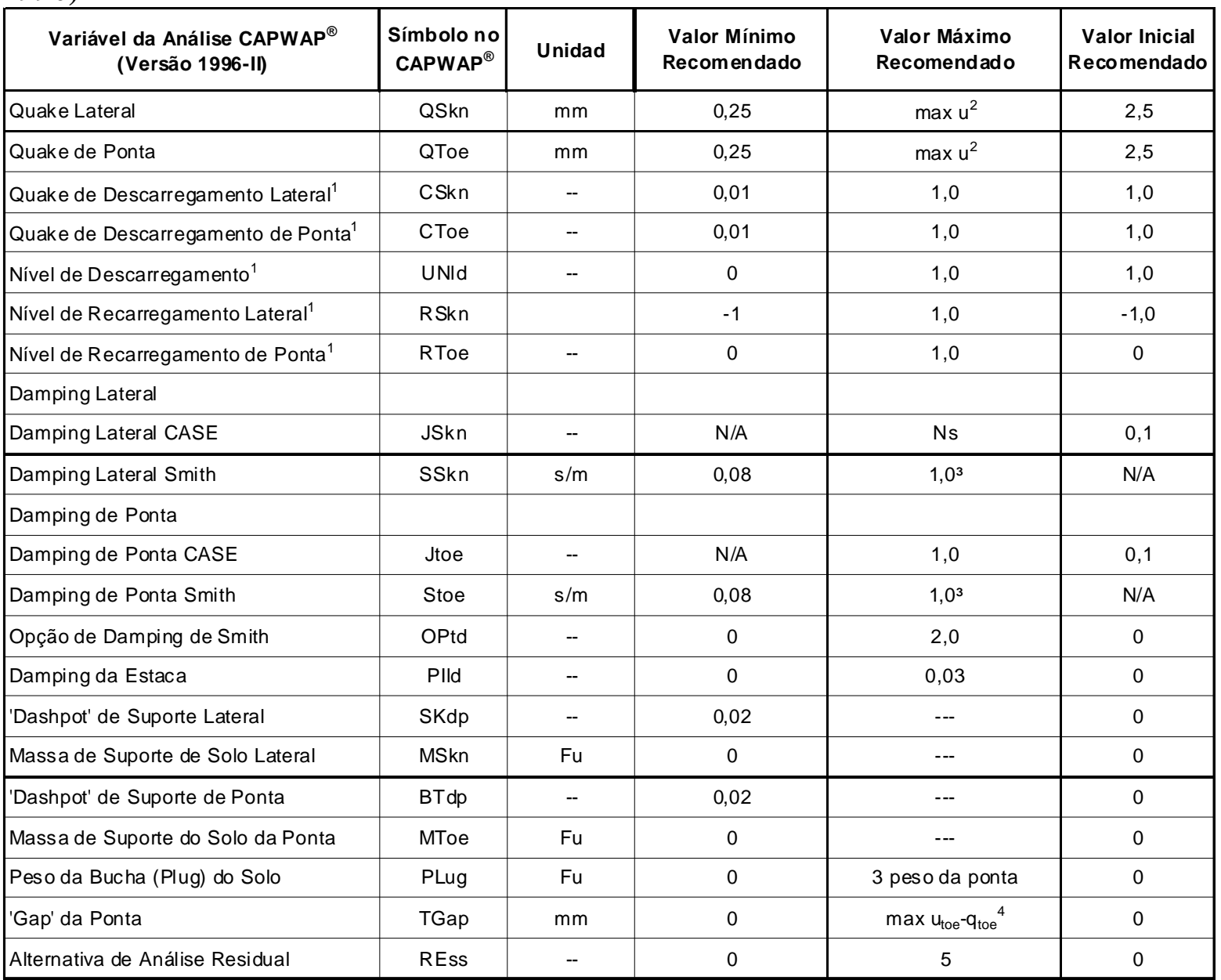
(1) Multiplicador
(2) Máximo deslocamento
(3) Valores maiores são possíveis mas incomunes
(4) Quake de ponta 


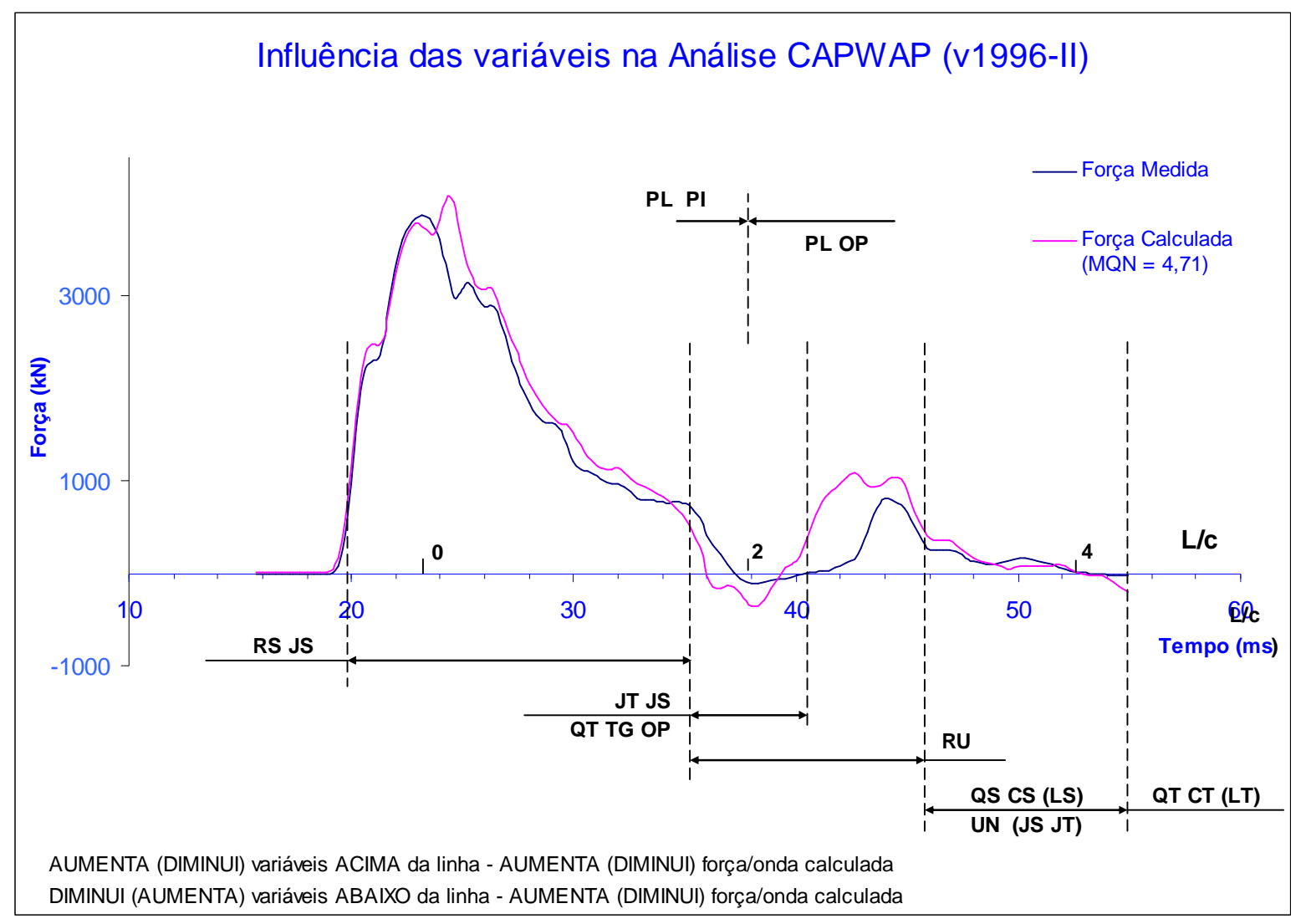

Figura D-1 Influência das variáveis dentro das Análises CAPWAP 


\section{ANEXO E - Match Quality Number 'MQN' na Análise inicial CAPWAP}

O texto apresentado a continuação é uma tradução livre do Manual CAPWAP (1990), e tem alguns comentários sobre o cálculo do MQN.

Uma estimativa da qualidade se semelhança entre as curvas calculada e medida, de força ou velocidade, pode ser quantificada através do 'match quality number' $(M Q N)$.

O número $M Q N$ é calculado somando os valores absolutos das diferenças relativas entre os sinais medido e calculado da força ou velocidade.

O termo MQN é um medidor da aproximação entre as curvas em certo intervalo de tempo, k, e pode ser calculado seguindo a Eq. E-1. O valor de $M Q N$, calcula-se como a soma de quatro regiões, $\mathrm{k}=1, \ldots, 4$.

$$
M Q N_{k}=S O M\left[\frac{A B S\left(f_{j c}-f_{j m}\right)}{F m}\right]
$$

Com fjc e fjm = variável no topo da estaca calculada e medida no tempo $j, \mathrm{SOM}=$ somatória sobre um período de tempo, e $F m$ = máxima força medida no topo da estaca.

Visando o cálculo de MQN, os períodos de tempo considerados subdividem-se em quatro intervalos mostrados na Figura E-1.

1) $k=1$; o período I se estende a partir do 'começo do impacto' sobre o tempo de $2 \mathrm{~L} / \mathrm{c}$ (duas vezes o cumprimento da estaca abaixo dos sensores dividido pela velocidade de onda de tração). O começo do impacto revela-se claro nos valores da curva, sua definição é visual. Neste período o $M Q N_{I}$ é um indicador da qualidade da distribuição de atrito lateral.

2) $k=2$; o período II começa no final do período I e vai até " $t r$ " mais 03 ms A duração, tr, é o tempo a partir do começo do impacto, ponto ' $p$ ', até o ponto ' $s$ ', o tempo da 
máxima velocidade (tr está definido na Figura E-1). Este período de tempo usualmente importa na determinação apropriada da resistência de ponta.

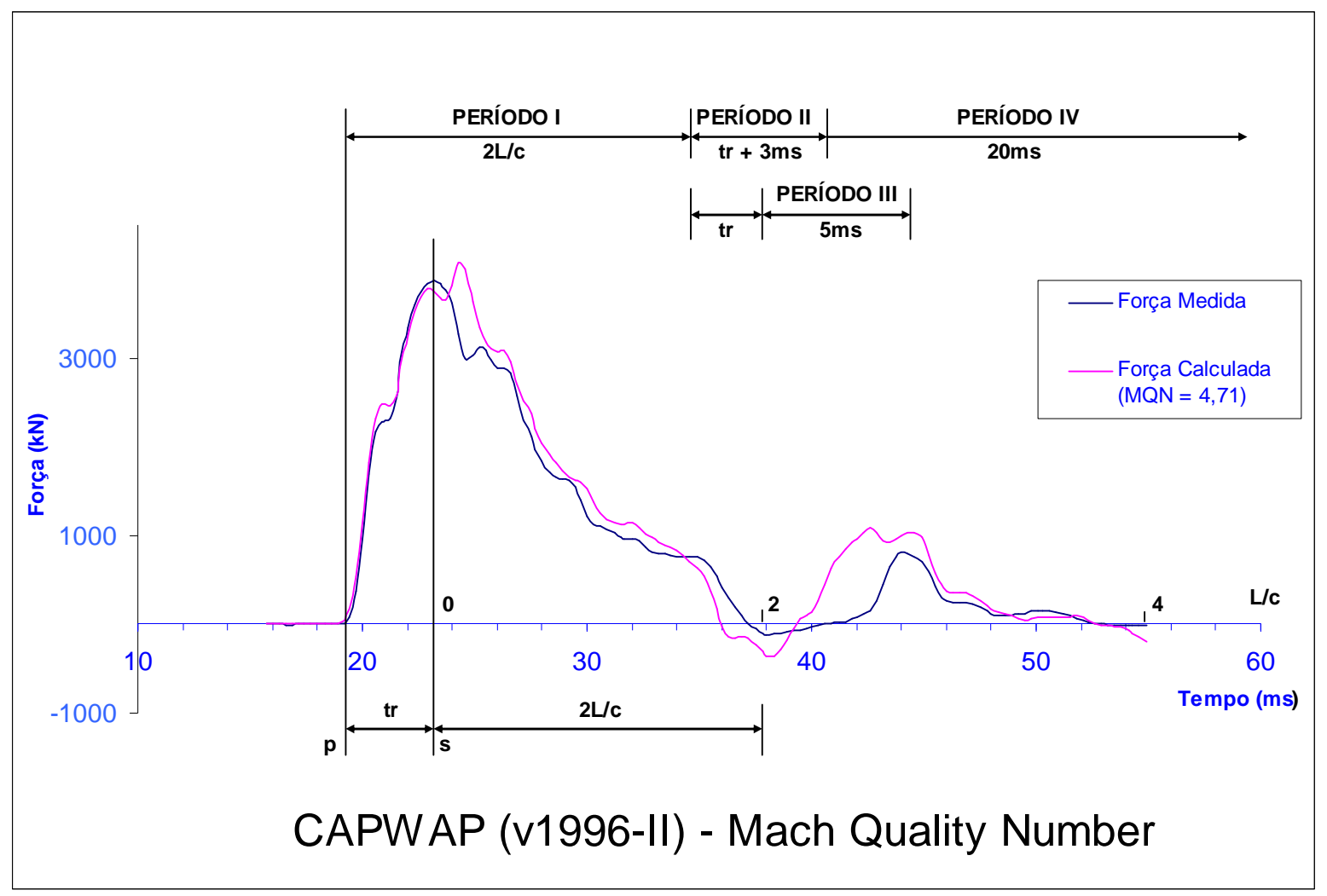

Figura E-1 Metodologia para o cálculo do MQN (CAPWAP Manual, 1990)

3) $k=3$; o período III começa $2 L / c$ após 'tr' e vai até $5 \mathrm{~ms}$. Durante esse intervalo a capacidade de carga total é mais representativa.

4) $k=4$; o período IV estende-se em pelo menos $20 \mathrm{~ms}$. Neste período o comportamento da variável de descarregamento do solo afeta significativamente o cálculo do sinal calculado (força ou velocidade).

Devido à interseção dos períodos II e III, o tempo que demora a onda no retorno da ponta, considera-se o dobro comparado com os outros intervalos, também o MQN vê-se afetado pela capacidade de carga total mais que outros parâmetros. Conforme visto na Figura D-1.

\section{Comentários.}


Com o intuito de mostrar o como é feito o cálculo interno do MQN do CAPWAP ${ }^{\circledR}$, utilizouse os sinais da análise inicial do CAPWAP ${ }^{\circledR}$ e como valor de comparação para os cálculos, o valor do MQN = 4,71.

Na Tabela E-1, apresenta-se um teste do cálculo do MQN a partir do sinal medido do PDA e do sinal calculado da análise inicial (da presente pesquisa), mediante a aplicação da metodologia apresentada no Manual do CAPWAP ${ }^{\circledR}$ (1990) apresentada na Figura E-1.

Na Figura E-2, apresenta-se a metodologia adotada para o cálculo do MQN (Liang, L., 2008)*.

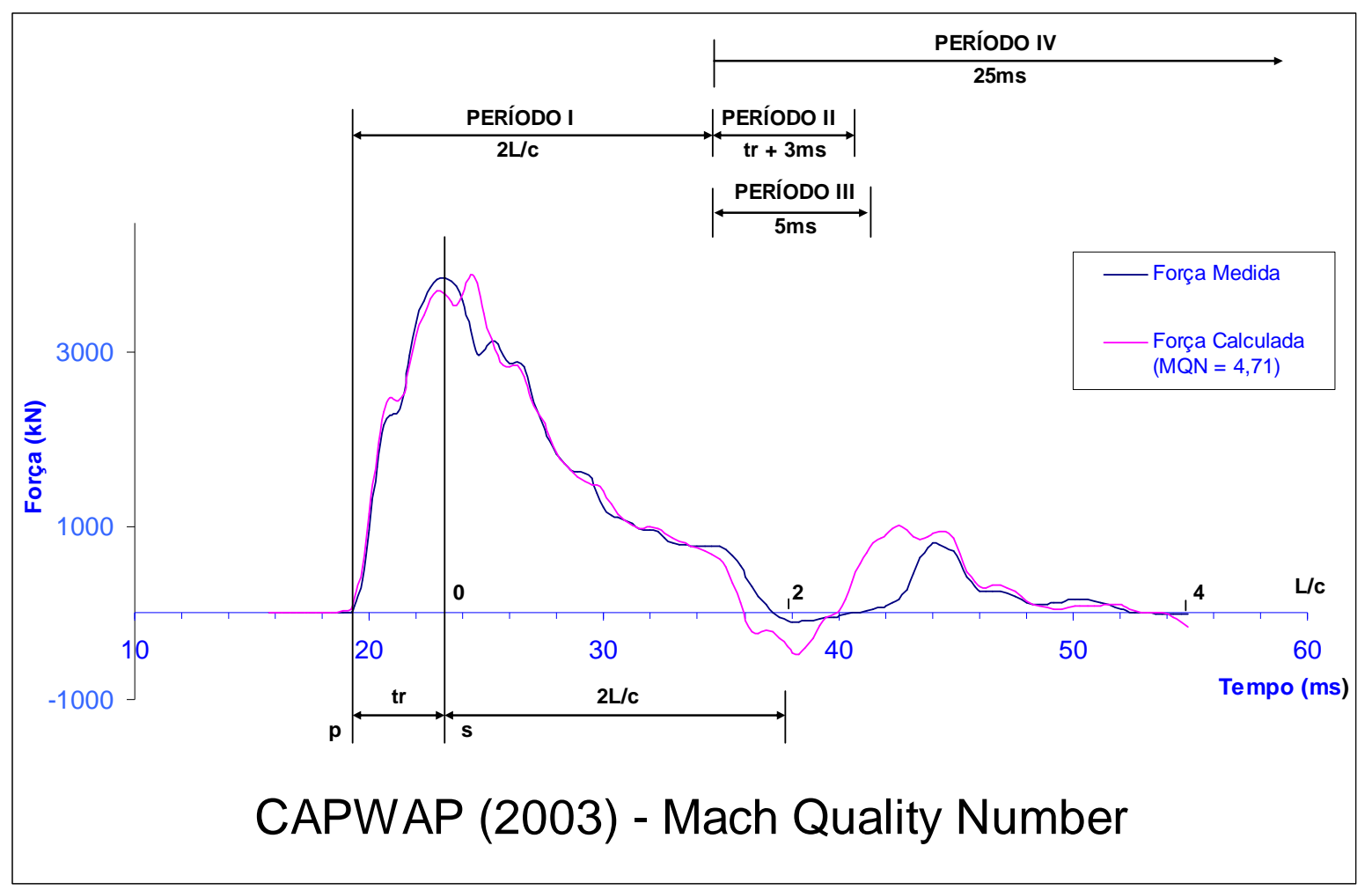

Figura E-2 Metodologia de cálculo do MQN (CAPWAP Manual, 2003)*

(*) Comunicação Pessoal com Liqun Liang, da Pile Dynamics, Inc (janeiro, 2008). 

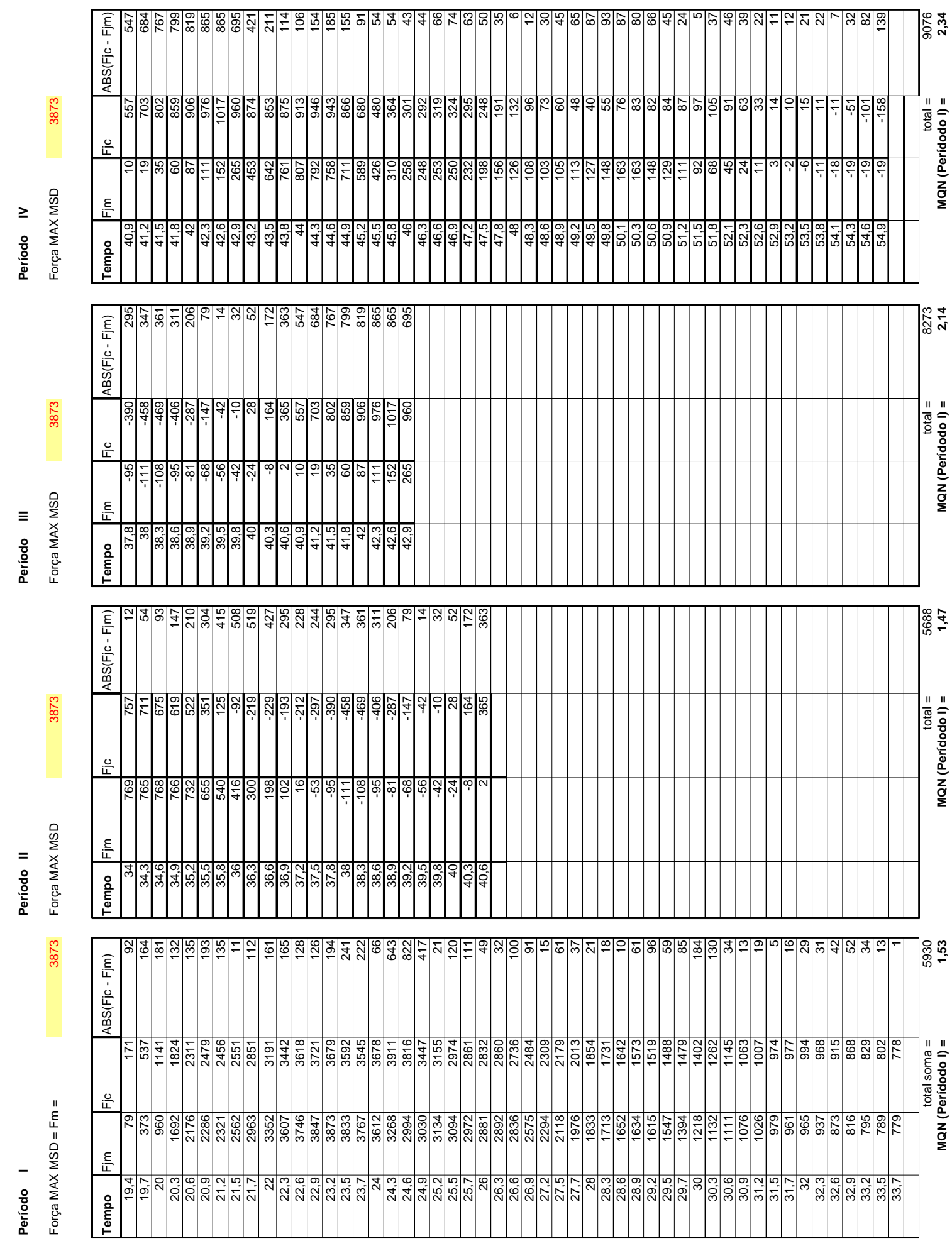

Tabela E-1 Cálculo do MQN para intervalos de tempo de $0,3 \mathrm{~ms}$, conforme Metodologia CAPWAP (1990) 
Na Tabela E-2, apresenta-se os resultados encontrados na aplicação de ambas as metodologias de cálculo do MQN: 1990 e 2003.

Tabela E-2 Valores de MQN em função do intervalo de tempo escolhido

\begin{tabular}{l|cc} 
& $\begin{array}{c}\text { Intervalos de } \\
\text { tempo 0,3 ms }\end{array}$ & $\begin{array}{c}\text { Intervalos de tempo } \\
0,6 \mathrm{~ms}\end{array}$ \\
\hline Valor MQN & 7,48 & 3,81 \\
(CAPWAP Manual, 1990) & & 3,84 \\
Valor MQN & 6,83 & \\
(CAPWAP Manual, 2003)* & &
\end{tabular}

Os valores encontrados discordam com o MQN calculado no CAPWAP da análise inicial (da presente pesquisa) que foi de 4,71. Liang $\left(2008^{*}\right)$ menciona duas hipóteses para explicar tal fato.

1) $\mathrm{O}$ indicador de qualidade MQN pode ser diferente quando existe diferença entre o 'blow count' calculado mediante o CAPWAP e o 'blow count' medido em campo e introduzido como dado nas análises. O CAPWAP utiliza tal comparação para interferir no cálculo do MQN.

2) Na Versão 2000 do CAPWAP , para o cálculo do MQN se considera o tempo final da análise, que já na versão 2006 do CAPWAP tem um tempo fico de análise.

Como recomendado pelo Liang $(2008 *)$, procedeu-se com as análises tanto de 'blow count' como do tempo final da análise em relação ao MQN. Na Tabela E-3, apresenta-se os resultados de uma análise da influencia da diferença de 'blow count' medido e calculado para o cálculo do MQN. 
Tabela E-3 relação do 'blow count' medido e calculado com o MQN.

\begin{tabular}{|c|c|c|c|}
\hline $\begin{array}{c}\text { 'Blow count' } \\
\text { Medido em Campo } \\
\text { (BLct-Msd) }\end{array}$ & $\begin{array}{c}\text { Nega } \\
\text { Medida em Campo } \\
\text { (mm) }\end{array}$ & $\begin{array}{c}\text { 'Blow count' } \\
\text { Calculado no CAPWAP } \\
\text { (BLct-Cpt) }\end{array}$ & $\begin{array}{c}\text { Número } \\
\text { MQN }\end{array}$ \\
\hline 500 & 2,0 & 209,8 & $4,71^{\star *}$ \\
\hline 333 & 3,0 & 209,8 & 4,71 \\
\hline 250 & 4,0 & 209,8 & 4,71 \\
\hline 200 & 5,0 & 209,8 & 4,71 \\
\hline
\end{tabular}

$\left(^{* *}\right)$ Análise inicial CAPWAP, para a presente pesquisa.

Observa-se que o MQN não apresenta mudanças de valor para diferentes valores de 'blow count' medidos em campo e introduzidos como dado 